\title{
LIFE CYCLE VALUATION
}

\author{
DESIGNING A MODULAR METHODOLOGY \\ FOR MANAGING THE COSTS AND BENEFITS \\ OF PHYSICAL ASSETS OVER THEIR LIFE CYCLE
}

Willem Haanstra 


\title{
LIFE CYCLE VALUATION
}

\author{
DESIGNING A MODULAR METHODOLOGY \\ FOR MANAGING THE COSTS AND BENEFITS \\ OF PHYSICAL ASSETS OVER THEIR LIFE CYCLE
}

\section{DISSERTATION}

to obtain

the degree of doctor at the Universiteit Twente, on the authority of the rector magnificus, prof. dr. ir. A. Veldkamp, on account of the decision of the Doctorate Board to be publicly defended on Friday the $21^{\text {st }}$ of May 2021 at 12.45 hours

by

\section{Willem Haanstra}

born on the 30th of April, 1986

in Groningen, The Netherlands 
This dissertation has been approved by:

Supervisor:

Prof.dr.ir L.A.M. van Dongen

Co-supervisor:

Dr. A.J.J. Braaksma

The research presented in this dissertation was funded by Liander N.V.

Cover design: Willem Haanstra

Printed by: Ipskamp printing, Enschede

Lay-out: Willem Haanstra

ISBN: $\quad$ 978-90-365-5184-7

DOI: $\quad 10.3990 / 1.9789036551847$

(c) 2021 Willem Haanstra, The Netherlands. All rights reserved. No parts of this thesis may be reproduced, stored in a retrieval system or transmitted in any form or by any means without permission of the author. Alle rechten voorbehouden. Niets uit deze uitgave mag worden vermenigvuldigd, in enige vorm of op enige wijze, zonder voorafgaande schriftelijke toestemming van de auteur. 
Graduation committee:

Chair / secretary: Prof.dr.ir. H.F.J.M. Koopman

Supervisor:

Prof.dr.ir. L.A.M. van Dongen

Co-supervisor:

Dr. A.J.J. Braaksma

Committee Members:

Prof.dr. J. van Hillegersberg University of Twente

Prof.dr.ir. J.I.M. Halman University of Twente Prof.dr.ing. S. Thiede University of Twente

Prof.dr.ir. T. Tinga University of Twente

Prof.dr. H.A. Akkermans Tilburg University

Prof.dr. A. Starr Cranfield University

Prof.dr. E.W. Berghout University of Groningen 
"There is nothing as practical as a good theory"

Kurt Lewin, 1945 


\section{Table of contents}

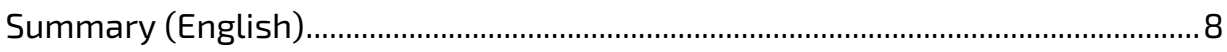

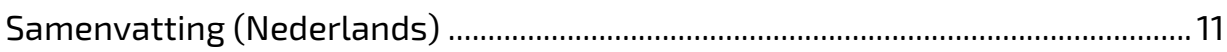

Chapter 1 - General Introduction ............................................................................ 14

Chapter 2 - Asset Management in the Energy Transition: An embedded case study on Life Cycle Cost-based decision-making in Dutch distribution grids.36

Chapter 3 - Designing a hybrid methodology for the Life Cycle Valuation of



Chapter 4 - Towards Life Cycle Value-driven Asset Management: An action research investigation into value-driven decision-making in an energy transition 94

Chapter 5 - Design of a framework for integrating environmentally sustainable design principles and requirements in train modernization projects

Chapter 6 - Design for Sustainable Public Transportation: LCA-Based Tooling for Guiding Early Design Priorities. 150

Chapter 7 - Integrating sustainability in asset management decision making: A case study on streamlined life cycle assessment in asset procurement ...174 Chapter 8 - Discussion and conclusion ................................................................188

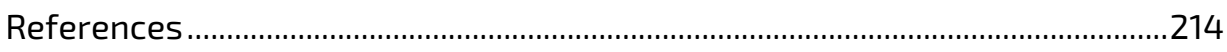

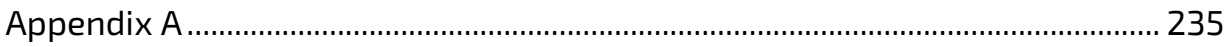

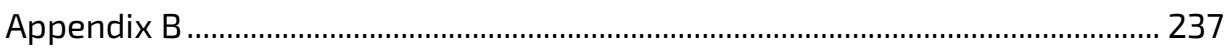

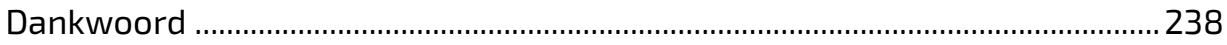




\section{Summary (English)}

Across the world, many physical public infrastructure systems are reaching the end of their useful lives and need replacing in the near future. Many Asset Management (AM) organizations are therefore faced with crucial decisions concerning the replacement of aging systems or the development of new systems to keep up with increasing demand in goods, energy, and transportation. These assets typically require significant upfront investments and require long-term commitments for the operation and maintenance over their typically decades-long lifespan.

Oftentimes, these types of strategic decisions are supported by instruments such as Life Cycle Costing (LCC). Despite the advantages of this instrument in gaining a better understanding of the costs incurred over the lifecycle, there are also several important limitations to this instrument, especially concerning the complex and multidimensional objectives and requirements of AM. LCC is primarily aimed at minimizing financial impact from a technical perspective, whereas AM is concerned with simultaneously balancing a wide selection of objectives such as reliability, safety, condition, deterioration, sustainability, and social concerns. Additionally, a whole-life cycle perspective also necessitates a multidisciplinary collaboration process to collect the required information and data, and for subsequently building life cycle models. This information, however, is often fragmented across different organizational departments or missing altogether. Lastly, approaches such as LCC tend to ignore external factors that are crucial for an asset's long-term viability, such as changes in technology, demography, legislation, interfaces with other technical systems, and the demands of various stakeholders.

Because the philosophies of LCC and AM seem to have partially misaligned objectives, LCC may not necessarily be the right decision-support instrument for AM. As such, AM organizations are looking for ways to assess and articulate what makes a physical system valuable over its entire life cycle. The main question that guides the research of the dissertation is therefore formulated as: 


\section{"How can the life cycles of physical systems be assessed to support value-driven decision-making that benefits Asset Management organizations and their relevant stakeholders?"}

In order to answer this research question, a new methodology called Life Cycle Valuation (LCV) was developed, following a Design Science Research approach. LCV is rooted in LCC but is expanded upon with concepts from Life Cycle Assessment (LCA), forming a hybrid methodology aimed at the assessment of both costs and benefits in the lifecycles of assets. The design of the LCV methodology includes a quantitative approach for the valuation of non-financial impacts, allowing them to be evaluated alongside financial impacts as well as relevant qualitative factors. Environmental impact can be included in LCV by utilizing streamlined variants of LCA that retain a high degree of validity but require fewer resources compared to comprehensive LCAs. LCV employs the four-stage framework of LCA to support the assessment and decision-making process. The main steps in this process involve determining the goal and scope, inventory analysis for the life cycle, impact assessment, and the interpretation of the results. Lastly, it includes the design of a modular tool that supports the inventory and impact assessment phases of the LCV process.

The LCV methodology is primarily demonstrated, tested, and evaluated at Liander, a distribution system operator (DSO) that is responsible for the development, operation, and maintenance of the energy grids that distribute natural gas and electricity to millions of households and businesses in the Netherlands. The decision-making context of Liander offers an interesting and emblematic research environment because its AM organization needs to deal with the complexities of managing an aging asset population while making fundamental changes in the design of existing energy systems due to the ongoing energy transition. Furthermore, Liander needs to balance multiple objectives in its decision-making such as costs, asset performance, safety, reliability, and sustainability, among other concerns.

Following a participatory research strategy, the design of the LCV methodology was used to study a broad range of AM decision-making contexts at the DSO. It was applied to develop and evaluate the design of individual asset lifecycles (e.g., transformers), entire asset populations (e.g., switchgear), complex systems of multiple assets (e.g., entire energy grids), and in developing strategies for deferring asset investments (e.g., using 
demand flexibility). Furthermore, the application of the designed LCV approaches also covered a wide range of life cycle stages, including early design, procurement, maintenance, operation, and end-of-life decisions such as replacement and refurbishment. Additionally, some aspects of the methodology, such as the inclusion of environmental sustainability, were also designed and tested in another decision-making context, in the form of the early design stages of train modernization at passenger railway organization Netherlands Railways.

The empirical findings indicate that the designed Life Cycle Valuation methodology can be an effective instrument to support AM decision-making by: (1) Providing a life cycle perspective for the long-term planning of individual assets and their relation to other assets and systems by setting appropriate scopes. (2) Revealing the links that exist between specific activities and opportunities in the lifecycle of assets and the costs and benefits that are relevant to the AM organization. (3) Increasing the support for investment proposals through multidisciplinary data and information inventory, and transparency about which impacts are included in the assessment and how. And (4) by facilitating the assessment process itself using a supporting framework, streamlining strategies, and the use of supporting tools.

The dissertation aims to further close the gap that currently exists between existing asset management and life cycle evaluation theories and the practice of real-world decision-making and its empirical challenges. The core design of the LCV methodology is based on well-established, empirically tested, and generalizable design principles, allowing for the method to be adapted to other organizations and asset types. Overall, the research provides a better theoretical and empirical understanding of how to evaluate strategic assetrelated decisions in complex and changeable AM environments. 


\section{Samenvatting (Nederlands)}

Onze samenleving wordt in grote mate draaiende gehouden door openbare infrastructuursystemen zoals die voor goederen, energie en transport. Veel componenten in deze systemen bereiken in de komende jaren het einde van hun nuttige levensduur, een probleem dat wereldwijd speelt, maar met name in Europa. Assetmanagement (AM) organisaties worden daarom steeds vaker geconfronteerd met cruciale vraagstukken over de vervanging, revisie, of aanschaf van nieuwe kapitaalgoederen om de groeiende vraag naar goederen, energie en transport te kunnen bijbenen. Deze kapitaalgoederen, ook wel 'assets' genoemd, vergen doorgaans aanzienlijke investeringen bij aanschaf en brengen hoge operationele en onderhoudskosten met zich mee over de decennia durende levensduur.

Beslissingen over deze assets zijn vaak strategisch van aard en worden daarom ondersteund door instrumenten zoals levenscycluskostenanalyse (LCC). Ondanks het inzicht dat LCC kan bieden in de levenscycluskosten, zijn er ook een aantal belangrijke beperkingen aan dit instrument, met name met betrekking tot de complexe en multidimensionale doelstellingen en eisen die aan AM gesteld worden. LCC is gericht op het minimaliseren van de financiële impact vanuit een technisch perspectief, terwijl AM zich bezighoudt met het gelijktijdig afwegen van een brede selectie van doelstellingen zoals die voor betrouwbaarheid, veiligheid, conditie, verslechtering, duurzaamheid en sociaal-maatschappelijke impact. Bovendien vraagt een levenscyclusbenadering ook om een multidisciplinair samenwerkingsproces om de vereiste informatie en gegevens te verzamelen die nodig zijn voor het maken van levenscyclusmodellen. Deze informatie ontbreekt vaak, of is versnipperd over verschillende afdelingen van de organisatie. Tenslotte neigen benaderingen zoals LCC ertoe om externe factoren te negeren die van cruciaal belang kunnen zijn voor de levensvatbaarheid van een asset op de lange termijn, zoals veranderingen in technologie, demografie, wetgeving, raakvlakken met andere technische systemen, en de eisen en wensen van diverse belanghebbenden.

Omdat de filosofieën en doelstellingen van LCC en AM niet goed op elkaar aan lijken te sluiten, is LCC niet altijd het juiste beslissingsondersteunende instrument voor AM. Daarom zijn AM organisaties op zoek naar benaderingen om te evalueren en te verwoorden wat een fysiek systeem waardevol maakt over de gehele levensduur. De hoofdvraag die het onderzoek van het proefschrift stuurt is daarom geformuleerd als: 


\section{"Hoe kunnen de levenscycli van fysieke systemen worden beoordeeld om waardegedreven besluitvorming te ondersteunen ten behoeve van assetmanagement organisaties en hun relevante stakeholders?"}

Om deze onderzoeksvraag te beantwoorden is door middel van ontwerpgericht wetenschappelijk onderzoek een nieuwe methodologie ontwikkeld, genaamd Life Cycle Valuation (LCV - wat vertaald kan worden levensduurwaardebepaling). LCV is geworteld in LCC, maar is uitgebreid met concepten uit levenscyclusanalyse (LCA), waardoor een hybride methodologie is ontstaan die gericht is op de beoordeling van zowel kosten als baten in de levenscycli van assets. Het ontwerp van de LCV-methodologie omvat een kwantitatieve benadering voor de waardering van niet-financiële effecten, waardoor deze kunnen worden geëvalueerd naast financiële effecten en relevante kwalitatieve factoren. Milieueffecten kunnen in LCV worden opgenomen door gebruik te maken van versimpelde varianten van LCA die een hoge mate van validiteit kennen, maar minder tijd en moeite kosten in de uitvoering dan uitgebreide LCA's. LCV maakt gebruik van het vierfasenkader van LCA om het beoordelings- en besluitvormingsproces te ondersteunen. De hoofdstappen in dit proces zijn het bepalen van het analysedoel en -kader, de inventarisatie van benodigde data en informatie voor het levenscyclusmodel, de effectbeoordeling, en de interpretatie van de resultaten. Ten slotte is er een modulair analyse-instrument ontworpen ter ondersteuning van de inventarisatie- en effectbeoordelingsfasen van het LCV-proces.

De LCV-methodologie is voornamelijk gedemonstreerd, getest en geëvalueerd bij Liander, een netbeheerder die verantwoordelijk is voor de ontwikkeling, het beheer, en het onderhoud van de distributienetten voor aardgas en elektriciteit die miljoenen huishoudens en bedrijven in Nederland bedienen. De besluitvormingscontext van Liander biedt een interessante en rijke onderzoeksomgeving omdat de AM organisatie moet omgaan met de complexiteit van het beheer van een verouderende assetpopulatie en tegelijkertijd fundamentele veranderingen moet doorvoeren in het ontwerp van bestaande energiesystemen als reactie op de huidige energietransitie. Bovendien moet Liander in haar besluitvorming meerdere doelstellingen tegen elkaar afwegen, zoals die voor kosten, prestaties van assets, veiligheid, betrouwbaarheid en duurzaamheid, en vele andere aandachtspunten.

De LCV-methodologie is ontwikkeld op basis van een participatieve onderzoeksstrategie en is toegepast op een breed spectrum aan AM besluiten 
bij netbeheerder Liander. Zo is LCV toegepast op de ontwikkeling en evaluatie van individuele assets (zoals transformatoren), volledige assetpopulaties (zoals schakelapparatuur), complexe systemen van meerdere assets (zoals volledige energienetten), en bij het ontwikkelen van strategieën voor het uitstellen van investeringen in assets (zoals het gebruik van flexoplossingen). Bovendien raakte de toepassing van de ontworpen LCV-benaderingen ook een breed scala van levenscyclusfasen, inclusief vroege fases van het ontwerp, de aankoop, het onderhoud, de exploitatie, en de beslissingen aan het einde van de levensduur, zoals vervangingen en opknapbeurten. Daarnaast werden sommige aspecten van LCV, zoals de integratie van milieuduurzaamheid, ook ontwikkeld en getest in een andere besluitvormingscontext, in de vorm van de vroege ontwerpfasen van de modernisering van treinen bij de passagiersspoorwegorganisatie Nederlandse Spoorwegen.

De empirische bevindingen geven aan dat de ontworpen Life Cycle Valuation methodologie een effectief instrument kan zijn om AM besluitvorming te ondersteunen door: (1) Het bieden van een levenscyclusperspectief voor de langetermijnplanning van individuele assets en hun relatie met andere assets en systemen door het vaststellen van passende scopes. (2) Het blootleggen van de verbanden die bestaan tussen specifieke activiteiten en kansen in de levenscyclus van assets en de kosten en baten die relevant zijn voor de AMorganisatie. (3) het vergroten van het draagvlak voor investeringsvoorstellen door multidisciplinaire gegevens- en informatie-inventarisatie, en transparantie over welke effecten worden meegenomen in de beoordeling. En (4) door het vergemakkelijken van het beoordelingsproces zelf met behulp van een ondersteunend kader, stroomlijningsstrategieën, en het gebruik van ondersteunende instrumenten.

Het proefschrift beoogt de kloof te dichten tussen de bestaande theorieën over assetmanagement en levenscyclusevaluatie, en de praktische kant van besluitvorming en uitdagingen hiervan binnen bestaande AM organisaties. Het ontwerp van de LCV-methodologie is daarom gebaseerd op gevestigde, empirisch geteste, en generaliseerbare ontwerpprincipes, waardoor de methode ook kan worden aangepast op verschillende organisaties en assettypes. In het algemeen geeft het onderzoek een beter theoretisch en empirisch begrip van hoe strategische asset-gerelateerde beslissingen geëvalueerd kunnen worden in complexe en veranderlijke AM omgevingen. 
Chapter 1 - General Introduction 


\section{Introduction}

Our society relies heavily on physical systems in the creation of a wide variety of products and services. Examples of these systems are buildings, vehicles, and industrial equipment, but also include infrastructural systems such as roads, bridges, and energy grids. Oftentimes, the existence of these systems is taken for granted, unless something unexpected happens such as power outages, train delays, or the malfunctioning of a production line. These objects are often referred to as 'assets', a word that can be used to describe both tangible assets (e.g., buildings, equipment) as well as intangible assets that lack physical substance (e.g., human capital, intellectual property, or financial constructs such as stocks, bonds, and loans). In this dissertation, the word 'asset' is used to describe tangible, physical assets, unless otherwise specified.

Assets tend to be designed and built to last multiple decades, with the aim of creating enduring value over its entire lifespan (Tranfield, Denyer, \& Burr, 2004). The considerable length of many asset lifespans is exemplified by the observation that, in Europe, many systems that were originally implemented in the period of economic growth after the second world war, are only now starting to reach the end of their useful lives. Additionally, technological and societal changes are making assets obsolete, despite their technical condition. An important challenge for many organizations is, therefore, that many of these assets need replacing in the near future (Boller, Starke, Dobmann, Kuo, \& Kuo, 2015; Hijdra, Woltjer, \& Arts, 2015; Qureshi \& Shah, 2014; Van Breugel, 2017). An estimation for the world-wide investments in infrastructural assets alone amounts to over $€ 41$ trillion $\left(41 \cdot 10^{12}\right)$ in the period between 2013 and 2030 (Van Breugel, 2017).

Because of the large financial stakes involved over a typically long life span, the management of assets requires a long-term and strategic management outlook (Tranfield et al., 2004). Many assets do not exist independently from other assets, but are part of larger, interconnected systems, and can often be seen as complex systems in their own right (Keating et al., 2003). Furthermore, assets are not called assets because of their cost, but because of their actual or potential value within these systems (Woodhouse, 2015). As such, the costs of assets over their life cycle are meaningless without also taking into account the benefits. An important challenge is that, whereas costs can be relatively easily measured, the measurement and allocation of benefits is much more 
challenging, mainly because it is difficult to do so objectively (Schuurman, Berghout, \& Powell, 2008). How stakeholders frame the expected value of assets in public projects is therefore central to the public debate and influences financing decisions (Martinsuo, Vuorinen, \& Killen, 2019). The evaluation of what makes an asset valuable over its lifecycle, therefore, represents an important, but difficult challenge. It should capture both costs and benefits over the entire life cycle, be able to deal with complex systems, needs to address subjectivity, needs to be practicable during decision-making, and the results should be publicly accepted. It is unlikely that there will be a single method that meets all these criteria for all types of assets. A useful starting point in the pursuit of such an approach, is by looking at the wellestablished theory of Life Cycle Costing (LCC).

\section{Theoretical background}

\subsection{Life Cycle Costing}

The life cycle of an asset typically starts with the design and construction of an asset, followed by its operation and maintenance, and ends with its disposal and possible needed replacement (Asiedu and Gu, 1998). The initial investment in many assets therefore only forms a small portion of all the costs incurred during an asset's life. Surprisingly, procurement costs are widely used as the primary (and sometimes only) criteria for equipment or system selection (Barringer \& Weber, 1996). The terms Life Cycle Costs (LCC) and Total Cost of Ownership (TCO) are often used to describe all costs incurred over the entire lifespan of an asset. Both concepts are strictly related to each other and are often used without distinction in literature (Roda \& Garetti, 2014).

The analogy of an iceberg is colloquially used to illustrate the relation between the known acquisition cost (the tip of the iceberg) and the rest of the life cycle costs (the part of the iceberg that is hidden underwater), as shown in figure 1.1. The procedure of identifying and evaluating this proverbial iceberg is also referred to as LCC, this time referring to the Life Cycle Costing process. In this dissertation, the catch-all abbreviation 'LCC' will be used to describe the total life cycle cost sum, as well as the life cycle costing process. 


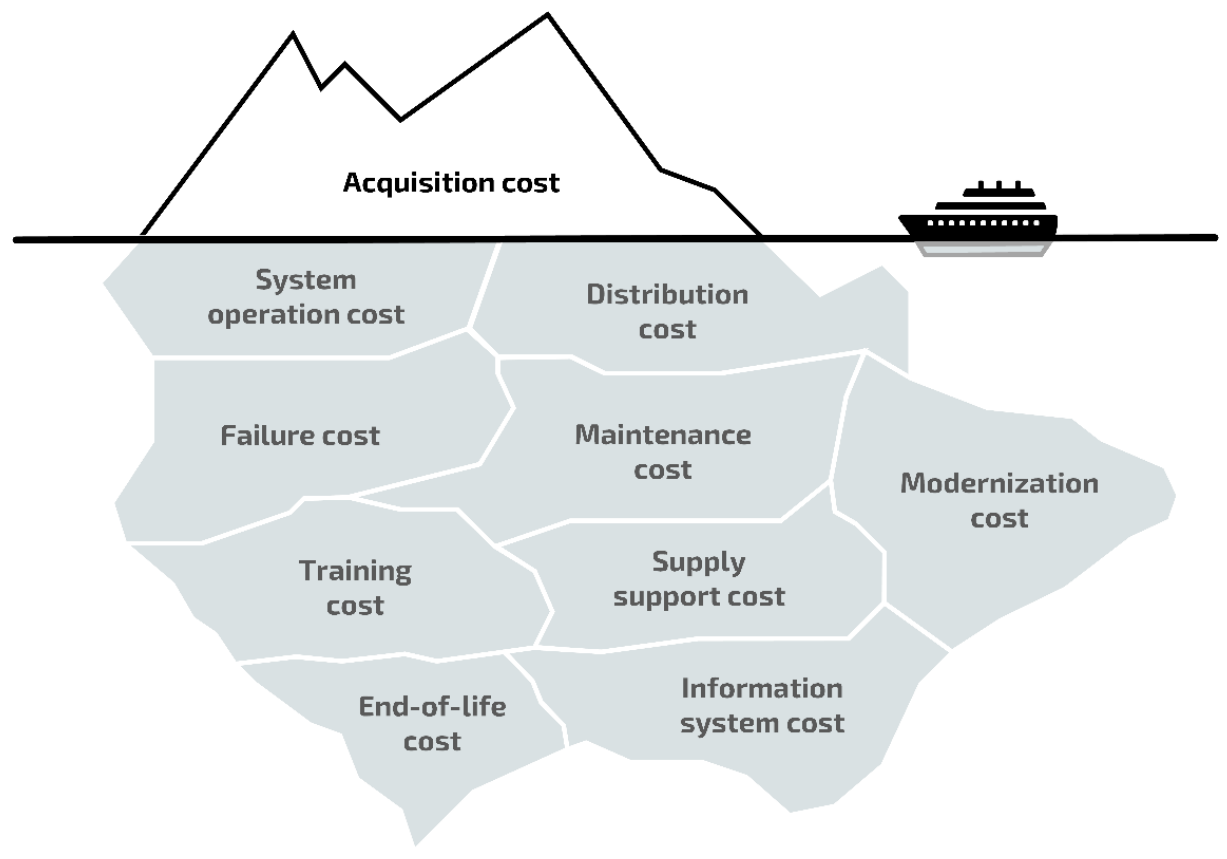

Figure 1.1: The life cycle costs represented as an iceberg (adapted from Clark, Piperias, \& Traill, 1999)

LCC is reported to be first formally applied in the 1960s by the U.S. Department of Defense for the procurement of costly items of military equipment (Fauzi, Lavoie, Sorelli, Heidari, \& Amor, 2019; Neugebauer, Forin, \& Finkbeiner, 2016; Okano, 2001; Sherif \& Kolarik, 1981). Since the inception of LCC, many different terms, techniques, and abbreviations have been proposed that describe a broad range of LCC-related concepts and variations (see table 1.1). Most definitions of LCC however, share several key aspects. Because the LCC of a physical asset begins when its acquisition is first considered and ends when it is finally taken out of service for disposal or redeployment, it should cover the entire lifecycle, from inception to the end of its useful life (Woodward, 1997). By definition, LCC, therefore, encompasses all costs associated with a product during, or because of this life cycle (Sherif \& Kolarik, 1981). 
Table 1.1: Overview of Life Cycle Cost-related concepts

\begin{tabular}{|c|c|c|c|}
\hline & Concept & Description & Reference \\
\hline FCA & $\begin{array}{l}\text { Full Cost } \\
\text { Accounting }\end{array}$ & $\begin{array}{l}\text { All direct, indirect, and intangible } \\
\text { costs in the life cycle }\end{array}$ & \\
\hline FCEA & $\begin{array}{l}\text { Full Cost } \\
\text { Environmental } \\
\text { Accounting }\end{array}$ & $\begin{array}{l}\text { All costs in the life cycle, } \\
\text { including environmental costs }\end{array}$ & \\
\hline TCA & $\begin{array}{l}\text { Total Cost } \\
\text { Assessment / } \\
\text { Accounting }\end{array}$ & $\begin{array}{l}\text { Financial analysis of costs and } \\
\text { cost savings in the life cycle }\end{array}$ & (Gluch \& Baumann, \\
\hline LCA & $\begin{array}{l}\text { Life Cycle } \\
\text { Accounting }\end{array}$ & $\begin{array}{l}\text { Product-specific cost } \\
\text { assessment framework }\end{array}$ & 2004) \\
\hline LCCA & $\begin{array}{l}\text { Life Cycle Cost } \\
\text { Assessment }\end{array}$ & $\begin{array}{l}\text { Evaluates costs of environmental } \\
\text { impacts }\end{array}$ & \\
\hline LCC & Life Cycle Costing & All costs in the life cycle & \\
\hline FCP & Full Cost pricing & Pricing strategy based on LCC & \\
\hline WLC & Whole Life Costing & All costs in the life cycle & \\
\hline TOC & $\begin{array}{l}\text { Total Ownership } \\
\text { Cost }\end{array}$ & $\begin{array}{l}\text { All costs in the life cycle, } \\
\text { including R\&D (US navy) }\end{array}$ & \\
\hline TCO & $\begin{array}{l}\text { Total Cost of } \\
\text { Ownership }\end{array}$ & $\begin{array}{l}\text { All direct and indirect costs in the } \\
\text { life cycle (business) }\end{array}$ & \\
\hline ABB & $\begin{array}{l}\text { Activity-Based } \\
\text { Budgeting }\end{array}$ & $\begin{array}{l}\text { Links budgets to a product's } \\
\text { costs and services }\end{array}$ & \\
\hline$A B C$ & $\begin{array}{l}\text { Activity-Based } \\
\text { Costing }\end{array}$ & $\begin{array}{l}\text { Links costs to activities in the } \\
\text { product's life cycle }\end{array}$ & $\begin{array}{r}\text { (Huppes et al., } \\
2004)\end{array}$ \\
\hline TCA & $\begin{array}{l}\text { Total Cost } \\
\text { Accounting }\end{array}$ & $\begin{array}{l}\text { Direct, indirect, and less tangible } \\
\text { costs of company operations }\end{array}$ & \\
\hline FCA & $\begin{array}{l}\text { Full Cost } \\
\text { Accounting }\end{array}$ & $\begin{array}{l}\text { Internal costs and savings } \\
\text { required for environmental } \\
\text { projects }\end{array}$ & \\
\hline CEA & $\begin{array}{l}\text { Cost-Effectiveness } \\
\text { Analysis }\end{array}$ & $\begin{array}{l}\text { Identifies the most cost-effective } \\
\text { options for a specified objective }\end{array}$ & \\
\hline TLC & $\begin{array}{l}\text { Through-Life } \\
\text { Costing }\end{array}$ & $\begin{array}{l}\text { All costs, including non-monetary } \\
\text { performance }\end{array}$ & $\begin{array}{r}\text { (Settanni, Newnes, } \\
\text { Thenent, Parry, \& } \\
\text { Goh, 2014) }\end{array}$ \\
\hline WLCC & $\begin{array}{l}\text { Whole Life Cycle } \\
\text { Costing }\end{array}$ & All costs in the life cycle & (Datta \& Roy, 2010) \\
\hline CBA & $\begin{array}{l}\text { Cost-Benefit } \\
\text { Analysis }\end{array}$ & $\begin{array}{l}\text { Assesses all costs and benefits } \\
\text { of projects }\end{array}$ & $\begin{array}{r}\text { (Hoogmartens, Van } \\
\text { Passel, Van Acker, } \\
\text { \& Dubois, 2014) }\end{array}$ \\
\hline
\end{tabular}


The goal of LCC is not necessarily to just assess cumulative life cycle costs but to use the method to support the decision-making process about the asset life cycle. As such, LCC can be applied in several ways. (Korpi \& Ala-Risku, 2008) name affordability studies, source selection studies, design trade-offs, repair level analysis, warranty \& repair costs, and supplier sales strategies as potential applications. Oftentimes, LCC is used as a technique aimed at minimizing costs or optimizing performance within certain cost constraints (Barringer \& Weber, 1996; Okano, 2001; Sherif \& Kolarik, 1981). Within optimization aim, LCC is often used in finding and making trade-offs. Depending on the asset, trade-offs can be made on costs in different life cycle stages (see figure 1.2), or between different cost drivers such as finding an optimal balance between maintenance costs and the costs of downtime (see figure 1.3).

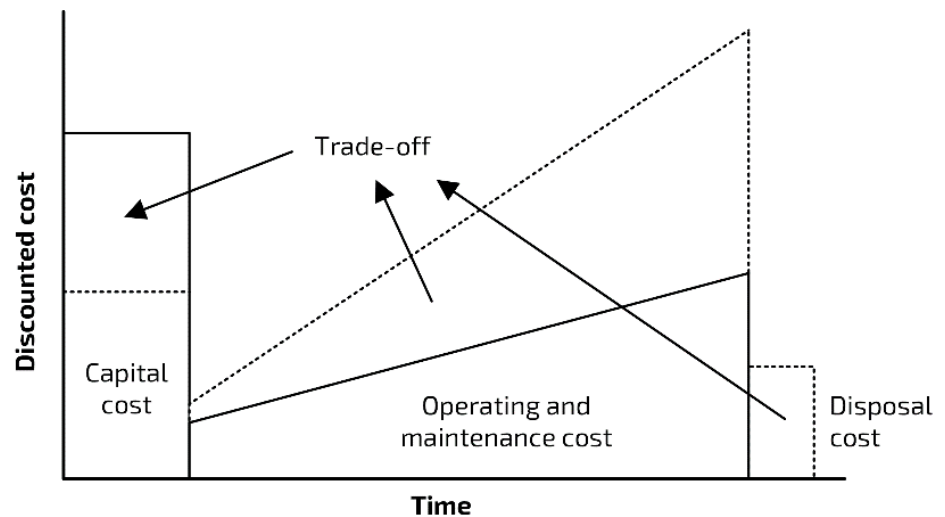

Figure 1.2: Trade-off between cost drivers in different life cycle stages (based on Taylor, 1981)

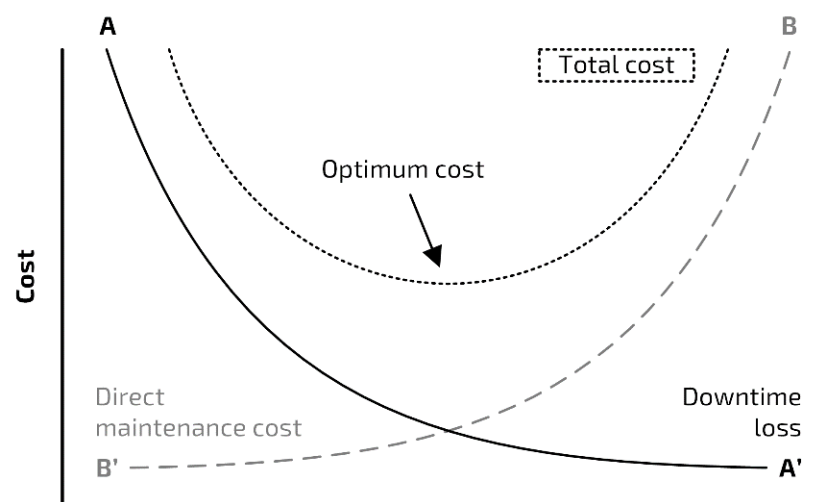

Figure 1.3: Trade-off between maintenance and downtime cost (Woodward, 1997) 
Although LCC has been widely known and discussed for many decades, and despite the apparent advantages of applying it, the method is often not (fully) used in practice (Gray, Helper, \& Osborn, 2020; Higham, Fortune, \& James, 2015). The low adoption rate can be explained by the context-specific nature of LCC, making it difficult for guidelines to fully support all kinds of LCC analyses (Korpi \& Ala-Risku, 2008). The scope of existing LCC approaches in literature can therefore vary greatly between various methodologies and applications, leading to an unsystematic and fragmented LCC landscape (Duran, Roda, \& Macchi, 2016).

An important question in the application of LCC is whose costs will be included. A question with an answer that can range from specific firms or groups to our entire global society (Huppes et al., 2004). As such, the costs in LCC can refer to direct, indirect, intangible, and contingent cost types, as well as external costs borne by other stakeholders or society in general (Cole \& Sterner, 2000; Norris, 2001). Asiedu \& Gu (1998) also state that the LCC of a product is made up of all costs, including the costs borne by the manufacturer, user, and society. The most dominant perspective for LCC, however, is to focus only on the costs directly covered by actors in a product's life cycle, excluding externalities (Kambanou \& Lindahl, 2016). This raises the question from which stakeholder perspective the costs of an asset should be assessed.

A similar scoping challenge exists that concerns the asset system. Many assets are highly interconnected with other assets or are part of a larger, and often complex system. Their value is therefore realized through the combined performance within these systems, such as electricity networks, manufacturing processes, or transport systems (Woodhouse, 2015). To support investment or managerial decisions concerning these complex systems, there is a need for a life cycle cost model able to assume an integrated and systemic focus (Roda \& Garetti, 2014). LCC should therefore not just focus on any singular cost object, but rather on multiple cost objects if they interact simultaneously (Settanni et al., 2014). In practice, however, LCC assessment predominantly deal with one object at a time and assume that all the relevant costs are directly related to that object (Settanni et al., 2014).

LCC relies heavily on the collection of data, which need to be identified, collected, tested, prepared, maintained, stored, and when deemed insufficient, supported by estimations (Kawauchi \& Rausand, 1999). Besides these requirements, decision-makers need quick and accurate estimates of the 
financial consequences of his/her design decisions and procedures to determine optimal design parameters in the life cycle (Asiedu \& Gu, 1998). Not all data, however, is always available or of sufficient quality for LCC (Wenjuan Zhang \& Wang, 2014). Furthermore, the limited availability of the data required for LCC can result in an apparent paradox (Kambanou \& Lindahl, 2016), where a (design) decision needs to be supported by sufficient data, but much of the data can only be obtained after the completion of the design itself. In other words, LCC does not allow answering the question of which costs are attributed to activities in the life cycle, but rather, the application of LCC relies on answering this question beforehand (Settanni et al., 2014).

Because of the long life span and complexity of many assets, dealing with long-term uncertainty remains an important challenge in LCC, even with the support of advanced statistical and probabilistic approaches (Gluch \& Baumann, 2004; Ilg, Scope, Muench, \& Guenther, 2017; Zoeteman, 2001). Especially external uncertainty, concerning factors that lie outside of the direct scope of the asset life cycle itself, is an important factor to consider, even if it is often overlooked in literature (Arja, Sauce, \& Souyri, 2009).

\subsection{Asset Management}

Over the last decennia, industrial maintenance has evolved from a non-issue into a strategic concern (Pintelon \& Parodi-herz, 2008). First, maintenance was seen as something that is mostly reactive (fix it when it breaks) and a necessary evil, into a discipline called maintenance management, which involves optimization models, maintenance techniques, scheduling, and information systems, etc. (Garg \& Deshmukh, 2006). Asset Management (AM) can be seen as another evolution of maintenance management, albeit with a much broader and holistic scope. AM not only involves the entire life cycle of an asset, but also links asset-related activities to organizational strategy (ELAkruti, Dwight, \& Zhang, 2013). The fundamentals of AM have been collected and formalized in the ISO 55000 (2014) series standards on Asset Management, providing a management system for asset-oriented organizations. Implementing AM (as understood under ISO 55000) can have a positive effect on financial, customer, business processes, and learning and growth perspectives, indicating that organizations adopting it will be able to achieve better performance from the effective and efficient management of their assets (Alsyouf, Alsuwaidi, Hamdan, \& Shamsuzzaman, 2018). 
In their respective PhD theses, both Pudney (2010) and Ruitenburg (2017) share a broad definition of Asset Management. They state that AM (1) is a coordinated multidisciplinary practice; (2) concerns the whole life cycle; (3) is aimed at achieving certain objectives; (4) acknowledges risk and asset performance; And (5) determines the allocation of an organizations resources (Pudney, 2010; Ruitenburg, 2017). As such, an important challenge for AM lies in balancing different costs and benefits during decision-making. AM needs to be multidisciplinary because it takes into account technical, economic, compliance, and commercial perspectives. AM, therefore, requires the collection and coordination of both tacit and explicit knowledge of experts related to these perspectives (Ruitenburg, Braaksma, \& van Dongen, 2014). AM involves managing assets over their entire lifecycle, presenting different decision-making challenges and requirements for investment, utilization, maintenance, and renewal/disposal during the different life cycle phases (Woodhouse, 2015). The asset management process should therefore extend from design, procurement, and installation through operation, maintenance, and retirement, i.e., over the complete life cycle (Schuman \& Brent, 2005). AM has multiple objectives and includes balancing multiple asset performance criteria. The realization of value from assets involves balancing financial, environmental, and social costs, risk, quality of service, and performance related to assets (ISO, 2014). AM organizations utilize various performance indicators for aspects such as safety, serviceability, tolerance to damage, cost, sustainability, redundancy, reliability, resilience, risk, robustness, or vulnerability (Frangopol, Saydam, \& Kim, 2012). Furthermore, an organization's objective can be strategic, tactical, or operational in nature, and co-exist alongside other organizational objectives (ISO, 2014; Zhuang \& Janssen, 2015). Strategic AM can be a source of creating sustainable advantages both for competitive and regulated environments when all levels of decision-making are connected (Gavrikova, Volkova, \& Burda, 2020). Strategic AM should therefore not be seen as something independent from asset operations but should involve linking concrete asset-related activities to strategic enterprise objectives (El-Akruti et al., 2013). Where traditional asset-related decision-making focuses predominantly on cost, within AM there is an inherent need to understand the value of infrastructure assets to various stakeholders and to utilize this value to drive decisions (Srinivasan $\&$ Parlikad, 2017). AM is therefore not just about owning or operating assets, but ultimately about creating enduring value. Assets are called assets by virtue of 
their actual or potential value, which can be provided in different ways and over multiple time frames (Woodhouse, 2015). Because AM concerns both the allocation of resources as well as goal oriented asset-related activities, its implementation requires a high degree of alignment, especially between financial and non-financial functions (ISO 55010, 2019). How this alignment can be achieved, and what constitutes this value, will differ between AM organizations and depends on the nature, objectives, and purpose of the organization and the needs and expectations of its stakeholders (ISO, 2014).

\section{Practical Background}

The theoretical background that has been introduced so far already reveals a societal need for research into how the cost and benefits of physical assets can be assessed. Besides the societal relevance of contributing to the academic discussion in this research area, this dissertation also aims to provide research results that can be applied to support the work of Asset Managers and that can be immediately useful in practice. This section, therefore, introduces the practical background of Liander N.V., the company that has sponsored the research project described in this dissertation.

\subsection{Company description}

Liander N.V. is the largest Distribution System Operator (DSO) in the Netherlands. As DSO, Liander is responsible for the distribution of energy, mostly in the form of natural gas and electricity. Liander has approximately 3,1 million electrical grid customers and 2,5 million gas grid customers in 2019 in certain areas of the country (see figure 1.4). Liander has operated under its current name as DSO since 2008 in response to the 2006 Dutch 'Independent Network Management' act that 'unbundled' the management of energy grids from the production or trading in energy. DSOs in the European Union act as 'regulated monopolies' for the distribution of energy, meaning that no other DSO is allowed in a specific area, and can therefore be considered key players in the energy supply chain (Ruester, Schwenen, Batlle, \& Pérez-Arriaga, 2014). As such, Liander is responsible for energy distribution, and the development and care for energy distribution systems. Liander's mission statement indicates multiple objectives for the organization:

"We stand for an energy supply where everyone has access to reliable, affordable, and renewable energy on equal terms." (Alliander, 2020). 
This vision statement includes technical objectives (reliability, availability), financial objectives (affordability), and social and environmental sustainability (equal terms, renewable energy), indicating the multidimensional nature of Liander's objectives. To deal with the aforementioned responsibilities and objectives, Liander has adopted an Asset Management system in its organization, obtaining the PAS 55 (and its Dutch translation NTA 8120) certification in 2008 and the 15055001 certification in 2014.

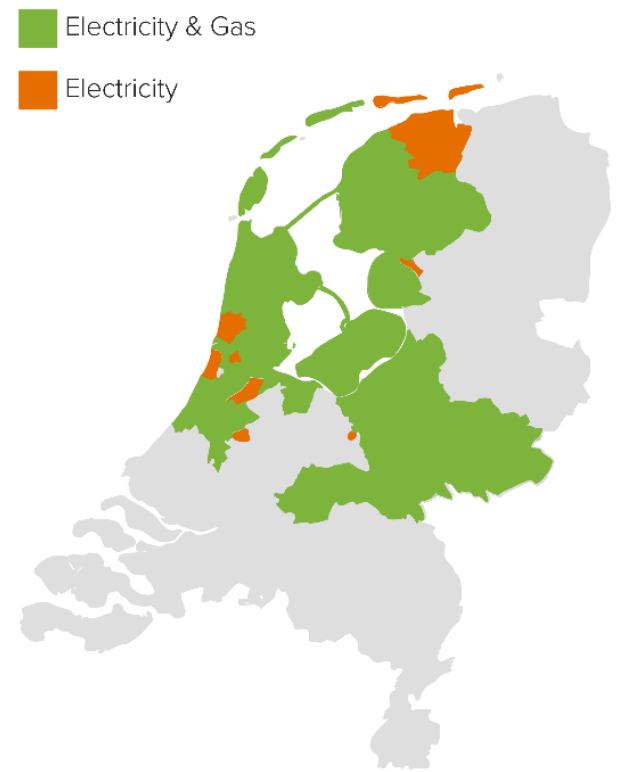

Figure 1.4: Gas and electricity distribution grids of Liander in the Netherlands (Alliander, 2020).

\subsection{Practical challenges in the asset management of energy grids}

As DSO, Liander faces several important challenges in the management of its energy distribution grids. From an operational perspective, there is an ongoing pressure to guarantee that energy is supplied without interruption, that the assets that comprise the energy grids are kept in good condition, and that these assets are operated safely. An important long-term challenge for DSOs is posed by what is commonly referred to as the energy transition. This is "not a single energy transition, but a multitude of more or less interrelated processes of change that occur in different regions, at different speeds and with different synchronicities" (Markard, 2018). In Europe, the energy transition can be characterized by four main aspects: (1) the liberalization of 
the energy sector; (2) the shift towards renewable and more sustainable energy sources (Markard, 2018); (3) the decentralization of energy production; and (4) changes in energy consumption patterns (Verbong \& Geels, 2007). The emerging technological developments within this transition, such as distributed generation, local storage, electric vehicles, and demand response, are driving changes in the design and operation of power systems (Ruester et al., 2014). The energy transition also expresses itself through increasingly higher and intermittent peaks in both energy production and demand, which demands a high degree of flexibility from energy systems (Gallo, SimõesMoreira, Costa, Santos, \& Moutinho dos Santos, 2016). Many assets, however, are designed to last decades in a stable and unchanging operational context and were not originally developed with agility in mind (Ruitenburg, Braaksma, \& van Dongen, 2016).

Liander not only needs to keep up with the developments of the energy transition but also plays a key role to actively support and enable this transition, because of its unique position between the supply and demand side in the energy sector. To ensure cost-effective energy distribution in the present, and to prepare for the energy transition, Liander continuously requires to invest in new assets, for the replacement of existing assets and the development of new energy grids. In the period between the years 2015 and 2019, new asset investments have already risen from $€ 456$ million to $€ 765$ million annually (see figure 1.5) and are expected to continue to rise towards $€ 1500$ million annually in 2030.



Figure 1.5: Annual new asset investment of Alliander (parent company of Liander) (Alliander, 2020). 
As discussed in section 1.1 about LCC, these asset investments only form the tip of the proverbial iceberg of the costs that Liander commits during acquisition. As such, there was increased attention to the life cycle costs of Liander's existing and future assets.

In practice, however, the application of LCC appeared to mirror the challenges found in the existing literature. LCC was used to support some asset-related decisions, but oftentimes these decisions tended to focus only on the acquisition or looked no further ahead than 10 years. This was partially because Liander's Weighted Average Cost of Capital (WACC) was relatively high (approximately between 6\%-10\%) compared to the time this dissertation was written. This meant that investment calculations were heavily weighted towards short-term costs, i.e., those in the first decade. Furthermore, existing LCC models were applied in a fragmented way, each discipline using its own instruments and assessment approaches that were mostly incompatible with each other. The inherent technical complexity of the energy grids themselves also translated into increased complexity in their assessment. Costs were not the only asset performance factor that was deemed important to Liander, but also other aspects such as safety, reliability, sustainability, etc. needed to be taken into account. And lastly, the time, effort, and resources required to perform LCC analyses were seen by many to be a major limitation, requiring too much time, resulting in LCC to be used mainly for supporting the assessment of larger projects. Because of these limitations, Liander was looking for pragmatic ways to support AM decision-making from a life cycle perspective, but that also address the aforementioned limitations of LCC in this application context.

\section{Research motivation}

The challenges experienced by Liander appear to mirror the challenges found in the existing literature, as discussed in the previous two sections. This makes Liander a highly relevant and scientifically interesting environment to research. A conventional LCC focus seems to be inappropriate here, because the problem context calls for a broader AM approach. This leads to several areas where LCC can be at odds with the objectives and requirements of AM.

Firstly, LCC is conventionally aimed at assessing singular objects, whereas AM needs to simultaneously consider individual components, entire asset portfolios of similar asset types, and complex asset systems (ISO 55000, 
2014); This reductionistic approach is not appropriate for systems-oriented assessments (Settanni et al., 2014), especially when asset value is realized through the combined performance within complex systems, such as electricity networks, manufacturing processes or transport systems (Woodhouse, 2015). This challenge is especially felt by DSOs such as Liander in the management of its energy grid.

Secondly, LCC is primarily aimed at assessing costs, as its name suggests. AM, however, calls for a value-oriented approach (ISO 55000, 2014), that accounts for and needs alignment between both financial and non-financial impacts (ISO 55010, 2019). Decisions in this context are not focused solely on cost reduction but can be called value-driven or value-oriented and emphasize balancing multiple objectives in achieving organizational goals (Browning $\&$ Honour, 2008; Gray et al., 2020; Haarman \& Delahay, 2016; Heitz, Goren, \& Sigrist, 2016; Rosqvist, Laakso, \& Reunanen, 2009; Srinivasan \& Parlikad, 2017). An important challenge in assessing value, however, is that the value provided by a system is difficult to quantify as it is largely subjective, and individuals have difficulty articulating exactly what makes a complex system valuable (Browning \& Honour, 2008). For Liander to fulfill its social responsibility as DSO, it needs to be able to demonstrably make decisions that are aimed at creating the most value, against the lowest (societal) costs.

Thirdly, LCC appears to be ill-equipped to deal with the external uncertainties associated with a continuously changing environment, such as that posed by the energy transition. LCC models are essentially predictive in nature and typically include several parameters that are sensitive to uncertainty (Asiedu \& $G u, 1998)$. Despite the significant presence of uncertainties in LCC, the approach was traditionally considered in a deterministic fashion ( $\mathrm{Xu}$ et al., 2012), and almost half of the LCC case studies that were investigated by (Korpi \& Ala-Risku, 2008) remained deterministic. To account for internal risk and uncertainty, probabilistic approaches such as stochastic models and simulation are typically used (Reddy, Kurian, \& Ardakanian, 2015; Wenjuan Zhang \& Wang, 2014). These approaches of dealing with uncertainty, however, are focused on what Arja et al. (2009) classify as internal uncertainty, relating to the internal unpredictability of parameters related to the asset such as failures or wear and tear. Where relatively simple systems can benefit greatly from these types of predictive LCC approaches, the assessment of more complex systems or additional external changes significantly increases the 
difficultly of finding optimal solutions (Herrmann, Kara, \& Thiede, 2011). These external developments can easily defy sensitivity analysis or probabilistic simulation because of the complexity and interrelationships between its causal factors (Fuller \& Petersen, 1996). Existing management literature does discuss strategies to deal with external uncertainties, such as agility (Gunasekaran, 1999; Sharifi \& Zhang, 1999) and resilience (Gay \& Sinha, 2013; Yang, Ng, Xu, Skitmore, \& Zhou, 2019). Little guidance, however, exists on how external uncertainty can be included in LCC assessments (Arja et al., 2009). DSOs like Liander are currently dealing with an extreme kind of external uncertainty in the form of the energy transition, resulting in unpredictable, but considerable socio-technical changes.

In both theory and practice, there is currently a knowledge gap in how valuedriven asset-related decisions can be assessed. Furthermore, there appears to be a need for a methodology that is conceptually similar to LCC, but which is more aligned with the objectives and requirements of $A M$, and which can be tailored to different specific application contexts. The main question that guides the research of the dissertation is therefore formulated as:

"How can the life cycles of physical systems be assessed to support valuedriven decision-making that benefits Asset Management organizations and their relevant stakeholders?"

\section{Methodology}

The research question is cast in the form of a 'how' question. This type of question requires an answer that describes how the world should be, instead of what the world is currently like. In contrast with explanatory research, which is about explaining or predicting something that already exists, this calls for an exploratory research approach that is aimed at creating an artificial phenomenon and solving a pragmatic problem (Holmström, Ketokivi, \& Hameri, 2009). As explained in section 2 of the introduction, this research aims to have a combined practical and theoretical contribution. To achieve these combined goals, a Design Science Research (DSR) strategy is adopted. 


\subsection{Design Science Research strategy}

The design cycles of DSR should not only seek relevance in the practical domain but also requires rigor in the creation of theoretical knowledge (Hevner, 2007). DSR is different from many other applied research areas in this regard because it aims to bridge practice with theory, rather than theory with practice (Holmström et al., 2009), and thus needs to be grounded in both (Wieringa, 2014).

The core research products of DSR are well-tested, well-understood, and well-documented innovative generic designs, that deal with authentic field problems or opportunities (J. van Aken, Chandrasekaran, \& Halman, 2016). These designed products are often referred to as artefacts (or artifacts) in literature (Järvinen, 2007; Peffers et al., 2006; Winter, 2008). The mission of DSR is to develop knowledge for the design and realization of artifacts that help solve problems, or to be used in improving the performance of existing entities (J. E. van Aken, 2004). DSR artifacts can take many forms and can be applied for different purposes. Costa, Soares, $\&$ de Sousa (2020) provide a comprehensive overview of the different types of artifacts that have been recognized in existing literature. These include (1) Conceptual artifacts (constructs, models, methods, and frameworks); (2) Formal logic instructions (algorithms and instantiations); (3) System design, language/notation, guidelines, requirements, patterns, and metrics; (4) Social innovations; (5) New properties of technical, social, or informational resources; (6) Architectures, design principles, and design theories; And (7) Design propositions; (Costa et al., 2020).

DSR is not just about the utilization of scientific knowledge to create these problem-solving artifacts. Instead, it should be regarded as using design as a scientific instrument, following an explicitly organized, rational, and wholly systematic approach (Cross, 2001). The justification of design concerns, not truth, but effectiveness, and goes from answer to question: this is our design (an answer to a design problem), this is how we have tested it in various contexts, and this is how the design solves the problem or satisfies given specifications (J. van Aken et al., 2016). Even though DSR is not a specific method with fixed rules, existing guidelines for conducting and presenting DSR in a rigorous way tend to focus on solving a certain problem, through iterative design cycles, utilizing artifacts designed to certain goals and specifications, which are tested and evaluated in a real-world environment, and ultimately 
result in the creation of new knowledge and artifacts (Denyer, Tranfield, \& Van Aken, 2008; Gregor \& Hevner, 2013; Hevner, 2007; Peffers et al., 2006; J. van Aken et al., 2016; Wieringa, 2014). The outline of how DSR was applied in the research of this dissertation is sketched in figure 1.6.

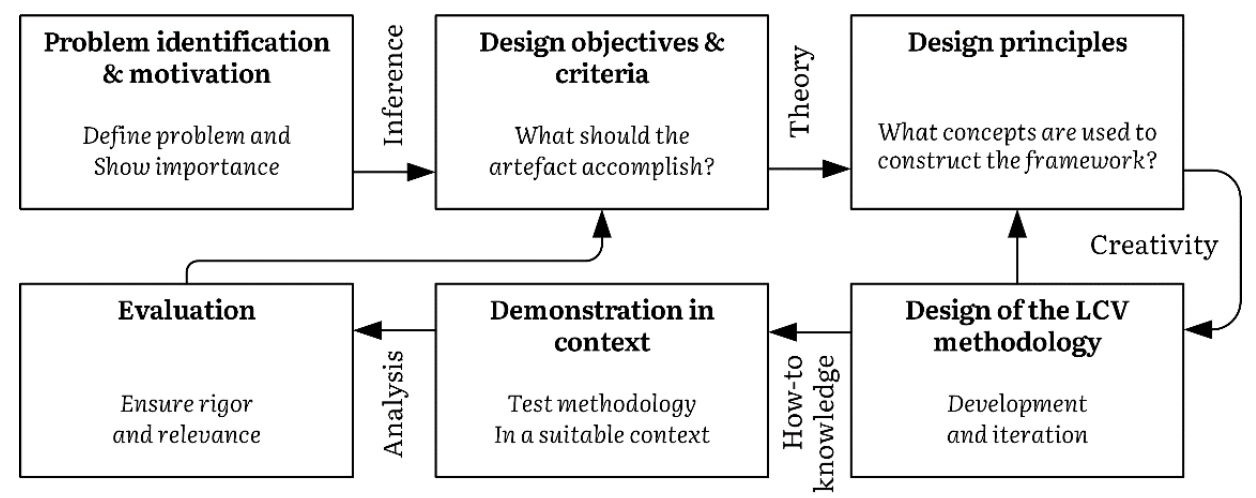

Figure 1.6: Outline of the Design Science Research approach

\subsection{Participatory research implementation and evaluation}

Oftentimes organizational problems are fuzzy, ill-structured, and complex, and to address such problem situations effectively and holistically, researchers need to be in situ (Avison, Davison, \& Malaurent, 2018). To support the implementation and evaluation of the designed artifacts in practice, research strategies from Action Research (AR) are integrated into the DSR process. AR is an orientation to knowledge creation that arises in a context of practice and requires researchers to work with practitioners (Huang, 2010). AR can be seen as similar to DSR, as it involves the intervention of a researcher, that drives change, involves the evaluation of the outcome, in a real-world context, and is aimed at creating knowledge (Järvinen, 2007). livari \& Venable (2009) have a contrasting perspective, indicating that AR and DSR seem similar, but their paradigmatic assumptions, research interests, and activities can differ dramatically, depending on the purpose of research. Crucially, however, AR does overlap with DSR concerning evaluation. As a qualitative and interpretive method, AR activities can be used as appropriate for naturalistic, in situ evaluation of DSR outputs (livari \& Venable, 2009). By intervening through concurrent building and evaluation, researchers are well-positioned to analyze the continuing development of artifacts and the local practices of its use, which can serve as the basis for generalization (Sein, Henfridsson, 
Purao, Rossi, \& Lindgren, 2011). An artifact that can be explained at a high level of abstraction is more easily transferred to other application domains, especially when its design rules are expressed as generalized statements that can be tested (Gregor \& Hevner, 2013). The outcome of the research is therefore not only discussed with respect to the efficacy of the designed artifact but includes a reflection of the underlying design principles and their generalization.

\section{Reading Guide}

In order to join the scientific debate about the research outcome as early as possible, the choice was made to not wait for the PhD dissertation to start publishing and discussing the research outcomes. During the PhD research, a publication strategy was adopted that was aimed at publishing and presenting the core findings of the research in academia by means of conference proceedings and journal publications. As a result of this approach, the dissertation consists of a collection of individual publications that each have a specific, mostly design-oriented, focus.

\subsection{Chapter structure}

Together with the introduction and the conclusion, these publications form the main structure of the dissertation, resulting in a total of eight chapters. Because they are intended for academic publication, chapters 2-7 can also be read as standalone pieces of research. A summary of the content is given at the start of each chapter in the form of an abstract. Each individual chapter is divided into sections (e.g., this text is part of chapter 1, section 5.1). Throughout the dissertation, references to sections that do not specifically mention a chapter number will refer to sections within the same chapter. 


\subsection{Research themes}

Chapters 2-7 of the dissertation cover two main research themes and two AM organizations, Liander and Netherlands Railways (see figure 1.7). Given the design-oriented nature of the research, the first theme focuses on the usefulness of the research, and the role that the assessment of asset life cycles plays in AM decision-making. The second part focuses more on improving the usability of existing and newly developed assessment instruments in practice by making them quicker and easier to apply. Both themes, however, remain centered around the question of how AM organizations can assess the value generated by assets over their entire life cycle to support decision-making. Chapter 8 discusses the synthesis between the two parallel research themes and reflects on the overall design of the LCV methodology and its generalization.



Figure 1.7: Relation between the research themes, chapters, and organizations

\section{Research theme 1 - Assessing the value created by assets over their life cycle}

The first theme is focused on assessing the value created by assets. It contains three chapters that roughly follow the design research process of the main artifact in this dissertation, the design of a methodology called Life Cycle Valuation (LCV). The research within this theme is aimed at linking the broad, long-term, and general themes of AM to decisions about what should be done to or with individual assets, projects, and policies within AM. The main artifact in this design theme (the LCV methodology) was used in a broad range of decision-making contexts within Liander, providing a diverse selection of applications, as indicated in table 1.2. 
Table 1.2: The six main decision-making contexts that were used to test and demonstrate the LCV methodology at Liander

\begin{tabular}{|c|c|c|c|c|}
\hline \multicolumn{2}{|c|}{ Decision context } & \multirow{2}{*}{$\begin{array}{l}\text { Description } \\
\text { Finding optimal placement of fault } \\
\text { detection \& localization components in } \\
\text { electrical grids }\end{array}$} & \multirow{2}{*}{$\begin{array}{l}\text { Asset objects } \\
\text { Local energy grids } \\
\text { (complex system) }\end{array}$} & \multirow{2}{*}{$\begin{array}{c}\text { Life } \\
15 \\
\text { years }\end{array}$} \\
\hline 1 & $\begin{array}{l}\text { Fault } \\
\text { Detection }\end{array}$ & & & \\
\hline 2 & $\begin{array}{l}\text { Ageing } \\
\text { Transformers }\end{array}$ & $\begin{array}{l}\text { Considering revision or replacement } \\
\text { options for aging transformers in a } \\
\text { substation }\end{array}$ & Individual asset(s) & $\begin{array}{c}40 \\
\text { years }\end{array}$ \\
\hline 3 & Substation & $\begin{array}{l}\text { Solving a capacity issue for a substation } \\
\text { and its components by means of } \\
\text { replacement or revision }\end{array}$ & Individual asset(s) & $\begin{array}{c}60 \\
\text { years }\end{array}$ \\
\hline 4 & $\begin{array}{l}\text { Grid } \\
\text { Architecture }\end{array}$ & $\begin{array}{l}\text { Studying significant revision of the } \\
\text { network architecture of the grid in a dense } \\
\text { urban area }\end{array}$ & $\begin{array}{l}\text { Major energy grid } \\
\text { (complex system) }\end{array}$ & $\infty$ \\
\hline 5 & $\begin{array}{l}\text { Demand } \\
\text { Flexibility }\end{array}$ & $\begin{array}{l}\text { Using demand flexibility as a viable option } \\
\text { for solving (temporary) congestion issues }\end{array}$ & $\begin{array}{l}\text { Local energy grids } \\
\text { (complex system) }\end{array}$ & $\begin{array}{c}3-5 \\
\text { years }\end{array}$ \\
\hline 6 & $\begin{array}{l}\text { Switchgear } \\
\text { Procurement }\end{array}$ & $\begin{array}{l}\text { Performing a pilot study on the inclusion } \\
\text { of a streamlined form of LCA in the } \\
\text { procurement of Medium voltage } \\
\text { switchgear }\end{array}$ & Portfolio of assets & $\begin{array}{c}40 \\
\text { years }\end{array}$ \\
\hline
\end{tabular}

\section{Chapter $\mathbf{Z}$ - Asset Management in the Energy Transition: An embedded case} study on Life Cycle Cost-based decision-making in Dutch distribution grids

This chapter explores the research problem of the application of LCC in the decision-making process of Liander $A M$ in the challenging context of the energy transition. It discusses why LCC is a limited tool for this application and it indicates the need for a life cycle-based evaluation approach and its requirements. 
Chapter 3 - Designing a hybrid methodology for the Life Cycle Valuation of capital goods

This chapter discusses the design principles of the Life Cycle Valuation (LCV) methodology and its application in the real-world decision-making context of Liander. LCV is designed based on the premise that the decisions of AM organizations need to consider changing environments, shifts in organizational goals, and continuously changing notions of what makes an asset valuable.

Chapter 4 - Towards Life Cycle Value-driven Asset Management: An action research investigation into value-driven decision-making in an energy transition

This chapter is aimed at the longitudinal evaluation of two artifacts and their long-term effect on how the AM organization of Liander approaches decisionmaking. The first artifact (for Asset Life Cycle Planning) was previously developed in another $\mathrm{PhD}$ research project and is aimed at the early identification of important factors that can affect the asset life cycle. The second artifact that is evaluated is the LCV methodology and its use to support the development of life cycle-oriented measures that address the aforementioned life cycle factors.

\section{Research theme 2 - Improving the usability of life cycle-oriented assessments in AM decision-making}

Compared to the first theme, the second theme assumes a more pragmatic approach, with a focus on making specific life cycle-oriented decisions easier and quicker to use. The topic of integrating and translating the broad paradigm of sustainability alongside other decision-making criteria, such as environmental impact, is used as the main research topic. In this regard, these applications can be seen as self-contained AM challenges, but in a much smaller, and arguably much more manageable, problem context. 
Chapter 5 - Design of a framework for integrating environmentally sustainable design principles and requirements in train modernization projects

This chapter focuses on the inclusion of design-for-environment (DfE) principles in train modernization processes at Netherlands Railways, which is similar to the challenges faced by DSOs. Three key design mechanisms were the early inclusion of DfE in the design process, improving the (perceived) ease-of-use of DfE, and the inclusion of DfE focused design goals and requirements. These three mechanisms enabled decision-makers to leverage the early insight into important lifecycle impacts in the earliest possible design stages, where design solutions are still malleable.

Chapter 6 - Design for sustainable public transportation: LCA-based tooling for guiding early design decisions

This chapter discusses the use of a streamlined Life Cycle Assessment (LCA) tool that can help guide design decisions in the early design phases of a modernization process at Netherlands Railways. The design of the tool allows for an earlier application of LCA in the design process, it can be used under uncertainty, and it requires less expertise compared to conventional LCA applications.

Chapter 7 - Integrating sustainability in asset management decision making: A case study on streamlined life cycle assessment in asset procurement

This chapter demonstrates the development of a streamlining of LCA that can be used in the procurement of new assets. The main design challenge was formed by reducing the complexity and time required for the application of LCA to include it in a public tender. The design shows how the simplification of the inputs and outputs of a full LCA assessment can be used to create a greatly simplified and accessible model that retains a high degree of validity. 


\title{
Chapter 2 - Asset Management in the Energy Transition: An embedded case study on Life Cycle Cost-based decision-making in Dutch distribution grids
}

\begin{abstract}
:
The purpose of this article is to explore Asset Management in the Energy Transition, especially with regard to the applicability of Life Cycle Cost assessment to support decision-making. This is done by formulating five theory-based postulates comparing these with the findings of an in-depth, longitudinal investigation into the application of LCC in AM, as implemented by Dutch Distribution System Operators. This comparison revealed a number of fundamental limitations to the application of the method. DSOs are not only interested in individual asset performance, but also require an understanding of how multiple assets interact to create value, for example from the holistic perspectives of energy grids or asset portfolios. Additionally, DSOs are motivated to evaluate the cost-effectiveness of their decisions with respect to multiple tangible and intangible value factors, whereas LCC typically limited to financial impact only. DSOs need to also consider aspects such as system reliability, safety, sustainability, multiple stakeholder interests, and the merits of operational, tactical and strategic plans to deal with the long-term change and uncertainty caused by the energy transition. The results reveal that for DSOs, the application of LCC in AM is also subject to a number of fundamental limitations, making their practical application increasingly challenging.
\end{abstract}

\section{Publication history:}

This chapter was submitted to the International Journal of Production Research and is under review at the time of writing. 


\section{Introduction}

\subsection{Asset Management}

Physical systems are indispensable in fulfilling societal functions and services such as the production of goods or providing the infrastructure for transporting people, freight and energy. Successfully performing these functions in a sustainable and uncompromised way in terms of safety and availability under ever increasing budget constraints, is a great challenge. This relies on the effective management of individual assets within a system-wide perspective (Rama \& Andrews, 2016). The life cycle cost and profit objectives, and cost structure have a significant influence on the asset strategy and strategic choices (Komonen, Kortelainen, \& Räikkönen, 2012).

Asset Management (AM) has a key role to play in strategy development and implementation by means of planning and controlling asset-related activities (El-Akruti et al., 2013). These activities include the design, commissioning, operation, maintenance, repair, modification, replacement and decommissioning of physical systems. It is common for assets to have their lifespan expressed in decades, rather than years. Moreover, the investments and operational costs required to obtain, maintain and operate these assets are considerable, which requires careful consideration of the total life cycle costs.

AM can be considered 'a multidisciplinary practice that applies human, equipment and financial resources to physical assets over their whole lifecycle to achieve defined asset performance and cost objectives at acceptable levels of risk whilst taking into account the relevant governance, geopolitical, economic, social, demographic and technological regimes' (Pudney, 2010). The ISO 55000 standard established in 2014 provides an overview of asset management, its principles, terminology and the expected benefits from adopting asset management and can be applied to all types of assets and by all types and sizes of organizations (ISO, 2014). AM is not just the operational management of individual assets and how one deals with these, but has a much broader and holistic focus. In 2019, a supplementary guideline for AM was released in the form of the ISO 55010 standard. This guideline enables organizations to better understand why and how alignment between financial and non-financial functions is important in realizing value from assets (ISO, 2019). The aim of this standard is to bridge the gap between 
financial and non-financial spheres in an AM organization. According to the ISO/TC 251 workgroup behind both AM standards, an 'Asset Management focus' concerns the purpose of the entire organization, creation of lasting value, collaboration and dealing with long term change and uncertainty (see Table 2.1). Through the coordinated actions of an organization to realize value from assets, AM organizations address both the actions performed directly on the assets (Managing Assets) and the strategies and plans of the organization to derive value from those assets (Asset Management) (ISO/TC 251, 2017).

The focus difference between the management of assets and AM can be compared with the difference between Systems Engineering (SE) and Systems of Systems Engineering (SoSE). Keating et al. (2015) characterize SE as being aimed at solving single complex system problems in the pursuit of system performance optimization, and distinguishes it from SoSE which focusses on integrating multiple complex systems while satisficing multiple objectives under uncertainty. Furthermore, Keating et al. (2015) add, that from the perspective of SoSE, true optimization is a fallacy because a system must be appropriate to both present and future conditions and needs to evolve based on demands that cannot be anticipated in advance.

Table 2.1: Focus difference between Managing assets and the broader perspective of Asset Management

\begin{tabular}{|c|c|c|c|c|}
\hline Focus & Mindset & Scope & Objective(s) & Attitude \\
\hline $\begin{array}{l}\text { Managing } \\
\text { assets } \\
\text { (narrow) }\end{array}$ & $\begin{array}{l}\text { Activities } \\
\text { performed } \\
\text { directly on } \\
\text { the assets } \\
\text { (action } \\
\text { driven) }\end{array}$ & $\begin{array}{l}\text { Concerning mainly } \\
\text { individual } \\
\text { departments or } \\
\text { functions }\end{array}$ & $\begin{array}{l}\text { Budgets, KPIs, } \\
\text { cost of } \\
\text { maintenance } \\
\text { and current } \\
\text { performance }\end{array}$ & Reactive \\
\hline $\begin{array}{l}\text { Asset } \\
\text { Management } \\
\text { (broad) }\end{array}$ & $\begin{array}{l}\text { Strategies } \\
\text { and plans to } \\
\text { derive value } \\
\text { from assets } \\
\text { (purpose } \\
\text { driven) }\end{array}$ & $\begin{array}{l}\text { Encompassing } \\
\text { many } \\
\text { organizational } \\
\text { levels and } \\
\text { applying to all } \\
\text { functions or } \\
\text { departments }\end{array}$ & $\begin{array}{l}\text { How assets } \\
\text { contribute to } \\
\text { sustainable } \\
\text { stakeholder } \\
\text { value }\end{array}$ & Proactive \\
\hline
\end{tabular}




\subsection{Asset Management in the Energy transition}

The energy transition refers to significant and structural re-orientations in the energy systems that power our world. The main characteristics of this transition in Europe are the liberalization of the energy sector, the shift towards renewable energy sources, decentralization of energy production and changes in energy consumption patterns (Verbong \& Geels, 2007). 'The newly emerging broad range of distributed energy resources, be it distributed generation, local storage, electric vehicles or demand response, are driving changes in power systems' (Ruester et al., 2014). These changes are not just technical in nature, but they also fundamentally change the way society produces and consumes energy, making the energy transition one of the larger socio-technical challenges of our time.

Distribution System Operators (DSOs) are responsible for the management and operation of energy distribution grids, which usually consist of electrical grids, natural gas grids or a combination of both. DSOs are not only responsible for these distribution systems at the grid level, they also need to manage the individual physical assets that comprise these grids, such as transformers, distribution cables and switchgear installations in the case of electrical grids. DSOs have a challenging position in the energy transition, as they are situated between the supply and demand sides of these energy systems. The optimal architecture of distribution networks is no longer characterized as a robust one-way system, but is shifting towards a flexible and adaptable interface between distributed energy producers and consumers. In this context, merely taking care of the assets themselves does not suffice. Therefore, holistic and long-term strategic outlooks are required, the combination of which can be supported by the adoption of Asset Management. The combination of constant investment needs and the long term socio-technical developments of the energy transition requires rational decision making, which can be found in the value based AM approach of ISO 55000 (Förster \& Zdrallek, 2017).

In the broader context of the energy transition, the Asset Management organizations of DSOs represent uniquely extreme examples of why AM is relevant and how it can be applied. The AM departments of DSOs are expected to deliver a continuously safe, reliable and affordable energy system. The consideration of individual components and their relation to the entire grid requires both a system-wide perspective as well as individual asset care. Energy grids and their components typically require considerable investments 
and operational expenses throughout their decades-long lifespans. This necessitates a proactive attitude to managing the asset lifecycle in a complex decision-making environment.

\subsection{Life Cycle Costing}

Cost control from a lifecycle perspective is essential in AM due to the considerable capital investments and operational expenses required to operate and maintain assets. The general concept of taking into account all costs of an asset, throughout its entire lifecycle, is referred to by various terms such as Life Cycle Costing (LCC), Whole Life Costing (WLC), Total Cost of Ownership (TCO), Through Life Costing (TLC) and many more (Durairaj, Ong, Nee, \& Tan, 2002; Gluch \& Baumann, 2004; Huppes et al., 2004). In this article, the term LCC is used to refer to the shared concept behind these terms. LCC is not a new concept, but has existed in various forms for many decades. According to Korpi \& Ala-Risku (2008) LCC was originally designed for procurement purposes, i.e., to be used from the point of view of a client.

Over time, it has developed from a relatively straightforward concept of considering the total costs of a product (instead of only its purchase price), into a diverse range of approaches that rely on this concept. As indicated in table 2.2, LCC gradually developed from a 'total cost of ownership' figure, into analysis techniques, optimization approaches, management methods and cost control systems. Recently, Kambanou \& Lindahl (2016) highlighted the importance and widespread use of LCC in Product Service Systems (PSS) as a tool to provide decision makers, designers and stakeholders with relevant financial information. For the purposes of this article, we regard LCC as having three core features that are shared by most LCC approaches. (1) It covers the entire lifecycle of an asset or product (from its inception to the end of its life).

(2) It is concerned with all costs incurred during or because of that lifecycle. And (3) It analyses what is expected to happen or which choices are desirable with respect to these costs. 
Table 2.2: Descriptions of Life Cycle Costing

Reference Description of LCC

White \& Ostwald 'The sum of all funds expended in support of the item from its (1976) conception and fabrication through its operation to the end of its useful life.'

Sherif \& Kolarik (1981)

'An analysis technique which encompasses all costs associated with a product from its inception to its disposal.'

Woodward

'Optimizing the cost of acquiring, owning and operating (1997) physical assets over their useful lives by identifying and quantifying all significant costs involved in that life.'

Rebitzer \& Hunkeler (2003)

'Not a method for financial accounting. Rather, it is a cost management method with the goal of estimating the costs associated with the existence of a product.'

Huppes et al. (2004)

'A method of calculating the total cost of a product induced throughout its life cycle, belonging to the group of the life cycle approaches.'

Duran, Roda, \& Macchi (2016)
'A managerial system that is focused on the modelling, quantification and control of all the costs that are present during the design and operation stages which ends with its disposal of a physical asset.'

At a glance, LCC appears to be well suited to supporting AM decision-making, given the recognition of the entire lifecycle, financial \& non-financial factors and the management $\&$ control of an asset's costs. 'The value of LCC as a management tool is ... incontrovertible because it places a premium on the best use of resources - financial, technical and manpower - to the benefit of the organization. It is an essential ingredient in medium and long-term planning because it aims to ensure the optimum value from the use of capital assets' (Taylor, 1981). Cole \& Sterner (2000) reveal that despite its usefulness, LCC is not commonly used in building design, citing lack of user motivation, contextual factors, methodological limitations and data restrictions. Ferrin $\&$ Plank (2002) conclude their survey on LCC by stating that LCC valuation is a difficult process, but that it is likely to be worthwhile to firms that apply it well. 


\subsection{Aim and focus}

This research aims to better understand the applicability of LCC as a decisionmaking instrument for organizations that adopt an Asset Management focus. The purpose of this article is to explore to what extent the principles behind LCC remain valid when applied in challenging AM decision-making contexts, such as those encountered by a DSO during the energy transition. This is done by examining whether a number of common assumptions about, and descriptions of LCC found in literature can be supported by empirical evidence, allowing for insights from both theoretical and practical perspectives. The approach used in this article consists of the combination of postulates and case study methodologies.

This article is structured as follows; it starts with an explanation of the methodology in section 2 . In section 3, the design and description of our embedded case study is presented. Sections 4 - 8 consist of the formulation and discussion of five postulates that are based on the main descriptions of, and assumptions about LCC in literature. The article concludes with section 9, which provides a summary and discussion of the findings as well as the implications for both theory and practice.

\section{Methodology: Case study and postulates}

The methodology that is adapted in this article consists of applying postulates within a case study research. Case studies are the preferred strategy when 'how' or 'why' questions are being posed. The use of case studies allows for an investigation into how to retain the holistic and meaningful characteristics of real-life events including individual lifecycles, organizational \& managerial processes and the maturation of industries (Yin, 2003). Furthermore, case studies represent an effective research strategy for the exploratory research in this study as it investigates a contemporary phenomenon within its real-life context, especially when the boundaries between the object of study and its context are not clearly evident (Dul \& Hak, 2008).

The approach of applying postulates within a case study methodology is similar to that of Meredith (1987). This article translates the themes outlined in the introduction into postulates. These postulates are subsequently either refuted, qualified or elaborated on, based on the empirical findings from the case study. Following the example set by Veldman et al. (2011), each postulate is derived from a focused review of the relevant literature related to its 
respective theme. And lastly, following the approach of Braaksma et al. (2013), the postulates are structured according to an existing and well-established framework.

However, in a review of published case studies, Korpi \& Ala-Risku (2008) found that despite a long history of its application, a shortage of standards and formal procedures exists for LCC. As indicated in section 1.3 application of LCC is also considered to be quite challenging. The postulates in this paper are therefore structured in accordance with the ISO 14040 standard (ISO, 2006a) which provides a clear and standardized framework for the main steps applied in the assessment of life cycles (see figure 2.1). Even though this framework was originally intended for the assessment of environmental impacts, its main structure also applies to the assessment of LCC (Bierer, Meynerts, \& Götze, 2013; Heijungs, Settanni, \& Guinée, 2013; Rebitzer, Hunkeler, \& Jolliep, 2003; Swarr et al., 2011).



Figure 2.1: Main steps of the ISO 14040 framework (ISO, 2006a) and the positioning of the postulates.

\section{Embedded case study design}

\subsection{Procedure}

In case study research, data collection procedures are not routinized, increasing the reliance on a well-defined procedure as well as the skills of the researcher (Yin, 2003). Yin also emphasizes that the researcher requires an inquiring mind during data collection and needs to pose good questions in order to reach the desired result: establishing a rich dialogue with the evidence. To support this process, the main author was embedded within the 
case company, and was included in multiple decision-making processes (see table 2.4 - Researcher involvement column). The authors recognize that by posing the case study questions (Appendix) the researcher is actively affecting the process of decision-making itself, likely altering the subject of study. However, this approach also allows the researcher to more closely study the phenomenon in its real-world context. In this regard, this aspect of our approach resembles Action Research, where the researcher is immersed in the setting and whose actions are purposefully participative (Coughlan $\&$ Coghlan, 2002). In order to address the potential downsides of this participatory approach, several measures were taken to ensure the rigor of our case study design, as proposed by Gibbert et al. (2008) (table 2.3).

Table 2.3: Ensuring validity and reliability of the case study

\begin{tabular}{ll} 
Criterion & Implementation \\
\hline Internal validity & $\begin{array}{l}\text { Research framework, pattern matching using } \\
\text { postulates }\end{array}$ \\
\hline Construct & Participatory observation by researcher, involvement \\
validity & of multiple participants, multiple documents, follow- \\
& up discussions with participants, validation by \\
& participant \\
\hline External validity & $\begin{array}{l}\text { Selection of case studies with various goals, scopes } \\
\text { and asset types, } \\
\text { (generalization) }\end{array}$ \\
& $\begin{array}{l}\text { authors' expert opinions on uniqueness of case } \\
\text { subjects }\end{array}$ \\
\hline Reliability & Structured case study protocol, fixed case study \\
& questions \\
\hline
\end{tabular}

\subsection{Case context - Electricity distribution in the Netherlands}

In the Netherlands, several parties are responsible for the distribution of energy. DSOs are semi-public enterprises that are owned by shareholders comprised of various provinces and municipalities and are funded by their inhabitants. In Europe, DSOs are generally natural monopolies, overseen by energy regulators to ensure that they provide value for money to consumers. As all Dutch DSOs operate under the same legislation, use similar assets and operate in comparable regions, a single large DSO can be regarded as a representative example of how energy distribution systems are operated and managed in the country. 
Case company Liander serves approximately 3.1 million electrical grid customers, making it the largest DSO in the country. Liander has adopted the AM system in its organization, obtaining the ISO 55001 certification in 2014. A high degree of transparency and accountability is expected of Liander given its semi-public source of funding and critical role in the energy sector. Given the long lifespan and considerable Total Cost of Ownership (TCO) of its assets, the investment board of Liander expects project proposals to include an assessment based on life cycle costs, allowing for a better insight into the finances committed in the short, medium and long term.

\subsection{Sample selection}

The research approach presented in this article adopts a single case study design using multiple embedded units of analysis. The main concern of the case study is the utilization of Life Cycle Cost assessment in the decision making of an Asset Management organization in the energy transition. Our rationale for adopting a this case study design is twofold, as recognized by Yin (2003): Firstly, it is suited for a longitudinal study, allowing for an in-depth investigation of multiple LCC applications, from beginning to end. Secondly, it is suitable for studying extreme or unique cases, which is appropriate given the ongoing development of AM principles and the unique challenges faced by the case company during the energy transition (see section 1.2). The multiple embedded units of analysis within the case study consist of individual decision-making cases were LCC was used as the primary decision-making instrument. To ensure that the case studies were aligned with the aim identified in section 1.4, the cases were selected using the following criteria:

1. The unit of analysis consists of a decision-making context affecting the physical assets managed by an AM organization.

2. The assets being studied have a long enough lifespan to require some form of forecasting or life cycle planning.

3. The unit of analysis should concern decision-making with considerable financial impact for the organization.

4. To provide a diverse sample of practical applications to study and discuss and to improve external validity, the selected cases cover examples from a range of decision objectives, scopes and asset types. 
Our sample consists of eight instances where LCC was used to support AM decision-making at the case company. Table 2.4 provides a description and overview of our case samples. The research presented in this article took place in the period between early 2016 and late 2019.

Table 2.4: Selected units of analysis at the case company

(continues on next page $\rightarrow$ )

\begin{tabular}{|c|c|c|c|c|}
\hline & Case sample & Description & Subject & $\begin{array}{c}\text { Assessment } \\
\text { time frame }\end{array}$ \\
\hline 1 & $\begin{array}{l}\text { Circuit } \\
\text { Breakers }\end{array}$ & $\begin{array}{l}\text { Determining optimal replacement } \\
\text { moment for each circuit breaker in } \\
\text { the asset portfolio }\end{array}$ & $\begin{array}{l}\text { Portfolio of } \\
\text { assets }\end{array}$ & 40 years \\
\hline 2 & $\begin{array}{c}\text { Fault } \\
\text { Detection }\end{array}$ & $\begin{array}{l}\text { Finding optimal placement of fault } \\
\text { detection \& localization components } \\
\text { in electrical grids }\end{array}$ & $\begin{array}{l}\text { Local energy } \\
\text { grids } \\
\text { (system of } \\
\text { assets) }\end{array}$ & 15 years \\
\hline 3 & $\begin{array}{c}\text { Ageing } \\
\text { Transformers }\end{array}$ & $\begin{array}{c}\text { Considering revision or replacement } \\
\text { options for ageing transformers in a } \\
\text { substation }\end{array}$ & $\begin{array}{l}\text { Individual } \\
\text { asset(s) }\end{array}$ & 40 years \\
\hline 4 & Substation & $\begin{array}{l}\text { Solving capacity issue for a } \\
\text { substation and its components by } \\
\text { means of replacement or revision }\end{array}$ & $\begin{array}{l}\text { Individual } \\
\text { asset(s) }\end{array}$ & 60 years \\
\hline 5 & $\begin{array}{c}\text { Grid } \\
\text { Architecture }\end{array}$ & $\begin{array}{l}\text { Study on significantly revising the } \\
\text { network architecture of the grid in a } \\
\text { dense urban area }\end{array}$ & $\begin{array}{l}\text { Major energy } \\
\text { grid (system of } \\
\text { assets) }\end{array}$ & Continuous \\
\hline 6 & $\begin{array}{l}\text { Demand } \\
\text { Flexibility }\end{array}$ & $\begin{array}{l}\text { Using demand flexibility as a viable } \\
\text { option for solving (temporary) } \\
\text { congestion issues }\end{array}$ & $\begin{array}{l}\text { Local energy } \\
\text { grids (system } \\
\text { of assets) }\end{array}$ & $3-5$ years \\
\hline 7 & Grid losses & $\begin{array}{l}\text { Creating policy standards for } \\
\text { calculating and reducing the costs of } \\
\text { grid losses, supporting business } \\
\text { cases }\end{array}$ & $\begin{array}{l}\text { Portfolio of } \\
\text { assets \& } \\
\text { Energy grids } \\
\text { (system of } \\
\text { assets) } \\
\end{array}$ & Continuous \\
\hline 8 & $\begin{array}{l}\text { Switchgear } \\
\text { Procurement }\end{array}$ & $\begin{array}{l}\text { Pilot study on including a } \\
\text { streamlined form of LCA in the } \\
\text { procurement of Medium voltage } \\
\text { switchgear }\end{array}$ & $\begin{array}{l}\text { Portfolio of } \\
\text { assets }\end{array}$ & 40 years \\
\hline
\end{tabular}


Table 2.4: Selected units of analysis at the case company

$$
\text { ( } \leftarrow \text { continued from previous page) }
$$

Dominant value factors Scope change? $\begin{gathered}\text { Implementation } \\ \text { in organization }\end{gathered} \begin{gathered}\text { AM team } \\ \text { composition }\end{gathered} \quad \begin{gathered}\text { Researcher } \\ \text { involvement }\end{gathered}$

$1 \begin{gathered}\text { OPEX, CAPEX, Remaining } \\ \text { Useful Life, Outage risk }\end{gathered}$ no $\quad \begin{gathered}\text { Optimization tool } \\ \text { (proof-of-concept) }\end{gathered} \begin{gathered}\text { Mono- } \\ \text { disciplinary }\end{gathered}$ Observative

\begin{tabular}{|c|c|c|c|c|c|}
\hline 2 & $\begin{array}{l}\text { OPEX, CAPEX, Remaining } \\
\text { Useful Life, Outage risk }\end{array}$ & no & $\begin{array}{l}\text { Implemented } \\
\text { optimization tool }\end{array}$ & $\begin{array}{l}\text { Multi- } \\
\text { disciplinary }\end{array}$ & Participative \\
\hline 3 & $\begin{array}{c}\text { Major investments } \\
\text { (CAPEX) } \\
\text { Transformation losses } \\
\text { (OPEX) }\end{array}$ & no & $\begin{array}{l}\text { Approved } \\
\text { investment } \\
\text { decision }\end{array}$ & $\begin{array}{l}\text { Mono- } \\
\text { disciplinary }\end{array}$ & Observative \\
\hline 4 & $\begin{array}{c}\text { CAPEX, Transformation } \\
\text { losses (OPEX) }\end{array}$ & $\begin{array}{l}\text { Yes } \\
\text { (enlarged } \\
\text { scope) }\end{array}$ & $\begin{array}{l}\text { New assessment } \\
\text { with larger scope } \\
\text { (no. 5) }\end{array}$ & $\begin{array}{l}\text { Multi- } \\
\text { disciplinary }\end{array}$ & Participative \\
\hline 5 & $\begin{array}{c}\text { CAPEX, Transformation } \\
\text { losses (OPEX) }\end{array}$ & $\begin{array}{c}\text { Yes } \\
\text { (time frame) }\end{array}$ & $\begin{array}{c}\text { Investment } \\
\text { decision postponed }\end{array}$ & $\begin{array}{l}\text { Multi- } \\
\text { disciplinary }\end{array}$ & Participative \\
\hline 6 & $\begin{array}{c}\text { Conventional capacity } \\
\text { expansion (CAPEX), } \\
\text { demand flexibility (OPEX), } \\
\text { Societal cost of transport } \\
\text { restrictions } \\
\end{array}$ & $\begin{array}{c}\text { yes } \\
\text { (multiple } \\
\text { subsequent } \\
\text { cases) }\end{array}$ & $\begin{array}{l}\text { New decision- } \\
\text { making processes }\end{array}$ & $\begin{array}{l}\text { Multi- } \\
\text { disciplinary }\end{array}$ & Participative \\
\hline 7 & $\begin{array}{l}\text { Transformation losses } \\
\text { (OPEX) }\end{array}$ & $\begin{array}{c}\text { yes } \\
\text { (externalities) }\end{array}$ & $\begin{array}{l}\text { Formal } \\
\text { implementation } \\
\text { pending }\end{array}$ & $\begin{array}{l}\text { Multi- } \\
\text { disciplinary }\end{array}$ & Participative \\
\hline 8 & $\begin{array}{l}\text { CAPEX, OPEX, RAMS, } \\
\text { Environmental impact } \\
\quad \text { (externalities) }\end{array}$ & $\begin{array}{c}\text { Yes } \\
\text { (value factors) }\end{array}$ & $\begin{array}{l}\text { New procurement } \\
\text { format } \\
\text { (proof-of- } \\
\text { concept) }\end{array}$ & $\begin{array}{l}\text { Multi- } \\
\text { disciplinary }\end{array}$ & Participative \\
\hline
\end{tabular}




\section{Goal Definition}

\subsection{Postulate formulation}

Life Cycle Costing can be used for a wide range of different purposes (Korpi $\&$ Ala-Risku, 2008) and products, including different facets of that product (Asiedu \& Gu, 1998). The general applicability of LCC does not mean that every application follows the same approach. Ferrin \& Plank (2002) indicate that a standard model for LCC is almost never appropriate, but that different models are required to suit specific applications.

An important initial step for analyzing LCC is therefore the classification of the analysis objectives and the bounding of the problem so that it can be studied in an efficient and timely manner (Asiedu \& Gu, 1998). Though the objectives of existing LCC models vary, their goal is the same, they intend to reduce the total cost of a product, or a system, or an asset, or human factors, such as labor (Durairaj et al., 2002). This notion is captured in the first postulate:

\section{Postulate 1}

Life Cycle Cost models are aimed at reducing the total costs of individual asset lifecycles

\subsection{Results}

The selection of LCC as an instrument was deemed appropriate by the case company and researchers, given the dominance of capital \& operational expenditures combined with long lifespans. Our findings also show that there was indeed a need for a wide variety of LCC approaches in order to achieve specific objectives, even within the boundaries of a single AM organization (see table 2.4). The cases varied from calculating optima (case 1 \& 2 ), replacement decisions (case 3 \& 4 ), grid engineering (case 5 \& 6), policy development (case 7) to procurement (case 8). This observation is in line with existing literature. 'Whatever the characteristics may be of specific applications and the procedures involved in them, the analytical support by LCC clearly has to cover quite different situations' (Huppes et al., 2004). Even though some industry-specific standards exist, LCC cannot be called a uniform concept or framework, as many different approaches are used, which differ in goal, scope and methodology (Rebitzer \& Hunkeler, 2003). 
In our sample, the goal was not necessarily only the reduction of the total cost of an individual asset. All but two of our samples concerned energy grids and portfolios of assets, in line with the principles of AM: 'An organization may choose to manage its assets as a group, rather than individually, according to its needs, and to achieve additional benefits. Such groupings of assets may be by asset types, asset systems, or asset portfolios' (ISO, 2014). In our samples, technical performance factors such as outage risk or grid losses occur at the grid level, policy decisions affect the asset portfolio level and financial commitments are made at the individual asset level.

Furthermore, the asset managers are not necessarily tasked with finding the solution with the absolute lowest cost. Instead, they are expected to find solutions that strike a balance between the reliability, availability, maintainability, safety and sustainability of the grid alongside favorable life cycle costs. Therefore, the reduction of costs is not the only goal of LCC assessments. Instead, LCC is also applied as an instrument for assessing the extent of alignment between financial and non-financial factors in decisionmaking. This seems to suggest that LCC is indeed a management-oriented decision-support instrument, rather than a purely financial optimization instrument. These findings align with those of Roda \& Garetti (2014), who state that 'in order to support managerial decisions, LCC models also need to assume a similarly integrated and systemic focus as AM'.

\section{Scope Definition}

\subsection{Postulate formulation}

It is evident that LCC has developed more as a result of specific applications rather than because of hypothetical models (Sherif \& Kolarik, 1981). However, the objective of LCC on its own, is not enough to sufficiently motivate what is included in the assessment. As LCC is always tailored to its intended use, it can be seen as a reflection of its cost object, scope and boundaries (Kambanou $\&$ Lindahl, 2016). The goals and scopes of LCC assessments are mutually interrelated, as changes in the goal need to be reflected in the scope and changes in the scope may be incompatible with the stated goal. This interdependence necessitates careful consideration of the scope, and given the quantitative nature of LCC, it also requires a distinction to be made between what is included in the assessment and what is not. 'The definition of boundaries and scope of the analysis draws a distinction between what is 
exogenous and what is endogenous to the delivery system and clarifies the level of granularity in examining what happens within those boundaries' (Settanni et al., 2014). In this regard, choices need to be made about what to include in LCC assessments and to what level of detail it is to be included. This leads to the second postulate:

\section{Postulate 2}

LCC assessments are subject to limitations with respect to scope and level-ofdetail

\subsection{Results}

In the sample concerning a capacity issue at a substation (case 4), it became apparent that the replacement decision would have significant implications for the feasibility of future plans for the entire distribution grid the transformers are part of. Initially, the system boundary only included the small number of assets in the substation itself, but it was quickly expanded to also include the additional consequences for future grid architecture plans. This scope expansion was large enough to result in the commissioning of a new assessment of the surrounding grid architecture (case 5) that, in principle, served the same objective as case 4, but with a much broader system boundary and lower level-of-detail. Furthermore, this expanded scope also required additional assessment effort and resources.

Scoping challenges with respect to the time horizon presented themselves in the 'demand flexibility' assessments (case 6). In these case studies, temporary solutions were compared to more conventional immediate solutions of buying and operating new assets. In choosing a fair assessment timeframe, multiple options were considered. Past lifecycle costs were considered sunk costs and therefore irrelevant to future decisions, resulting in the preference for starting the timeframe in the present. For determining the final year of the assessment, the decision was made to base this on the final year of the temporary measures, and their lifespan-extending effects on the existing assets. Within this timeframe, the option to immediately replace an asset would be cut off after only a couple of years, resulting in an unfair comparison. To negate this, the option for immediate replacement was allocated annual equivalent costs for the years within the time scope. This annual equivalent cost was based on the total cost of ownership of the new asset. Furthermore, this also meant that 
the time frames of the 'demand flexibility' cases spanned only 3 to 5 years, whereas other LCC assessments spanned multiple decades. These findings confirm a statement from the ISO 55000 principles: 'The balancing of costs, opportunities and risks against the desired performance of assets, to achieve the organizational objectives, might need to be considered over different time frames' (ISO, 2014).

The empirical findings suggest that arriving at a suitable assessment scope is not necessarily as self-evident as that of a 'cradle to grave' assessment for an individual asset. In AM practice, different scopes may need to be actively discussed and motivated as part of the decision-making process, taking care to align the scope with the intended objective of the assessment.

\section{Inventory analysis}

\subsection{Postulate formulation}

According to the ISO 14040 standards, inventory analysis involves data collection, calculation and allocation procedures to quantify relevant inputs and outputs of a product system (ISO, 2006a). For LCC, this means that performing an inventory analysis involves the development of cost models. Cost Breakdown Structures (Fabrycky \& Blanchard, 1991) can be used to systematically identify and summarize a model's cost elements. Costing methods such as Activity Based Costing (Emblemsvåg, 2003) assign costs to specific activities in the lifecycle, thus making it possible to trace the origin of LCC to specific activities in that lifecycle. Depending on the expected level of detail and stage of the analysis, LCC may depend on the use of cost estimation, as the available data is often limited (Asiedu \& Gu, 1998). Cost estimation requires a high degree of judgement, placing importance on the experience and expertise of the estimator (Korpi \& Ala-Risku, 2008). The third postulate is defined as:

\section{Postulate 3}

Life cycle inventories require data collection and good judgement in cost estimation 


\subsection{Results}

The cost model of the circuit breakers (case 1), was created using the data of an earlier (non-LCC) study on the condition of the current population, making this the only data-driven sample in our research. However, the other cases lacked sufficient data at the start of the LCC assessment and required a process of inventory. In order to build a model of the lifecycle, data and knowledge about different aspects of that lifecycle needed to be collected and integrated. All but two of the cases required the involvement of individuals from multiple disciplines, such as cost engineers, grid planners, operations managers and various asset specialists.

For the ageing transformers (case 3), an LCC specialist was asked to perform the LCC assessment, including the inventory process. As part of the inventory process, the relevant asset managers were extensively consulted, and their data and assumptions were consolidated into a single LCC model. When this model was used to support an investment decision, assumptions in the inventory were challenged by some of the reviewers, to the point of calling into question the entire LCC assessment. Only after the confidence in these judgements was restored by elaborating on the LCC assessment, did the board accept the investment proposal.

Based on the empirical findings in this study, the collected data was generally not directly applicable to the assessment. Some issues were found concerning missing or old data, and the authors also encountered issues with conflicting information from different sources and datasets that were too large or detailed. In all of these cases, the judgments of the respective asset managers were used to make informed assumptions.

Simpson, Lamb, Finch, \& Dinnie (2000) indicate that decision makers often lack the confidence to base the outcome of their decisions solely on the outcome of quantitative analyses, and instead rely on additional influences such as habit, instinct, intuition or imitation for their judgements. The ageing transformers case demonstrated that the process of inventory not only relies on data collection and assumptions, but that it also requires a process of building support and trust that the model sufficiently reflects the asset lifecycle being studied. The importance of building support also aligns with the findings of Settanni et al. (2014), who stress the importance of developing and demonstrating a through-life cost consciousness as the basis for decision making, which is understood as a fundamental understanding of the 
functioning of the system being modelled. These findings appear to confirm the third postulate, with the added observation that data collection and good judgement are not only required, but also appear to be both interdependent and complementary.

\section{Impact Assessment}

\subsection{Postulate formulation}

By informing different kinds of actors through the 'language of money', LCC can be seen as a powerful communication instrument (Roda \& Garetti, 2014). A common characteristic of LCC is that it applies to the lifecycle of one particular object, and that it is aimed at addressing the financial impact, usually for one stakeholder (see table 2.2). However, not all LCC approaches take this financial perspective. Various Life Cycle Cost assessment approaches have been introduced that focus on different types of cost impact, most notably dealing with either financial, environmental or social concerns (Hoogmartens et al., 2014). Rebitzer \& Hunkeler (2003) imply that financial LCC without additional assessment cannot serve as a sole indicator for good (sustainable) Life Cycle Management practice, unless there is a validated correlation between low life cycle costs and low environmental and social impacts. In order to create maximum value from physical assets, it is essential to consider not only technical and economic aspects, but to also consider commercial, compliance and organizational lifecycle perspectives (Gluch \& Baumann, 2004; Ruitenburg \& Braaksma, 2017). The ISO 55000 standard for AM (ISO, 2014) also states that the objective of AM is not necessarily to improve financial impact, but to create sustained stakeholder value: 'Assets exist to provide value to the organization and its stakeholders'. The impact assessment phase is aimed at evaluating the significance of potential impacts using the Life Cycle Inventory results (ISO, 2006a). This results in the fourth postulate:

\section{Postulate 4}

The outcome of LCC assessments sufficiently captures the creation of stakeholder value 


\subsection{Results}

In their decision making, asset managers need to strike a balance between the life cycle costs of an asset and the resulting asset performance. Within the AM organization of Liander, risk mitigation policies exist concerning how to measure and appreciate asset performance factors such as availability, reliability, dependability, safety and environmental impact of its assets. These policies indicate how much the AM organization is willing to spend to mitigate risk or improve its asset performance. As such, this policy was used in all LCC assessments in this article in order to express various asset performances in monetary terms.

Given the public function and funding of energy grids, Liander's expenses can be considered to be social costs as they are ultimately borne by the people using the energy grid. In the eyes of some asset managers, the total life cycle cost impact for Liander did not fully reflect the full extent of stakeholder value creation.

For example, as part of the policy for Grid losses (case 7), Liander is required to financially compensate any energy losses that occur in their energy distribution networks. In addition to financial impact, Liander also aims to reduce its greenhouse gas (GHG) emissions, most of which occur due to grid losses. To compensate for this negative externality, Liander's grid loss policy includes not only the cost to the AM organization itself, but also the environmental cost of GHG emissions. This stimulates asset managers to invest more in grid loss reduction than before, when only financial impact was considered.

Another example of stakeholder value presented itself in the LCC assessments concerning 'demand flexibility' (case 6 ). In this case, rapidly developing local congestion issues, coupled with the multi-year timeframe for developing and implementing permanent solutions, and the obligation to connect new clients within 18 weeks, led Liander to consider issuing transport restrictions. This means that new commercial clients are physically connected to the grid, but can be temporarily restricted in the amount of power they are allowed to draw from it. Liander was allowed to implement these measures within the boundaries of existing regulations and without the need to financially compensate their clients. Initially, some AM employees regarded the compulsory measures of transport restrictions as a cost-effective option in order for the organization to deal with congestion issues. However, this option 
also creates a significant social impact, as local commercial clients could be negatively affected by these restrictions. As a result, Liander's asset managers are now considering the use of 'demand flexibility' (further explained in 0) in cases where their customers are significantly disadvantaged. Rather than imposing compulsory transport restrictions, Liander chose to take its social responsibility by developing its capabilities in applying non-compulsory demand flexibility, despite being more costly to the organization than transport restrictions.

The results indicate that in the AM practice of Liander, the Life Cycle Costs of the assets are not just evaluated to improve its own bottom line, but these are also used to actively control and balance the trade-off between costs, asset performance and even the impact on other stakeholders (see table 2.4 Dominant Value factors column). Srinivasan \& Parlikad (2017) state that "traditional asset management decisions focused predominantly on cost, and there is an inherent need to understand the value of an infrastructure asset to various stakeholders and to utilize this value to drive AM decisions". As the creation of stakeholder value depends on balancing different goals, the notion of rational decision-making is also being challenged. Judgements about the relative importance of these value factors need to be made explicit and accepted throughout the organization in order for the outcome to be accepted. In conclusion, this means that LCC assessments do not necessarily or sufficiently capture the creation of stakeholder value unless there is an agreed upon judgement about this value in place.

\section{Interpretation}

\subsection{Postulate formulation}

'Interpretation' summarizes and discusses the results of the study as the basis for conclusions, recommendations and decision making (ISO, 2006a). There are multiple reasons for not preferring the option with the lowest life cycle costs. The first reason is that infrastructure assets tend to have various interdependencies among themselves that need to be taken into account (Srinivasan \& Parlikad, 2017). Given the limited scope of LCC, these cannot always reasonably be part of all assessments (see postulate 2 ). The second reason, and as discussed in postulate 4 , is that stakeholder value is rarely limited to financial impact alone but also relies on other types of quantifiable impact as well as less tangible value factors. When dealing with alternatives 
that can only be compared using multiple characteristics, identifying which option is preferred, in a well-defined manner, becomes a major issue (Mardani et al., 2015). Therefore, a crucial part of the interpretation phase is to establish to what extent value creation is sufficiently evaluated, which requires a degree of sensemaking. In straightforward situations it may be possible to shorten the sensemaking process to a simple 'information' phase, but in complex, ambiguous, multi-level situations it is necessary to allow for and foster sensemaking interactions (Thiry, 2001).

\section{Postulate 5}

The interpretation of Life Cycle Cost assessments may require sensemaking

\subsection{Empirical findings}

Instead of finding optima in LCC models, asset managers are expected to demonstrate the added value of future-proofing their assets using robust, flexible or adaptable solutions which often come at additional cost - but the value of which is often challenging to model and quantify.

In the pilot phase of the 'demand flexibility' assessment (case 6) it became apparent that the lowest cost long-term option did not necessarily constitute the most valuable lifecycle option. For this initial study, a conscious decision was made to start a pilot on 'demand flexibility' despite this having unfavorable lifecycle costs compared to other, more conventional alternatives. The merit of this option was that it not only served as a solution to a pressing short-term congestion issue, but also served as an opportunity for the AM organization to pilot an innovative technique of 'demand flexibility'; a technique where congestion issues can be solved by managing energy transportation demand rather than increasing transportation capacity. In the pilot case, dependencies on third parties also resulted in uncertainties concerning the timeframe in which the permanent measures could be implemented. 'Demand flexibility' is not only an effective additional instrument for congestion management, but it can also be used to defer physical network expansion (Spiliotis, Ramos Gutierrez, \& Belmans, 2016). The AM investment board therefore agreed with the proposal recommending the (more expensive) 'demand flexibility' option, but not unanimously, and not without a thorough discussion of the costs and benefits involved in this multilevel decision. 
In the circuit breaker assessment (case 1), the failure modes and condition data were used to determine the optimal replacement moment for each individual breaker in one of the case company's asset portfolios. The aim was to find the optimum in a trade-off between the risk of age-related failure (resulting in outage) and the cost of early replacement (wasting remaining useful life). Though the calculated optimum could be determined using these characteristics, the overall cost-effectiveness for the entire organization also relied on other interdependencies such as grouping maintenance schedules and expansion plans for multiple electrical grids. These elements were not part of the LCC model, but were relevant to the sensemaking of the assessment outcome.

In these cases, the quantified outcome of the LCC assessments alone was not enough to provide a full overview of the best lifecycle option. Despite not indicating an absolute preference, these assessments were still deemed useful by providing insight into the financial consequences of specific decisions. These findings confirm the fifth postulate: the outcome of the assessment alone is not always enough to unequivocally determine which decision is optimal. Instead, additional sensemaking may be required in order to consider tactical and strategic perspectives as well.

\section{Summary, discussion and implications}

LCC is widely considered to be a well-established and advantageous instrument for evaluating decisions that concern assets with long lifespans and considerable financial impacts. As illustrated by the context of the energy transition, the application of LCC in AM creates an interesting contrast. On the one hand, the long lifespan and considerable financial impacts of assets make the application of LCC an undeniably relevant instrument to include during decision-making. The application of LCC requires the consideration of the entire lifecycle and therefore introduces a combined short- and long-term perspective into the decision-making context. This usefulness was also found in the embedded case study, where the use of LCC increased the confidence of AM staff in proposing technical solutions with long-term, and considerable financial impacts.

On the other hand, conventional applications of LCC are already considered to be challenging to apply in practice, mainly due to a lack of formal standards and a fragmented landscape of LCC approaches and methods. Furthermore, 
the socio-technical environment that AM organizations find themselves a part of are likely to change during the technical lifespan of its assets, sometimes significantly or rapidly so. When applied in more challenging decision-making contexts, such as those found by AM organizations of DSOs faced with the energy transition, the usability of LCC starts to deteriorate.

The purpose of this article was to explore to what extent the LCC remains applicable when it is applied to the advanced decision-making contexts of AM, exemplified by the AM of electricity grids that are undergoing an energy transition. By formulating postulates and through the use of a longitudinal embedded case study at the AM organization of a DSO, several theoretical and practical factors were compared and discussed. The results of our exploratory research (summarized in table 2.5 ), reveal that commonly held beliefs about LCC may start to lose their validity when they are applied in this advanced application context.

Table 2.5: Summary of the results

\begin{tabular}{llll} 
\# & Topic & Postulate & $\begin{array}{l}\text { Results with respect } \\
\text { to AM focus }\end{array}$ \\
\hline $\mathbf{1}$ & $\begin{array}{l}\text { Goal } \\
\text { definition }\end{array}$ & $\begin{array}{l}\text { Life Cycle Cost models are } \\
\text { aimed at reducing the total } \\
\text { costs of individual asset } \\
\text { lifecycles }\end{array}$ & Limited support \\
\hline $\mathbf{2} \quad \begin{array}{l}\text { Scope } \\
\text { definition }\end{array}$ & $\begin{array}{l}\text { LCC assessments are subject } \\
\text { to limitations with respect to } \\
\text { scope and level-of-detail }\end{array}$ & $\begin{array}{l}\text { Supported, but not } \\
\text { self-evident }\end{array}$ \\
\hline $\mathbf{3}$ & Inventory & $\begin{array}{l}\text { Life cycle inventories require } \\
\text { data collection and good } \\
\text { judgement in cost estimation }\end{array}$ & Supported \\
\hline $\mathbf{4}$ & $\begin{array}{l}\text { Impact } \\
\text { Assessment }\end{array}$ & $\begin{array}{l}\text { The outcome of LCC } \\
\text { assessments sufficiently } \\
\text { captures the creation of } \\
\text { stakeholder value }\end{array}$ & Not supported \\
\hline $\mathbf{5}$ & Interpretation & $\begin{array}{l}\text { The interpretation of Life } \\
\text { Cycle Cost assessments may } \\
\text { require sensemaking }\end{array}$ & Supported \\
\hline
\end{tabular}


This exploration uncovered a number of important limitations. Conventionally, LCC assessments tend to assume a singular asset lifecycle and focus on evaluating or improving the costs borne by a single stakeholder, usually the asset owner or user. AM, however, requires a careful consideration of how multiple assets interact to create value, not just by means of the optimal use of individual assets, but also by considering systems and portfolio perspectives. Asset-oriented decisions not only affect the financial bottom line, but they can also influence much broader AM factors such as the lifecycle plans of other assets, long-term organizational goals, strategies for dealing with uncertainty and multiple stakeholder values. This makes the selection of an appropriate LCC assessment scope critical. Our findings suggest that what one should include in these assessments is not always self-evident nor without value judgement. These considerations mean that in more challenging AM decision-making contexts, the outcomes of LCC should not always be taken at face value. Instead, a process of sensemaking may be required to establish to what extent the outcome of an LCC assessment is aligned with other, non-financial, and less-tangible value factors.

These limitations are likely to be generalizable to AM contexts where systems (or system-of-systems) perspectives apply, when dealing with portfolio or fleets of assets, and when dealing with uncertainty and significant changes in the environment within the lifespan of the asset(s). In the opinion of the authors, these limitations should be addressed both in practice and academia. AM professionals should be aware of these shortcomings of LCC and carefully consider the goal, scope, inventory, impact assessment and interpretation of LCC assessments and future research is needed on the development of methods and tools that support this process.

\section{Acknowledgements}

The authors wish to sincerely thank the case company Liander and their Asset Management organization for their participation in this research.

Funding: This research was supported by Liander N.V. 


\title{
Chapter 3 - Designing a hybrid methodology for the Life Cycle Valuation of capital goods
}

\begin{abstract}
:
Decision-makers are increasingly required to assess the value created by complex physical systems over their entire life cycle. The commonly applied Life Cycle Costing approach fails to fully capture value, as it is primarily aimed at costs, takes a reductionist approach, and does not account for continuously changing industrial environments. To address these shortcomings, the Life Cycle Valuation methodology is proposed, designed as a hybrid of LCC and Life Cycle Assessment. LCV facilitates the assessment of costs and benefits from multiple complementary perspectives and can be tailored to specific decision contexts, as demonstrated by applying LCV during Asset Management decision-making.
\end{abstract}

\section{Publication history:}

This chapter was published in the CIRP Journal of Manufacturing Science and Technology:

Haanstra, W., Braaksma, A. J. J. \& van Dongen, L. A. M. (2021). Designing a hybrid methodology for the Life Cycle Valuation of capital goods. CIRP Journal of Manufacturing Science and Technology (32), p.382-395. https://doi.org/10.1016/j.cirpj.2021.01.017 


\section{Introduction}

\subsection{Generating value from enduring physical assets}

Enduring physical assets form the backbone of many manufacturing systems. Machinery, production lines, buildings, and infrastructure need to perform in safe, cost-effective, and reliable ways in order to produce a steady supply of high-quality products (Ruitenburg \& Braaksma, 2017). The lifespans of these assets are commonly expressed in decades, rather than years, as is common for describing the lifespans of products that these assets produce. Furthermore, these capital assets are very expensive to acquire or replace. For physical assets, the majority of the Life Cycle Costs (LCC) are attributed to the in-service phase of these systems, with maintenance costs often exceeding the initial capital investment over the lifetime of the asset (Igba, Alemzadeh, Durugbo, \& Eiriksson, 2017). This means that a consideration of the entire lifecycle is indispensable when committing to costly decisions that affect, or are affected by, these long-lived assets. To comprehend the full potential of physical assets, a deep and thorough understanding of their complete lifetimes is needed (Ruitenburg et al., 2014).

Therefore, a significant challenge in managing these long-lived assets lies in the fact that, despite a sound understanding of the lifecycle of the asset itself, the context in which it operates is subject to continuous change. Developments in governance, (geo)politics, the economy, society, demography, and technology all need to be taken into account when managing assets (Pudney, 2010). In automotive industries, for example, strategic and tactical decision-making and flexibility are essential for adapting manufacturing systems to ever-changing environments and for warranting optimal performance (Lanza, Peters, \& Herrmann, 2012). "Because of increasing market dynamics and competition, companies in the manufacturing industry have to consider the flexibility of their manufacturing system in early planning phases and especially in investment decisions" (Kampker, Burggräf, Wesch-Potente, Petersohn, \& Krunke, 2013). Among these investment decisions are those concerning mid-life upgrades of capital equipment, which can be used to extend the useful life and functionality of the asset, adding value during this period (Khan, West, \& Wuest, 2019). Furthermore, many capital goods consist of, or are part of, interconnected and/or complex systems that are often being used for purposes beyond their original mission (Madni \& Sievers, 2014). As such, there is an increasing emphasis on making 
decisions that not only take the costs, potential benefits, and long lifespan into account but also need to include the systems perspective alongside long-term strategic objectives. Therefore, rational and lifecycle-oriented decisionmaking surrounding these physical systems is crucial, especially given the lasting and considerable consequences of committing to these types of decisions. Comprehensive and rigorous LCC applications are rare, even in literature (Korpi \& Ala-Risku, 2008). Because LCC is often considered to be too laborious, (Kunttu, Välisalo, Kettunen, \& Sakari Aulanko, 2016). In practice, many firms, therefore, seem to rely on relatively simple payback calculations to make asset replacement decisions.

Asset Management (AM) is a commonly used systematic approach aimed at the realization of value from physical systems over their entire lifecycle. It involves the balancing of costs, opportunities, and risks against the desired performance of assets, to achieve the organizational objectives of the managing organization (ISO 55000, 2014). A striking example of the challenge of managing long-lived physical assets in a rapidly changing future context is found in the Energy Transition. The main characteristics of this transition in Europe are the liberalization of the energy sector, the shift towards renewable energy sources, decentralization of energy production, and changes in energy consumption patterns (Verbong \& Geels, 2007). In energy production, the share of wind energy has grown exponentially over the last two decades and is likely to continue to do so (Igba et al., 2017). The emergence of distributed energy resources, such as distributed generation, local storage, electric vehicles, and demand response, is driving changes in power systems (Ruester et al., 2014). These changes mean that the requirements and needs of future energy systems are different from those of the past. Decisions at the individual asset lifecycle level therefore have a larger consequence on the possibilities and limitations of the surrounding architecture than ever. Furthermore, a large part of the infrastructure and industrial assets in Western Europe is currently approaching its expected end-of-life (Haarman $\&$ Delahay, 2016; Tinga, 2013). Despite their age, assets designed and built decades ago still fulfill vital functions in manufacturing, as well as in society at large (Ruitenburg \& Braaksma, 2017). The combination of constant investment needs and long-term socio-technical developments of the energy transition requires rational decision-making and a long-term strategic perspective. 


\subsection{Problem identification}

Life Cycle Costing (LCC) is a commonly used instrument for supporting investment decisions concerning physical systems with long lifespans. LCC allows for the assessment and reduction of costs in the short, medium, and long-term, making it an essential instrument for long-term planning (Taylor, 1981; Woodward, 1997). LCC can therefore be regarded as a major contributor to successful Asset Life Cycle Management (Roda \& Garetti, 2014). From its early beginnings in the 1950s, the understanding of LCC has progressed from a relatively straightforward cost calculation concept to a management system in its own right. White \& Ostwald (1976), for example, define LCC as "the sum of all funds expended in support of the item from its conception and fabrication through its operation to the end of its useful life". Duran, Roda, \& Macchi (2016), on the other hand, regard LCC as "a managerial system that is focused on the modeling, quantification, and control of all the costs that are present during the design and operation stages which ends with [the] disposal of a physical asset."

From the perspective of AM decision-making, however, the application of LCC is not without limitations. LCC is already criticized because it has difficulties assessing complex systems, challenges in data collection, lack of transparency and trust, and long-term uncertainties, and thus poses both practical and methodological challenges for the development of Product Service Systems (Aurich, Mannweiler, \& Schweitzer, 2010; Bertoni \& Bertoni, 2018; Kambanou \& Lindahl, 2016). Similar challenges also form limitations when using LCC to support AM centered decisions. The first of these limitations is that AM is focused on realizing value from physical assets (Heitz et al., 2016), whereas the principles of LCC are mainly focused on the costs borne by asset owners. Therefore, LCC does not include the consideration of various stakeholders associated with the asset (Srinivasan \& Parlikad, 2017). AM supports the realization of value while balancing financial, environmental, and social costs, risk, quality of service, and performance related to assets (ISO 55000, 2014). This value-oriented perspective shifts the focus of life cycle cost analysis from the minimization of the cost of ownership of a product to the perception of service and maintenance cost as 'design variables' in order to form a trade-off with product features and performances (Bertoni $\&$ Bertoni, 2018). Realizing value by means of trade-offs can be achieved in multiple ways, such as value-driven maintenance planning (Rosqvist et al., 
2009), future-proofing assets by applying changeable system design (Ross, Rhodes, \& Hastings, 2008), functional product (re)design (Janz, Sihn, \& Warnecke, 2005) or the development of sustainable business models (Marlow, Beale, $\&$ Burn, 2010). Despite the existence of these approaches, however, the concept of value remains largely subjective, making it difficult for individuals to articulate exactly what makes a complex system valuable (Browning $\&$ Honour, 2008). For applications in AM, the financial perspective, therefore, must be supplemented by a non-financial perspective to form a satisfactory basis for the evaluation of asset value.

The second limitation is that LCC assessments tend to take a reductionist approach, focusing on one cost object at a time, such as single processes or stand-alone instances of products, services, or time (Settanni et al., 2014). Focusing on a single cost object at a time does not provide an appropriate cost estimation because many manufacturing systems consist of interconnected and interacting cost objects (Bertoni \& Bertoni, 2018; Kambanou \& Lindahl, 2016). Furthermore, $A M$ organizations may choose to manage their assets in three distinct ways: (1) at the individual asset level, (2) in portfolios of multiple assets of similar types or classes, and (3) in groupings of assets that comprise an asset system (ISO 55000, 2014). The latter two of these management perspectives also seem incompatible with the reductionist nature of LCC. Roda \& Garetti (2014) argue that "in order to support managerial decisions, LCC models also need to assume a similarly integrated and systemic focus as AM".

The third and last limitation is that despite the long and rich history of LCC, a general application framework for LCC appears to be missing. In both theory and practice, there is a shortage of guiding principles and standards for LCC (Korpi \& Ala-Risku, 2008). Unlike the Life Cycle Assessment (LCA) methodology, LCC is not structured in accordance with an international standard, with the exception of the ISO 15686-5:2008 standard which only applies to the building sector (Toniolo, Tosato, Gambaro, \& Ren, 2020). Additionally, the IEC 60300-3-3 standard on dependability management (IEC, 2017) standard provides a general introduction to the concept of LCC but is predominantly aimed at assessing the cost associated with the dependability of an item. Kambanou \& Lindahl (2016) indicate that LCC is always tailored to fulfill the requirements of its intended use, and that this tailoring will be reflected in the cost object, scope, and boundaries of the assessment. Likewise, it appears that the guidelines on how to apply LCC are also mostly 
tailored to specific application contexts, and that a more generally applicable guideline for LCC is still missing. A potential avenue to explore is to look at the aforementioned framework for LCA. Rebitzer \& Hunkeler (2003) indicate that "a general LCC guidance [framework], similar to the ISO 14040 series for LCA, seems to be desirable". Swarr et al. (2011) also state that there needs to be a consensus on an international standard for applying LCC, which parallels the ISO 14040 standard for LCA. Hunkeler \& Rebitzer (2005) called for the prioritization and development of an accepted and standardized methodology for LCC, a code of practice, an international standard for the framework, and indicated the need for methodological compatibility of LCC with LCA.

\subsection{Research motivation}

Decisions that shape the lifecycle of capital goods, such as the physical systems in use in energy grids, have an enormous impact on AM organizations and for society as a whole. LCC, though widely adopted, is methodologically limited in supporting the types of decisions that, for example, AM organizations are now required to make in the ever-changing context of the energy transition. Given the lack of a generic guiding framework for LCC and the existence of conceptual overlap between LCC and LCA, various researchers see the application of the principles and framework of LCA as a promising starting point for the development of guiding principles for LCC, which can be used to improve the methodology. Rebitzer, Hunkeler, \& Jolliep (2003) argue that the Life Cycle Inventory ( $\mathrm{LCl}$ ) of LCA is an "excellent basis for allocating LCC to the entire lifecycle of a product". Huppes et al. (2004) indicate that "the procedural standards for LCA as specified in 15014040 may, with slight adaptations, be used for LCC as well". ISO 14040 states that the principles and framework described in the standard can be beneficially applied to LCC and asset (life cycle) management (ISO 14040, 2006). Sakao \& Lindahl (2015) took inspiration from LCA for the development of their method for evaluating and improving LCC-based industrial Product-Service Systems (PSS). Similarly, Zhang, Guo, Gu, \& Gu (2018) combined LCA and LCC for the development of a PSS for high-energy consuming equipment. In this regard, the framework and principles of LCA seem to be at least partially compatible with LCC, providing a promising basis for research on how they can be combined. 
This article, therefore, aims to explore the concept of combining the guiding principles of LCA with those of LCC, to form a hybrid evaluation methodology that is aimed at providing a multi-dimensional and adaptable perspective on the asset life cycle. Considering the relevance and widespread acceptance of LCC in the assessment of asset cost and performance, LCC is used as the conceptual starting point for the development of the proposed Life Cycle Valuation (LCV) methodology. In addition, the LCV methodology borrows from the guidelines and framework of LCA but is tailored to the requirements of AM and aimed at assisting decision-makers in evaluating and articulating what makes a complex system valuable during its lifecycle.

\section{Literature on LCC and LCA}

Existing research on the application of life cycle-oriented assessment methods reveals that despite the lack of a unified framework for LCC, the methodology is often combined with other lifecycle-oriented methodologies to gain a broader understanding of the lifecycle impact beyond mere costs. A common strategy to account for the limitations in LCC is combining it with the environmental perspective of LCA. Peças et al. (2016) argue that LCC and LCA should be applied in an integrated manner to serve as core elements of Life Cycle Engineering (LCE). Swarr et al. (2011) have developed a code of conduct that aims to apply LCC in parallel with LCA, by integrating the former into the latter. Heijungs, Settanni, \& Guinée (2013) propose that the matrix-based computational structure of LCA can be applied to LCC in order to enable the simultaneous assessment of LCC and LCA in a single study. Miah, Koh, \& Stone (2017) developed a new framework for merging LCC and LCA by combining six existing frameworks. Atia, Bassily, \& Elamer (2020) propose a framework that integrates LCC and LCA by looking at the sequence of activities in a particular value chain. Hoogmartens, Van Passel, Van Acker, \& Dubois (2014) investigated the connections between various sustainability assessment tools and how they relate to arriving at a triple bottom line Life Cycle Sustainability Assessment (LCSA). Neugebauer, Forin, \& Finkbeiner (2016) have developed a macroeconomic impact pathway that combines assessment perspectives from LCA, LCC, and Social LCA in order to support an LCSA. Additionally, economic input-output models are used to link macroeconomic activities with a broad spectrum of environmental burdens, allowing the two to be assessed simultaneously (Kjær et al., 2015; Nakamura \& Kondo, 2009). 
Besides the parallel application of LCC and LCA, another research focus can be found in the investigation of the methodological differences and similarities between the two. Norris (2001) investigated the differences between LCA and LCC to better understand how they can be applied in parallel to assist in combined economic- and environmentally-focused decision-making in the private sector. Huppes et al. (2004) investigated the fundamental differences between LCA, Cost-Benefit Analysis (CBA) and Budget-focused LCC approaches in order to develop a meta-framework. They cite dimensions of cost categories, cost bearers, cost models, and cost aggregation methods as the main differentiators between life cycle methodologies. Bierer, Meynerts, \& Götze (2013) investigated mutual points of contact and methodological relationships between LCC and LCA with the aim of integrating the two methods. Overall, there appears to be a significant conceptual overlap between the LCC and LCA methodologies, with differences manifesting in the adopted evaluation concepts (see table 3.1).

Table 3.1: Conceptual overlap of and differences between LCC and LCA

\begin{tabular}{|c|c|c|c|c|c|c|c|}
\hline & \multirow{2}{*}{$\begin{array}{c}\text { Conceptual } \\
\text { overlap }\end{array}$} & \multicolumn{6}{|c|}{ Conceptual difference } \\
\hline & & purpose & inventory & flows & units & $\begin{array}{c}\text { time } \\
\text { treatment }\end{array}$ & aggregation \\
\hline LCC & $\begin{array}{l}\text { Lifecycle- } \\
\text { oriented } \\
\text { Need for } \\
\text { system } \\
\text { boundaries } \\
\text { Need for }\end{array}$ & $\begin{array}{l}\text { Assessing } \\
\text { cost- } \\
\text { effectiveness }\end{array}$ & $\begin{array}{c}\text { Activity- } \\
\text { based } \\
\text { Cost } \\
\text { engineering } \\
\text { Annual } \\
\text { timeline }\end{array}$ & $\begin{array}{l}\text { Cashflows } \\
\text { Mainly } \\
\text { OPEX\& } \\
\text { CAPEX }\end{array}$ & $\begin{array}{l}\text { Monetary } \\
(€, \$, \text { etc.) }\end{array}$ & $\begin{array}{l}\text { Timing is } \\
\text { critical due } \\
\text { to the time } \\
\text { value of } \\
\text { money }\end{array}$ & $\begin{array}{c}\text { Cumulative } \\
\text { NPV } \\
\text { Annuity } \\
\text { Rate-of- } \\
\text { return }\end{array}$ \\
\hline LCA & $\begin{array}{l}\text { scenarios } \\
\text { Reliance on } \\
\text { forecasting, } \\
\text { estimation \& } \\
\text { assumptions } \\
\text { Reliance on } \\
\text { sensitivity an } \\
\text { improvement } \\
\text { analysis }\end{array}$ & $\begin{array}{l}\text { Assessing } \\
\text { environ- } \\
\text { mental } \\
\text { performance }\end{array}$ & $\begin{array}{l}\text { Process- } \\
\text { based, } \\
\text { supply chain } \\
\text { oriented } \\
\text { Adoption of a } \\
\text { functional } \\
\text { unit }\end{array}$ & $\begin{array}{l}\text { Mass, } \\
\text { energy, } \\
\text { and } \\
\text { pollutant } \\
\text { flows }\end{array}$ & $\begin{array}{c}\text { Primarily } \\
\text { mass, } \\
\text { energy and } \\
\text { volume }\end{array}$ & $\begin{array}{l}\text { Timing of } \\
\text { emissions } \\
\text { are } \\
\text { irrelevant } \\
\text { Broad } \\
\text { temporal } \\
\text { scopes } \\
\text { apply }\end{array}$ & $\begin{array}{c}\text { Multiple } \\
\text { impact areas } \\
\text { Weighted } \\
\text { indication of } \\
\text { the overall } \\
\text { impact }\end{array}$ \\
\hline
\end{tabular}


Existing research streams appear to primarily focus on combining LCC and LCA. As such, they retain their respective advantages and disadvantages when combined into a single application. Even though this combined application provides a broader value perspective than financial or environmental impact alone, the outcomes of such assessments are inherently limited to the quantitative aspects of economic and environmental impacts. Furthermore, the combined application of these methodologies remains primarily reductionist and object-focused in nature and is therefore ill-suited to deal with external uncertainties such as long-term systemic changes or continuously shifting organizational goals, as discussed in section 1.2.

In the literature on production environments, an increasing focus on value creation can be observed as the conventional producer-consumer model has begun to be replaced by the concept of value creation in society, which can be viewed from multiple viewpoints and disciplines (Kaihara et al., 2018). Kumar, Shirodkar, Camelio, \& Sutherland (2007) present value as an ever-changing flow of value creation during manufacturing, value consumption in the use phase, and post-use reclamation of value during recovery in order to establish the most valuable strategy at different life cycle stages. Ross, Rhodes $\&$ Hastings (2008) describe how flexibility, adaptability, scalability, modifiability, and robustness can be used as design strategies to create and maintain a system's life cycle value, as well as providing perspectives from which to perceive value. Bosch-Mauchand, Belkadi, Bricogne, \& Eynard (2013) use a combined product lifecycle management and knowledge management approach to model value for different stakeholders in the value chain. as providing perspectives from which to perceive value. Bosch-Mauchand, Belkadi, Bricogne, \& Eynard (2013) use a combined product lifecycle management and knowledge management approach to model value for different stakeholders in the value chain. Value is also discussed in the context of the development of Product Service Systems (PSS). A potential explanation for this trend could be that the costs of providing a service via PSS are considered by many to be equivalent to the cost of an in-service stage of a durable product, requiring increased attention to how the outcome of the PSS relates to its costs (Settanni, Thenent, Newnes, Parry, \& Goh, 2015). Matschewsky, Lindahl \& Sakao (2020) therefore provide an approach to analyze and improve PSS value capture over the entire lifecycle. In these examples from literature, as well as colloquially, value is generally understood as something desirable, positive, important, or useful. Renkema $\&$ 
Berghout (1997), however, use a multidimensional view on positive and negative aspects of financial and non-financial consequences to clarify the concepts used in the evaluation of IT investment evaluation. Martinsuo, Vuorinen \& Killen (2019) also frame the value of infrastructure projects as being multi-dimensional and having both positive and negative dimensions. In LCC, the convention is to quantify costs using positive numbers, resulting in cost savings having a negative cost impact. Likewise, in LCA, environmental impact is conventionally quantified using positive numbers (and avoided impacts using negative numbers). Because the LCV methodology is intended to evaluate both positive and negative values in the life cycle and is rooted in both LCC and LCA, it is positioned as a methodology that is aimed at the assessment of both positive and negative value factors. In this research, 'bad' factors such as costs and environmental impacts are represented using positive numbers. As such, the LCV methodology is positioned as a valuation approach, aimed at evaluating and assigning value factors in the life cycle using monetary units.

\section{Design Science Research}

The methodology used to structure the development of the proposed LCV methodology is Design Science Research (DSR) which is defined as "an explicitly organized, rational, and wholly systematic approach to design; not just the utilization of scientific knowledge of artefacts, but design in some sense as a scientific activity itself" (Cross, 2001). DSR is an advantageous approach given the professional engineering settings where the aforementioned problems arise, indicating the need for a new guiding framework for lifecycle-oriented assessment. Denyer, Tranfield, \& Van Aken (2008) characterize the design sciences paradigm by (1) research questions being driven by an interest in field problems, (2) an emphasis on the production of prescriptive knowledge, and (3) a justification of research products largely based on pragmatic validity. Holmström, Ketokivi, \& Hameri (2009), indicate that DSR is different from many other applied research areas because it aims to bridge practice with theory, rather than theory with practice. DSR, therefore, starts with the identification and motivation of a relevant research problem (see sections 1.2-1.3), the development of a design that fulfills certain objectives and criteria, and results in the application and evaluation of a design in a real-world context (Peffers, Tuunanen, Rothenberger, \& Chatterjee, 2007; Wieringa, 2014). 
The type of DSR applied in this article is called 'exaptation', a process by which features acquire functions for which they were not originally adapted or selected, extending existing solutions to new problems (Costa et al., 2020; Gregor \& Hevner, 2013). An example of technological exaptation can be found in the re-adherable strip that is used in sticky notes, which was discovered in an experiment that was originally aimed at finding a more permanent adhesive. In this research, the proposed solution is established by adapting the guiding framework and principles of LCA to the application of LCC, creating a new, hybrid methodology. This new methodology is then applied to the new problem of assessing the life cycle value of physical assets in Asset Management.

Testing the application of designed artefacts in the real world comprises an essential step in DSR (Wieringa, 2014). The application of the Life Cycle Valuation methodology is demonstrated, tested, and evaluated in multiple decision-making instances at the Asset Management department of Distribution System Operator (DSO) Liander, which operates in the Netherlands. As the largest DSO in the country, Liander is responsible for distributing natural gas and electricity to homes, businesses, and industrial customers. Liander's 3.1 million electrical grid customers are supplied by complex distribution grids consisting of physical systems with long lifespans such as transformers, overhead and underground cables, switchgear, constructions that house installations, and other capital goods. An important challenge in the management of these physical systems is that while some systems have a long lifespan (e.g., transformers) and others have a short lifespan (e.g., digitization components), they often need to be considered simultaneously as part of a larger system or asset portfolio. The LCV methodology was used in these types of decision contexts that previously relied on LCC as the main assessment instrument. It has been used to guide and support the assessment of multiple asset life cycle-related decisions within the electrical side of the AM organization of Liander (excluding the distribution of natural gas). Given the variances in lifespan and asset objects (i.e., individual assets, asset portfolios, and complex systems) this set of application contexts was selected to mirror the broad range of AM decisionmaking contexts, as discussed in the introduction.

Hevner (2007) indicates that in DSR the artefact not only needs to provide utility in practice (relevance) but that it must also contribute to the knowledge 
base (rigor). The outcome of DSR therefore not only leads to pragmatic designs (often referred to as artefacts) but also results in a better understanding of the problem and the solution, thus providing theoretical knowledge as well. Sein, Henfridsson, Purao, Rossi, \& Lindgren (2011) stress the need for reconceptualizing the highly organization-specific solutions into generalizable design principles for classes of problems, capturing the knowledge gained throughout the design process. As such, the efficacy of the design is not just evaluated according to its design objectives and criteria, but also includes a reflection on the most important design principles that form the core of the design of the LCV method. Lastly, unstructured interviews with the AM staff that were involved in the practical application of the LCV methodology were used to evaluate whether the methodology is practicable. The overall structure of the used DSR methodology is summarized in figure 3.1, based on the outline provided by Peffers et al. (2007).



Figure 3.1: Design Science Research methodology (adapted from Peffers et al., 2007) 


\subsection{Design objectives and criteria}

As discussed in the introduction, the practice of applying LCC and LCA does not necessarily provide a complete picture of the value generated in the asset lifecycle when regarded from an AM perspective. In order for the design of the LCV methodology to sufficiently support AM decision-making, several design criteria are used that are tailored to the specific characteristics and requirements of AM decision-making (see table 3.2).

Table 3.2: Summary of the AM-based design criteria for the LCV methodology

\section{Criterion}

1

Ability to consider the entire lifecycle of an asset and apply to all stages within an asset lifecycle

2

Ability to consolidate information, data, and expertise from multiple disciplines and management perspectives

Ability to account for, and differentiate between, multiple financial and non-

3 financial value factors such as economic, environmental, social, and technical impacts as well as the needs of relevant stakeholders

4

Ability to apply to different system definitions, such as at the level of individual assets, portfolios of similar assets, or (complex) systems of assets.

5

Ability to link decisions at the level of the asset life cycle to the level of the organizational strategy

The first criterium is that a successful design should be able to consider the entire lifecycle of an asset and should apply to all stages within an asset lifecycle (Haffejee \& Brent, 2008; ISO, 2014; Schuman \& Brent, 2005). The second criterium is that the design should be able to consolidate information, data, and expertise from multiple disciplines and management perspectives (Ruitenburg et al., 2014). Furthermore, the design should be able to account for and differentiate between, multiple financial and non-financial value factors such as economic, environmental, social, and technical impacts as well as the needs of relevant stakeholders (ISO, 2019; Srinivasan \& Parlikad, 2017). It also must be able to apply to different system definitions, such as at the level of individual assets, portfolios of similar assets, or (complex) systems of assets (ISO, 2014; Roda \& Garetti, 2014). And lastly, the designed methodology should 
be able to link decisions at the level of the asset life cycle to the level of the organizational strategy (El-Akruti et al., 2013; Komonen et al., 2012).

\section{Design principles}

The design of the LCV methodology borrows from various design principles from different methodologies. To clarify the role of these principles in the design of the LCV methodology, their origins and implementations are briefly discussed.

\subsection{Life Cycle Costing and the time value of money}

AM is concerned with continuous improvement and alignment of financial and non-financial functions (ISO 55010, 2019), therefore, life cycle cost control forms an important activity (El-Akruti et al., 2013). As such, the conceptual starting point for the design of the LCV methodology is rooted in Life Cycle Costing. For the purposes of this article, LCC can be understood as: "An analysis technique which encompasses all costs associated with a product" (Sherif \& Kolarik, 1981), "from its conception and fabrication through its operation to the end of its useful life" (White \& Ostwald, 1976), "with the goal of estimating the costs associated with the existence of a product" (Rebitzer \& Hunkeler, 2003).

Unlike in the case of LCA, where no explicit differentiation is made between emissions as well as impacts at different moments in time, the financial perspective does have a time preference due to (1) changes in price levels, (2) pure time preference, (3) productivity of capital and diminishing marginal utility of consumption and (4) uncertainties (Hellweg, Hofstetter, \& Hungerbühler, 2003). An important characteristic of LCC is that it accounts for the 'time value of money'. In LCC, cash flows that occur at different moments in time are discounted back to a base period by using the Net Present Value (NPV) technique (Woodward, 1997). The 'time value of money' concept is used in the design of the LCV framework in two ways: the first is the use of discounting using the NPV technique (see equation 1), the second is the application of Equivalent Annual Annuity (EAA) (see equation 2). The latter allows for a comparison based on a discounted yearly average (Rødseth, Schjølberg, Kirknes, Bernhardsen, \& Inge, 2016), enabling a fair comparison of mutually exclusive options with unequal lifespans. A common practice for AM 
organizations is to base the discount rate on the firm's Weighted Average Cost of Capital (WACC ${ }^{1}$ ), as was the case at case company Liander.

NPV $=$ Net Present Value ${ }^{2}$

$\mathrm{R}_{\mathrm{t}}=$ net cash flow

$$
N P V=\frac{R_{t}}{(1+i)^{t}}
$$

$\mathrm{i}=$ discount rate

$\mathrm{t}=$ year of the impact

$\mathrm{EEA}=$ Equivalent Annual Annuity ${ }^{3}$

$$
E A A=\frac{i(N P V)}{1-(1+i)^{-n}}
$$

$\mathrm{n}=$ elapsed number of years

\subsection{Four stage Life Cycle Assessment framework}

Even though LCC is the conceptual starting point for the design of the LCV methodology, another prominent design principle is the adoption of the four stages of LCA (see figure 3.2). The basic outline of the four iterative steps of defining the goal and scope, performing an inventory analysis, assessing the resulting impact, and interpreting the whole can be adapted to provide general guidance and structure other types of life cycle assessments than just LCA (ISO, 2006a, 2006b).

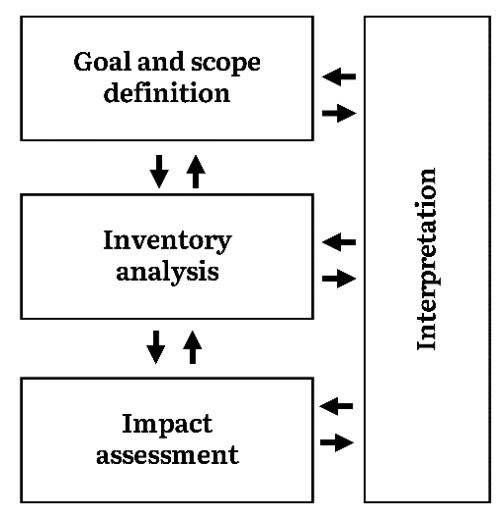

Figure 3.2: Four stages of Life Cycle Assessment (ISO 14040, 2006)

\footnotetext{
${ }^{1}$ WACC: Is the rate that an organization is expected to pay when financing its assets. It is mostly dictated by external market forces.

${ }^{2}$ NPV: Allows for the evaluation of cash flows at different moments in time (e.g. €10 now vs. $€ 10$ in 5 years) compensating for the (usually decreasing) time value of money. ${ }^{3}$ EEA: Can be regarded as the average yearly cost over the entire lifespan of an asset, but includes compensation for the time value of money using the NPV technique.
} 


\subsection{Defining the system of interest}

Complex system environments are characterized by ill-defined and potentially tacit, divergent, or pluralistic goals that are value-laden, shifting, and challenging to make entirely explicit (Keating et al., 2003). Therefore, another LCA-inspired design principle consists of defining the 'system of interest', which is similar to the concept of the system boundary in LCA. This can be used to distinguish between what is exogenous and endogenous to the system, it clarifies the level of granularity in examining what happens within the system's boundaries, which can be viewed as the actions performed on or outcomes related to the system of interest (Settanni et al., 2014).

\subsection{Combined breakdown structures}

Another design principle that has been applied to the LCV framework is the application of a breakdown of individual lifecycle elements, a concept that is similar to the breakdown into cost elements in LCC (Kawauchi \& Rausand, 1999). This concept borrows from Cost Breakdown Structures (CBS) but allows for the breaking down into more aspects of value creation than just costs. These breakdown structures constitute a logical subdivision by functional activity, area, a major element of a system, and/or more discrete classes of common items that can be used to link objectives to activities and available resources (Fabrycky \& Blanchard, 1991). A common CBS is that of ActivityBased Costing (ABC), which links life cycle costs to activities that occur throughout the lifecycle (Durairaj et al., 2002; Emblemsvåg, 2003). This allows resource consumption to be traced to distinct activities. The breakdown structure applied in the LCV methodology functions similarly but adopts a three-dimensional breakdown structure, similar to the structures of Kawauchi \& Rausand (1999) and Götze, Koriath, Kolesnikov, Lindner, \& Paetzold (2012). The breakdown structure that we propose is briefly explained below and illustrated in figure 3.3.

In the breakdown structure of LCV, all activities in the lifespan of an asset are made up of individual 'lifecycle elements'. Multiple lifecycle elements can be placed on a timeline that represents the (remaining useful) lifespan of the asset, creating an Activity Breakdown Structure (ABS). Each lifecycle element can have an impact that can affect one or more types of value, as structured by the Value Breakdown Structure (VBS). Combinations of multiple lifecycle elements are then used to build a modular, three-dimensional representation 
of the lifecycle which allows for either a value-based perspective (using aggregated activities from the ABS) or an activity-based perspective (using aggregated values from the VBS) of value creation over time during the asset lifespan in segments of individual years.



Figure 3.3: Three-dimensional breakdown structure of an LCV model adapted from Kawauchi \& Rausand (1999) and Götze, Koriath, Kolesnikov, Lindner, \& Paetzold (2012).

\subsection{Monetary valuation}

Conventional LCC does not require an impact assessment phase, because all inventory data comprises a single unit of measure, namely currency (Swarr et al., 2011). As indicated in design criterion 3, the LCV framework needs to simultaneously consider multiple financial and non-financial value factors, which the aforementioned VBS required. Various value-related impacts are therefore aggregated and expressed in financial terms.

Monetary valuation is the practice of converting measures of social and biophysical impacts into monetary units and is used to determine the economic value of non-market goods, i.e., goods for which no market exists (Pizzol, Weidema, Brandão, \& Osset, 2015). In AM, monetary valuation is typically already implicitly applied as part of risk management, where resources are allocated to mitigate different kinds of risk. Risk matrices are 
commonly used to identify, analyze, and evaluate risks, based on likelihood, consequence, and risk tolerance criteria (Syed \& Lawryshyn, 2020). As such, the realization of value through managing risk and opportunity already depend on balancing of cost, risk, and performances (ISO 55000, 2014). The performance indicators for checking the desired objectives or targets during the operation and maintenance phase of a product or system can be arrived at by taking reliability, availability, maintainability, and safety (RAMS) into consideration (Fourie \& Tendayi, 2016). Risks can be modeled as a single life cycle element by multiplying the expected likelihood and consequence for each risk (Syed \& Lawryshyn, 2020). While risk and opportunity are usually managed from an internal company perspective, taking the consequences for other stakeholders into account is also increasingly expected. Simplified indicators of environmental and social impact can be translated into external social and environmental costs, allowing the integration with conventional cost assessment such as LCC (Kara, Manmek, Kaebernick, \& Kaebemick, 2007). These 'shadow costs' are expressions of environmental impact in monetary terms, using financial units (e.g., $€$ or \$) and are usually based on abatement or damage costs.

\section{Design and demonstration of the Life Cycle Valuation (LCV) methodology}

The Life Cycle Valuation (LCV) methodology consists of two main elements: (1) a four-phased framework (see figure 3.4) that guides the process of performing an LCV assessment, and (2) a combination of calculations and the aforementioned modeling principles that have been programmed into an LCV tool using commonly available spreadsheet software. 
- Determining the goal

- Defining the system of interest

- Determining the temporal scope

- Determining the Value

Breakdown Structure (VBS)

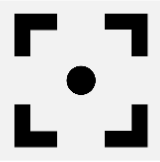

\section{$\downarrow \uparrow$}

- Determining the Activity Breakdown Structure (ABS)

- Application of data,

multidisciplinary expertise and assumptions

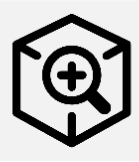

Life Cycle Inventory<smiles>[121In]</smiles>

- Total LCV impact

- Activity-based impact profile

- Value-based impact profile

- Equivalent Annual Annuity (EAA)

- Comparison of alternatives

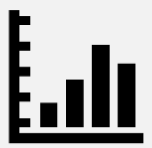

Impact

Assessment
(1)

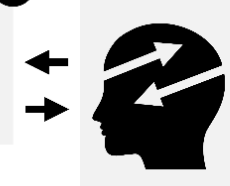

2

- Financial impact

- Non-financial and/or non-organizational

impact

- Organizational objectives

- Limitations of the goal

- Limitations in scope

- Qualitative factors

Sensitivity analysis

Recommendations for decision-makers

Figure 3.4: Life Cycle Valuation (LCV) assessment framework (adapted from ISO 14040)

\subsection{Step 1: Formulation of the goal and scope}

\subsubsection{Determining the goal}

The first step in performing an LCV assessment is to determine the goal. This makes it explicit what the main reason for performing the assessment is and what the requirements of a successful assessment are. For example, in AM, the goal can be operational (such as optimization as a part of a continuous improvement cycle) or strategic in nature (such as: linking to a specific organizational long-term goal).

It also provides the opportunity to state whether the assessment is of an attributional or a consequential type. An attributional assessment is aimed at identifying which value is created over the lifecycle of the asset, thus requiring the $\mathrm{LCl}$ to include all relevant impacts associated with the lifecycle. A consequential assessment may leave out certain elements that are the same for all alternatives within the scope, for example in comparative studies. 


\subsubsection{Defining the system of interest}

The system of interest is used to determine which system or systems is or are considered to be the main subject of study and provides or provide the opportunity to clarify which parts of the system or systems is or are included in the assessment and which parts are considered out-of-scope. The system definition is also used to indicate whether the system of interest consists of a single asset, a portfolio of similar assets, or a complex system of multiple interdependent assets. If necessary, allocation and attribution procedures can be explained in this step as well.

\subsubsection{Determining the temporal scope}

The time frame is used to specify the scope of the LCV assessment concerning its temporal dimension. It is used to determine the section of time that the LCV assessment covers, by indicating the starting year of the assessment and the duration up to and including the last year. For AM, the lifespan or remaining useful life of the asset can be used to guide the determination of the time frame.

Another aspect of the temporal scope is the discount rate that is used to calculate the NPV of impacts that occur at different moments in time.

\subsubsection{Determining the Value Breakdown Structure (VBS):}

The Value Breakdown Structure (VBS) is used to indicate which value factors are included in the assessment and how they are quantified. These value factors can depend on the goal of the assessment, or be coordinated within an AM organization. This is similar to, for example, a component of risk management, in that it allows for differentiation between multiple value factors such as:

- Financial impacts such as capital expenses (CAPEX) and operational expenses (OPEX)

- Technical impacts such as reliability \& availability of the system (e.g., failure rate)

- Externalities such as environmental impacts (e.g., $\mathrm{CO}_{2}$ emissions) or safety (accident rate)

- Other relevant value factors 
In order to allow for calculation, these 'impacts' need to be expressed in units (e.g., $€, \mathrm{~kg}, \mathrm{m3}, \mathrm{min}$ ) and have a value equivalent per unit of impact (e.g., $€ / \mathrm{kg}$, $€ / \mathrm{m} 3 € / \mathrm{min}$.). By differentiating between different impacts in the VBS, their relative contributions can later be traced back to the aggregated impact results. Table 3.3 shows a selection of the most frequently used impacts in the VBS which were used during the application of the LCV methodology at the AM organization of DSO Liander. The value equivalences ( $€$ /unit) for Liander are considered sensitive information and are therefore not shown. Note that impacts in the VBS can have a financial impact for the AM organization, a nonfinancial and/or non-organizational impact, or a combination of both.

Table 3.3: Examples illustrating a selection of commonly used impacts in the VBS at Liander

\begin{tabular}{|c|c|c|c|}
\hline Impact & Unit & $\begin{array}{l}\text { Financial impact } \\
\text { for the AM } \\
\text { organization (€) }\end{array}$ & $\begin{array}{l}\text { Non-organizational } \\
\text { and/or non-financial } \\
\text { impact ( } € \text { eq.) }\end{array}$ \\
\hline $\begin{array}{l}\text { Capital Expenses } \\
\text { (CAPEX) }\end{array}$ & $€$ OPEX & $1 €$ & \\
\hline $\begin{array}{l}\text { Operational Expenses } \\
\text { (OPEX) }\end{array}$ & $€$ CAPEX & $1 €$ & \\
\hline $\begin{array}{l}\text { System Average } \\
\text { Interruption Duration } \\
\text { Index (SAIDI) }\end{array}$ & minutes & $\begin{array}{c}\text {... } € / \text { min } \\
\text { (actual costs to re- } \\
\text { establish power } \\
\text { distribution) }\end{array}$ & $\begin{array}{c}\text {... } € / \min \\
\text { (inconvenience of } \\
\text { outage for } \\
\text { customers) }\end{array}$ \\
\hline $\begin{array}{l}\text { Global Warming } \\
\text { Potential (GWP) }\end{array}$ & $\begin{array}{c}\mathrm{kg} \mathrm{CO}- \\
\text { equivalent }\end{array}$ & & $\begin{array}{c}\ldots € € / \mathrm{kg} \mathrm{CO}- \\
\text { equivalent } \\
\text { (environmental } \\
\text { damages) }\end{array}$ \\
\hline
\end{tabular}




\subsection{Step 2: Life Cycle Inventory}

The Life Cycle Inventory ( $\mathrm{LCl}$ ) is constructed using discrete 'lifecycle elements' that can have one or multiple impacts associated with them. For example, a lifecycle element of one day of operation can result in the cumulative impact of $€ 100$ of OPEX and the emission of $24 \mathrm{~kg}$ of $\mathrm{CO}_{2}$-equivalents (see the example in table 3.4). These elements can be constructed using data, expertise and, if necessary, assumptions.

Table 3.4: Examples illustrating two lifecycle elements and their associated impacts

\begin{tabular}{llll} 
Lifecycle element & Unit & Amount & Unit \\
\hline Acquisition & apiece & 10.000 & E CAPEX \\
\hline Operation & day(s) & 100 & $€$ OPEX \\
\cline { 3 - 4 } & & 24 & $\mathrm{~kg} \mathrm{CO}$-equivalent
\end{tabular}

Multiple lifecycle elements can be placed on a timeline to construct a complete $\mathrm{LCl}$ of all relevant aspects and activities within the lifecycle of the asset, forming an Activity Breakdown Structure (see example in figure 3.5). Multiple units can be entered for each lifecycle element on the timeline. The ABS enables the user to trace the overall LCV impact resulting from individual lifecycle elements and that occur at specific moments in time.

The creation of the lifecycle elements and the timeline is likely to require the integration of multiple disciplines, as it should describe all relevant activities in the asset lifecycle. Lifecycle elements can be updated individually, with the changes propagating into an overall impact score.

Lifecycle element (dropdown)
ABS item 1 (e.g. acquisition)
ABS item 2 (e.g. operation)
ABS item 3 (e.g. planned maintenance)
ABS item 4 (e.g. inspection)
ABS item 5 (e.g. outage risk)
ABS item 6 (e.g. energy losses)
ABS item 7 (e.g. end-of-life)

\begin{tabular}{c|c|c|c|c|c|c|c|c|c|}
\hline & \multicolumn{1}{c}{1} & 2 & 3 & 4 & 5 & 6 & 7 & 8 & 9 \\
\hline Unit & 2020 & 2021 & 2022 & 2023 & 2024 & 2025 & 2026 & 2027 & 2028 \\
\hline $\begin{array}{c}\text { apiece } \\
\text { day(s) }\end{array}$ & 1 & & & & & & & & \\
\hline occurence & 1 & 3 & 3 & 3 & 4 & 4 & 4 & 5 & 5 \\
\hline occurence & 4 & & & & 4 & & & 4 & \\
\hline SAIDI (min) & 12 & 11 & 5 & 4 & 3 & 3 & 3 & 7 & 11 \\
\hline MWh & 120 & 120 & 125 & 125 & 130 & 130 & 135 & 135 & 140 \\
\hline occurence & & & & & & & & & 1 \\
\hline
\end{tabular}

Figure 3.5: Activity breakdown showing discrete lifecycle elements on a timeline 


\subsection{Step 3: Impact Assessment}

After modeling and placing each lifecycle element on the timeline, the total impact can be calculated. For example, if the user enters ' 2 days of Operation' on the timeline as input in a specific year, this would result in a total LCV impact of $€ 243,20$ ( $2 \times € 100 \times 1 € O P E X+2 \times 24 \times € 0,90 \mathrm{CO}_{2}$ equivalents), as indicated in table 3.5. Note that the LCV impact is expressed in EUR $(€)$, but that this does not necessarily represent financial value alone, as it may also include non-financial impacts.

Table 3.5: Breakdown of the total LCV for 2 days of the lifecycle element 'Operation'

\begin{tabular}{|c|c|c|c|c|c|c|c|}
\hline \multicolumn{3}{|c|}{ Lifecycle element } & \multicolumn{3}{|c|}{ Value Breakdown } & \multicolumn{2}{|c|}{ LCV impact } \\
\hline Name & Amount & Unit & Amount & Unit & $\begin{array}{c}\text { Value } \\
\text { eq. }\end{array}$ & Value eq. & Sum \\
\hline \multirow{2}{*}{ Operation } & \multirow{2}{*}{2} & \multirow{2}{*}{ day(s) } & 100 & $€$ OPEX & $€ 1$ & $€ 200$ & \multirow{2}{*}{$€ 243,20$} \\
\hline & & & 24 & $\begin{array}{c}\mathrm{kgCO} \\
\text { equivalent }\end{array}$ & $€ 0,90$ & $€ 43,20$ & \\
\hline
\end{tabular}

As LCV deals with different impacts at different moments in time, a discount rate should be provided to support the calculation of the Net Present Value of all impacts throughout the lifecycle. When dealing with comparative assessments with different timeframes, the Equivalent Annual Cost technique can be used to compare impacts based on yearly averages.

The combined implementation of the Activity Breakdown Structure and the Value Breakdown Structure, using discrete lifecycle elements, allows for a multi-perspective insight into the results of the assessment. In order to support interpretation, the dashboard of the LCV tool offers multiple options and cross-sections (also referred to as impact profiles), such as:

- Adjustment of parameters (e.g., discount factors) and related assessment perspectives (see figure 3.6 )

- Overview of impact over time (see figures 3.7, 3.8, and 3.9)

- Activity-based breakdowns of the LCV impact (see figure 3.8)

- Value-based breakdown of the total LCV impact (see figure 3.9) 


\author{
Parameters: \\ First year \\ WACC Cashflow \\ WACC Value \\ Options: \\ Net Present Value (NPV) \\ Cumulative (required for EAA) \\ Cashflow \\ Value
}

Scenario selection:

Scenario

Error detection

\section{Input \\ 2020 \\ $3,7 \%$ \\ $3,7 \%$}

\section{On / Off $\downarrow$}

on

on

on

on

LCV:

calc0

OK

\section{Current Selection:}

incl. 3,7\% WACC

yearly

cashflows \& values

Figure 3.6: Parameters of the LCV assessment

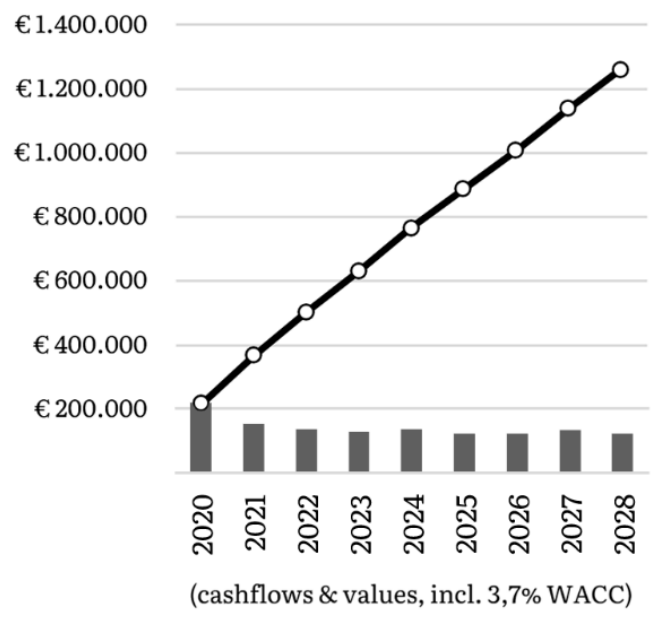

Figure 3.7: An example of total LCV over time (annual and cumulative views combined) 

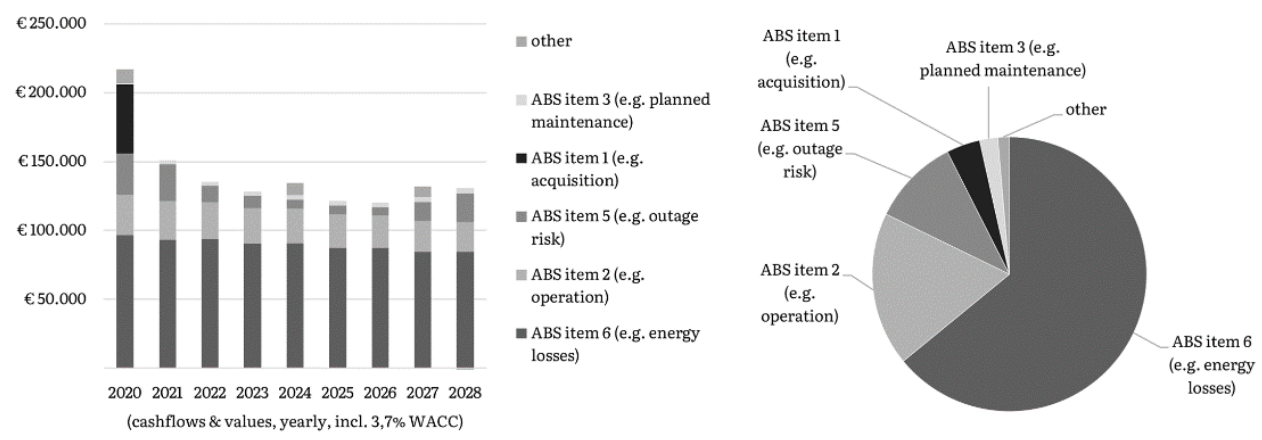

Figure 3.8: Example of activity-based breakdown over time (left) and overall impact contribution (right)
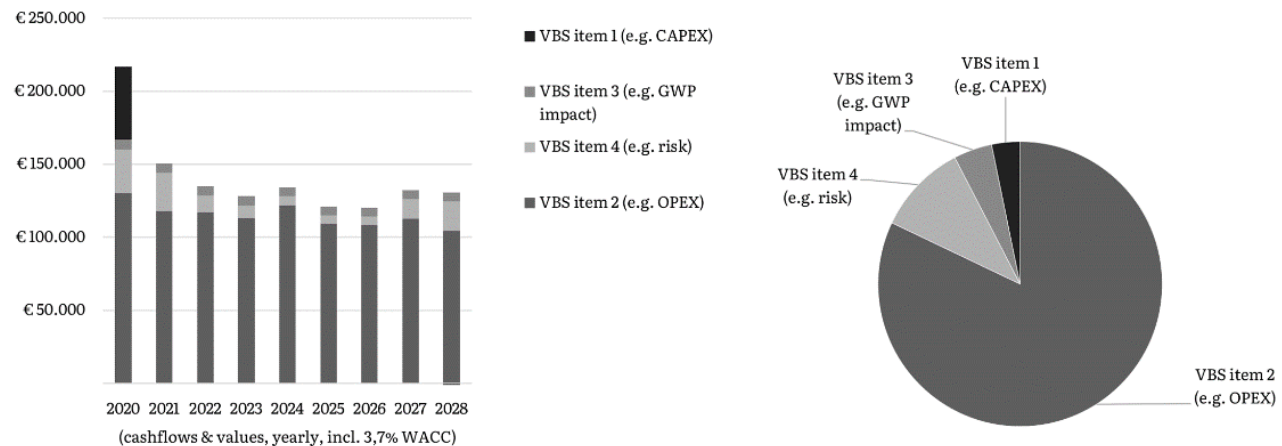

Figure 3.9: Example of value-based breakdown over time (left) and overall impact contribution (right)

\subsection{Step 4: Interpretation}

The profiles in the dashboard support the interpretation of the results in several ways. It allows for a quantitative overview of the financial and nonfinancial value of everything within the assessment scope. It can be used to trace the origin of these impacts back to individual lifecycle elements. This can be used to support additional investigation and development of the assessment outcome by means of sensitivity analysis, completeness \& consistency checks, and improvement analysis.

The total LCV impact (expressed in monetary units such as $€$ ) can be used to indicate the lifecycle option that has the best overall impact score. In straightforward situations, it may be possible to shorten the sensemaking process to a simple 'information' phase, but in complex, ambiguous, multilevel situations it is necessary to allow for, and foster, sensemaking interactions (Thiry, 2001). For example, elements for which quantification is not (yet) possible should not be neglected (Hunkeler \& Rebitzer, 2005) and 
considered in the decision of which lifecycle option is preferred. Furthermore, due to the strategic nature of many AM goals, the option with the best LCV impact is not necessarily the most valuable one. More than in LCC and similar to LCA, the interpretation phase of LCV and its reflection on the limitations in the goal and scope of the assessment is a critical final step in making sense of the assessment outcome.

\section{Evaluation of the LCV methodology}

The application of the LCV methodology at the AM organization of Liander revealed both anticipated and unanticipated outcomes. Using observation, unstructured interviews during the application of the LCV method, and evaluation sessions after each application, these outcomes were linked to the design principles, summarized in table 3.6, providing a condensed overview of how the LCV functions in practice. 
Table 3.6: Design principles of the LCV methodology and their consequences

\section{Design}

Outcomes

principles

Formulation

- Focused the attention of the AM staff to the entire asset

of the goal \& lifecycle (instead of only the initial phases) and stimulated a

scope, and the definition of long-term timeframe and future-oriented mindset.

the system of

- Initiated discussions about the consequences of asset interest lifecycle decisions at the systems (energy grid) and/or asset portfolio levels (and how these effects should be included in the assessment).

- The goal, scope, and system of interest were often initially perceived by the AM staff as self-evident (thus sometimes even skipped entirely), but regularly needed further investigation, adjustment, and explanation in the later stages of the assessment.

Value

Breakdown

Structure

(VBS) \&

Monetary

Valuation
- Enabling the assessment of quantitative factors with a broad value scope beyond only LCC (e.g., including factors such as environmental impact or stakeholder value)

- Clarified which quantitative elements are included in the assessment, how they are quantified and what (monetary equivalent) value they are given.

- Required the coordination of the quantification procedures and monetary valuation factors within the AM organization (e.g., how to measure and value $\mathrm{CO}_{2}$ emissions).
Life Cycle Inventory (LCl) and Activity Breakdown Structure (ABS)

- Initiated the formulation of a life cycle plan for the activities and consequences in the remaining useful life of the asset.

- Required the creation of LCl's for multiple alternative solutions and/or future scenarios.

- Required the collection of expertise, data, and assumptions from multiple disciplines (related to all relevant elements in the asset lifecycle).

- Tended mainly to include dominant cost \& value drivers (thus cutting-off less significant impacts) to speed up and simplify assessment.
Impact

Assessment

- Allowed for a simultaneous quantitative assessment of financial and non-financial impacts (as determined in the VBS).

- Enables the comparison between a conventional LCC impact (sum of all OPEX and CAPEX) and 'LCV impact' (LCC + other quantitative value factors).

- Allows the tracking of specific impacts that result from individual life cycle elements facilitating sensitivity and improvement analyses.

Interpretation - Provides the opportunity to acknowledge and discuss phase relevant decision-related factors that are not (easily) quantified.

- Provides the opportunity to acknowledge and discuss the sensitivity of the assessment to long-term changes. 
Overall, the general outline of the four stages of the LCA framework (as illustrated in figure 3.2) seemed to be well suited for structuring LCV assessments of different types of assets in different lifecycle stages. The four iterative phases were seen by Liander's AM staff as both rational and reasonable, but also as something clearly different from the way LCC has been assessed within the organization in the past. The explicit discussion of the goal, scope, and system of interest stimulated a long-term and lifecycleoriented perspective that is broader in scope than conventional LCC applications. As such, the LCV methodology was effective in stimulating the consideration of the entire lifecycle and proved to apply to multiple lifecycle stages (design criterion 1). A grid architect reflected on this new way of supporting decisions: "the decisions of a grid architect used to be focused on short-term financial impact instead of long-term value". The goal and scope definition also initiated discussions about what to include in the assessment, how to include it, and how to ensure a fair assessment. Despite the benefits of discussing the goal and scope, however, this activity did not come 'naturally' to the AM staff, who tended to skip this step and start the assessment with data collection. Early design iterations, therefore, included the introduction of a brief kick-off session where the goal, scope, and system of interest are specifically discussed and defined.

The application of the LCV methodology proved to be appropriate for different types of objects that were included in the decision-making contexts described in table 3.7. This evaluation included individual assets, portfolios of assets, and (complex) systems of assets (design criterion 4) and allowed for investigating multiple value perspectives for each case. For example, the Energy Flexibility case studies included not only the financial impact for Liander but also accounted for the costs incurred by Liander's customers, as well as the environmental impact associated with potentially having to restrict the production of renewable energy. A junior grid architect reflected that without these considerations, "the grid architects would likely make a decision based solely on [Liander's] immediate costs and not consider a broader value perspective at all“. 
Table 3.7: Decision-making cases that were used to test and demonstrate the LCV methodology and their key value perspectives

\section{Decision context Description Asset objects Lifespan Key value factors}

\begin{tabular}{|c|c|c|c|c|c|}
\hline 1 & $\begin{array}{l}\text { Fault } \\
\text { Detection }\end{array}$ & $\begin{array}{l}\text { Finding optimal } \\
\text { placement of fault } \\
\text { detection \& } \\
\text { localization } \\
\text { components in } \\
\text { electrical grids }\end{array}$ & $\begin{array}{l}\text { Local energy } \\
\text { grids } \\
\text { (complex } \\
\text { system) }\end{array}$ & 15 years & $\begin{array}{ll}\text { - } & \text { Life Cycle Costs } \\
\text { - } & \text { Outage risk } \\
\text { - } & \text { Alternative } \\
& \text { configurations }\end{array}$ \\
\hline 2 & $\begin{array}{l}\text { Ageing } \\
\text { Transformers }\end{array}$ & $\begin{array}{l}\text { Considering } \\
\text { revision or } \\
\text { replacement } \\
\text { options for aging } \\
\text { transformers in a } \\
\text { substation }\end{array}$ & $\begin{array}{l}\text { Individual } \\
\text { asset(s) }\end{array}$ & 40 years & $\begin{array}{ll}\text { - } & \text { Life Cycle Costs } \\
\text { - } & \text { Outage risk } \\
\text { - } & \text { Climate change } \\
\text { - } & \text { Replacement moment }\end{array}$ \\
\hline 3 & Substation & $\begin{array}{l}\text { Solving a capacity } \\
\text { issue for a } \\
\text { substation and its } \\
\text { components by } \\
\text { means of } \\
\text { replacement or } \\
\text { revision }\end{array}$ & $\begin{array}{l}\text { Individual } \\
\text { asset(s) }\end{array}$ & 60 years & $\begin{array}{ll}\text { - } & \text { Life Cycle Costs } \\
\text { - } & \text { Alternative } \\
\text { - } & \text { Enfigurations } \\
\text { - } & \text { Climate change }\end{array}$ \\
\hline 4 & $\begin{array}{l}\text { Grid } \\
\text { Architecture }\end{array}$ & $\begin{array}{l}\text { Studying significant } \\
\text { revision of the } \\
\text { network } \\
\text { architecture of the } \\
\text { grid in a dense } \\
\text { urban area }\end{array}$ & $\begin{array}{l}\text { Major energy } \\
\text { grid (complex } \\
\text { system) }\end{array}$ & $\begin{array}{c}\text { Continuo } \\
\text { us }\end{array}$ & $\begin{array}{l}\text { - } \quad \text { Life Cycle Costs } \\
\text { - } \quad \text { Network architecture } \\
\text { - } \quad \text { Timailability of labor } \\
\text { concerns }\end{array}$ \\
\hline 5 & $\begin{array}{l}\text { Demand } \\
\text { Flexibility }\end{array}$ & $\begin{array}{l}\text { Using demand } \\
\text { flexibility as a } \\
\text { viable option for } \\
\text { solving (temporary) } \\
\text { congestion issues }\end{array}$ & $\begin{array}{l}\text { Local energy } \\
\text { grids (complex } \\
\text { system) }\end{array}$ & $\begin{array}{c}3-5 \\
\text { years }\end{array}$ & $\begin{array}{ll}\text { - } & \text { Life Cycle Costs (DSO) } \\
\text { - } \quad \text { Customer costs } \\
\text { Climate change (when } \\
\text { dealing with } \\
\text { congestion of } \\
\text { renewable energy } \\
\text { sources) }\end{array}$ \\
\hline 6 & $\begin{array}{l}\text { Switchgear } \\
\text { Procurement }\end{array}$ & $\begin{array}{l}\text { Performing a pilot } \\
\text { study on the } \\
\text { inclusion of a } \\
\text { streamlined form of } \\
\text { LCA in the } \\
\text { procurement of } \\
\text { Medium voltage } \\
\text { switchgear }\end{array}$ & $\begin{array}{c}\text { Portfolio of } \\
\text { assets }\end{array}$ & 40 years & $\begin{array}{ll}\text { - } & \text { Costs } \\
\text { - } & \text { Technical } \\
\text { - } & \text { Performance } \\
\text { - } & \text { Formatochemical Ozone } \\
\text { - } & \text { Climate Change } \\
\text { - } & \text { Fossil Depletion } \\
\text { - } & \text { Fine Particulate } \\
& \text { Matter formation }\end{array}$ \\
\hline
\end{tabular}


In many cases, the data, information, and results of previous LCV assessments could be re-used in other assessments. The information required in the LCI phase rarely came from a single source but tended to be spread throughout the organization, corresponding with the different disciplines that are required in different life cycle stages. In creating the $\mathrm{LCl}$ and the $A B S$, the decision-makers not only gathered data expertise and information, but they also needed to develop a plan for the (remaining) lifecycle of the asset, usually consisting of competing alternatives or divergent future scenarios. Within an LCV assessment, the activity of Life Cycle Planning (LCP) and the information found in existing life cycle plans therefore played key roles. Integrating these multidisciplinary perspectives required an iterative process of modeling and verification, which increases the time required for performing $\mathrm{LCl}$ and can be considered a disadvantage. However, the main advantage of this approach lies in the fact that involving multiple disciplines reduces the potential for omitting relevant factors, which builds support for, and trust in, the outcome of the assessment. A senior AM policy advisor reflected: "The LCI is all about collecting perspectives which are formed by different 'realities' that emerge from divergent understandings and needs. It is these perspectives that you try to capture in the model, in such a way that it is recognizable for everyone involved". As such, the design of the LCV fulfills design criterion 2 by consolidating information, data, and expertise from multiple disciplines and management perspectives.

The three-dimensional breakdown structure of an LCV model allows for an assessment of three complementary perspectives of the impact. One breakdown of the impact is possible in the time dimension, which is a necessity in LCC but typically ignored in LCA. The time dimension is necessary for LCV because of the time value of money involved in asset investments as well as the role of timing in LCP. Another breakdown of the impact can be made using the VBS, enabling the assessment of multiple financial and non-financial value factors such as economic, environmental, social, and technical impacts as well as the costs and benefits of relevant stakeholders, fulfilling design criterion 3 . The last breakdown of the impact can be made using the ABS, making it possible to assess impacts at the level of activities in the asset life cycle. This allows these activities to be linked to either operational performance or organizational strategy, depending on the goal and scope of the assessment (design criterion 5). In this regard, the impact assessment phase of the LCV methodology resembles that of LCA, as multiple impact categories can be 
assessed simultaneously or individually. This profiling step differs from LCC, where it is commonplace to aggregate all costs into a single LCC figure or an aggregated sum of the Total Cost of Ownership (TCO). Even though it was technically possible to perform a financially focused (LCC style) assessment by including only financial impacts, every LCV assessment at Liander included relevant quantitative value factors that were either a non-financial impact or affected the finances of other stakeholders, such as those of the customers who rely on the energy grid in order to generate their revenues. To conceptually distinguish the financial perspective from the non-financial one during the impact assessment stage, different terminology was used by various decision-makers (see table 3.8). This not only indicates the desire to be able to conceptually separate the two but also a need to combine both perspectives during decision-making. A decision-maker responsible for future-proof grid design phrased this as follows: "You shouldn't blindly aggregate all costs and benefits in a single figure. We want distinct insights into all direct, indirect and societal impacts before making a decision".

Table 3.8: Terminology used by decision-makers to differentiate between financial and non-financial impacts

\section{Terminology used to describe financial impact for the organization}

Terminology to describe non-financial or non-organizational impact

Soft value, social impact, societal money, environmental impact/costs, externalities, multiple benefits

Conventional LCC does not require an impact assessment phase, because all inventory data comprises a single unit of measure, namely currency (Swarr et al., 2011). LCV however, is designed to assess multiple value factors simultaneously and takes into account that a reductionist perspective on a single asset lifecycle may be too limited for AM purposes. The LCV supported decisions at Liander were usually sensitive to only a limited number of lifecycle elements or impact categories. This meant that for some assessments at Liander, the results were not sensitive to rough assumptions and limited data quality when they applied to non-dominant impacts, greatly reducing the time required to arrive at an informed LCV-supported decision. The interpretation phase is also useful in considering qualitative factors for 
which quantification is not (yet) possible. Such factors are often neglected in both LCC as well as social assessments (Hunkeler \& Rebitzer, 2005). The interpretation phase provides the opportunity for the decision-maker to judge the most important quantitative, qualitative, and normative factors related to the decision. Senior AM policy advisor 2 commented on the role of structuring the LCV assessment in this way: "LCV is not about the act of calculation, but about the process of arriving at an appropriate calculation". LCV interpretation is therefore not aimed at arriving at a definitive answer to how valuable a life cycle option is, but rather, it invites the decision-maker to view the assessment (which has an inherently limited) scope, from a much broader and holistic (AM) perspective.

\section{Discussion and conclusion}

LCV is designed based on the premise that the decisions of AM organizations need to consider changing environments, shifts in organizational goals, and continuously changing notions of what makes an asset valuable beyond its costs. While LCC can be an extremely useful instrument for organizations that manage and invest in capital goods, it is also inherently limited in assessing to what extent these assets create and maintain value over the course of their entire lifespan. Firstly, LCC is primarily focused on costs, whereas AM is fundamentally value-focused and aims to balance and align various financial and non-financial value factors, such as asset performance, risk, environmental and social impacts, and stakeholder needs, alongside life cycle costs and profits. Secondly, LCC is traditionally a reductionist and single object-focused approach, making it less suitable for assessing complex systems, assets with interconnected or interacting objects, or portfolios of multiple similar types of assets. Lastly, the unguided application of LCC takes long-term changes and uncertainty beyond the technical scope of the asset lifecycle itself into account inadequately. This leaves conventional LCC essentially 'blind' to long-term organizational goals, technological developments, (geo)political shifts, and societal changes that may render an asset obsolete before its technical end-of-life. LCA on the other hand already provides a mature systems-oriented framework for the comprehensive assessment of various types of non-financial impacts and explicit guidance on how to manage the goal and scopes of such assessments. LCA, however, is usually focused on environmental, and to a lesser extent, social impacts, forming a perspective that may be valuable and rich in information but fails to 
fully align with the objectives of $A M$, which also requires the consideration of the aforementioned factors such as technical performance, cost, and risk.

Given these limitations of LCC and LCA with respect to AM decision-making, a combined application of LCC and LCA would be insufficient as it would inherit the downsides of both methodologies. Instead, a hybrid approach is proposed that selectively combines the most effective design principles from LCC and LCA, and aims to avoid their respective limitations for AM decision-making. The resulting Life Cycle Valuation methodology can be considered a novel hybrid approach that is methodologically distinct from applications that merely combine applications of LCC and LCA. The LCV methodology combines five main design principles that are borrowed from both LCC and LCA, including (1) using the four-stage framework for LCA, (2) defining the system of interest, (3) accounting for the time value of money, (4) combining activity-based and value-based breakdown structures, and (5) using monetary valuation as a means to aggregate financial with non-financial results.

LCV models make it possible to quickly and easily view the value created over the lifecycle from multiple, complementary perspectives. LCV goes beyond simply adding non-financial impacts to LCC, as it allows for viewing the same life cycle model from different perspectives, including a financial one. These perspectives can be tailored to the specific goals and preferences of the organization or even other stakeholders and can include value factors alongside costs, such as environmental impact, technical performance, risk, or any other relevant metric. By viewing the assessment outcome from these different perspectives, it is possible to gain a better understanding of how different costs and benefits in the life cycle contribute to value creation (or destruction) and which parameters and life cycle activities present themselves as being the most critical or important concerning the decision context. Because of the existence of multiple value perspectives and the subjective nature of valuation, the LCV methodology does not necessarily aim to seek the most optimal allocation of resources, as what is considered optimal by one stakeholder, may be sub-optimal to another. Instead, LCV utilizes the 4 phase framework of LCA to focus on making the assessment and valuation process itself as transparent and objective as possible, thereby helping professionals better understand and articulate what makes a complex system valuable in a specific decision context. The LCV methodology, therefore, consists not just of a flexible and adaptable calculation method for 
value that can be tailored to specific organizational contexts, but also emphasizes the process that facilitates the assessment itself. As suggested by other researchers, the guidelines and principles that were originally developed to guide LCA applications, proved to be highly effective in practice, as demonstrated by the case study at Liander.

\subsection{Limitations and future research}

Even though the LCV methodology calls for an explicit formulation and reflection on the goal and scope of the assessment, the process of arriving at a suitable formulation for this remains a challenge in practice that requires attention in future research. Similarly, the Value Breakdown Structures that quantitatively capture value factors for an AM organization, proved to be challenging to develop and agree upon in practice, not only because some of these value factors can be subjective, but also because they were in continuous flux during the research period. An interesting avenue for future research could be to help structure VBS for particular organizations or industrial sectors using similar principles as those employed in impact assessment methods for LCA.

Additionally, the application of the LCV methodology at DSO Liander mainly resulted in modeling and avoiding 'bad' impacts, such as costs, outage risk, and environmental damages. 'Good' impacts such as revenue were possible but were also much less common, and sometimes only described qualitatively, instead of being included in the model quantitatively. Whether this is due to the challenging nature of articulating value, or because this is a remnant of the tendency of both LCC and LCA, which LCV is based on, to focus on 'bad' impacts, remains a question that requires further investigation.

\section{Acknowledgments}

The authors wish to thank Liander N.V. for the funding of this research project. The authors would also like to thank Liander for their participation in testing this research, especially the professionals that were involved in the application and practical evaluation of the method.

\section{Declaration of interest}

The authors have no competing interests to declare. 


\title{
Chapter 4 - Towards Life Cycle Value-driven Asset Management: An action research investigation into value-driven decision-making in an energy transition
}

\begin{abstract}
:
Asset Management calls for strategic and life cycle-oriented decision-making to achieve organizational objectives with physical assets. As the energy sector is going through a socio-technical energy transition, Distribution System Operators are looking for ways to drive changes in their energy systems while continuing to operate an increasingly aging asset population in a reliable, safe, cost-effective, and sustainable way. If strategic decisions are to succeed in the long term, they must therefore be aligned with the planning and control of asset-related activities. Given the systemic nature of energy grids and the scope of the energy transition, this challenge requires a pro-active, multidisciplinary, value-driven, and strategic life cycle planning approach.

This article focuses on the organizational changes resulting from the design and implementation of two novel interrelated approaches (research artefacts) aimed at supporting strategic Asset Management decision-making. The Asset Life Cycle Planning approach is designed for the early identification of important factors that affect the asset life cycle. The Life Cycle Valuation approach is designed for the assessment of the life cycle plans of mitigating measures and their expected impacts on organizational values and objectives. These complementary approaches were tested and evaluated at a Dutch DSO in a longitudinal action research study, providing a rich and in-depth research context spanning eight years, resulting in a set of actionable propositions on strategic AM decision-making.

The results indicate that the combination of both approaches leads to increased decision transparency, improved alignment between financial and non-financial functions, and increased support for taking strategic measures, despite long-term uncertainty.
\end{abstract}

\section{Publication history:}

This chapter was submitted to the Journal of Operations Management at the time of writing. 


\section{Introduction}

Across the world, the energy sector is currently going through a systemic socio-technical change that is commonly referred to as the energy transition. Even though the word transition is singular, the energy transition is not a single transition but "a multitude of more or less interrelated processes of change that occur in different regions, at different speeds and with different synchronicities" (Markard, 2018). In Europe, the energy transition can be characterized by four main aspects: (1) the liberalization of the energy sector; (2) the shift towards renewable and more sustainable energy sources (Markard, 2018); (3) the decentralization of energy production; and (4) changes in energy consumption patterns (Verbong \& Geels, 2007). From a technological perspective, the newly emerging broad range of distributed energy resources such as distributed generation, local storage, electric vehicles, and demand response, are driving changes in power systems (Ruester et al., 2014). These changes also result in higher and intermittent peaks in both energy production and demand, requiring a high degree of flexibility from energy systems (Gallo et al., 2016).

Distribution System Operators (DSOs) are responsible for operating, maintaining, and developing new systems for the distribution of energy, mostly in the form of gas and electricity. In Europe, DSOs connect around 260 million customers, operate 10 million km of power lines, and supply $2700 \mathrm{TWh}$ of energy per year for the distribution of electricity alone (Mateo et al., 2018). DSOs are responsible for ensuring the long-term ability of the system to meet reasonable demands for the distribution of electricity and need to do so without discriminating between the system users (EU directive 2009/72/EC article 25,2009 ). As such, DSOs are uniquely positioned between the supply and demand sides of European energy systems and are expected to independently meet the demands and needs of both sides under strict regulations. As such, DSOs play a key role in driving the technical changes that are required for such a transition.

Meanwhile, another important challenge across the world is that many of the physical assets that comprise public infrastructure systems are reaching the end of their useful lives and need replacing in the near future (Boller et al., 2015; Hijdra et al., 2015; Qureshi \& Shah, 2014; Van Breugel, 2017). Many infrastructure asset management organizations are therefore faced with crucial planning decisions for these assets. Should these systems be repaired 
or replaced? If they are replaced, what system will it be replaced by, and when? Because of the costs involved over the lifespan of these physical assets, these questions also require a financial perspective. Likewise, the physical assets that comprise the energy grids that are operated by DSOs are also aging, as many of them are more than 40 years old, no longer meet desired levels of reliability, or are unable to keep up with growing energy demands (Willis \& Schrieber, 2013). The combination of an aging asset population and the socio-technical changes of the energy transition means DSOs are facing a lot of important strategic technical decisions with longlasting consequences. Not only because of a high need for asset replacement but also from the need to fundamentally restructure or extend existing networks (Förster \& Zdrallek, 2017). Thus, DSOs are looking for ways to harmonize the day-to-day operation of existing (and aging) assets with the strategic developments that are required to deal with the long-term, but largely uncertain developments of the energy transition, especially in decisions where large capital investments are made. As such, the archetypical AM context of a DSO provides an interesting opportunity to investigate how AM organizations can support strategic asset planning, the lessons of which can be transferred to other AM organizations and environments.

\subsection{The need for strategic life cycle planning}

Historically, AM literature has tended to focus on short-term, operational, and tactical issues, instead of long-term and strategic matters (Amadi-Echendu et al., 2007; Komonen et al., 2012; Murthy, Atrens, \& Eccleston, 2002). In addition, they also tended to focus mainly on technical and maintenance aspects (Campbell, Jardine, \& McGlynn, 2011; Frangopol et al., 2012). In other publications, however, strategic planning is being emphasized as an important competence for asset managers (Bish, Newton, Browning, O'Connor, \& Anibaldi, 2014; Stapelberg, 2006). The long-term planning of assets and the financial perspective of its required investments rely on each other and need to be reconciled in order to uncover a deeper understanding of strategic choices (Myers, 1984). If strategic decisions are to succeed in the long term, they must therefore be aligned with the planning and control of asset-related activities (El-Akruti et al., 2013). Gavrikova, Volkova, \& Burda (2020) indicate that strategic Asset Management (AM) can be a source of sustainable advantage both for competitive and regulated environments, as long as strategies across all levels of decision-making are interconnected and 
primarily focused on the configuration and management of the asset portfolio while taking into account the external pressures, competitive environment, and budget. Seeking an optimal mix of value-for-money from individual assets while optimizing systems performance and maximizing whole portfolio value, however, is a complex business (Woodhouse, 2015) for which guidance is required. Regardless of whether decisions are operationally, tactically or strategically motivated, investments in these systems require a conscious decision because of their long lifespan.

\subsection{The limitations of Life Cycle Costing}

Because of this long lifespan, investment decisions not only need to take into account the capital expenses but consider the Total Cost of Ownership (TCO) (ISO 55010, 2019). The concept of TCO and similar conceptual variations with their own abbreviations (Gluch \& Baumann, 2004; Huppes et al., 2004) are strictly related to the concept of Life Cycle Cost (LCC) and are often used without distinction in literature (Arja et al., 2009; Roda \& Garetti, 2014). Life Cycle Costing (LCC) has a critical and essential role to play in asset management decision-making processes, particularly for replacement optimization, maintenance policies, and procurement policies (El-Akruti et al., 2013). As the life cycle costs, profit objectives, and cost structure have a significant influence on the asset strategy and strategic choices, the economic sustainability aspects of asset solutions should be integrated into corporate asset strategy (Komonen et al., 2012). Although LCC has been widely discussed for decades, it is not often applied in practice by many firms (Gray et al., 2020; Roda \& Garetti, 2014). There are several explanations for this lack of implementation. Firstly, LCC is not just about costs but also requires a balanced assessment that takes into account long-term system performances such as condition, safety, reliability, and deterioration (Frangopol \& Liu, 2007). Secondly, costs are isolated and addressed in a fragmented way throughout various life cycle stages, each with different drivers and perspectives that all need to be considered (Roda \& Garetti, 2014). Thirdly, the long lifespan of assets makes the outcome of LCC sensitive to external factors and long-term uncertainties (Arja et al., 2009).

Cole \& Sterner (2000) argue that LCC is not just a tool for comparing or ranking alternatives, but that the approach should have a major role in providing a comprehensive decision-making framework that links life cycle costs across different stages in the lifecycle. From this perspective, LCC is not just used as 
an analytical tool to find the most cost-effective solution, but also as an instrument for creating awareness of where cost drivers originate from, which trade-offs exist with other factors in the lifecycle, and to better understand how these factors can be improved. Furthermore, organizations are increasingly expected not to just think about costs, but to judge on 'value'. Physical systems are not called 'assets' because of their high costs but by virtue of their actual or potential value (Woodhouse, 2015). Furthermore, this value is often realized through the combined performance within interconnected and complex systems, not just individual assets (Woodhouse, 2015). Because firms compete on value instead of costs, Gray et al. (2020) suggest that firms should not just focus on cost reduction, but on a 'total value contribution' that consists of costs and benefits. Ideally, LCC should therefore be factored together with non-financial aspects of the decision-making process (ISO 55010, 2019).

\section{The design of two strategic asset management support approaches}

A commonly used framework for AM can be found in the documents of the ISO 55000 standard which enables an organization to examine the need for, and performance of, assets and asset systems at different levels (ISO 55000, 2014). This standard stresses the need for the consideration of the entire lifecycle, as it enables the application of analytical approaches towards managing an asset over the different stages of its lifespan (which can start with the conception of the need for the asset, through to its disposal, and includes the managing of any potential post disposal liabilities) (ISO 55000 , 2014). Even though the ISO 55000 standard clearly outlines a general overview of the principles and requirements of AM, it also needs to apply to a broad range of asset-oriented organizations. It, therefore, tends to avoid addressing how these generic $A M$ principles and requirements can be implemented into the specific managerial systems and objectives of individual asset management organizations.

Based on a survey on successful AM practices, Tranfield, Denyer, \& Burr (2004) have developed a strategic AM framework that is based on answering two fundamental strategic AM questions. The first of these pragmatic questions ("Why should I be bothered?") is essentially about taking stock of the present and looking ahead for potential issues that may arise in the future. 
This process does not tend to occur naturally in practice, as many engineers and managers are already juggling a myriad of urgent tasks and rarely get an opportunity to prioritize long-term activities, resulting in what Bohn (2000) calls the 'firefighting' syndrome: Chaotically rushing from one 'fire' to the next without taking the time to take preventive action or mitigating measures. The second question ("What should I do about it?") boils down to making an informed decision to act upon any strategic concerns that have been identified, either through action or through inaction. This section therefore introduces and discusses the design and implementation of two artifacts:

1. The design of the Asset Life Cycle Plans (ALCP) for the early identification of important factors that will affect the asset life cycle

2. The design of the Life Cycle Valuation (LCV) approach for the development and assessment of mitigating measures that address these factors.

\section{Method}

Research in AM often lacks the binding of theoretical credibility and practical validation and qualitative methodologies have the potential to serve in exploring the holistic AM system, as an interdisciplinary, cross-functional, and strategic activity of capital-intensive organizations (El-Akruti \& Dwight, 2010). Because of the multidisciplinary nature of AM research, non-experimental and quasi-experimental methods are the most suitable (Kusumawardhani, Gundersen, \& Tore, 2017). The research strategy that is adopted in this article is, therefore (1) intervention-oriented, (2) participatory, (3) longitudinal, and (4) is structured using Design Science Research.

\subsection{Intervention-based research strategy}

The AM problem described in the introduction can be characterized as being ill-defined and wicked (Churchman, 1967; Simon, 1973), belonging to a "class of social system problems which are ill-formulated, where the information is confusing, where there are many clients and decision-makers with conflicting values, and where the ramifications in the whole system are thoroughly confusing" (Churchman, 1967). This 'wickedness' leads to indeterminacy about 
problems and solutions, which is common in design thinking (Buchanan, 1992). Our research is therefore grounded in the Design Science Research (DSR) strategy, which is aimed at developing generalizable knowledge on actions, processes, and systems for field problems, based on a thorough understanding of its problems and opportunities (J. van Aken et al., 2016). Within this DSR strategy, our approach leverages the use of interventions as the primary research mechanism. These interventions take place in a realworld situation, following a methodological strategy that is informed by existing theories (Checkland \& Holwell, 1998; Oliva, 2019). Specifically, CIMOlogic is used to structure and document the interventions, starting with formulating a problematic Context (C), in which an informed Intervention (I) is applied, to produce generative Mechanisms (M), leading to a certain Outcomes (0) (Denyer et al., 2008; J. van Aken et al., 2016). This approach is similar to Action Research, which is aimed at bringing change in an organization as well as generating robust, actionable knowledge (Coghlan, 2011; A. B. (Rami) Shani, Coghlan, \& Cirella, 2012). An important characteristic of this approach is that it is an iterative sequence of events, consisting of multiple cycles of actions and reflections (Coughlan \& Coghlan, 2002; A. B. (Rami) Shani et al., 2012; A. B. Shani \& Pasmore, 1985; J. E. van Aken, 2004). This iterative cycle of testing, reflection, and developing knowledge is summarized in figure 4.1.

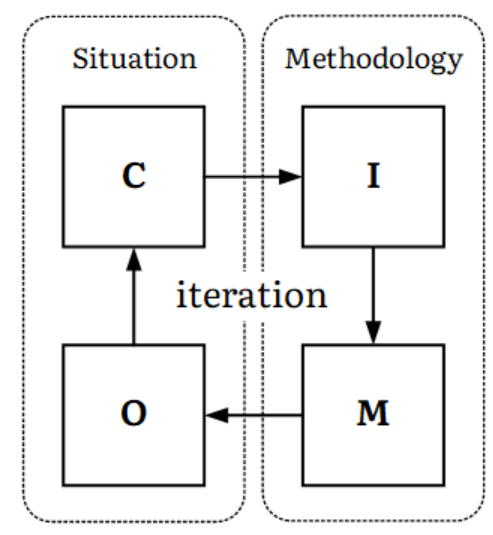

Figure 4.7: Intervention-based research approach based on Checkland \& Holwell, (1998) and Denyer et al. (2008) 


\subsection{Case company Liander}

Liander N.V. is the largest DSO in the Netherlands, serving approximately 3,1 million electrical grid customers and 2,5 million gas grid customers in 2019. Liander has operated under its current name as DSO since 2008 as the result of the 2006 Dutch 'Independent Network Management' act that 'unbundled' the management of energy grids from the production or trading in energy. As such, Liander is the result of a merger of multiple smaller grid operators. Liander has adopted the AM system in its organization, obtaining the ISO 55001 certification in 2014. Like many DSOs, Liander's AM organization is currently faced with the complex task of enabling and supporting the energy transition whilst managing a large portfolio of complex energy grids and steadily aging assets.

\subsection{Data collection}

Organizational problems can be complex and ill-structured. To address such problem situations effectively and holistically, researchers need to be in situ (Avison et al., 2018). Rather than observing or describing events that happen within an organization, our research seeks to develop robust actionable knowledge that is grounded in improving practice (Maestrini, Luzzini, Shani, \& Canterino, 2016). This quest for actionable knowledge arises in a context of practice and requires researchers to work with practitioners (Huang, 2010). Action Research is participative in nature as members of the system which is being studied participate actively in the research process (Coughlan \& Coghlan, 2002). Unlike conventional social science, the purpose of AR is not primarily or solely to understand social arrangements, but also to effect desired change as a path to generating knowledge and empowering stakeholders (Huang, 2010). The action researcher, therefore, acts directly as an agent of change, instead of being an external observer (Maestrini et al., 2016). AR, therefore, focuses on research through action, instead of research about action (Coughlan \& Coghlan, 2002; Huang, 2010). To do justice to the illdefined problem, a broad data collection strategy was adopted, similar to that of Groop, Ketokivi, Gupta, \& Holmström (2017), illustrated in figure 4.2. 




Figure 4.2: Researcher engagement, problem framing, and solution development, adapted from Groop et al. (2017) 
Field observations were made by researchers 1 and 2 and collected in the form of a daily journal to improve the recoverability of the findings (Checkland $\&$ Holwell, 1998). These field observations contain information of all relevant insitu interaction, structured by a strict separation between observed factual events (field notes) and a critical reflection of these events (theory), as advised by Coghlan \& Brannick (2019). Semi-structured interviews were used to understand the viewpoints of relevant stakeholders and to evaluate the efficacy of the implemented solutions with the organizational staff. Academics and practitioners are laypersons to each other and need to find a common ground, requiring effective communication (Kieser \& Leiner, 2012). To support this communication and to ensure simultaneous practical and theoretical relevance, a steering group was created, consisting of at least three university staff and three company staff, which held quarterly meetings. Several workshops were held to support the implementation of individual solutions (e.g., TECCO sessions and 'Goal \& Scope' sessions). Lastly, internal AM-related documents (e.g., SAMP, annual reports, and policy documents) were studied to better understand the organization's motivation as well as sources of information required in the implementation of specific solutions.

The core research team consists of two daily supervisors (one from the organization and one from the university) and the participatory researcher. Researcher engagement was ensured by embedding two university researchers in the AM organization of Liander. Each researcher was engaged over a period of 4,5 years, spanning a total of approximately 8 years (20132020). The first researcher was engaged in Asset Life Cycle Planning (ALCP). The second researcher was first engaged in the application of asset Life Cycle Costing (LCC) in decision-making, which was later developed into the implementation of Life Cycle Valuation (LCV). Being in-situ 'in the real-world', allowed the researchers to understand the complexities and richness of the organizational context, enabling problems to be addressed through taking action, intervening in the way the organization would normally approach problem-solving. Overall, several solutions were developed and instances of these solutions were implemented by the research team over the 8 years, indicated in figure 4.3. 
Solution development and the implementation of the results at the case company

\begin{tabular}{|c|c|}
\hline Method & Introduction of Asset Life Cycle Plans \\
\hline ACLP & ALCP MV switchgear \\
\hline Method & Introduction of TECC(O) \\
\hline Method & Introduction of lifetime impacts \\
\hline Method & Introduction of expert sessions \\
\hline ACLP & ALCP Distribution transformers \\
\hline Method & Reformulating ALCP \\
\hline ACLP & ALCP Electricity cables \\
\hline ACLP & ALCP Gas transportation \\
\hline ACLP & ALCP Power transformers \\
\hline ACLP & ACLP Gas delivery stations \\
\hline ACLP & ALCP High voltage switchgear \\
\hline ACLP & ALCP Gas distribution \\
\hline Vision & Vision for LCC in AM \\
\hline LCC & LCC of HV transformer replacement \\
\hline Method & Introducing LCA framework for LCC \\
\hline LCC & LCC of urban grid architecture \\
\hline Tool & Introducing spreadsheet based LCV tool \\
\hline Method & Introduction of Activity Based Costing \\
\hline LCC & LCC of Energy Flexibility pilot phase 1 \\
\hline LCC & LCC of Fault detection configuration \\
\hline LCC & LCC of HV circuit breaker \\
\hline Policy & One-page grid losses \\
\hline Method & Introduction of Goal \& Scope sessions \\
\hline LCC & LCC of Energy Flexibility pilot phase 2 \\
\hline Policy & Allocation rules for residual value \\
\hline LCC & LCC of low votage power monitoring \\
\hline Vision & Vision refinement: From LCC to LCV \\
\hline Policy & Policy for grid loss calculation \& valuation \\
\hline LCV & LCV distribution transformer refurbishment \\
\hline Tool & First version of LCV tool \\
\hline ALCP & ALCP for electricity connections \\
\hline LCV & LCV on revision of $\mathrm{HV}$ transformers \\
\hline LCV & 10+ LCVs of various Energy Flexibility cases \\
\hline Vision & Formation of Impact Model committee \\
\hline Vision & Vision for LCC and cost control \\
\hline Vision & Formation of LCV team \\
\hline Policy & LCV-based policy for Demand Flexibility \\
\hline Tool & Prognosis tool for Demand Flexibility \\
\hline $\mathrm{LCV}$ & LCV Remote switching \\
\hline LCV & LCV Remote telemetry \\
\hline Tool & Final version of spreadsheet-based LCV tool \\
\hline Tool & LCV tool API \\
\hline Policy & LCV underground cable policy \\
\hline
\end{tabular}

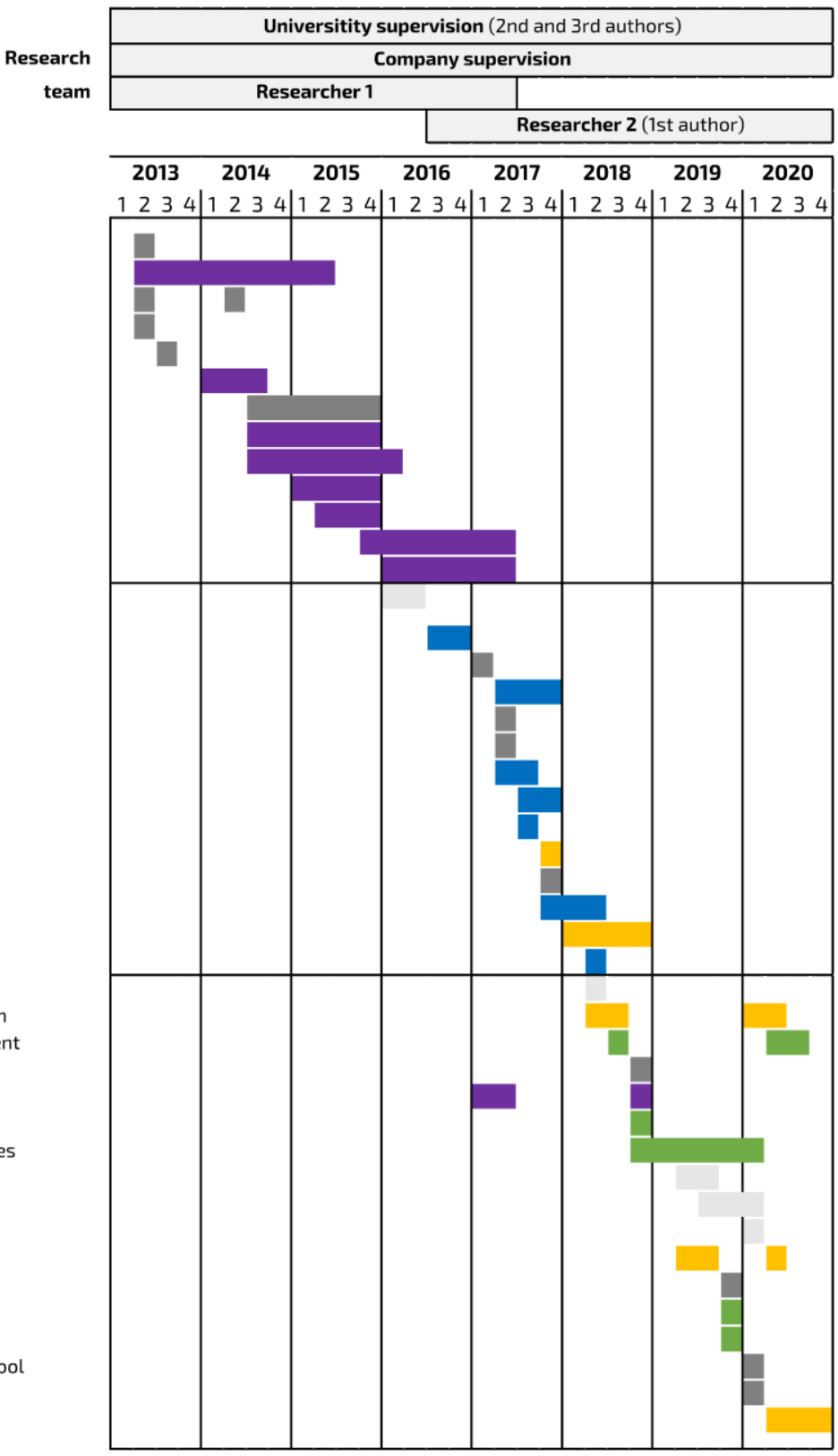

Figure 4.3: Action Research timeline, showing the involvement of the research team 


\section{Context: Ensuring optimal asset performance during an energy transition}

\subsection{Contextual factor $\mathrm{C} 1$ : The desire to know the expected end-of- life of individual assets}

At the beginning of the research period, Liander needed a clear outlook on the long-term life cycle plans for the physical systems that comprise its energy grids. The core challenge for Liander lies in the combination of the long-term and fundamental changes of the energy transition, and the multi-decade long lifespan of the physical assets in its care. Like many infrastructural assets in the Netherlands, a large portion of the asset population was constructed in the period of economic growth after the second world war (Willis \& Schrieber, 2013). A major concern at the time was the possibility of an incoming 'replacement wave', a sudden and large increase in the need to replace many aging assets in a short period. This scenario would not only require significant reinvestments, but Liander also did not have the operational capacity to deal with a large and sudden influx of replacement projects. In July 2014 there was "a limited and dispersed insight in the remaining useful lifetime of the assets (on the medium and long term)" within the organization. The initial desire of Liander was therefore to determine the remaining useful lifetime (RUL) ( $\mathrm{Si}$, Wang, Hu, \& Zhou, 2011) of the existing asset population, to better understand when they are expected to require replacement, as $27 \%$ of all outages in (2019) could be related to aging and wear (see figure 4.4). 


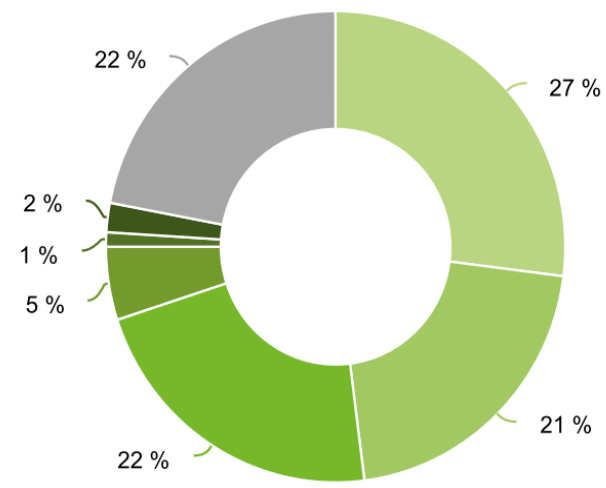

Ageing, wear: $27 \%$

Excavation work: $21 \%$

Internal defect: $22 \%$

Safety system: $5 \%$

Manufacturer: $1 \%$

Ground movement: $2 \%$

Other: $22 \%$

Figure 4.4: Causes of electrical grid outage duration in 2019 (Alliander, 2020)

\subsection{Contextual factor C2: Limited data availability and quality}

A major limiting factor in determining the RUL of many of Liander's assets was the limited availability and quality of asset-related data. These data limitations exist because of an interplay of several factors. Firstly, many assets are simply too old to have digital records that span their entire life duration. Secondly, the formation of Liander as a regulated DSO in 2008 was the result of a merger of multiple smaller grid operators. Each of these grid operators had its own data structures, information management systems, preferred asset types, and policies, leaving Liander with a legacy of fragmented and incomplete asset data. The availability and quality of data were steadily improving over time, but especially data on the older assets was often limited or of insufficient quality.

\subsection{Contextual factor C3: A growing need for asset investments}

Besides the operation and maintenance of the grid and the compensation for power outages, there was a growing need for investments in new assets at Liander because of growing energy demand and aging assets. The combined expenses of network investments and operations reached a level of about $€ 1$ billion in the year 2019 (see figure 4.5). 


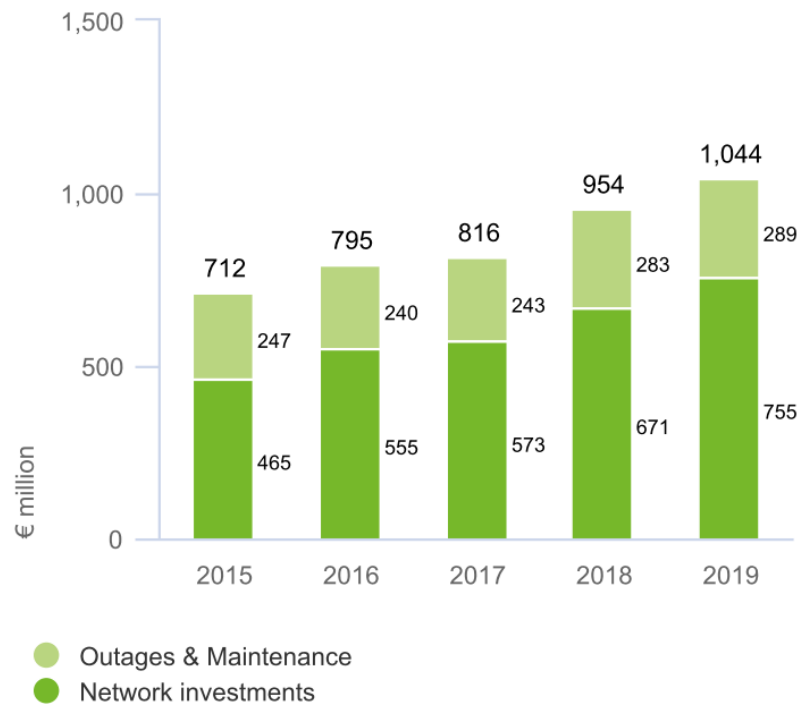

Figure 4.5: Maintenance costs and network investments of Liander (Alliander, 2020)

Asset investment decisions at Liander are typically initiated in two ways. The first reason is in response to emerging technical issues in existing grids that require resolution because they form unacceptable reliability or safety concerns. The second reason is the need for additional distribution capacity due to growing electricity demand in existing grids or in new locations where new residential or commercial development is planned. Investment proposals that deal with these issues are typically prepared by the AM staff and are judged by higher management (depending on the magnitude of the investment). Because of the increasing and considerable costs committed by investments in long-lived assets, the total cost of ownership became an increasingly important factor in Liander's AM decision-making.

\subsection{Contextual factor C4: An increased focus on cost-effectiveness}

The main source of income of DSOs in the Netherlands comes from distribution tariffs paid by clients. DSOs can do little to alter these fees themselves as they are strictly regulated. As such, the income of DSOs is largely determined by the number and types of customers it is required to serve. Furthermore, the Netherlands Authority for Consumers and Markets (ACM) oversees the reliability of all DSOs in the country. The ACM requires that, depending on the duration and frequency of interruptions, DSOs financially compensate their clients for interruptions in the distribution network. In addition, the regulations also state that the allowable height of the customer tariffs needs 
to be adjusted based on the deviation from the average cost-reliability effectiveness of all DSOs in the country. Lower cost-effectiveness over the last few years is translated into lower tariffs. This arrangement, which effectively penalizes unreliability, incentivizes the DSOs in the country to continuously improve their level of service and cost-effectiveness.

During the research timeframe, benchmarks indicated that Liander had lowerthan-average cost-effectiveness in the benchmark. The energy distribution grids still needed to be reliable, safe, and affordable in the present day. On the other hand, significant investments were required in light of the energy transition, but many asset investments take decades before they pay themselves back. This, in turn, led to internal debates on how to best spend Liander's resources and how to balance short and long-term objectives. For Liander, this meant that there was an increased focus on the life cycle costeffectiveness of its current activities and plans.

\subsection{Contextual factor C5: A broadening view on value creation}

As DSO, Liander has a complex and multidimensional organizational objective. Its core business may be defined as providing access to energy distribution through the care and operation of energy grids. Within this responsibility, multiple factors need to be balanced, such as reliability, safety, costs, social fairness, and environmental impact. Furthermore, DSOs such as Liander can also be considered key stakeholders in enabling and supporting the energy transition, because of the unique position of DSOs at the interface between energy demand and supply sides. As such, Liander is increasingly expected to demonstrate to the outside world what makes its activities valuable, beyond conventional metrics such as financial performance. For example, in all annual reports since 2016, Liander has included reports on six capitals (i.e., Financial, Manufactured, Intellectual, Human, Social, and Natural) following the Integrated Reporting guidelines proposed by the International Integrated Reporting Council (IIRC) (de Villiers, Venter, \& Hsiao, 2017).

\section{Design and implementation of the interventions}

\subsection{Design of the Asset Life Cycle Planning (ALCP) approach}

An organization may choose to manage its assets as a group (e.g., by asset types, asset systems, or asset portfolios) rather than individually, according to its needs, and to achieve additional benefits (ISO 55000, 2014). To support 
the strategic AM planning of individual assets as well as asset groups, the Asset Life Cycle Planning (ALCP) approach was developed (Ruitenburg, Braaksma, \& Van Dongen, 2017). The ALCP approach can be broken down into two parts. The first part consists of the creation of Asset Management Plans (AMPs), which consists of five elements (see figure 4.6). Its main purpose is to identify necessary asset (life cycle) interventions that derive from strategic objectives while taking into account current as well as expected asset performance.

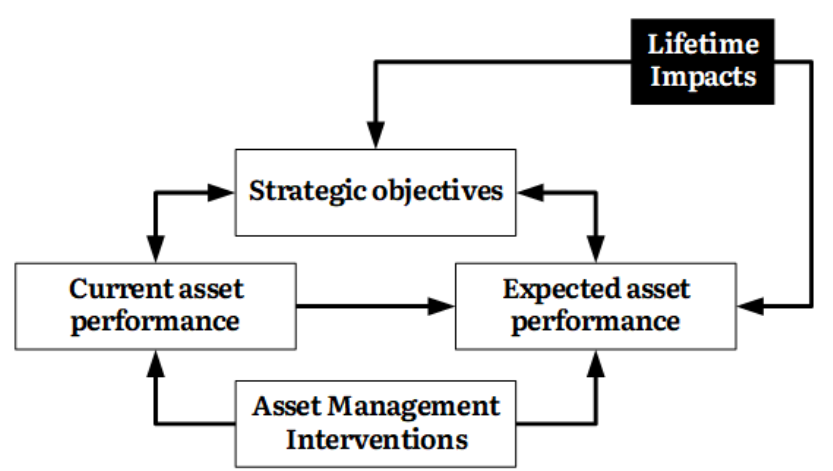

Figure 4.6: The main structure of an ALCP (Ruitenburg et al., 2017)

The second part of the ALCP approach is a refinement of one of the core elements of an ALCP, called the Lifetime Impact Identification Analysis (LIIA). In an LIIA, technical, economic, compliance, commercial, and organizational (TECCO) perspectives across the lifespan of assets are collected using expert sessions (Ruitenburg \& Braaksma, 2017; Ruitenburg et al., 2017). Based on these expert sessions, several 'lifetime impacts' can be identified, representing relevant risks and opportunities in the lifespan of the asset group from multiple (TECCO) perspectives. The ALCP approach, and especially the LIIA, provide an opportunity for experts from multiple disciplines to identify relevant impacts in the life cycles of assets as well as relevant external factors. This provides an opportunity to take timely and proactive actions to deal with long-term challenges and strategic considerations and to avoid running into proverbial 'icebergs' that could have been avoided by early identification. 


\subsection{Intervention 1: Implementation of ALCP}

The ALCP approach was first introduced in 2013, based on existing applications of a similar approach at the Netherlands Railways for the life cycle planning of rolling stock. This approach was adapted to fit the context of Liander AM, starting with the development of an ALCP for medium voltage switchgear. With this application, the LIIA and TECCO approaches were introduced. In the following years (2013 - 2017) seven additional ALCPs were made for populations of assets for both electrical grids as well as natural gas grids under Liander's care.

\subsection{Design of the Life Cycle Valuation (LCV) approach}

Life Cycle Valuation (LCV) is an approach that is designed for the assessment of the costs and benefits of capital goods over their lifespan (Haanstra, Braaksma, \& Van Dongen, 2021). It can be regarded as a hybrid between LCC and Life Cycle Assessment (LCA), as it combines elements from both, but is adapted to address the aforementioned shortcomings of LCC in AM (as discussed in section 1.2).

LCV combines conventional (cost-oriented) LCC with the quantification and monetary valuation of other relevant factors in the lifecycle, such as asset performance (e.g., reliability, availability, maintainability, safety) with other relevant factors such as environmental impact (e.g., $\mathrm{CO}_{2}$-emissions, resource depletion). Which factors are included and how they are valued depends on the organizational goals, KPIs, and asset type. In addition to the quantitative assessment, it also includes a qualitative evaluation for those impacts that are not (easily) quantifiable (see figure 4.7).

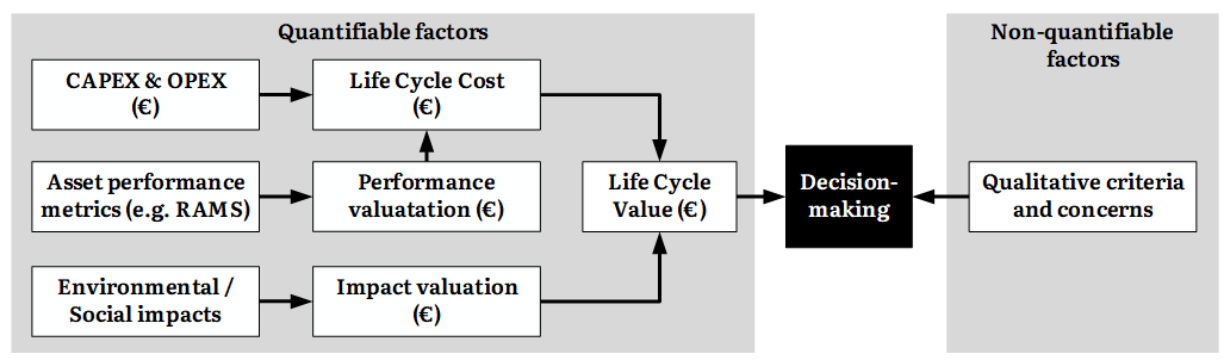

Figure 4.7: Decision-support using the Life Cycle Valuation approach 
To structure LCVs, the procedural standards for LCA as specified in (ISO 14040, 2006) have been adapted with slight adaptations, as proposed by Huppes et al. (2004). This framework (see figure 4.8) delineated four phases that support both the assessment process itself, as well as the reporting structure of the assessment outcomes.



Figure 4.8: Framework for the LCV approach, based on the framework for LCA (ISO 14040, 2006)

In the first phase, the goal and scope are defined, stating the purpose of the assessment, indicating which impacts are taken into account, which (parts of the) system is studied, and which lifecycle alternatives are considered. The second phase consists of an expert-based inventory analysis, where all relevant data, information, and estimations about the various lifecycle alternatives are collected from multiple disciplines, including both qualitative and quantitative information. The third phase uses the quantitative part of the analysis to provide an impact profile, representing an overview of all relevant quantifiable impacts in the lifecycle. This profile is used to investigate which impacts occur over the lifecycle and what their relative contributions are with respect to the overall impact sum. In the last phase, this quantitative outcome is combined and compared with the qualitative elements to interpret the results, providing AM staff with the holistic overview that is needed to make informed decisions about which lifecycle alternative best fits the organizational objectives and requirements. 


\subsection{Intervention 2: Implementation of the LCV approach}

The development of the Life Cycle Valuation approach started with the conscious decision to start with the implementation of Life Cycle Costing in 2016, which at the time was applied infrequently and in a fragmented way at Liander. Initially, these LCC applications were aimed at financial impact over the lifecycle, including indirect financial risks such as outage risk and reliability issues. Over the research period, the LCC (and later LCV) approach was applied to multiple types of asset-related decision-making for electrical grids (see figure 4.3), including individual assets (e.g., transformers), a population of similar types of assets (e.g., switchgear population), a system of assets (e.g., complete energy grids), and on over ten decisions aimed at deferring investments in new assets (e.g., energy flexibility). Because of the multidimensional objectives of $A M$, and the diverging requirements at the levels of individual assets, asset populations, and energy grids, it quickly became apparent that correct scoping of the LCC was an important challenge. This issue was addressed by the implementation of the LCA framework (figure 4.8) in early 2017 and the organization of 'Goal \& Scope' sessions (workshoplike meetings) in late 2017. Also in 2017, a spreadsheet-based LCV tool was developed and implemented, based on the principle of Activity-Based-Costing (ABC) (Emblemsvåg, 2003), allocating costs (and later also other impacts) to an expendable list of recognizable lifecycle activities (e.g., operation, maintenance, inspection, or end-of-life).

As anticipated from previous experiences with the TECCO perspectives, the financial perspective of LCC was often too limited to fully address all objectives and criteria of AM, especially concerning value creation (C5). In early 2018, and after an intentional delay of about 1,5 years, the 'Goal \& Scope' framework and the $A B C$ approach were therefore extended by the integration of additional value factors (see figure 4.7). Furthermore, the name LCC was superseded by the name LCV, which stands for Life Cycle Value (analogous to the Total Cost of Ownership) or the Life Cycle Valuation process (analogous to the process of LCC assessment), to further invite the AM staff to look beyond cost impact during AM decision-making. 


\section{Mechanisms}

\subsection{Mechanism M1: Identifying and prioritizing the most relevant issues and solutions}

The ALCP and the LCV approach both make use of the mechanism of the identification of the most relevant issues in the asset life cycle and the subsequent prioritization of the most promising solution for the organization. In the application of ALCP, it quickly became apparent that an exact figure for the RUL estimations of Liander's aging assets could not be determined with sufficient certainty. Firstly because of the data limitations (C2), but more importantly, because the RUL depends on multiple factors. Each asset could reach the end of its useful life in multiple but distinct mechanisms, resulting in technical, economic, commercial, compliance, or organizational end-of-lives respectively. The main goal of the ALCP was therefore to focus on the identification and prioritization of the most important factors that influence the RUL of an asset, instead of determining numerical RUL estimations.

Similarly, from the application of the $A B C$ technique, it was observed that the LCC and LCV of assets are usually driven by only a limited set of cost and value drivers. When these drivers are ranked, usually there are only a few dominant drivers in the lifecycle, followed by an ever-decreasing set of less relevant cost and value drivers, similar to the 'Pareto principle', also known as the ' $80 / 20$ rule'. The use of LCV should therefore be aimed at identifying key value drivers in the life cycle and aimed at finding life cycle solutions that affect the cost and value creation the most and that the organization itself can control (Asiedu \& Gu, 1998). 


\subsection{Mechanism M2: Transparency of financial and non-financial value factors in decision-making}

The LCV assessment approach is designed to enable a breakdown of the quantitative impact in the lifecycle in three complementary ways (see figure 4.9). Firstly, it is possible to break down the life cycle impact using $A B C$, showing the contribution of life cycle activities (e.g., purchase, maintenance, repair). Secondly, it is possible to make a breakdown in value, showing the contribution of different value drivers (e.g., costs, reliability, outage, environmental impact). Lastly, it is possible to make a breakdown of how the LCV impacts develop over time, enabling an overview of the consequences in the short, medium, and long-term of the asset lifespan as well as a total impact figure. This three-dimensional breakdown structure enables the AM staff to make a transparent and recognizable quantitative model of the asset lifecycle. To build LCV models, it is required to make the activities, values, and timing of all elements in the lifecycle explicit.

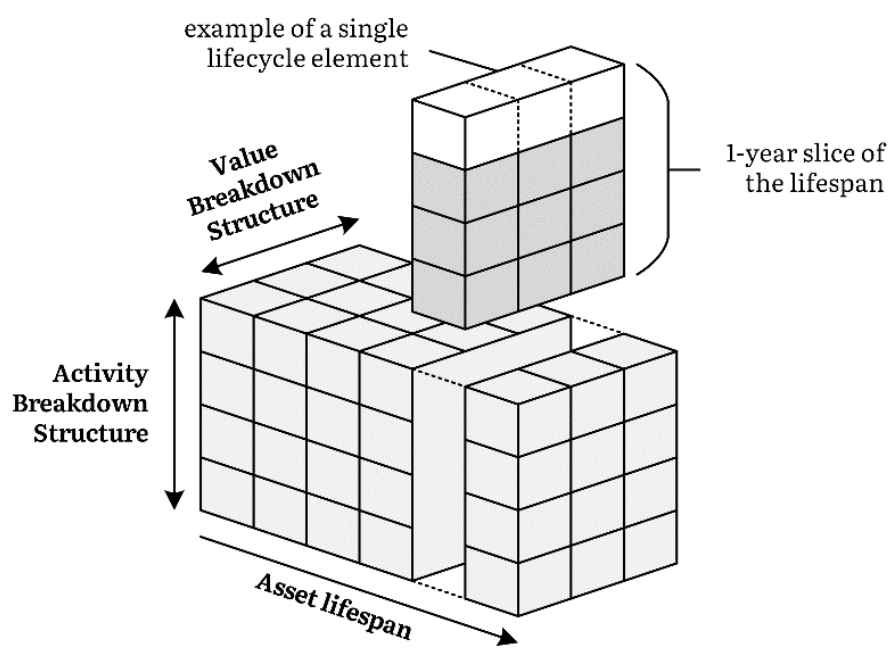

Figure 4.9: The quantitative breakdown structure of an LCV model

Because few, if any, decisions are based solely on quantitative analysis (Simpson et al., 2000), the interpretation phase of the LCV approach purposefully invites AM staff to reflect on the quantitative outcome of the assessment and also provide an additional overview of relevant qualitative factors. These factors may include elements that are difficult or impossible to 
quantify but can be important in deciding which alternative is preferred, especially when the quantitative outcomes are similar. For example, the pilot case on Energy flexibility in late 2018 was given the go-ahead because of its strategic value, despite having somewhat higher LCC.

\subsection{Mechanism M3: The construction of multidisciplinary intersubjective life cycle perspectives}

Both the ALCP and the LCV approach made use of expert-based and multidisciplinary input in the collection of information about the relevant life cycle stages and lifetime impacts. Instead of having a single person perform ALCP or LCV assessments, the use of a multidisciplinary group of experts was employed to collectively make sense of the asset lifecycle. This process is used to build a shared intersubjective model of the required strategic interventions and intended outcomes (Thiry, 2001). This not only enables a broad and holistic perspective, but the intersubjectivity also means that trust and acceptance are built during the sensemaking process itself.

\subsection{Mechanism M4: Enabling a holistic consideration of asset-related factors}

The ALCP and the LCV approaches both provide opportunities to asset managers to break out of the operational routine and 'firefighting' attitude often associated with the management of technical systems. Both approaches invite AM staff to take a long-term outlook of the entire lifespan of their assets. For Liander, this often meant imagining their assets in a post-energy transition future, "long after [their] own retirement". Furthermore, the approaches also invite a holistic outlook on the asset lifespan. In ALCP, this is expressed by the five TECCO perspectives. In the LCV approach, the 'Goal $\&$ Scope' framework invites AM staff to think about individual assets with respect to other assets in multiple ways. The optimal lifecycle of an individual asset may conflict with the optimal management of the entire asset portfolio, posing a trade-off between flexibility and standardization. Energy grids have no clear end-of-life at the system level because they are composed of multiple assets with various lifespans. Furthermore, the benefits of these grids are generated at the system level, whereas costs are incurred at the individual asset level. Lastly, LCV invites the simultaneous assessment of both cost and value factors in the same scope. 


\section{Outcomes of the interventions}

\subsection{Outcome 01: Increased acceptance of physical asset investment decisions}

The ALCP approach results in a comprehensive list of lifetime impacts. Likewise, the outcome of an LCV provides an explicit overview of all relevant quantitative and qualitative impacts in the current or the proposed new lifecycle of the asset. This not only provides a transparent (MZ) overview that makes it easy to identify if important elements or perspectives are missing. Furthermore, it also allows estimations to be made for situations where data was not available, as long as the outcome of the assessment is not too sensitive to errors in these estimations. Trust in the outcomes of ALCPs and LCVs was further stimulated by the intersubjective lifecycle perspective that is built during the assessment process itself (M3), enabling experts from multiple disciplines to develop a shared perspective of the life cycle. Lastly, even in the assessment of a single lifecycle, the 'Goal \& Scope' sessions of the LCV approach enable a holistic consideration of multiple asset-related factors (M4), including strategic concerns. The combination of these three mechanisms allows for decision-making that is well-informed, transparent about its considerations and makes clear how the proposed asset life cycle decisions best fit the organizational objectives and requirements.

\subsection{Outcome 02: Increased alignment of financial and non-financial functions}

The implementation of the LCV approach helped in the alignment of financial and non-financial functions (ISO 55010, 2019) by enabling the evaluation of the cost impacts of environmental and social changes, and the resilience of assets to these changes. It supported this process through the assessment of the life cycle costs and benefits of assets, providing the financial and non-financial information necessary to make evidence-based asset management decisions.

Because of the partially quantitative nature of LCV, this alignment was also required at the level of balancing financial impact (OPEX and CAPEX) with other non-financial impacts (e.g., environmental impact), as exemplified by the vision change from LCC to LCV in 2018. One of the outcomes of the implementation of LCV was that a company formed a steering group for the valuation of these impacts, called the MMO (Dutch acronym for societal model consultation) in 2019. The MMO consists of chief staff members from the 
Asset Management, Financial and Corporate Social Responsibility departments, and was used to propose agreed upon valuations for various non-financial impacts, such as the value of grid losses and $\mathrm{CO}_{2}$-emissions, to be used in investment proposals. These agreed-upon valuations enable AM staff to articulate what makes an asset valuable beyond its life cycle costs in a transparent (M2) way, helping them make more value-oriented decisions without sacrificing cost-consciousness.

\subsection{Outcome 03: Increased support for strategic AM measures despite uncertainty}

Increased confidence in making proactive decisions was achieved by the identification and prioritization of the most relevant issues and solutions (M1), despite considerable internal and external uncertainties. This allowed the focus of AM to be shifted to those elements that were (1) important to the organizational objectives, and (2) were able to be influenced by the organization itself. This, in turn, facilitates the formulation of proactive measures and can be used to break out of the 'firefighting' mentality that tends to prevail in technical asset-focused environments. To support this process, the AM organization of Liander formed a dedicated LCV team in 2020, tasked with proactively finding and evaluating opportunities for asset life cycle improvements. Of course, uncertainty is still an important factor to consider. The ALCP and LCV approaches, however, do enable more confidence and increased support for taking action under uncertainty because they provide an overview of the most important factors for the asset and organization.

An interesting side-effect of the overview provided by the ALCP and LIIA approaches was that it could also result in a somewhat confrontational overview of problems that weren't entirely clear to the organization before. Once unavoidable challenges are out in the open, they also need to be addressed, which means designating responsibility and accountability. Therefore, besides the aim of looking ahead for opportunities, there were also concerns about potentially uncovering confrontational findings that could be damaging to the organization when revealed. In none of the ALCPs, however, did the outcome reveal any new confrontational insights, making these worries unfounded. It does suggest that ALCP can support the development of an organizational culture that is willing to face uncertainty and vice versa. 


\section{Discussion of actionable design propositions}

Our complete CIMO framework is summarized in figure 4.10, showing the context (C) of the AM challenge, the design of the interventions (I), the mechanisms (M) that were triggered by these interventions, and the resulting outcome (0) of these interventions.

\section{Context}

C1: The desire to know the expected end-of-life of individual assets

C2: Limited data availability and quality

C3: The need for a proactive outlook for asset investments

C4: An increased focus on costeffectiveness

C5: A broadening view on value creation

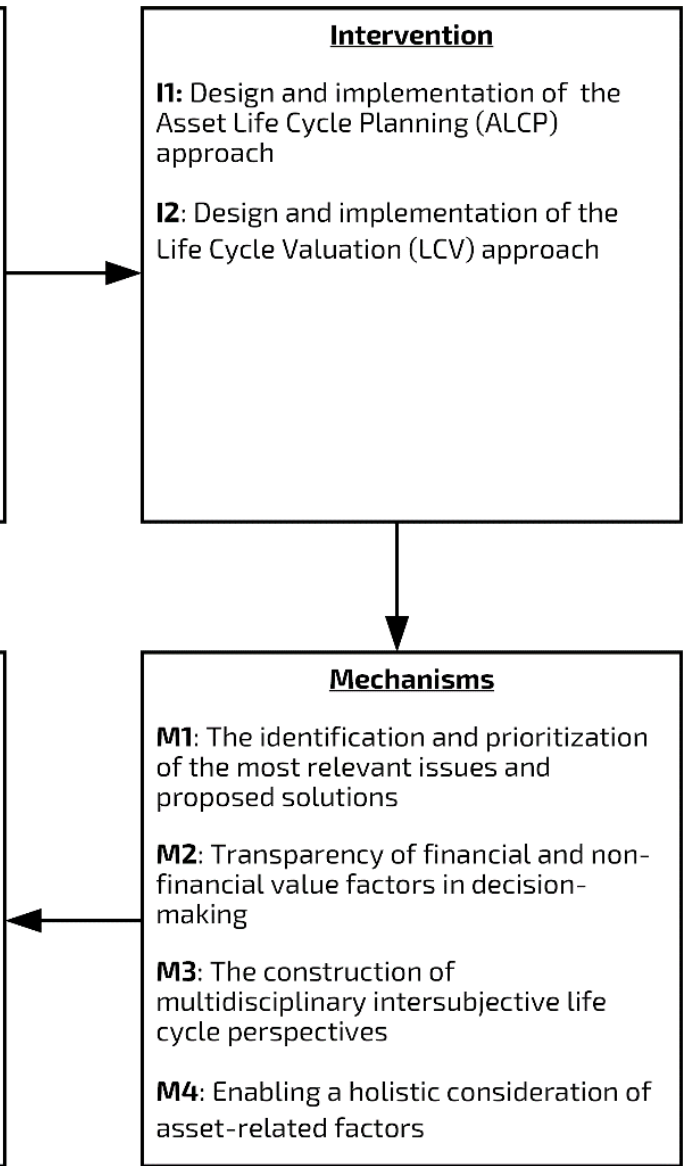

asset-related factors

Figure 4.10: CIMO framework for Life Cycle Value-based decision-making

Based on the outcome of the investigation presented in this article, we put forward three actionable design propositions (Akkermans, Van Oppen, Wynstra, \& Voss, 2019; Kaipia, Holmström, Småros, \& Rajala, 2017; Joan E. Van Aken, 2004) for the implementation of the Asset Life Cycle Planning and Life Cycle Valuation approaches. These condensed propositions are intended to generalize the knowledge gained during the investigation and are intended to be both useful to practitioners as well as theoretically robust for scholars 
(Adler, Shani, \& Styhre, 2004). Through a process of abductive logic, these propositions are aimed at capturing the generated knowledge of the action research using pragmatic logic (Chandrasekaran, de Treville, \& Browning, 2020). We present this 'know-how' in the form of actionable propositions, similar to Akkermans et al. (2019), which can be used to improve the performance of individual managers, the organization, or even a network or society (A. B. (Rami) Shani et al., 2012).

P1: The acceptance of physical asset investment decisions is supported by increased transparency, an intersubjective understanding of the life cycle, and a holistic consideration of asset-related factors.

P2: The LCV approach supports the alignment of financial and non-financial functions by making the internal and external, costs and benefits in the lifecycle explicit quantitatively and qualitatively.

P3: Support for taking strategic AM can be created by first identifying the most relevant life cycle factors, and subsequently focusing on improvements to the elements that the organization is capable of changing.

The implementation of the LCV approach at Liander followed Lewin's Change Management Model (Lewin, 1947) of taking LCC as a well-established starting point, 'unfreezing' it to allow it to be changed into LCV and finally 'freezing' it once more to cement the changes. This implementation strategy was intentional, as, at the time, limited support existed for the implementation of LCC, let alone for LCV which is much broader and challenging to apply than LCC. An important challenge for other organizations is that the implementation of AM processes is a long-term development that takes time (Shah, McMann, $\mathbb{A}$ Borthwick, 2017) and needs to be adapted to the organization (Rajala \& Hukka, 2018). The implementation of ALCP and LCV in another organization, therefore, needs to be carefully managed, as it requires a process of change, a process in which, for example, Kotter's change model can be applied (Appelbaum, Habashy, Malo, \& Shafiq, 2012). 


\section{Conclusion}

The context that DSOs like Liander find themselves in can be seen as a compelling case in point of what makes AM different from more conventional maintenance management. In its decision-making, DSO Liander needs to simultaneously address the issues of an aging asset population, with the challenges and uncertainty of the energy transition, while ensuring reliable, affordable, safe, and sustainable energy distribution services, using increasingly complex and flexible energy systems.

To deal with this complex and multidimensional challenge, two complementary approaches are presented that use the lifecycle perspective to investigate and develop plans for individual assets, asset groups of similar types, or complex systems of multiple assets. We posit that the two artifacts discussed in this article represent novel contributions to theory and practice. The Asset Life Cycle Planning (ALCP) approach can be used to identify and prioritize important risks and opportunities in the lifecycle of assets. Subsequently, the Life Cycle Valuation (LCV) approach can be used, in the place of life cycle costing, to assess the costs and benefits of the proposed life cycle designs that best fit the organizational objectives. Three actionable propositions for the implementation of these two approaches are presented that can be used to adapt and implement these approaches in other AM organizations.

The findings of the longitudinal and participatory investigation of the design and application of ALCP and LCV indicate that, even under considerable data limitations and external uncertainty, strategic decision-making is still viable. It is arguably more straightforward and more valuable to identify the most important factors that influence the RUL or the TCO of an asset than it is to determine an exact, but meaningful, RUL or TCO figure. An important consideration, however, is that these factors need to be collected using multidisciplinary perspectives, expert-based judgments, and the data sources that are available. As such, an intersubjective understanding of the most valuable life cycle option can be built that is crucial for building support for investing in mitigating or preventative measures before it becomes too challenging to deal with reactively in the future. 


\section{Acknowledgments}

The authors wish to sincerely thank Liander N.V. and its AM staff for their participation and long-term commitment in this research, and Richard Ruitenburg for his research on Asset Life Cycle Planning. 


\title{
Chapter 5 - Design of a framework for integrating environmentally sustainable design principles and requirements in train modernization projects
}

\begin{abstract}
:
Environmental sustainability is an increasingly important subject in the railway sector. Literature reveals that transportation companies target multiple sustainability-related improvement areas and follow different strategies to improve in these. For railway operators, train modernization provides key opportunities for technical, financial, and environmental improvements halfway through the lifecycle. Using Design Science Research, a framework was developed that is aimed at integrating sustainable design principles and sustainability-focused requirements in train modernization. The framework was tested and demonstrated by means of application to the train modernization project of an intercity train at the Nederlandse Spoorwegen in the Netherlands. The results reveal three key design mechanisms for sustainable modernization frameworks. Firstly, sustainability should be considered as early as possible in the design process. Secondly, such frameworks require efforts to simplify the way sustainability principles and impacts are considered, being careful not to oversimplify. Thirdly, the use of sustainability-focused requirements and budgets facilitate the process of prioritizing design decisions in relation to the effects they have on various environmental impacts. The design process of the framework not only provided a better understanding of the challenge of integrating sustainability, it also presents a generalizable approach that can be adapted by other organizations in the transportation sector.
\end{abstract}

\section{Publication history:}

This chapter was published in the Journal of Sustainability:

Haanstra, W., Martinetti, A., Braaksma, J., \& van Dongen, L. A. M. (2020). Design of a Framework for Integrating Environmentally Sustainable Design Principles and Requirements in Train Modernization Projects. Sustainability (Switzerland), 12(15), [6075]. https://doi.org/10.3390/su12156075 


\section{Introduction}

Sustainable development is often considered to consist of a three-pronged fork of social sustainability (people), environmental sustainability (planet), and economic sustainability (profit), also known as the triple bottom line (Elkington, 1997). Stimulating the use of public transport can be seen as an important means for achieving sustainable transportation in general (Miller, de Barros, Kattan, $\&$ Wirasinghe, 2016). In this regard, a better understanding of the preferences of passengers (Eldeeb \& Mohamed, 2020) and accessibility of people to railway transportation (Eliasson, Kopsch, Mandell, \& Wilhelmsson, 2020) are vital prerequisites. While all three aspects of the triple bottom line are of great importance to the transportation sector, they are also fundamentally different in scope. Public transport is regarded as a significant factor towards achieving societal goals and values, particularly those related to economic and environmental issues (Stjernborg \& Mattisson, 2016).

This article focuses on the fork of environmental sustainability, which can be described as the maintenance of natural capital, the stock of environmentally provided assets that provides a flow of useful goods or services (Goodland $\&$ Daly, 1996). Environmental sustainability thus aims to preserve environmental assets to ensure they can still be used in the future. The transportation sector has an instrumental role to play in achieving the goal of environmental sustainability (Banister, 2007; Wanke, Chen, Zheng, \& Antunes, 2020). For the transportation of freight in China, the modal shift from road towards rail transportation will result in lower carbon emissions, but may also lead to higher freight transportation costs (Chen, Wu, \& Zong, 2020). For the EU, the shift towards renewable energy land transportation would save a greater amount of fossil energy (and therefore, $\mathrm{CO}_{2}$ ) per unit of investment than airand ship-based transport (García-Olivares, Solé, Samsó, \& Ballabrera-Poy, 2020). However, for the railway sector to be an environmentally sustainable option, its products and services also need to be delivered in a sustainable way. To this end, the individual actors in the railway sector are continuously looking to improve their environmental impact. 


\subsection{Recent Trends in Sustainable Railway Transportation}

A review of recent literature revealed that individual railway companies target multiple sustainability-related improvement areas and follow different strategies, depending on their roles.

Firstly, current efforts of railway companies are mainly focused on reducing greenhouse gas (GHG) emissions and energy consumption. According to Lee et al. (Lee et al., 2010), in the case of rail transport, 90\% of GHG emissions are associated with the use phase of the life cycle of a carriage. Many GHG reduction efforts are therefore aimed at changing the ways transportation assets are operated. The introduction of coasting in the operations of urban transport is believed to save up to $45 \%$ of energy during operation (Thong $\&$ Cheong, 2012). Powell et al. (Powell, González-Gil, \& Palacin, 2014) showed that energy consumption by auxiliary systems in stabled vehicles accounts for approximately $11 \%$ of the vehicle's yearly energy consumption. Creating new operational protocols to reduce the unnecessary use of these systems during stabling hours can therefore have a significant impact on the life cycle energy use. In high speed rail (HSR), there is a large improvement possible in triple bottom line reporting practices, including a wider range of environmental sustainability factors (Azzouz \& Jack, 2020). Additionally, smart maintenance capabilities can be applied to provide environmental benefits through improved resources utilization (Johansson, Roth, \& Reim, 2019). 
From a design perspective, the development of new transport systems has focused on improving the energy efficiency of vehicles and their propulsion systems (Manojlović, Papić, Filipović, \& Jovanović, 2011). Common approaches for achieving higher efficiency are the use of regenerative braking, more advanced propulsion technology, and applying energy efficient driving strategies (Nicola, Rosen, Bulucea, \& Brandusa, 2010; Powell et al., 2014). Manufacturers of rolling stock have already embraced EcoDesign in their design processes. Although the exact understanding and application of these principles varies per company, four measures appear to be universally applicable (Ander et al., 2001; Överstam, 2016; Ribeiro \& Gomes, 2014):

1. Elimination of hazardous materials and substances

2. Use of design for disassembly, reuse, and remanufacture

3. Optimization for energy efficiency

4. The use of life cycle assessment (LCA) to facilitate more environmentally sustainable decision-making

Another observable trend is that manufacturers seek to reduce the weight of their products by using lightweight materials such as aluminum alloys and composite materials, and through the redesign of parts. These strategies are used for structural as well as interior parts of the asset (Lee et al., 2010; Towle, Johnston, Lingwood, \& Grant, 2004). This includes the reduction of glass usage, utilization of skeletal cable trays, installation of aluminum diffusers and side interior panels, and placement of lighter seats (Thong \& Cheong, 2012). 
Furthermore, literature has indicated the existence of efforts that are focused around the sustainable use of natural and material resources, especially for end-of-life product phases. Manufacturers seek to minimize the number of different materials, select recycling-friendly materials, and minimize the use of hazardous substances. Literature has also noted that the product should be designed in such a manner that disassembly is made straightforward by making easily detachable connections (Merkisz-Guranowska, Merkisz, Jacyna, Pyza, \& Stawecka, 2014). Thus, the use of bolts and rivets, for instance, is preferred over the use of glue and other permanent connections. Moreover, adopting a modular design can reduce the need for complex modifications during the use phase. The absence of such modifications can facilitate a better end-of-life phase (Kaewunruen \& Lee, 2017).

It is important to acknowledge the existence of a trade-off between design for enhanced recycling and for environmental sustainability in other life cycle phases (Överstam, 2016). The use of more advanced and lighter materials, for instance, increases environmental sustainability during the use phase. It can, however, also complicate proper disposal of a transport asset. Efforts are made to mitigate this problem by enabling the recycling of new materials such as carbon fiber-reinforced plastics (Towle et al., 2004). Another important factor in optimizing the end-of-life phase is providing the right information about the asset and its parts. In the automotive sector, a system called IDIS (International Dismantling and Info System) is used to provide dismantling centers with information, such as parts lists, service handbooks, 3D drawings, and information about the materials used (Ander et al., 2001). There is no similar system currently in use for the railway industry. The UNIFE Railway Industry Substance List can be used to identify prohibited materials, and the corresponding material declaration template can be used to provide information on materials used (Garnier de Falletans, 2016). Unfortunately, this information is not commonly shared between companies. Therefore, material marking can improve recyclability (Silva \& Kaewunruen, 2017). 


\subsection{Problem Identification and Motivation}

Engineering and design decisions play a key role in many of the efforts described in the literature on environmentally sustainable railway transportation. In the lifecycle of any product, the earlier design stages offer the most opportunity for lifecycle improvements. However, during these early design stages, the least knowledge about the lifecycle is available ( $M$. Hauschild, Jeswiet, \& Alting, 2005). Train modernization projects, therefore, represent a promising environment in which to research the relation between train design and environmental sustainability. Experience with the premodernized train provides a knowledge base that would be lacking when dealing with new product development. Furthermore, the pre- and postmodernized train designs can be directly compared, providing an opportunity for evaluating the efficacy of various design choices.

Given the wide range of potential environmental improvement principles, the first problem that passenger railway organizations face is the selection of the most appropriate environmentally sustainable design principles for specific train modernization projects. Secondly, the consideration of environmental design should also be reflected in the formulation of requirements and criteria that govern the design process of the modernized train. The integration of economic, environmental, ecological, and social factors in engineering decisions can be a complex and ill-defined endeavor because of conflicting goals and criteria (Jajac, Kilič, \& Rogulj, 2018). As train modernization processes are already complex and constrained with respect to resources such as time, data, and knowledge, the integration of these environmental sustainability factors should be designed to be sufficiently easy-to-use to be considered in practice. In summary, this article aimed to develop a practically applicable integration approach for environmental sustainability in train modernization projects through two main activities:

1. The integration of environmentally sustainable design principles in (early) design stages.

2. The integration of environmental sustainability-focused design criteria. 


\section{Materials and Methods}

\subsection{Design Science Research}

In order to explore the problem that has been stated in the introduction, this article followed a design science research (DSR) approach, in which an appropriate solution for the research question is designed. Within DSR, that which is being designed-often called the artifact-is not the only element of interest. DSR is an explicitly organized, rational, and wholly systematic approach to design, which includes not only the utilization of scientific knowledge in the development of artifacts, but can be seen as a scientific activity in itself (Cross, 2001). A DSR strategy focuses on developing artifacts as well as knowledge creation, and aims to produce improvements based on a thorough understanding of problems or opportunities (J. van Aken et al., 2016). Therefore, the outcome of DSR is not only relevant to the practical application domain, but is also explicitly aimed at the creation of theoretical knowledge (Hevner, 2007; Wieringa, 2014). In case-based design research, abductive reasoning can be used to find plausible explanations for case observations (Wieringa, 2014).

As a research strategy, DSR can be operationalized in various ways (J. van Aken et al., 2016). This article built on the iterative approach suggested by Peffers et al. (Peffers et al., 2007), who provided a model for producing and presenting DSR. The DSR approach that was followed is illustrated in Figure 5.1. In the first phase, the main (design) research question was identified and motivated. In the next phase, the design objectives and criteria were introduced, indicating what a successful design should be able to accomplish. Subsequently, the phase of framework design and development shows the final design of the framework and the rationale behind design principles that were considered and implemented into the design. The application of the designed framework was then demonstrated and evaluated by means of a case study on train modernization at the Nederlandse Spoorwegen (NS), which has been supported by a MSc graduation project of 9 months. In conclusion, these applications were evaluated with respect to both the practical improvements they provide to NS as well as their contribution to the theoretical body of knowledge the consideration of environmental sustainability during train modernization. 
It should be noted that this design process is nonlinear, including an iterative design cycle that terminates when a satisfactory solution has been found.

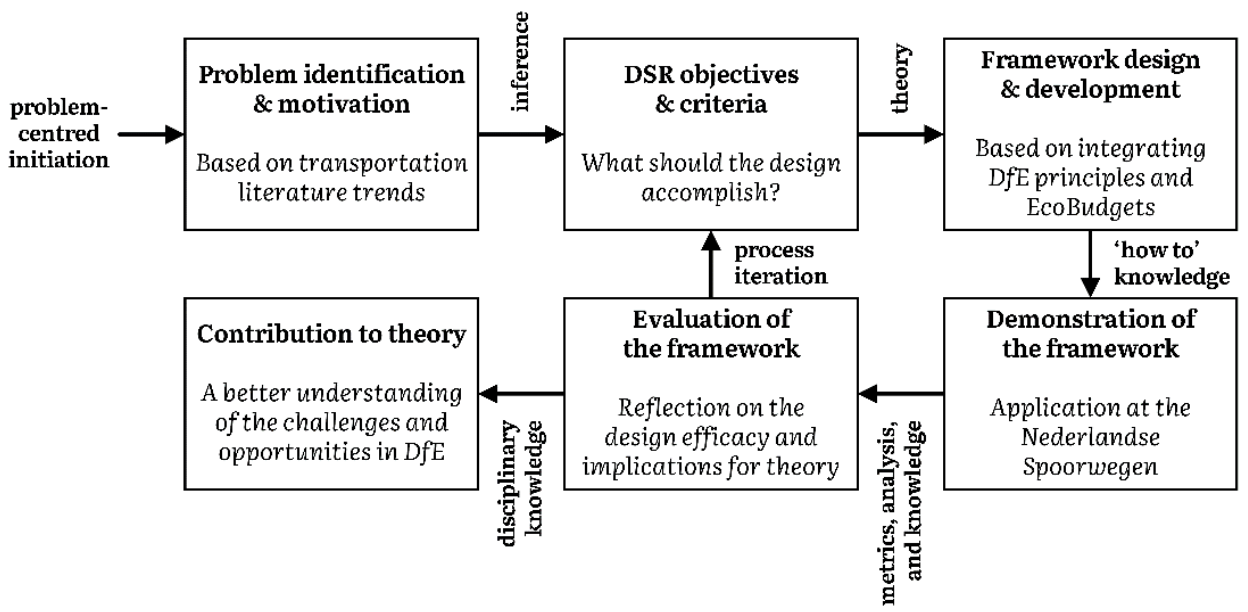

Figure 5.1: Design science research approach (modified from (Peffers et al., 2007) to reflect its adaptation to this research).

\subsection{Design Objectives and Criteria}

The approach followed in this research was to incorporate the environmental sustainability-focused design principles and the design criteria into the design of a framework. The next step in the DSR process was to formalize what the framework should accomplish and the criteria by which its success is judged during evaluation. The design objective was twofold:

1. The framework should enable the integration of environmental sustainability in train modernization processes.

2. The framework should facilitate the discovery of improvement opportunities for environmental sustainability in train modernization. 
The framework was designed for the modernization of passenger trains. The primary target audiences for the framework are the design and production management teams responsible for train modernization, as they have the most influence over design decisions that affect the train's lifespan such as energy and material use. The secondary target audience is the policy department of asset management (AM) organizations, who are required for the implementation and standardization. To evaluate to what extent the framework accomplishes the stated design goals, several design criteria have been formulated (see Table 5.1). The usability and function-related criteria focus on the efficacy of the framework with respect to the stated design goals. The process-related criteria focus in integration into practice and have therefore been formulated together with the case company, as part of a process iteration cycle of the DSR approach.

Table 5.7: Overview of identified design criteria.

\begin{tabular}{|c|c|c|}
\hline Topic & Criterion & Description \\
\hline Usability & U1 & $\begin{array}{l}\text { The framework should not require extensive knowledge about } \\
\text { environmental sustainability for its application }\end{array}$ \\
\hline \multirow{3}{*}{ Process } & P1 & $\begin{array}{l}\text { The framework should include environmental impact in all relevant } \\
\text { stages of train modernization projects }\end{array}$ \\
\hline & P2 & $\begin{array}{l}\text { The integration of the framework should not significantly disrupt } \\
\text { existing decision-making processes within the organization }\end{array}$ \\
\hline & P3 & $\begin{array}{l}\text { Environmental sustainability should be implemented in a SMART way } \\
\text { (specific, measurable, attainable, relevant, and time-based) }\end{array}$ \\
\hline \multirow{2}{*}{ Function } & $\mathbf{F 1}$ & $\begin{array}{l}\text { The application of the framework should allow for a clear overview of } \\
\text { environmental sustainability efforts }\end{array}$ \\
\hline & F2 & $\begin{array}{l}\text { The framework should provide a means for evaluating the efficacy of } \\
\text { the design choices with respect to environmental sustainability }\end{array}$ \\
\hline
\end{tabular}




\subsection{Framework Design and Development}

This section introduces existing principles that were used or adapted to create a suitable solution to the stated design problem. By discussing these solution principles separately, the core features of the framework design are made explicit and transparent. Rather than designing an entirely new environmental sustainability approach, existing literature was investigated to identify suitable approaches that can be included in, or adapted for, the framework.

\subsubsection{Overview of Existing EcoDesign Tools}

EcoDesign tools aim to develop products with their environmental performance in mind, in line with the concept of environmentally sustainable development (Pigosso, Zanette, Filho, Ometto, \& Rozenfeld, 2010). Rossi, Germani, and Zamagni (Rossi, Germani, \& Zamagni, 2016) found that more than a hundred EcoDesign tools, which span a wide range of applications, exist. Researchers have created different taxonomies for these tools. Rousseaux et al. (Rousseaux et al., 2017) provided a taxonomy based on regulatory, nonregulatory normative, and nonregulatory non-normative tools, while Rossi, Germani, and Zamagni (Rossi et al., 2016) distinguished between LCA tools, Computer-Aided Design (CAD) integrated tools, diagram tools, checklists and guidelines, design-for- $\mathrm{X}$ approaches, and various methods. Bovea and Pérez-Belis (Bovea \& Pérez-Belis, 2012) made a more general division into qualitative, semiqualitative, and quantitative tools.

The framework that was designed in this article drew inspiration and borrowed design principles from existing EcoDesign tools. Based on the taxonomies mentioned above, and on the literature research carried out in the introduction, Table 5.2 provides a selection of EcoDesign tools that were considered to be useful in the design. Each tool is briefly described, including an overview of their main advantages and disadvantages with respect to its application in train modernization. 
Table 5.2: Overview of reviewed EcoDesign tools (selected tools are highlighted).

(continues on the next page $\rightarrow$ )

\begin{tabular}{cl}
\hline Tool & \multicolumn{1}{c}{ Description } \\
\hline & $\begin{array}{l}\text { Qualitative tool used to select and visualize strategies to be taken } \\
\text { for making the design more environmentally sustainable. }\end{array}$ \\
$\begin{array}{c}\text { D4S Strategy Wheel and } \\
\text { Rules of Thumb } \\
\text { (Crul \& Diehl, 2009) }\end{array}$ & $\begin{array}{l}\text { Provides a list of simple rules of thumb to follow in order to } \\
\text { ensure a more environmentally sustainable design, providing } \\
\text { practical guidance for improving the product based on these } \\
\text { strategies. }\end{array}$ \\
\hline
\end{tabular}

\begin{tabular}{cl}
\hline MECO Matrix & Simple qualitative assessment based on materials, energy, \\
(M. Hauschild, Wenzel, \& & chemicals, and other aspects in order to compare the impact of \\
Alting, 1999) & two design alternatives during the life cycle.
\end{tabular}

Ten Golden Rules

(Luttropp \& Lagerstedt, 2006)

Ten qualitative rules that can be used as guidance for making the overall product design more environmentally sustainable.

Eco-functional Matrix

(Lagerstedt, 2003)

Semiqualitative linking technique based on QFD using a matrix that links functional and environmental aspects of a product. Identifies which aspects are important for the product and which aspects correlate in order to highlight critical points.

\begin{tabular}{cl}
\hline $\begin{array}{c}\text { SCPD } \\
\text { (Schöggl, Baumgartner, \& } \\
\text { Hofer, 2017) }\end{array}$ & $\begin{array}{l}\text { Semiqualitative checklist for environmentally sustainable } \\
\text { product design consisting of } 49 \text { yes/no questions that encourage } \\
\text { engineers to think about the whole life cycle. Generates a task list } \\
\text { of follow-up actions based on the answers. }\end{array}$ \\
\hline $\begin{array}{c}\text { Design for Environment } \\
\text { Matrix (DfE) }\end{array}$ & $\begin{array}{l}\text { Semiqualitative matrix with questions about various } \\
\text { environmental factors grouped according to life cycle stage. Each } \\
\text { cell consists of one or more questions and is worth 5 points. } \\
\text { (Yarwood \& Eagan, 1998) } \\
\text { Answering all questions provides a score for each issue and } \\
\text { makes it possible to compare products. }\end{array}$ \\
\hline $\begin{array}{c}\text { ReSICLED } \\
\text { Moszkowicz, 2008) }\end{array}$ & $\begin{array}{l}\text { Quantitative assessment of the recoverability of a product based } \\
\text { on the weight and economic and environmental costs or benefits. } \\
\text { Accounts for both material attributes and product design } \\
\text { characteristics. }\end{array}$ \\
\hline $\begin{array}{c}\text { Simple Eco-indicators } \\
\text { (Cerdan, Gazulla, Raugei, } \\
\text { Martinez, \& Fullana-I- } \\
\text { Palmer, 2009) }\end{array}$ & $\begin{array}{l}\text { Set of simplified quantitative indicators of the environmental } \\
\text { attributes of a product. Easy to calculate figures that correlate } \\
\text { with indicators of a more complicated LCA. }\end{array}$ \\
\hline $\begin{array}{c}\text { EcoPas } \\
\text { (Duflou \& Dewulf, 2004) }\end{array}$ & $\begin{array}{l}\text { Quantitative model for calculating environmental impact using } \\
\text { basic product parameters. So-called eCERs (eco-cost estimating } \\
\text { impact. }\end{array}$ \\
\hline
\end{tabular}


Table 5.2: Overview of reviewed EcoDesign tools (selected tools are highlighted).

$$
\text { ( } \leftarrow \text { continued from the previous page) }
$$

\begin{tabular}{|c|c|c|}
\hline Advantages & Disadvantages & Selected \\
\hline $\begin{array}{l}\text { - Ease of use } \\
\text { - Clear visualization of what path to } \\
\text { take } \\
\text { - Provides practical advice }\end{array}$ & $\begin{array}{l}\text { - No way to measure the } \\
\text { product } \\
\text { - Only provides general } \\
\text { guidance }\end{array}$ & $\begin{array}{l}\text { No, the more } \\
\text { specific guidance } \\
\text { of Ten Golden } \\
\text { Rules was } \\
\text { preferred }\end{array}$ \\
\hline $\begin{array}{l}\text { - Ease of use } \\
\text { - Forces designers to think about a } \\
\text { range of different issues } \\
\text { - Provides a means for comparison }\end{array}$ & $\begin{array}{l}\text { - Very general } \\
\text { - Does not suggest solutions }\end{array}$ & $\begin{array}{l}\text { No, due to lack of } \\
\text { solution focus }\end{array}$ \\
\hline $\begin{array}{l}\text { - Ease of use } \\
\text { - Can promote environmental } \\
\text { sustainability awareness for } \\
\text { employees }\end{array}$ & $\begin{array}{l}\text { - Very general } \\
\text { - Some rules can be } \\
\text { contradictory }\end{array}$ & Yes \\
\hline $\begin{array}{l}\text { - Combines functionality with } \\
\text { environmental performance } \\
\text { - Clearly links different issues }\end{array}$ & $\begin{array}{l}\text { - Issues are considered at a } \\
\text { high level; outcome for a train } \\
\text { is always similar } \\
\text { - Does not suggest solutions }\end{array}$ & $\begin{array}{l}\text { No, due to high } \\
\text { abstraction level } \\
\text { of application }\end{array}$ \\
\hline $\begin{array}{l}\text { - Possibility to score and compare } \\
\text { products } \\
\text { - Generates clear task list of follow-up } \\
\text { actions } \\
\text { - Dialogic approach improves } \\
\text { communication }\end{array}$ & $\begin{array}{l}\text { - Environmental } \\
\text { sustainability expertise } \\
\text { required to reach full } \\
\text { potential }\end{array}$ & $\begin{array}{l}\text { No, based on } \\
\text { expertise } \\
\text { requirement }\end{array}$ \\
\hline $\begin{array}{l}\text { - Scores products without needing very } \\
\text { specific information } \\
\text { - Questions can raise awareness of } \\
\text { environmental sustainability issues }\end{array}$ & $\begin{array}{l}\text { - Questions can be hard to } \\
\text { answer at the train level } \\
\text { (but is suitable for subsystem } \\
\text { level) }\end{array}$ & Yes \\
\hline $\begin{array}{l}\text { - Quantitative assessment makes } \\
\text { comparison easy } \\
\text { - Accurate description of recyclability }\end{array}$ & $\begin{array}{l}\text { - Complexity } \\
\text { - Involves a lot of data } \\
\text { gathering and calculations } \\
\text { - Only takes into account the } \\
\text { EOL stage }\end{array}$ & $\begin{array}{l}\text { No, due to } \\
\text { limitations in } \\
\text { usability }\end{array}$ \\
\hline $\begin{array}{l}\text { - Easy method for quantifying product } \\
\text { characteristics } \\
\text { - Can be used to compare design } \\
\text { alternatives }\end{array}$ & $\begin{array}{l}\text { - Noncomprehensive list of } \\
\text { indicators } \\
\text { - May induce } \\
\text { oversimplification when } \\
\text { applied at train level }\end{array}$ & $\begin{array}{l}\text { No, DfE matrix was } \\
\text { deemed more } \\
\text { usable for the } \\
\text { framework }\end{array}$ \\
\hline $\begin{array}{l}\text { - Comprehensive quantification of } \\
\text { product characteristics based on } \\
\text { available information } \\
\text { - Can be used to compare design } \\
\text { alternatives }\end{array}$ & $\begin{array}{l}\text { - eCERs have to be defined for } \\
\text { each system } \\
\text { - Realistic representation of a } \\
\text { train is challenging }\end{array}$ & $\begin{array}{l}\text { No, due to } \\
\text { limitations with } \\
\text { usability }\end{array}$ \\
\hline
\end{tabular}




\subsubsection{Selected EcoDesign Tools}

From the list of potential EcoDesign tools that align for the stated design goals, a combination of two tools were deemed to best fit the stated design criteria and the application context at the case company. This led to a selection of two applicable EcoDesign tools that were included in the framework: the 10 Golden Rules (Luttropp \& Lagerstedt, 2006) and the Design for Environment (DfE) matrix (Yarwood \& Eagan, 1998). An important consideration in this selection was that the existing train modernization process would not be significantly disrupted by the inclusion of the DfE principles (criterion P2). This was achieved by aligning the application of existing EcoDesign tools with the basic structure of a train modernization process and including only instruments that are easy to use and applicable in that context. This was done in collaboration with the case company. The framework should also allow for means of evaluating the efficacy of the design choices (criterion F2). A combination of accessible qualitative and (semi-)quantitative elements allows for the inclusion of generic design guidelines as well as a way to measure the efficacy of the proposed solutions, while still ensuring usability (criterion U1).

Life cycle assessment was not deemed suitable for the framework for two main reasons. Firstly, LCA is usually conducted by environmental specialists and rarely by designers during the design phase (Umeda et al., 2012). Secondly, the application at the design stage can be difficult because of its laborious, expansive, and time-consuming nature (Jiyeon Ryu, Ik Kim, Eunsun Kwon, $\mathbb{a}$ Tak Hur, 2003). Streamlined variants of LCA may be able to provide essentially the same type of results as a detailed LCA in a more superficial manner (M. Z. Hauschild, 2017), but less complex methods such as simple eco-indicators were already deemed unsuited with respect to usability (criterion U1). 


\section{Results}

\subsection{EcoDesign Framework for Train Modernization}

The developed framework integrated modified versions of two existing EcoDesign tools and their principles into train modernization processes, as well as providing environmental sustainability-related design requirements (see Figure 5.2). This integration framework focuses on the earliest train modernization stages where the engineering freedom, and therefore the potential for sustainability improvements, is highest (criterion P1).

$$
\begin{array}{llll}
\text { Preliminary study } & \text { Project start } & \text { Early design } & \text { Design evaluation }
\end{array}
$$

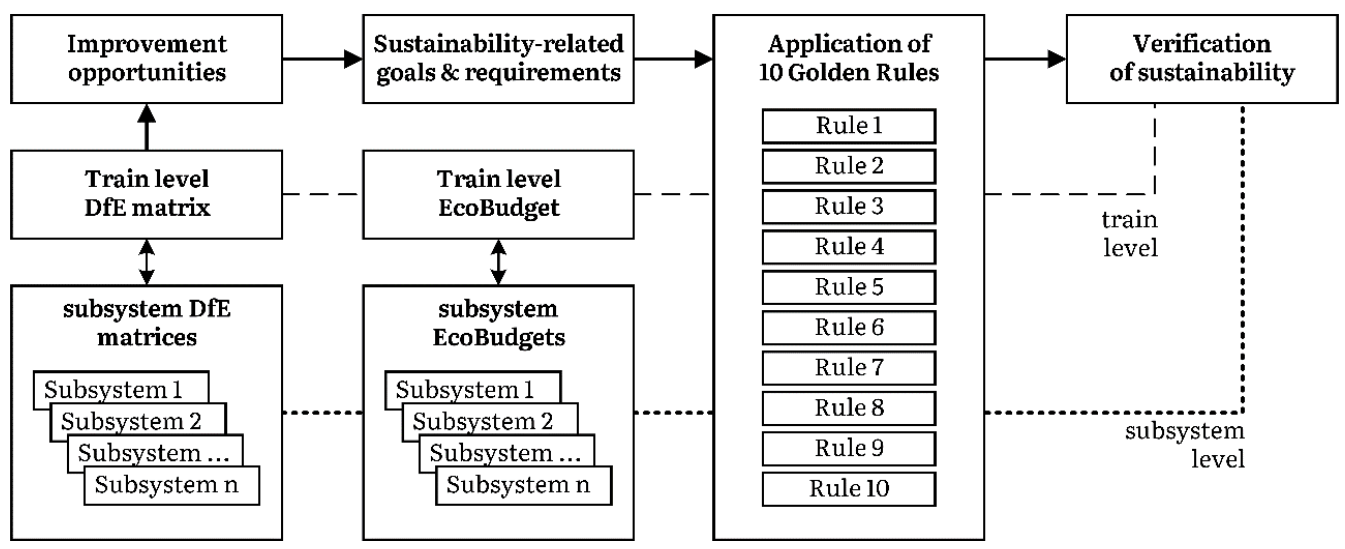

Figure 5.2: EcoDesign framework for train modernization.

\subsubsection{Stage 1: Preliminary Study}

In the early stages of train modernization projects, the Design for Environment (DfE) matrix (Yarwood \& Eagan, 1998) is adapted as the starting point for a kick-off brainstorm session by quickly determining a semiquantitative improvement profile of the premodernized train and its subsystems. Each matrix consists of an axis indicating multiple lifecycle stages and an axis illustrating relevant environmental concerns. Each of the cells in the matrix is assigned a number of qualitative questions. These questions are answered with 'Yes', 'No', or 'Not Applicable'. These answers can then be used to semiquantitatively assess specific designs according to different categories of environmental impact. The questions contained in the DfE matrix may be too general, making them difficult to answer at the train level. However, it is possible to apply DfE matrices to each of the subsystems and aggregating the scores to the level of the entire train. 


\subsubsection{Stage 2: Project Start}

The outcome of the DfE matrix can not only be used to evaluate an environmental profile of the existing train, but also for setting meaningful, yet accessible, goals and requirements for the modernized train design (criterion P3). These requirements can take both qualitative and quantitative forms. For example, qualitative goals can be based on the answers resulting from the DfE matrix of the existing train. Other, more specific, goals can also be included in this phase, for example quantifiable performance metrics such as energy use, GHG emissions, or recycled material content. These requirements can be viewed as environmental sustainability budgets. The selection of requirements and budgets depends on the subject of study, the environmental issues that the organization intends to address, and the targets set for these efforts.

\subsubsection{Stage 3: Early Design}

In the previous two stages, the baseline environmental performance of the old train and the environmental sustainability targets for the modernized train were established. In order to support the creative process of developing new design options, the golden rules of EcoDesign (Luttropp \& Lagerstedt, 2006) can be used to guide earlier development stages (Table 5.3). Even though these 10 rules are rather generic in their formulation and can be contradictory, they are also easy to use, promote awareness of environmental sustainability, and focus efforts towards likely effective improvement areas without requiring environmental sustainability-related expertise (criterion U1). When combined with the DfE matrix, these 10 rules can be used to both structure and prioritize the efforts taken to improve different environmental sustainability measures (criterion F1). These efforts should result in a new design for the modernized train and its components in which specific environmentally sustainable design principles are included. 
Table 5.3: 10 Golden Rules of EcoDesign (Luttropp \& Lagerstedt, 2006).

\begin{tabular}{cl}
\hline Rule & \multicolumn{1}{c}{ Description } \\
\hline $\mathbf{1}$ & $\begin{array}{l}\text { Do not use toxic substances and utilize closed loops for necessary but toxic } \\
\text { ones }\end{array}$ \\
\hline $\mathbf{2}$ & $\begin{array}{l}\text { Minimize energy and resource consumption in the production phase and } \\
\text { transport through improved housekeeping }\end{array}$ \\
$\mathbf{3}$ & $\begin{array}{l}\text { Use structural features and high-quality materials to minimize weight in } \\
\text { products. If such choices do not interfere with necessary flexibility, impact } \\
\text { strength, or other functional priorities }\end{array}$ \\
\hline $\mathbf{4}$ & $\begin{array}{l}\text { Minimize energy and resource consumption in the usage phase, especially } \\
\text { for products with the most significant aspects in the usage phase }\end{array}$ \\
\hline $\mathbf{5}$ & $\begin{array}{l}\text { Promote repair and upgrading, especially for system-dependent products. } \\
\text { (e.g., cell phones, computers, and CD players) }\end{array}$ \\
\hline $\mathbf{6}$ & $\begin{array}{l}\text { Promote long life, especially for products with significant environmental } \\
\text { aspects outside of the usage phase }\end{array}$ \\
\hline $\mathbf{8}$ & $\begin{array}{l}\text { Invest in better materials, surface treatments, or structural arrangements } \\
\text { to protect products from dirt, corrosion, and wear, thereby ensuring } \\
\text { reduced maintenance and longer product life }\end{array}$ \\
\hline $\mathbf{9}$ & $\begin{array}{l}\text { Prearrange upgrading, repair, and recycling through access ability, } \\
\text { labelling, modules, breaking points, and manuals }\end{array}$ \\
\hline $\begin{array}{l}\text { Promote upgrading, repair, and recycling by using few, simple, recycled, not } \\
\text { blended materials and no alloys }\end{array}$ \\
\hline scenario
\end{tabular}

\subsubsection{Stage 4: Design Evaluation}

The results from the previous modernization stages are verified during the design evaluation stage. When all environmental performances of the modernized train design(s) are calculated, the scores can be compared against the previously stated qualitative and quantitative environmental requirements. Alternatively, different design options can be compared against each other. As design processes are iterative in nature, part of the evaluation is expected to be concurrent with the earlier design stages. A final evaluation of the design of the entire modernized train (including all of its subsystems) can be used to determine the overall environmental sustainability score and whether or not the environmental sustainability goals have been achieved (criterion F2). 


\subsection{Application Context}

As mentioned in the abstract, the designed framework was applied using a real-world train modernization project at Nederlandse Spoorwegen (NS) (translated: Netherlands Railways). This not only allowed for an authentic demonstration of the designed framework, but also fostered the development of a thorough understanding of the challenges of integrating environmental sustainability in train modernization processes.

As the main passenger operator on the railway network in the Netherlands, NS plays a vital role in providing sustainable mobility in the country. NS is constantly striving to make their operations more sustainable. A notable achievement on the environmental sustainability front on the part of the organization is the switch to using $100 \%$ renewable energy to power the trains.

NS Train Modernization (NSTM) is the branch of NS in charge of the complete overhaul of part of the fleet of rolling stock. Its long-term vision is to improve the environmental sustainability of the rolling stock that needs to be modernized in order to face the second part of its useful life. At NSTM, different phases in the train modernization process are distinguished. As the environmental sustainability of the train series is mainly determined by the earlier design decisions, the case study focuses on the first four train modernization process stages, up to and including the evaluation of early design (see Figure 5.3).

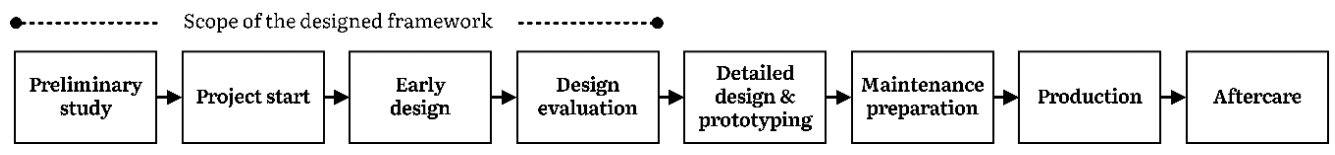

Figure 5.3: Stages of train modernization at Nederlandse Spoorwegen Train Modernization (NSTM). 
The VIRM (acronym for lengthened interregional rolling stock in Dutch), is a double decker train (see Figure 5.4) that currently forms the backbone of the intercity fleet of NS. This train series was taken into service at three different points in time. The first in 1994, the second in 2003 and the third in the year 2008, resulting in the technically identical subseries VIMRm1, VIRMm2/3, and VIRMm4 respectively.

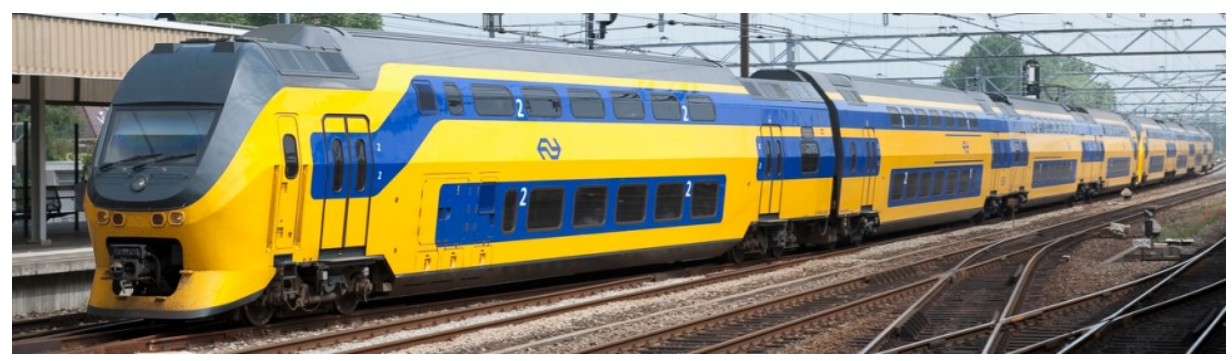

Figure 5.4: VIRM train before modernization.

The first of these subseries (VIRMm1) has already been through a modernization stage. The VIRMm2/3 builds on the already completed modernization process of the VIRMm1 subseries. The specifications and design of this project were reused in the modernization of the VIRMm2/3, unless there were clear reasons to deviate from this earlier design. The VIRMm2/3 modernization project aims to revise and modernize the VIRMm2/3 train for another 18 years of use and consists of revising most technical systems, installing a new interior, and updating the exterior. An additional target of NSTM is to improve the environmental sustainability profile beyond that of the VIRMm1 project.

Given the reapplication of many of the design decisions of the original VIRMm1 project, the technical scope of the VIRMm2/3 modernization project was already reduced to a limited set of subsystems. Notable exceptions to this are the full replacement of the systems of all heating and air conditioning (HVAC) units (for passengers as well as train drivers) and the redesign of the coach's power supply. Furthermore, the toilets/sanitary systems will be modernized, as well as the catering/galley section. The interior of the floors, stairways, vestibules, and drivers' cabin are also being updated, alongside objects such as seats, tables, garbage bins, coat hooks, partition walls, luggage racks, ceiling panels, and side panels. Other systems are excluded from our scope as these are not likely to be significantly altered in the modernization process. 


\subsection{Demonstration of the Design-for-Environment Framework}

\subsubsection{Stage 1: Preliminary Study}

During the preliminary study stage, the DfE matrices for the original (premodernized) VIRMm2/3 train and all of the relevant subsystems were assigned scores using the responses to a structured interview with the members of the NSTM team and a Sustainable Business manager. A comprehensive list of the environmental sustainability questions used in the matrix can be found in Appendix A. Instead of using the matrix of Yarwood $\&$ Eagan (1998), a DfE matrix modified for NSTM was used, allowing for the inclusion of the environmental sustainability themes and issues that were relevant to NSTM. The environmental score for the VIRMm2/3 was defined by converting the 'yes' and 'no' answers of the DfE matrix into a percentage score for each of the subsystems. 'N/A' was used to indicate questions that did not have a clear yes or no answer in the assessment of the initial score. These answers were then aggregated to the train level, calculating an overall score for each environmental sustainability issue and theme. The resulting filled-in DfE matrix can be found in Table 5.4 . 
Table 5.4: Design for Environment (DfE) matrix showing the initial overall score for all subsystems of the (premodernized) VIRMm2/3.

\begin{tabular}{|c|c|c|c|c|c|c|c|c|c|c|c|c|}
\hline \multirow{2}{*}{ Theme } & \multirow{2}{*}{ Issue } & & \multicolumn{8}{|c|}{ Questions (See Appendix A) } & \multicolumn{2}{|c|}{ Score } \\
\hline & & & 1 & 2 & 3 & 4 & 5 & 6 & 7 & 8 & Issue & Theme \\
\hline \multirow{2}{*}{$\begin{array}{c}\text { Energy, } \\
\mathrm{CO}_{2} \\
\text { and } \\
\text { climate }\end{array}$} & Energy use & A & $20 \%$ & $10 \%$ & $38 \%$ & $20 \%$ & $56 \%$ & $100 \%$ & $0 \%$ & $86 \%$ & $41 \%$ & \multirow[b]{2}{*}{$41 \%$} \\
\hline & $\begin{array}{l}\text { Embedded } \\
\text { GHG emissions }\end{array}$ & $\mathrm{B}$ & $\mathrm{N} / \mathrm{A}$ & $\mathrm{N} / \mathrm{A}$ & & & & & & & $N / A$ & \\
\hline \multirow{3}{*}{$\begin{array}{l}\text { Circular- } \\
\text { ity }\end{array}$} & Material use & C & $70 \%$ & $N / A$ & $N / A$ & $N / A$ & $\mathrm{~N} / \mathrm{A}$ & & & & $70 \%$ & \multirow{3}{*}{$70 \%$} \\
\hline & $\begin{array}{l}\text { Recycled } \\
\text { material }\end{array}$ & $\mathrm{D}$ & $\mathrm{N} / \mathrm{A}$ & & & & & & & & $\mathrm{N} / \mathrm{A}$ & \\
\hline & $\begin{array}{l}\text { Recyclability } \\
\text { of new } \\
\text { components }\end{array}$ & $E$ & $\mathrm{~N} / \mathrm{A}$ & $\mathrm{N} / \mathrm{A}$ & $\mathrm{N} / \mathrm{A}$ & $N / A$ & $\mathrm{~N} / \mathrm{A}$ & $\mathrm{N} / \mathrm{A}$ & $\mathrm{N} / \mathrm{A}$ & & $N / A$ & \\
\hline \multirow{2}{*}{$\begin{array}{l}\text { Maintain- } \\
\text { ability }\end{array}$} & $\begin{array}{l}\text { Efficiency in } \\
\text { maintenance }\end{array}$ & $\mathrm{F}$ & $100 \%$ & $60 \%$ & $80 \%$ & $20 \%$ & $100 \%$ & $80 \%$ & & & $73 \%$ & \multirow[b]{2}{*}{$71 \%$} \\
\hline & $\begin{array}{l}\text { Hazardous } \\
\text { substances in } \\
\text { maintenance }\end{array}$ & G & $50 \%$ & $40 \%$ & $90 \%$ & $100 \%$ & $60 \%$ & & & & $68 \%$ & \\
\hline Toxicity & $\begin{array}{l}\text { Use of } \\
\text { hazardous } \\
\text { substances }\end{array}$ & $\mathrm{H}$ & $\mathrm{N} / \mathrm{A}$ & $\mathrm{N} / \mathrm{A}$ & $N / A$ & $83 \%$ & $78 \%$ & $0 \%$ & & & $54 \%$ & $54 \%$ \\
\hline \multirow{3}{*}{$\begin{array}{l}\text { Overhaul } \\
\text { process }\end{array}$} & $\begin{array}{l}\text { Sustainable } \\
\text { disassembly }\end{array}$ & I & $0 \%$ & $100 \%$ & & & & & & & $50 \%$ & \multirow{3}{*}{$41 \%$} \\
\hline & $\begin{array}{l}\text { Sustainable } \\
\text { manufacturing }\end{array}$ & $J$ & $0 \%$ & $0 \%$ & $100 \%$ & $100 \%$ & $0 \%$ & & & & $40 \%$ & \\
\hline & $\begin{array}{l}\text { Sustainable } \\
\text { logistics }\end{array}$ & $\mathrm{K}$ & $0 \%$ & $100 \%$ & $0 \%$ & $100 \%$ & $0 \%$ & $0 \%$ & & & $33 \%$ & \\
\hline Experience & $\begin{array}{l}\text { Customer } \\
\text { experience }\end{array}$ & $L$ & $0 \%$ & $0 \%$ & $0 \%$ & $0 \%$ & $0 \%$ & & & & $0 \%$ & $0 \%$ \\
\hline
\end{tabular}


Based on the outcome of the DfE matrix, multiple improvement opportunities could be identified. For example, the theme of 'energy, $\mathrm{CO}_{2}$, and climate' revealed multiple opportunities for the application of lightweight materials and structural reinforcements.

\subsubsection{Stage 2: Project Start}

Based on the issues identified and evaluated in the first stage, it was possible to formulate environmental sustainability-related improvement objectives and requirements, based on the outcome of the DfE matrix of Table 5.4. For each of the scores an indication is provided regarding whether a measurable improvement is required (indicated by 'yes') or not required (indicated by 'no') in Table 5.5. This is done using the same list of questions used in the first stage. Even the 'N/A' questions of the initial assessment (Table 5.4) could be answered in a 'yes or no' manner, as the questions of Table 5.5 are now answered with the aim of indicating improvement areas.

Table 5.5: DfE matrix indicating improvement goals for the modernized VIRMm2/3 train.

\begin{tabular}{|c|c|c|c|c|c|c|c|c|c|c|}
\hline \multirow{2}{*}{ Theme } & \multirow{2}{*}{ Issue } & & \multicolumn{8}{|c|}{ Questions (see Appendix A) } \\
\hline & & & 1 & 2 & 3 & 4 & 5 & 6 & 7 & 8 \\
\hline \multirow{2}{*}{$\begin{array}{l}\text { Energy, } \mathrm{CO}_{2} \\
\text { and climate }\end{array}$} & Energy use & A & yes & yes & yes & no & no & No & yes & yes \\
\hline & $\begin{array}{l}\text { Embedded GHG } \\
\text { emissions }\end{array}$ & $\mathrm{B}$ & yes & yes & & & & & & \\
\hline \multirow{3}{*}{ Circularity } & Material use & $\mathrm{C}$ & yes & yes & no & yes & no & & & \\
\hline & Recycled material & $\mathrm{D}$ & yes & & & & & & & \\
\hline & $\begin{array}{l}\text { Recyclability of new } \\
\text { components }\end{array}$ & $E$ & yes & no & yes & yes & yes & yes & yes & \\
\hline \multirow{2}{*}{ Maintainability } & $\begin{array}{l}\text { Efficiency in } \\
\text { maintenance }\end{array}$ & $\mathrm{F}$ & no & no & no & no & no & yes & & \\
\hline & $\begin{array}{l}\text { Hazardous substances } \\
\text { in maintenance }\end{array}$ & G & no & yes & no & no & yes & & & \\
\hline \multirow[t]{2}{*}{ Toxicity } & $\begin{array}{l}\text { Use of hazardous } \\
\text { substances }\end{array}$ & $\mathrm{H}$ & no & no & no & no & yes & no & & \\
\hline & Sustainable disassembly & I & yes & no & & & & & & \\
\hline \multirow[t]{2}{*}{$\begin{array}{l}\text { Overhaul } \\
\text { process }\end{array}$} & $\begin{array}{l}\text { Sustainable } \\
\text { manufacturing }\end{array}$ & $J$ & yes & no & no & no & yes & & & \\
\hline & Sustainable logistics & $\mathrm{K}$ & no & no & no & no & no & yes & & \\
\hline Experience & Customer experience & $\mathrm{L}$ & yes & yes & yes & yes & & & & \\
\hline
\end{tabular}


Alongside the binary goals related to the DfE questions and scores, specific environmental sustainability-related requirements were also formulated together with a requirements manager of NSTM. To distinguish these environmental sustainability-focused requirements from other modernization requirements, they will be referred to as the EcoBudget. This EcoBudget (Table 5.6) is quantitative in nature and are based on the baseline average lifecycle profile of the VIRMm1 train, including all subsystems. The EcoBudget is used to indicate the minimum level of performance required for each environmental theme. NSTM opted not to use a minimum requirement for recycled material, hence the value of zero in that category.

Table 5.6: The quantitative requirements of the EcoBudget

\begin{tabular}{clll}
\hline \multicolumn{1}{c}{ Theme } & \multicolumn{1}{c}{ Requirement } & \multicolumn{1}{c}{ Budget } & \multicolumn{1}{c}{ Unit } \\
\hline \multirow{2}{*}{$\begin{array}{c}\text { Energy, } \mathrm{CO}_{2} \text {, and } \\
\text { climate }\end{array}$} & Auxiliary energy & 22.436 & $\mathrm{kWh} /$ year \\
\cline { 2 - 4 } & $\begin{array}{l}\text { Embedded GHG } \\
\text { emissions }\end{array}$ & 56.807 & $\mathrm{~kg} \mathrm{CO}$-eq. \\
\hline \multirow{2}{*}{ Circularity } & Material use & 103.837 & $\mathrm{~kg} \mathrm{Fe}$-eq. \\
\cline { 2 - 4 } & Recycled material & 0 & $\mathrm{~kg} \mathrm{Fe}$-eq. \\
\cline { 2 - 4 } & Recyclability & 93.453 & $\mathrm{~kg} \mathrm{Fe}$-eq. \\
\hline
\end{tabular}

\subsubsection{Stage 3: Early Design}

During the early design phases of the train modernization project, compliance with the various environmental sustainability requirements is tested during the various reviews. The other main purpose of the framework in these phases is to guide the smaller design choices, which is done by means of the application of the 10 Golden Rules of EcoDesign created by Luttrop and Lagerstedt (Luttropp \& Lagerstedt, 2006). As indicated earlier, not all of these rules may be applicable and some might even be contradictory. However, the quantitative requirements established in the previous two phases of the framework help guide the selection of the rules that best fit the design goals and requirements.

To demonstrate the application of the framework during this stage, an example of one of these smaller design choices is provided by the selection of seating options as part of the interior design. Together with NSTM, the EcoBudgets and the ' 10 Golden rules' for the interior design were discussed, 
leading to the identification of reducing the weight (rule 4) of the seats in the train as a promising design direction. Two seating options were considered: a lighter weight seat $A$ or seat $B$, which is similarly shaped as seat $A$, but has a different material composition. As indicated in Figure 5.5, the EcoBudget impact for the two seating options differ from each other. Seat $A$ has a lighter weight, but contains more nonrenewable materials and has a higher embedded GHG impact than seat $A$. As neither option fully outscores the other, preference depends on how the seats contribute to the overall environmental budget scores. Seat A was eventually chosen as it best fit the overall requirements for the design for the modernized VIRMm2/3 train.

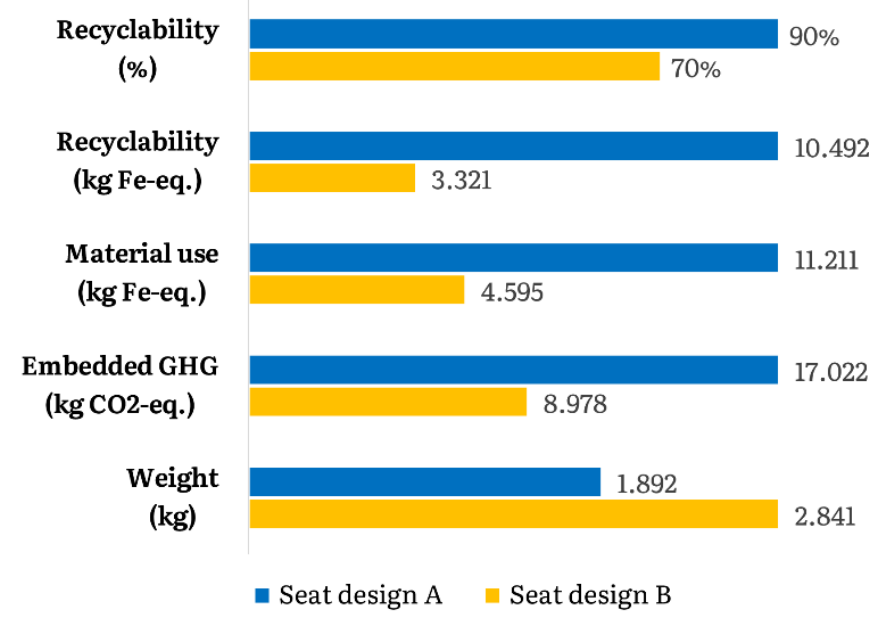

Figure 5.5: EcoBudget impacts of seating options.

\subsubsection{Stage 4: Design Evaluation}

The overall effectiveness of using the DfE matrix and environmental sustainability budgets was discussed in a general session, which included the project manager, the requirements manager, and the senior engineer of the train modernization process. Finding sufficient data for the existing train and the modernization options was challenging, taking up additional resources in the modernization process. In our application, not all subsystems could be included in the overall budget score for the modernized train for this reason. However, the EcoBudget score for the interior of the train could be determined (see Table 5.7). The EcoBudget for the entire train can be built up by aggregating the scores of the individual subsystems. Even though this 
application was not complete, the modernization staff agreed that the inclusion of this framework was useful, as it helped to systematically integrate environmental sustainability into the existing modernization process.

Table 5.7: EcoBudget score for the interior of the train.

\begin{tabular}{|c|c|c|c|c|c|}
\hline & \multicolumn{2}{|c|}{ Energy, $\mathrm{CO}_{2}$ and Climate } & \multicolumn{3}{|c|}{ Circularity } \\
\hline & $\begin{array}{c}\text { Auxiliary } \\
\text { Energy } \\
\text { (kWh/year) }\end{array}$ & $\begin{array}{l}\text { Embedded } \\
\text { GHG } \\
\text { Emissions } \\
\text { (kg CO -eq.) }\end{array}$ & $\begin{array}{l}\text { Material Use } \\
\text { (kg Fe-eq.) }\end{array}$ & $\begin{array}{l}\text { Recycled } \\
\text { Material } \\
\text { (kg Fe-eq.) }\end{array}$ & $\begin{array}{l}\text { Recyclability } \\
\text { (kg Fe-eq.) }\end{array}$ \\
\hline Total budgets: & 0 & 36.717 & 25.061 & 0 & 22.555 \\
\hline $\begin{array}{l}\text { Floors and } \\
\text { stairways, } \\
\text { vestibules }\end{array}$ & 0 & 9.989 & 7.150 & 0 & 6.435 \\
\hline Compartments & 0 & 17.861 & 12.675 & 0 & 11.408 \\
\hline $\begin{array}{l}\text { Toilet/sanitary } \\
\text { system }\end{array}$ & - & 2.864 & 1.845 & 0 & 1.661 \\
\hline Catering/galley & - & - & - & 0 & - \\
\hline HVAC & 117.445 & 6.002 & 3.391 & 0 & 3.052 \\
\hline Driver's cab & - & - & - & 0 & - \\
\hline
\end{tabular}

\section{Discussion}

The topic of sustainability demands increasingly more attention from companies. Many of the actions taken by industry are not a response to government actions, but are derived from actions taken in industry itself, resulting from a form of peer pressure (Priddy, 2017). It is through these concrete actions that the railway sector can improve its environmental sustainability from the bottom-up. For railway operators, actions to improve environmental sustainability can be traced back to the designs of their train series, which determine a large extent of environmental impact during production, operation, maintenance, and end-of-life.

To support this improvement process as early as possible, an EcoDesign framework was developed. Even though the framework was intended as a proof-in-concept, its application in a real-world setting and subsequent evaluation does allow for a rich reflection on its underlying principles, efficacy, and relevant considerations that need to be taken into account in the 
development of new approaches. The objectives for the framework were that it should enable the integration of environmental sustainability in train modernization processes (design goal 1) and that it should facilitate the discovery of improvement opportunities for environmental sustainability in train modernization (design goal 2). After considering a number of design principles and going through multiple design iterations, a suitable solution was found in the form of the EcoDesign framework for train modernization. The demonstration of the framework at NSTM illustrated that the framework was both feasible and useful for incorporating environmental sustainability in train modernization projects. Besides the creation of the framework as an artifact, the DSR approach also resulted in the development of a better understanding of the challenges and opportunities in the application of Design for Environment principles. Using abductive reasoning, plausible explanations for case observations are discussed by reflecting on the design of the framework and its application in the real-world context at NSTM.

Three main mechanisms appear to best explain which opportunities and limitations are addressed by the final design of the framework. The first mechanism consists of the consideration of environmental sustainability in the earliest phases possible. In these early stages, the design decisions are still malleable, providing the most engineering freedom for environmental sustainability measures. Experience with this design at NSTM revealed that the preliminary stage was the most influential with respect to the overall consideration of environmental sustainability of the VIRMm2/3 train. The design of the framework reflects this by making the identification of improvement opportunities the first step of the preliminary study.

The second mechanism is the focus on improving the accessibility and (perceived) ease-of-use of processes for the inclusion of environmental sustainability, to empower engineers to make sustainability-focused decisions. This mechanism is especially relevant during earlier design stages, when uncertainty is highest. In the design of the framework, the DfE matrix and the 10 Golden rules of EcoDesign were selected based on their accessibility and ease-of-use. The evaluation of the framework at NSTM however, revealed that despite its overall usefulness, the framework also added complexity to the modernization process and required additional efforts to apply. This indicates that when integrating environmental sustainability in train modernization processes, there is a trade-off to be made 
between accessibility and the level of detail in which the complex and broad topic of environmental sustainability is taken into account.

The third mechanism of the framework design consists of the inclusion of environmental sustainability-related design goals and requirements. In this regard, a common saying summarizes this mechanism well: "If you cannot measure it, you cannot improve it". It is therefore crucial to use concrete goals and requirements and to treat these requirements in a similar way to existing requirements (Mahaux, Heymans, \& Saval, 2011). By evaluating the design of the premodernized train with respect to environmental sustainability, and comparing this to the goals of the railway organization (in this case, the parent company NS), clear improvement goals could be formulated and applied during the evaluation of the modernized train design. Furthermore, the use of these requirements also revealed that environmental sustainability is not easily captured in a single criterion. It is likely that many design decisions have dissimilar environmental sustainability impact trade-offs, where one alternative is better in one regard, but worse in another (as indicated in the seating option example). The use of quantitative requirements, such as the EcoBudgets, do not provide guidance to suggest which design should be preferred. Instead, they focus the discussion towards the question of which complete set of train design decisions best fits the overall design requirements.

\subsection{Limitations, Recommendations and Future Research}

This article focused on the sustainability in the modernization of a train series intended for passenger transportation. Furthermore, the framework itself was designed to the needs of a single national railway operator. Even though the three aforementioned mechanisms are generalizable to similar application contexts, the exact EcoDesign principles and the alignment of the phases in the framework applied may therefore need to be slightly adapted to fit specific applications.

In the future, the usability of the designed framework can be further improved by digitally supporting the act of creating and communicating DfE matrices and EcoBudgets using ICT applications. Even though the use of LCA was deemed too unsuitable to be included in the design of the framework, further research is required on how, and to what extent, LCA can be effectively applied in the earliest design stages. 


\section{Conclusions}

As environmental sustainability becomes more and more important to society, the transportation sector is also working to reduce its environmental impact. A review of recent trends in literature reveals that there are many approaches to improving environmental sustainability in this sector. Universally applicable environmental sustainability principles in this sector appear to focus on four main areas: (1) the elimination of hazardous materials and substances; (2) the use of design for disassembly, reuse, and remanufacture; (3) the optimization for energy efficiency; and (4) the use of LCA to facilitate more environmentally sustainable decision-making. Key questions for individual organizations are which of these universal principles to apply and how to implement them during engineering and design decision-making processes? This research focused on these questions for the process of train modernization, as this provides an interesting halfway point for the life cycle of a train series. During this midlife update, there is both room for improvement as well as sufficient information to base these improvement decisions on.

To this end, a framework was designed that is aimed at integrating environmental sustainability into existing train modernization processes. By designing and testing this framework in a real-world application context, a better understanding of the challenges and opportunities surrounding the consideration of environmental sustainability during train modernization projects could be developed. The main findings could be explained using three key design mechanisms: (a) Environmental sustainability should be considered as early as possible in the design process. (b) This requires efforts to simplify the way environmental sustainability principles and impacts are considered, while being careful not to oversimplify. Finally, (c) environmental sustainability impact is not a single aspect to be optimized for design decisions, but requires trade-offs between various environmental impact aspects for each design decision. The use of sustainability-focused design criteria and environmental impact budgets was demonstrated to be an effective way to facilitate this decision-making process at a Dutch railway operator. This stimulated the organization to decide to what extent various environmental factors are prioritized, both in the organizational goals as well as in design decisions. 
Author Contributions: Conceptualization, A.M., W.H., and J.B.; methodology, W.H. and A.M.; validation, A.M., J.B., and W.H.; resources, L.v.D.; writingoriginal draft, W.H.; writing-review and editing, W.H., A.M., and J.B.; supervision, A.M. and J.D.; funding acquisition, J.B. and L.v.D.; All authors have read and agreed to the published version of the manuscript.

Funding: This research received no external funding.

Acknowledgments: The authors would like to thank the case company NS Trein Modernisering (NSTM) for their participation in this research. This article is based on the MSc graduation project findings of Ir. Dominick Viëtor.

Conflicts of Interest: The authors declare no conflicts of interest. 


\title{
Chapter 6 - Design for Sustainable Public Transportation: LCA-Based Tooling for Guiding Early Design Priorities
}

\begin{abstract}
:
Environmental sustainability is an increasingly important subject for public transportation organizations. For passenger train operators, modernization projects provide key opportunities to improve the environmental impact of their rolling stock by making informed design decisions at the midpoint of the life cycle of their trains. Life Cycle Assessment (LCA) is widely adopted as the main instrument for evaluating environmental impact. However, in the past LCA was rarely used in the earlier design stages, where it is most effective, due to constrained access to data, information, and LCA-specific expertise. To this end, a purpose-built streamlined LCA tool for train modernization is developed and demonstrated, following a Design Science Research approach. The developed tool simplifies the application of LCA employing four main design principles: (1) sacrificing the declarative function of LCA, (2) the use of InputOutput-based Life Cycle Inventory, (3) the inclusion of 'shadow costs', (4) the limitation of the included environmental impact categories. By streamlining the application of LCA in this way, it becomes possible to introduce LCA-based principles and ways of thinking into a process that would otherwise be inaccessible to performing LCA in: the early design stages of modernization projects.
\end{abstract}

\section{Publication history:}

This chapter was published in the Journal of Sustainability:

Haanstra, W., Rensink, W-J., Martinetti, A., Braaksma, J., \& van Dongen, L. A. M. (2020). Design for Sustainable Public Transportation: LCA-Based Tooling for Guiding Early Design Priorities. Sustainability (Switzerland), 12(23), [9811].
. https://doi.org/10.3390/su12239811 


\section{Introduction}

Environmental sustainability is increasingly important in the management of transportation systems as Europe moves towards a 100\% renewable transportation system for climate, energy, and sustainability reasons (GarcíaOlivares et al., 2020). This topic is being addressed in all major modes of transport, including road transport (Manojlović et al., 2011; Ou, Zhang, \& Chang, 2010), air transport (Melo et al., 2020), maritime transport (Iris \& Lam, 2019; Wen, Jin, Huang, Tandon, \& Zhu, 2017; X. Zhang, Lam, \& Iris, 2020), and railway transport (Yuan, 2017). Even though railway-based transportation has a relatively low environmental footprint in Europe when compared with other modes of transportation (Spreafico \& Russo, 2020), there are still many opportunities to improve (electric) railway travel concerning sustainability, for example by improving energy conversion (Nicola et al., 2010).

Train modernization projects are critical points halfway through the life cycle of rolling stock. These projects offer opportunities to learn from years of experience with an existing train series and to implement improvements to the existing design. In the building sector, for example, the refurbishment of existing constructions is generally seen as a favorable alternative for new buildings from an environmental point-of-view, though sometimes at the expense of lower utility or higher costs, depending on the pre-existing condition of the building (Langston, Chan, \& Yung, 2018). Similarly, train modernization offers an interesting opportunity to improve the environmental sustainability of rolling stock. Assessing sustainability in these projects, however, can be a complex challenge, demanding a proactive consideration of environmental sustainability aspects from project managers and projectrelated stakeholders (Simionescu \& Silvius, 2016).

\subsection{Front-Loading of Environmental Improvements}

The earlier phases of product development offer the most potential for improvement, but also offer the least knowledge about the product (Dewulf, 2013; M. Hauschild et al., 1999) (see Figure 6.1). An effective approach to deal with this knowledge trade-off can be found in front-loading, "a strategy that seeks to improve development performance by shifting the identification and solving of problems to earlier phases of a product development process" (Thomke \& Fujimoto, 2000). This strategy makes it possible to address problems before they become too costly or difficult to solve. The effectiveness 
of front-loading can be improved by transferring knowledge and problemspecific information from previous projects, as the information from the existing train can be used to support the redesign of the modernized train. For this reason, the research focuses on train modernization, where rolling stock receives a mid-life update.



Figure 6.1: The trade-off between improvement potential and knowledge about a product (M. Hauschild et al., 1999).

An important limitation of applying the 'front-loading' strategy to sustainability-focused measures is that it can often be unclear to what extent these measures are effective. To evaluate the potential of environmental improvements for specific (re)design propositions, there needs to be a tangible way to evaluate their efficacy.

\subsection{Life Cycle Assessment}

Academic interest in life cycle sustainability assessment has seen a rapid rise in the last decade, covering a broad range of methodological discussions as well as focused topics (Wulf, Werker, Ball, Zapp, \& Kuckshinrichs, 2019; Zimek et al., 2019). Although the exact understanding of environmental sustainability and its assessment varies per company, the use of Life Cycle Assessment (LCA) to facilitate more sustainable decision-making is widely recognized as the main approach and the most suitable basis to evaluate environmental sustainability (Ander et al., 2001; Överstam, 2016; Ribeiro \& Gomes, 2014). The ISO 14,040 (ISO, 2006a) and 14,044 (ISO, 2006b) standards provide internationally recognized principles and guidelines required for performing 
an LCA. This enables a commensurable quantitative assessment of all emissions of harmful substances, depletion of finite resources, and resulting damages to the environment of a product life cycle.

LCA is commonly applied to assess the cumulative potential environmental impact of the life cycle of a product or process. This can be done for various purposes, for example, for communication and marketing aims (ISO, 2006a). Many LCA reports and publications adopt this declarative style of LCA, as they are intended to be shared with professional or academic audiences. This declarative purpose is reflected in LCA-based reports and regulations such as Product Environmental Footprint (PEF) and Environmental Product Declaration (EPD) which require transparency and have set guidelines for their documentation. EPDs communicate the impacts of material extraction, energy use, and waste treatment and standardize the quantification of several environmental impacts of a specific product. Each product category has its specific regulations, summarized in its Product Category Rules (PCR). For example, for rolling stock the product category rules PCR 2009:05 for Rolling Stock Version 3.02 applies, belonging to the product group classification of UN CPC 495 (EPD, 2020). The PEF aims to increase the comparability between environmental impact assessments of similar products, which in the past, proved to be too difficult in communication with the customer (Dolezal $\mathbb{E}$ Boogman, 2016). PEF aims to improve comparability and communicability to various stakeholders by limiting the flexibility of methodological choices for these product categories, thus reducing the flexibility that LCA is known for (Bach, Lehmann, Görmer, \& Finkbeiner, 2018). Its implementation is not without its challenges, especially concerning (1) the expected policy outcome, (2) difficulties in application, (3) added value compared to regular LCA, (4) maturity of the underlying impact assessment methods, (5) a fair comparison of products (Lehmann, Bach, \& Finkbeiner, 2016).

Besides its declarative function, LCA can also be used to investigate environmental improvements, focusing on the aspects that are affected by decisions about certain products or processes (ISO, 2006b). An improvementfocused LCA is facilitated by linking processes in the product life cycle to environmental damages by tracking all material, energy and waste flows in the life cycle. However, the improvement analysis in LCA often receives little attention, despite its usefulness in actually lowering environmental burdens (Graedel, 1999). During product development, when design decisions are still 
flexible and typically confidential, there is a lowered burden of proof for the organization concerning claims about environmental impact. This allows for much lower requirements of LCA concerning certainty, transparency, and documentation than declarative applications such as eco-labeling or footprinting (Wenzel, 1998).

\subsection{Streamlined Life Cycle Assessment}

The requirements for regular LCA applications lead to high cost, time, and issues of data confidentiality and verifiability, even to the point that some consider it to be a flawed tool that cannot deliver what it promises (Kawauchi \& Rausand, 1999). The application of LCA in early design stages can be difficult because of its tedious, expansive, and time-consuming nature (Jiyeon Ryu et al., 2003). The practical use of LCA methods and software tools in industry, therefore, reveal the need for streamlined life cycle assessment methods that are derived from experience with the complex's full methods ( $M$. Hauschild et al., 2005). Streamlined LCA aims to provide essentially the same type of results as a full LCA, i.e., covering the whole life cycle, but superficially (e.g., using qualitative or generic data), followed by a simplified assessment, thus significantly reducing the expenses and time expended (M. Z. Hauschild, 2017). Streamlining draws parallels with the As Low As Reasonably Practicable (ALARP) approach (Melchers, 2001) which was originally intended for risk management. The core concept of ALARP is to set tolerable risk levels, instead of attempting to eliminate risk at all costs. This approach can also be applied to the evaluation of environmental impact, where the goal is not to perfectly evaluate impact but to choose a form of evaluation that is reasonably practicable.

Three levels of LCA can be distinguished, separated by an order of magnitude in the typical work required to perform them in decreasing order (Wenzel, 1998): (1) full LCA, (2) streamlined LCA (or screening LCA), and (3) matrix LCA (see Figure 6.2). Full LCA is understood as an ISO 14040/14044 compliant application, fit for communication with the general public, and places high demands on aspects such as data quality, interpretation and requires a critical review from a third party. Full LCA is thus usually conducted by environmental specialists and rarely by designers during the design phase (Umeda et al., 2012). Streamlined (or screening) LCA is a simplified version of LCA that is usually not ISO-compliant, but can be used to identify 'hotspots' in a product life cycle and are best suited to comparative studies where data limitations 
are likely shared by both options. Matrix LCA is the simplest form of assessment, providing only brief and mainly qualitative or semi-quantitative information at a basic level.

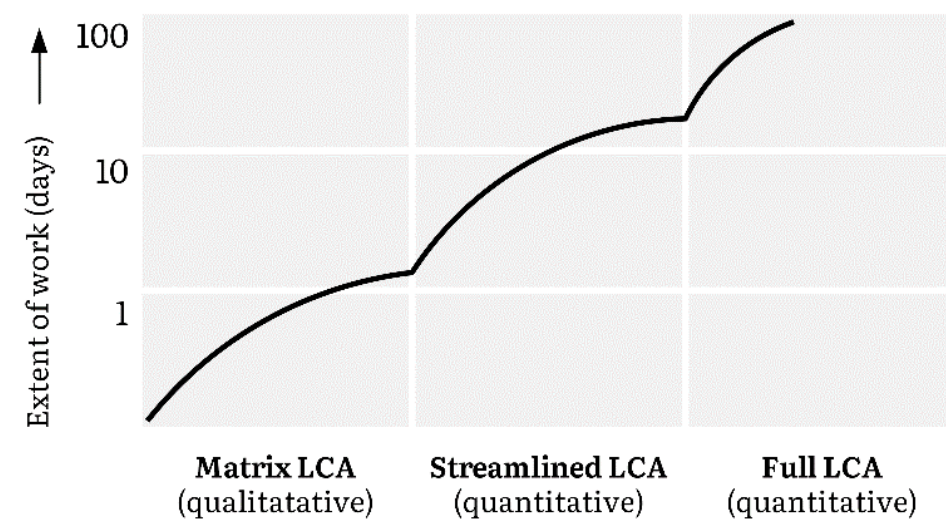

Figure 6.2: Three levels of $L C A$, indicating the typical extent of the work required (adapted from Wenzel, 1998).

Qualitative LCA approaches such as matrix LCA are unable to capture all the results of a full LCA, which may lead to a loss of important insights (Hochschorner \& Finnveden, 2003; Hur, Lee, Ryu, \& Kwon, 2005). Streamlined LCAs are also subject to a high degree of uncertainty when compared to a full LCA. An important distinction to make when talking about uncertainty in LCA is the difference between accuracy and precision, which are often perceived as synonyms, but are not (M. Z. Hauschild, 2017). Accuracy describes the closeness of a measured value to its 'true' value, whereas precision represents the spread of these measurements. In consequence, the accuracy of a model's result may be high while its precision can be low, meaning that the average of such model results will still represent meaningful information even though the results' spread (i.e., the standard deviation) may be large (M. Z. Hauschild, 2017). As simplification is required to allow the application of LCA in the earliest design stages, the focus of this research is positioned in this domain of high accuracy and low precision. 


\subsection{Research Aim}

Overall, the limitations of LCA mean that the method is rarely used as an improvement instrument by designers, especially in the most crucial early design stages. LCA typically relies too strongly on the expertise of the assessor, the availability of time, and availability of appropriate information and data, making its application in this early stage unfeasible. The research described in this article therefore aims to develop and present a streamlined LCA-based software application that is specifically designed for assessing early design decisions in train modernization projects. The results of the research indicate that it is possible to trade precision in the application of LCA in exchange for much lower reliance on the aforementioned data, information, and expertise. In this early stage, generic Life Cycle Inventory data can be applied to use LCA as an internal improvement analysis instrument, lowering the burden of proof that is typically associated with declarative uses of LCA, such as the PEF. This streamlining process lowers the barrier of applying LCA to the extent of making its application feasible in the earlier design stages, as demonstrated in the modernization process of a double-decker train used as a case study.

\section{Materials and Methods}

\subsection{Methodology}

To explore the problem that has been stated in the introduction, this article follows a Design Science Research (DSR) approach, which can be operationalized in various ways (J. van Aken et al., 2016). This article builds on an iterative DSR approach for producing and presenting DSR (Peffers et al., 2007), as illustrated in Figure 6.3. 




Figure 6.3: Structure of the Design Science Research approach (modified from Peffers et al., 2007).

\subsection{Design Criteria}

In this section, the design objectives and criteria are introduced, indicating what a successful streamlined LCA tool should be able to accomplish. To ensure the rigor of the design evaluation process, it is structured using a mostly formative, ex-ante, and naturalistic evaluation strategy (J. Venable, Pries-Heje, \& Baskerville, 2016; J. R. Venable, Pries-heje, \& Baskerville, 2012). The validity of the adopted DSR approach mainly stems from requirement validity, criterion validity, and theoretical validity (Larsen, Lukyanenko, Mueller, \& Storey, 2020). The design criteria for streamlined LCA concern relevance, validity, compatibility with computational procedures, reproducibility, and transparency (Rebitzer et al., 2004). These principles are adapted into five design criteria that a streamlined LCA model for use in asset procurement should meet (see Table 6.1). These criteria are evaluated together with a focus group within the train modernization department at Nederlandse Spoorwegen, including the (ex-post) evaluation of the first working design of the tool in a real environment. 
Table 6.1: Criteria for the streamlined LCA-based tool (Rebitzer et al., 2004)

\begin{tabular}{cc}
\hline Criterion & $\begin{array}{c}\text { Description } \\
\text { Relevance }\end{array}$ \\
Validity & $\begin{array}{c}\text { Compatibility in regards to the decision to be supported by } \\
\text { the LCA. In this application this relates to the design } \\
\text { decisions of train modernization. }\end{array}$ \\
\cline { 2 - 2 } $\begin{array}{c}\text { Compatibility } \\
\text { (with } \\
\text { computational } \\
\text { procedures) }\end{array}$ & $\begin{array}{c}\text { The streamlined LCA should show similar insights as a more } \\
\text { detailed study would have, though a lower resolution is } \\
\text { acceptable. }\end{array}$ \\
\cline { 2 - 2 } $\begin{array}{c}\text { Reproducibility } \\
\text { alongside other design criteria and into existing databases } \\
\text { and existing information technology environments related } \\
\text { to modernization. }\end{array}$ & $\begin{array}{c}\text { The streamlined tool should be able to be integrated } \\
\text { The tool should be designed so that different practitioners } \\
\text { arrive at the same LCA score or ranking result, given } \\
\text { identical asset characteristics (and goal and scope } \\
\text { definitions). }\end{array}$ \\
\cline { 2 - 2 } Transparency & $\begin{array}{c}\text { In order to be credible and to identify improvement } \\
\text { potentials, it should be easy and feasible for a practitioner } \\
\text { to understand the calculation of the final result and origins } \\
\text { of the main environmental issues. }\end{array}$ \\
\hline
\end{tabular}

\subsection{Design Principles}

In this research, three techniques are combined and incorporated into the design of the tool. (1) The use of streamlined Life Cycle Assessment, (2) the application of Input-Output-based Life Cycle Inventory, (3) the use of 'shadow costs' to express environmental impact in financial terms. The first of these techniques have already been discussed in the introduction. The latter two will be briefly explained.

\subsubsection{Input-Output Based Life Cycle Inventory}

Streamlining efforts within LCA mainly focus on the Life Cycle Inventory (LCl) analysis, which is typically the most time-consuming phase. LCI involves modeling all energy and material flows in the life cycle of a product. As this activity requires modeling of all relevant processes and their flows, streamlining efforts at the LCl phase have the greatest potential for savings, as it is the most time-consuming phase of LCA (Rebitzer et al., 2004). Missing data place an additional and considerable limitation on LCl concerning uncertainties and the speed of conducting a process-based LCl study (Fiksel, 2011; Lave, Cobas-Flores, Hendrickson, \& Mcmichael, 1995). When LCl data for specific materials are missing, relying on a generalized impact of a broader 
material group can be used to make suitable estimates (Rydh \& Sun, 2005). The use of generic data over specific data can be used to save time in developing the $\mathrm{LCl}$, but also increases the possibility of errors in the conclusion of that LCA.

An alternative for process-based $\mathrm{LCl}$ exists in the form of the Input-Output (IO) method, where the life cycle impact is modeled for specific industries and economic sectors. Using economic allocation, these direct impacts are then combined into embodied impacts for each produced good or service (i.e., how much impact is caused by the whole upstream processing of a good or service) (M. Z. Hauschild, 2017). IO tables reveal what each sector spends on the goods and services of another, making it possible to allocate the environmental impact of a single industry's flow based on the overall impact of a specific sector, or national and global economies (Rebitzer et al., 2004). Compared to process-based analyses, methods that utilize 10 analyses generally show smaller data requirements (Sangwon Suh \& Huppes, 2005). An IO-based approach is both fast and comprehensive as it has the whole economy as its system boundary, negating the need to make difficult system boundary choices (M. Z. Hauschild, 2017).

There are also drawbacks to the use of 10 methods. It is more challenging to fit specific data into the generic data structure for 10 matrices compared to process-based $\mathrm{LCl}$, due to the self-referencing and recursive nature of 10 tables (S Suh \& Huppes, 2001). Additionally, the used economic sectors mainly encompass the upstream and core processes, related to the production phase of the product life cycle, adopting a cradle-to-gate scope. Downstream processes (related to the use and end-of-life phases) are not commonly considered by the economic sectors. Lastly, it also requires a comprehensive, recent, and localized IO-based dataset that contains all metrics related to multiple environmental impacts. 


\subsubsection{Shadow Costs of Environmental Impact}

Natural capital is one of the six aspects that are required to be reported about in Integrated Reporting (IR), a reporting framework that proposes the integration of financial and non-financial information in a single report (de Villiers et al., 2017). LCA normally relies on normalization to aggregate multiple environmental impacts using a recognizable outside reference and to make sense of the magnitude of the impact. Many impact assessment methods (CML, ICLD, ReCiPe, TRACl, etc.) use Person Equivalents (PE) to normalize, expressing the calculated impact in terms of the average yearly impact of a person at the national, continent, or global level.

Even though the use of PE-based normalization is common in LCA, it is not common in corporate reporting. In recent years, industries have begun to show major interest in the use of environmental prices, mainly in the context of Corporate Social Responsibility (CSR) to quantify progress on certain sustainability issues (De Bruyn et al., 2018). These 'environmental' or 'shadow' costs are approaches that aim to express environmental impact in monetary terms, usually based on abatement or damage costs. Even though these costs are expressed using financial units (e.g., $€$ or $\$$ ), they can be seen as prices for something for which there is no market, having no actual financial value.

Conceptually, the use of shadow costs is similar to that of normalization to personal equivalence (see Figure 6.4). Both approaches use an outside reference to allow for the aggregation of multiple environmental effects and making sense of the magnitude of the impact. 

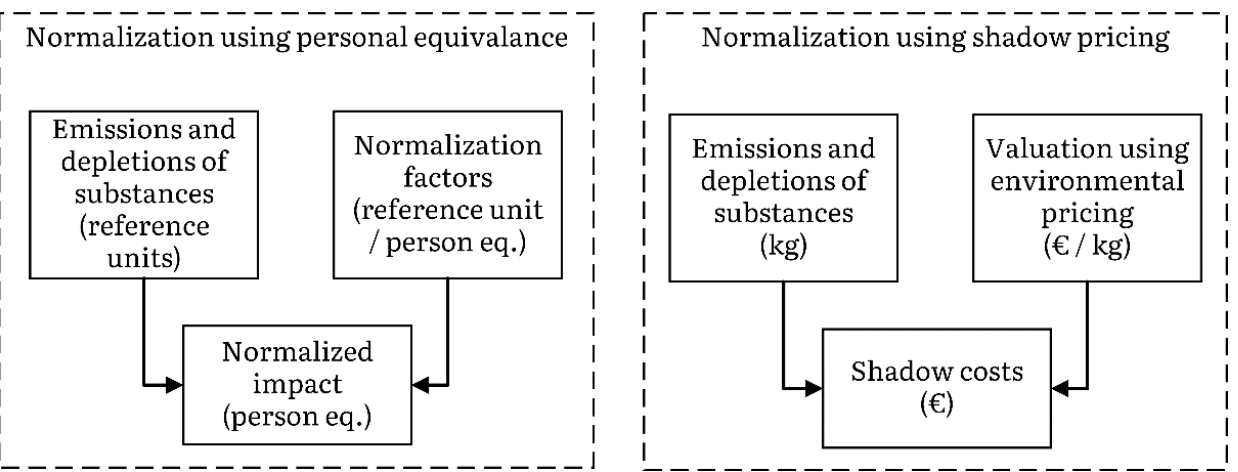

Figure 6.4: Relationships in conventional normalization and normalization using shadow costs.

The main difference between personal equivalence and shadow costs is that shadow costs are already expressed in monetary terms, making interpretation, decision-making, and communication of the results easier, as people are likely to have a better understanding of the value of money than of the average environmental impact of a single person. By expressing environmental impact in financial terms, it becomes easier to evaluate the two side-by-side (compatibility criterion). Furthermore, streamlined LCA and shadow costs can be effectively combined to evaluate the environmental impact of products in the early design stages of a product, but cannot be used as a substitute for full LCA (Kara et al., 2007) (which is not the aim of the design).

\subsection{An LCA-Based Tool for Guiding Early Design Priorities in Train Modernization}

A computer-assisted streamlined Life Cycle Assessment tool was developed to evaluate the environmental efficacy of various design decisions during the early stages of train modernization. The LCA tool supports the identification of environmental impact 'hotspots'. The tool takes the form of a standalone software application specific to this goal, which is intended for internal audiences within the Train Modernization department of Nederlandse Spoorwegen.

\subsubsection{Goal and Scope of the Streamlined LCA Tool}

The goal and scope of the application have been predetermined, to ensure that it is appropriately focused on the train modernization process (as required by 
the relevance criterion). By purposefully predetermining this first phase, the professionals who need to use the tool can skip this phase, further streamlining the LCA-based evaluation process. An overview of the characteristics associated with the 'goal and scope' phase of this LCA application is provided in Table 6.2 .

Table 6.2: Overview of the goal and scope characteristics of the streamlined LCA tool.

\begin{tabular}{|c|c|}
\hline Element & Description \\
\hline Goal & $\begin{array}{l}\text { To identify the 'hotspots' of environmental impact } \\
\text { associated with early design decisions in train } \\
\text { modernization to improve these design decisions. }\end{array}$ \\
\hline $\begin{array}{l}\text { Intended } \\
\text { audience }\end{array}$ & $\begin{array}{c}\text { The internal staff of the Train Modernization } \\
\text { department of the Nederlandse Spoorwegen (NSTM). } \\
\text { The outcome is not to be shared with external } \\
\text { audiences. }\end{array}$ \\
\hline Functional Unit & Passenger $\cdot$ kilometer \\
\hline $\begin{array}{c}\text { System } \\
\text { boundaries }\end{array}$ & $\begin{array}{c}\text { Economic system level } \\
\text { (as determined by the IO-table based inventory of the } \\
\text { Exiobase v3 database) }\end{array}$ \\
\hline $\begin{array}{l}\text { Alloca } \\
\text { metr }\end{array}$ & $\begin{array}{l}\text { Economic partitioning } \\
\text { (following the economic nature of using IO-based } \mathrm{LCl} \text {, } \\
\text { based on economic proportion in each } \\
\text { industrial/economic sector) }\end{array}$ \\
\hline $\begin{array}{l}\text { Environmental } \\
\text { impact } \\
\text { categories }\end{array}$ & $\begin{array}{c}\text { The impact categories have been chosen by } \\
\text { Nederlandse Spoorwegen and enable future } \\
\text { compatibility with EPD: Global Warming Potential (GWP), } \\
\text { Ozone Depletion Potential (ODP), Acidification Potential } \\
\text { (AP), Eutrophication Potential (EP), and Photochemical } \\
\text { Ozone Creation Potential (POCP) }\end{array}$ \\
\hline $\begin{array}{l}\text { Main } \\
\text { assumptions } \\
\text { \& limitations }\end{array}$ & $\begin{array}{c}\text { - Only the remaining useful life of a modernized train is } \\
\text { included in the scope. The lifespan before modernization } \\
\text { is excluded. } \\
\text { - The application is considered a streamlined LCA which } \\
\text { does not comply with ISO 14040/14044 norms. }\end{array}$ \\
\hline
\end{tabular}




\subsubsection{Inventory of the Streamlined LCA Tool}

The source for the IO-based inventory is the open-source database called Exiobase (Merciai \& Schmidt, 2018). Exiobase v3 contains inventory data on 164 economic sectors for 97 countries. It not only depicts the 10 matrices of individual countries, but also takes into account the interconnections between them. Furthermore, it contains data on the five environmental impact categories included in this application, enabling future compatibility with EPD. It thus allocates and specifies the emissions of harmful substances for multiple economic sectors in various regions.

A user interface is used to link the data of the 10 database to the life cycle of trains. A screenshot of the inventory window of the computer application is shown in figure 6.5 .

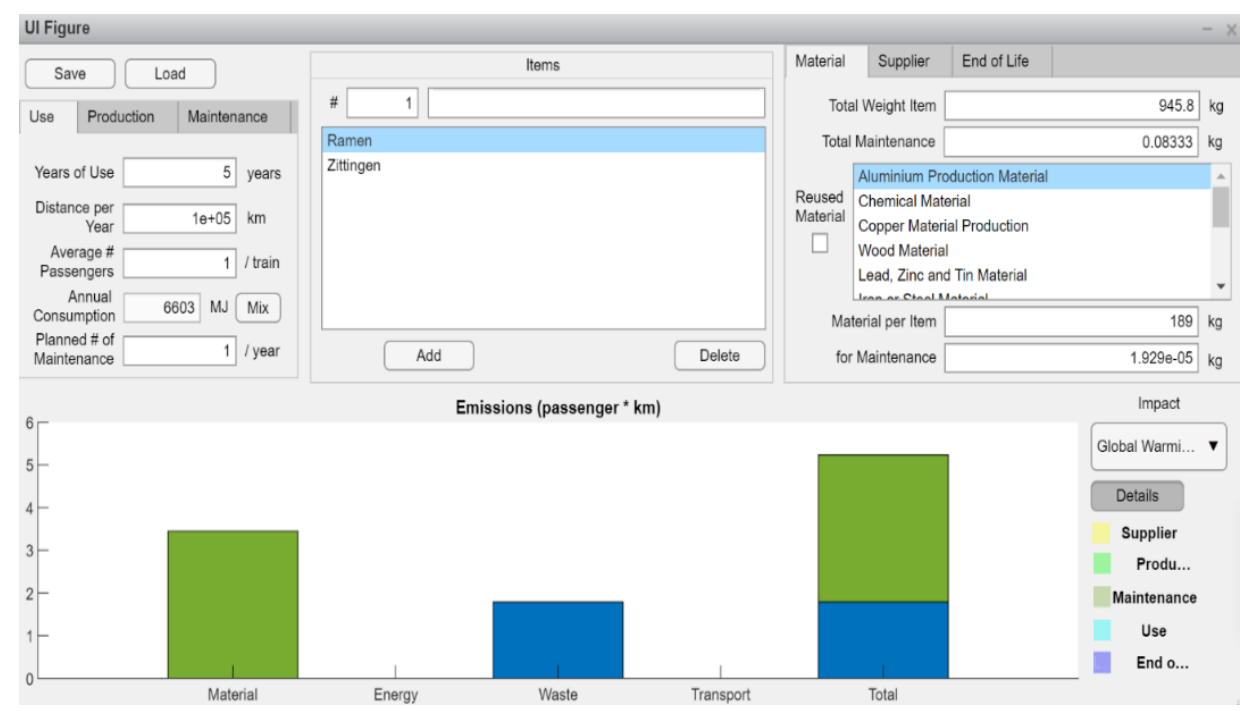

Figure 6.5: Screenshot of the streamlined LCA tool showing the inventory screen for train modernization.

The LCl model for the modernized train is built by modeling individual components of the train which are treated as an average item from a corresponding economic sector, as found in the 10 database. For example, the inventory data for seating is represented by the average item from the furniture sector. The remaining life cycle of the modernized train (including the modernization process itself) is thus modeled in an item-by-item way. The aspects that are used to build the $\mathrm{LCl}$ of the modernized train are summarized 
in Table 6.3. Information about the train's usage profile and remaining lifespan (years of use) is used to automatically calculate the environmental impact per functional unit for each user input. This not only simplifies the LCI process, it also ensures that different users should arrive at similar results, as the same data is used and the goal and scope have been fixed (reproducibility criterion).

Table 6.3: User input for the LCl of the modernized train.

\begin{tabular}{cl} 
Life Cycle Phase & \multicolumn{1}{c}{ User Input } \\
\hline (Raw) materials & $\begin{array}{l}\text { Material composition and weights of the parts and } \\
\text { components that comprise the train. }\end{array}$ \\
\cline { 2 - 2 } $\begin{array}{c}\text { Supply chain } \\
\text { Production } \\
\text { (train }\end{array}$ & $\begin{array}{l}\text { - Energy consumption and waste production at suppliers. } \\
\text { - Transportation from suppliers to the modernization facility. }\end{array}$ \\
\cline { 2 - 2 } $\begin{array}{c}\text { Maintenance } \\
\text { Unernization) }\end{array}$ & $\begin{array}{l}\text { Energy consumption and waste generation during the process } \\
\text { of modernizing the train. }\end{array}$ \\
\cline { 2 - 2 } & $\begin{array}{l}\text { Maintenance is treated as requiring additional components } \\
\text { and is modelled in the same way as (raw) materials. }\end{array}$ \\
\cline { 2 - 3 } & $\begin{array}{l}\text { - Component lifespan, expressed in years of use (time) } \\
\text { - Average daily use (time) }\end{array}$ \\
& $\begin{array}{l}\text { - Energy consumption (power) } \\
\text { - Source of (renewable) energy }\end{array}$ \\
\cline { 2 - 2 } End-of-life & $\begin{array}{l}\text { - Selection of end-of-life treatment options such as landfill, } \\
\text { incineration, } \\
\text { bio-gasification, recycling, re-manufacture, and re-use. } \\
\text { - Transportation to waste treatment facilities. }\end{array}$ \\
\hline
\end{tabular}

\section{Results}

This section shows the results of the design process in the form of an LCAbased tool for evaluating environmental sustainability in train modernization. The application of the designed LCA-based tool is demonstrated by means of a case study at Nederlandse Spoorwegen.

\subsection{Profiling in the Streamlined LCA Tool}

The design of the tool allows for the inclusion of multiple environmental impact categories. However, in line with the aim of simplification, only the environmental impact categories that were dictated by the EPD for the assessment of trains were included in the initial design of the LCA tool. The result is a selection of only five environmental impact categories at the midpoint level (see Table 6.4). 
An important limitation of this narrow selection is that the overall environmental impact profile of this application will be incomplete and lower overall when compared to other commonly used impact assessment methods that take into account a wider range of environmental impacts.

Table 6.4: Environmental impact categories included in the streamlined LCA tool

\begin{tabular}{|c|c|c|}
\hline Impact Category & Unit & $\begin{array}{c}\text { Environmental Effect (Midpoint } \\
\text { Level) }\end{array}$ \\
\hline $\begin{array}{l}\text { Global Warming } \\
\text { Potential (GWP) }\end{array}$ & kg CO 2 eq. & $\begin{array}{l}\text { The contribution to global warming by } \\
\text { the emission of greenhouse gases. }\end{array}$ \\
\hline $\begin{array}{l}\text { Ozone Depletion } \\
\text { Potential (ODP) }\end{array}$ & kg CFC-11 eq. & $\begin{array}{l}\text { The reduction of ozone concentration } \\
\text { in the stratosphere. }\end{array}$ \\
\hline $\begin{array}{l}\text { Acidification Potential } \\
\qquad(A P)\end{array}$ & mol H + eq. & $\begin{array}{c}\text { The acidification of water and soils } \\
\text { that is caused by the emission of } \\
\text { acidic substances. }\end{array}$ \\
\hline $\begin{array}{l}\text { Eutrophication Potential } \\
\text { (EP) }\end{array}$ & mol N eq. & $\begin{array}{l}\text { The eutrophication of water that is } \\
\text { caused by the emission of specific } \\
\text { substances (discharge of phosphoric, } \\
\text { nitrogenous, and organic matter). }\end{array}$ \\
\hline $\begin{array}{l}\text { Photochemical Ozone } \\
\text { Creation Potential } \\
\text { (POCP) }\end{array}$ & kg NMVOC eq. & $\begin{array}{l}\text { The formation of tropospheric ozone } \\
\text { (summer smog), caused by the } \\
\text { discharge of specific gases that have } \\
\text { an oxidizing action under the effect of } \\
\text { solar radiation. }\end{array}$ \\
\hline
\end{tabular}

As discussed in Section 2.3.2, shadow costs are used to normalize the results of these five midpoint environmental impact categories. The shadow cost valuation used for this step is already used by Nederlandse Spoorwegen to report on environmental impact in their annual reporting (NS, 2019) and follows the Handbook on Environmental prices (De Bruyn et al., 2018). This valuation approach uses the valuation of emission at the midpoint level, for the Netherlands (the geographical region of the case company) in the year 2015. 


\subsection{Interpretation Using the Streamlined LCA Tool}

The tool is used to find the weak points and hotspots for the existing train design, identifying improvement opportunities for the design of the modernized train. Using the LCA tool, it is possible to trace back five (EPD oriented) environmental issues to specific components in the train design or specific life cycle phases (transparency criterion). The use of shadow costs is used for normalization, allowing a direct comparison between different environmental impact mechanisms as well as aggregation into a single (total) impact score that can be used to indicate the preferred design options. Nederlandse Spoorwegen already makes use of shadow costs in its annual reports, facilitating its inclusion in the streamlined LCA tool.

\subsection{Demonstration of the Tool at Nederlandse Spoorwegen}

The LCA tool is demonstrated and evaluated in a real-world train modernization project at the Nederlandse Spoorwegen. As the main passenger operator of the Dutch railway network, the company plays a vital role in providing sustainable mobility in the Netherlands. The NS Train Modernization (NSTM) is the branch of Nederlandse Spoorwegen in charge of the overhaul of part of the rolling stock fleet. Its long-term vision is to improve the environmental sustainability of the rolling stock that needs to be modernized to face the second part of their useful life.

The VIRM train series is the current backbone of the intercity fleet of NS. In this article, the VIRMm1 train (see Figure 6.6) is used to demonstrate the streamlined LCA tool. The modernization project for the VIMRm1 train series has already been completed. However, the other two trains in the rolling stock series (VIMRm2/3 and VIMRm4) are technically similar, enabling the use of the LCA-based tool for identifying future improvements.

The information required for the $\mathrm{LCl}$ is derived from the bill-of-materials of the pre-modernized train using the material composition of each item that is considered within the scope of the modernization project. In this application, it is assumed that the new items have the same composition as the removed items. The production and maintenance phase are excluded from this train LCA, as insufficient data on these life cycle phases were available. 


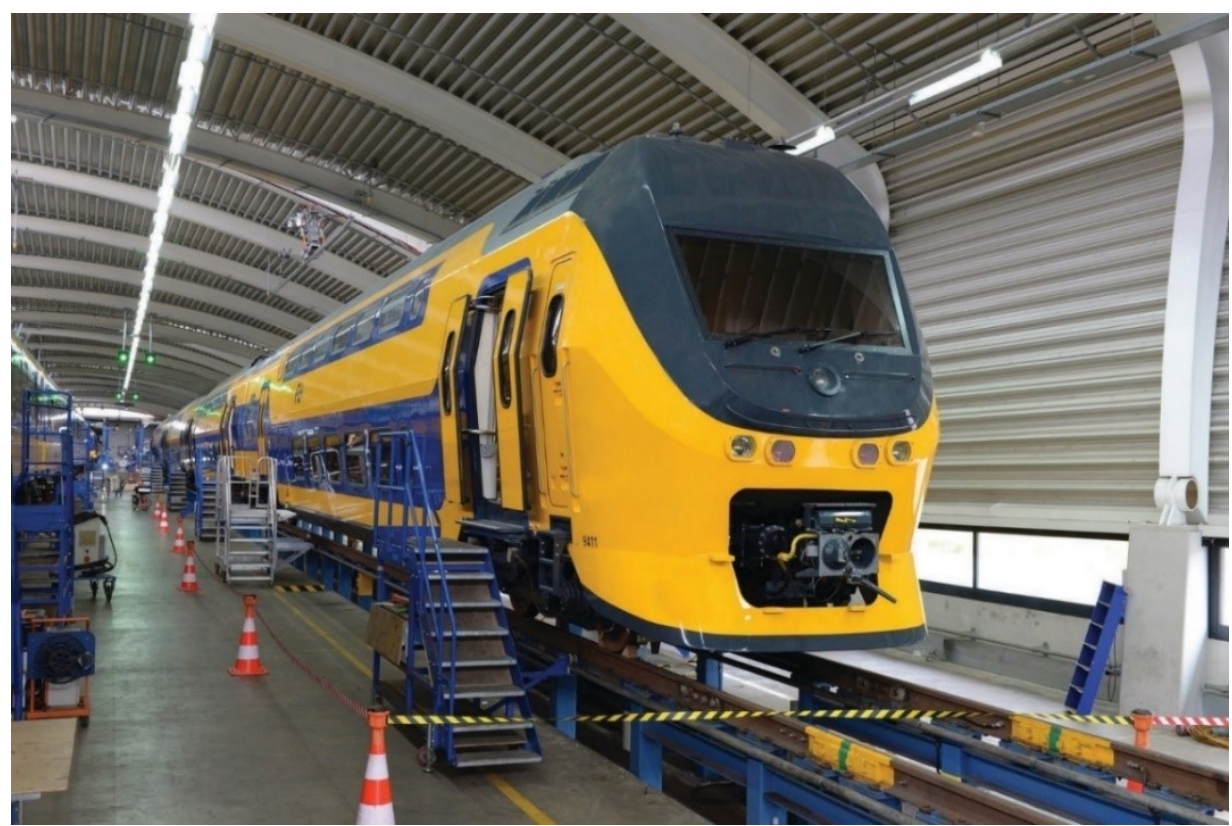

Figure 6.6: VIRMm1 train during modernization at NSTM, extending its life another 18 years.

The application of the streamlined LCA tool allows for determining the overall environmental impact per functional unit (passenger $\cdot \mathrm{km}$ ) for the various components of the train. The 'shadow cost normalized' impact results show that the seats especially have a big environmental impact, followed by the doors and windows (see Figures 6.7 and 6.8). These impacts are primarily related to the weight of these parts, as they need to be accelerated and decelerated during the daily operation of the train using traction energy. The outcome of this assessment made the areas the attention of the re-design efforts should focus on clear.

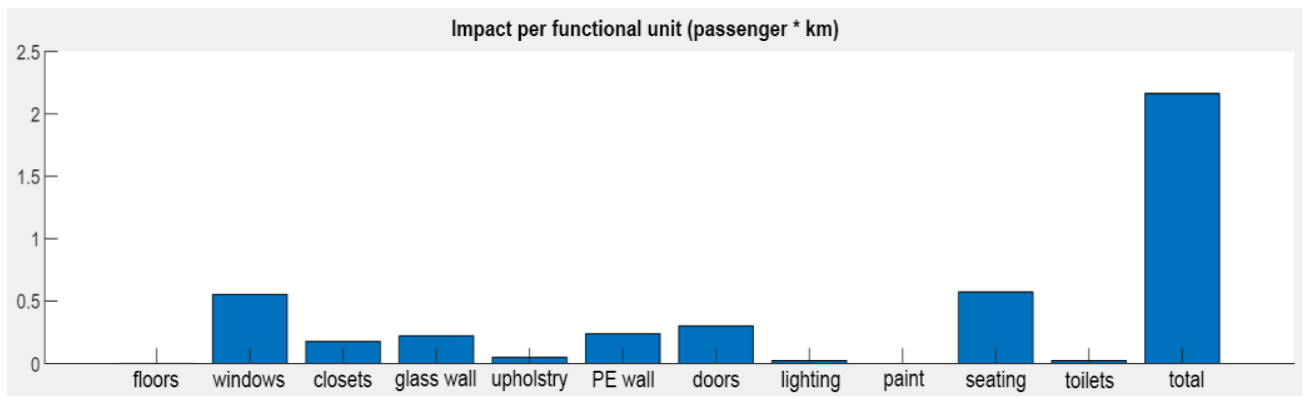

Figure 6.7: Screenshot of the streamlined LCA tool, showing 'shadow cost normalized' impact results. 


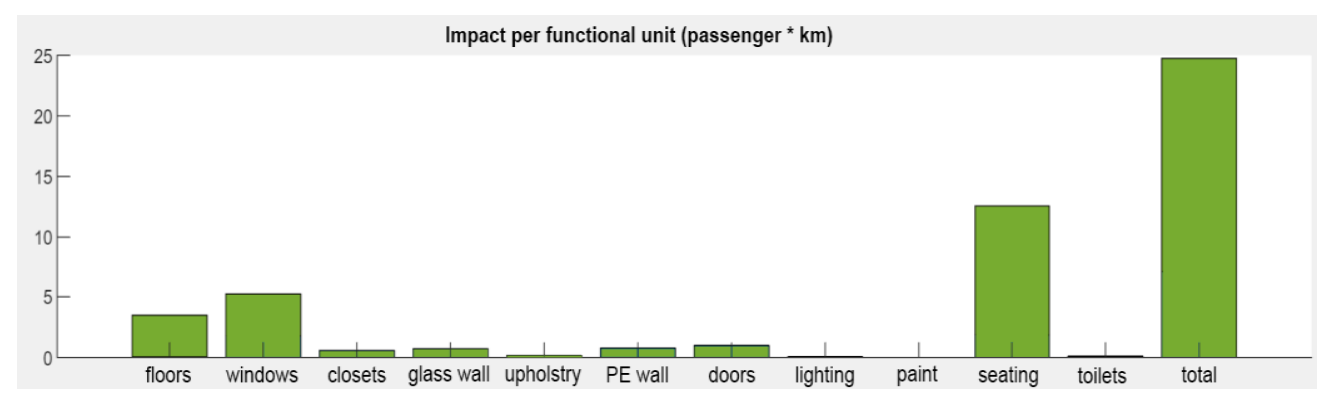

Figure 6.8: Screenshot of the streamlined LCA tool, showing the global warming impact results.

\subsection{Evaluation of the Streamlined LCA Tool}

The tool was evaluated together with the focus team of the train modernization department at Nederlandse Spoorwegen, demonstrating that is practically applicable and allows integration into the design stage of the train modernization process of a real-world railway operator. Furthermore, the resulting design meets the intended design criteria for streamlining (see Section 2.2) and the intended goal (see Section 2.4.1). Only the validity criterion proved to be difficult to fully evaluate without performing a full LCA (see Section 4.5), for which neither time nor resources were available in these early design stages. Instead of judging the validity of the LCA tool against a full LCA, it is more appropriate to judge the validity of not performing an LCA at all. Without the simplifications included in the design of the tool, LCA would not have been practically feasible in the first place. Compared to a lack of LCA, the tool was able to provide useful insights into the life cycle. With this tool, it is possible to identify and prioritize early design development directions, albeit at a low level of fidelity.

The ability of the LCA tool to support the assessment of various alternative design options was further evaluated by the staff from multiple departments of case company NS. These users had different levels of experience with train design and LCA applications. During these user tests, the users were asked to assess the impact on different environmental impact categories, thereby introducing the users to the full breadth of environmental impacts in the LCA tool. The users reported that the tool itself is useful for supporting the assessment of environmental impact, but that the ease-of-use of the interface of the LCA tool could be improved. 


\section{Discussion}

The design of the LCA-based tool was guided by the question of how to simplify LCA in such a way that the reliance on limited information, data and expertise is as low as reasonably possible. These simplifications are achieved by employing four main design principles, which are briefly discussed. Even though the designed LCA tool is intended as a proof of concept, its application in a real-world setting and subsequent evaluation does allow for a reflection about its underlying principles.

\subsection{Sacrificing the Declarative Function of LCA for Improvement Analysis}

The first design principle that was applied is sacrificing the 'declarative' function that is typically associated with LCA. Sacrificing the declarative function means that the developed tool is not intended for external audiences and should not function as a means to report or to communicate about environmental impact. Instead, the tool emphasizes an internal application of LCA for improvement purposes based on sensitivity analysis and the comparison of design options. In this context, it can be used as a rough, but accessible basis for the identification of 'hotspots' in the environmental impact profile of the modernized train. A low-precision improvement analysis can already be useful in this context for determining key areas (lacovidou et al., 2017) for (re)design, as long as the accuracy of the assessment is adequate. Furthermore, the reliance on data, information, and expertise can be much lower for improvement analyses than it is for declarative purposes, lowering the barrier to using LCA. Additionally, the streamlined LCA tool can also help familiarize staff with the concept of LCA in an approachable way, the lessons of which can also be used in later project stages where declarative LCAs such as PEFs are required, but require expertise to perform well (Lehmann et al., 2016).

\subsection{Lowering Data Requirements Using Input-Output Based Life Cycle Inventory}

The suitability of streamlined LCAs not only relies on the objectives of the study but also greatly depends on the databases that are incorporated (Arzoumanidis, Raggi, \& Petti, 2014). The second design principle that was incorporated into the design of the streamlined LCA tool was, therefore, the application of an IO-based Life Cycle Inventory. This allows for a fast but comprehensive way to model the LCl. This generalized approach not only 
needs less data input, but it also reduces the chance of missing critical datapoints when compared with a process-based $\mathrm{LCl}$, where information about each material flow and process step can be critical. Furthermore, the use of an IO-based inventory negates the process of making system boundary choices, a process that requires a high level of LCA expertise to perform well. The trade-off that is being made by using an IO-based $\mathrm{LCl}$ is that the results are also generalized to the level of national sectors or industries, resulting in an imprecise but accurate outcome of process-based $\mathrm{LCl}$. This means that the quality of the database becomes critical, especially with respect to the level of detail, completeness, and its geographical and temporal validity of the database.

\subsection{Lowering Interpretation Expertise Requirements Using Shadow Costs}

The third design principle that was used in the design of the streamlined LCA tool was the use of 'shadow costs' for normalization, instead of the more common practice of using person equivalence. This design decision serves two main functions. Firstly, for non-experts of LCA, the concept of 'shadow costs' is arguably easier to understand than personal equivalence as it uses the universally familiar language of money. This is especially useful for judging the magnitude of environmental impacts. Secondly, the use of 'shadow costs' makes it easier to evaluate the less tangible 'soft' environmental impact alongside the 'hard' financial criteria of design, as it already uses the same unit (in this application it was the $€$ ). This combination of functions makes it possible to use 'shadow costs' both as the basis for normalization within the scope of the LCA application (substituting person equivalence) as well as the basis in which to harmonize the financial and environmental impact performances within the design requirements (which lie outside the scope of the LCA). This fosters an intersubjective discussion about how to prioritize design decisions. An important limitation of this approach is that the use of 'shadow costs' is more subjective than the use of personal equivalence, making it unsuitable for declarative purposes (see Section 4.1). 


\subsection{Simplified Profiling Using a Limited Set of Environmental Impact Categories}

The fourth and last principle that was applied in the design of the streamlined LCA-based tool was to limit the number of environmental impact categories that were included in the application. The limited set of environmental impacts made it easier to interpret the result and to identify improvement areas, as there are not that many different types of impact to consider. Current demands on the breadth of environmental impacts that are included in LCA are often limited. For example, the EPD used to report on train modernization only requires reporting on five environmental mechanisms (the ones that were included in the designed tool), incentivizing organizations to focus mainly on these environmental factors.

This approach does carry a high risk of leaving blind spots in the evaluation of the environmental impact. Additionally, these blind spots may also result in burden-shifting to environmental impact mechanisms that are not included in the scope, potentially leading to a design that is only more sustainable 'on paper', as other environmental impact categories are not included. This characteristic, however, is not inherently part of the design of the tool but can be attributed to the current requirements of environmental reporting norms and ambition levels of the organization concerning environmental sustainability. To allow for future improvements in this regard, the tool can be easily extended to include other environmental impact mechanisms, provided the relevant data are available in the LCI database.

\subsection{Limitations and Future Research}

A discussion about the application of the tool with the staff of Nederlandse Spoorwegen did result in an additional insight about ownership and responsibility. The sources of expertise, data, and even environmental impacts could be traced to different departments within the organization of Nederlandse Spoorwegen. The use of the tool LCA not only required (and thus stimulated) collaboration between these departments, but also left an open question about the organizational level at which the responsibility for environmental impact and its assessment should be assigned in future modernization projects. A promising future development to address this challenge is to integrate sustainability into a digital twin of the system (Kaewunruen, Peng, \& Phil-Ebosie, 2020). 
Another avenue for future research is to further evaluate the magnitude and sensitivity of the uncertainty introduced by the streamlining approach compared to a full LCA. This could be studied by performing an exhaustive, peer-reviewed LCA of the same modernized train upon completion, comparing this outcome to that of the streamlined LCA tool, and subsequently judging to what extent the identified environmental 'hotspots' are similar. Alternatively, the results of the streamlined LCA can be compared with a sufficiently large and representative sample of existing rolling stock PEF reports.

\section{Conclusions}

Environmental sustainability is an increasingly important subject for public transportation organizations. Measuring the type and extent of environmental impact is crucial, as it is difficult to improve something if you cannot 'measure' it. LCA is widely adopted as the main instrument for evaluating environmental impact. However, LCA is rarely used for improvement analysis in earlier design stages due to limitations concerning access to data, information, and LCAspecific expertise. In earlier design phases, it is easy to make changes, but less information is available, whereas late in the process there is more information, but it is difficult to make meaningful changes. This knowledge trade-off is especially apparent in the application of LCA (Ylmén, Berlin, Mjörnell, \& Arfvidsson, 2020).

Intent on breaking this trade-off, a streamlined Life Cycle Assessment based tool is proposed that, aimed to take sustainability into account in the earliest development stages. This is achieved by purposefully trading-off the precision for the sake of making LCA accessible and usable in the early stages of train modernization while ensuring high accuracy by using an IO-based LCl. By limiting the goal and scope, impacts, and associated system boundaries, to only a single predetermined and archetypical application (Schrijvers, Loubet, \& Sonnemann, 2020), the LCA expertise and information requirements are lowered. The sum of these simplifications makes it possible to apply a rudimentary but focused form of LCA where it would otherwise be impossible to use.

By lowering the barriers of applying LCA, it becomes possible to make more informed decisions concerning environmental impact, as an assessment with low precision is arguably better than having no assessment at all. The quantitative nature of the tool helps with comparing and judging the 
magnitude of environmental impact and the efficacy of design options, finding hotspots in the rolling stock life cycle, and integrating the result alongside other design criteria, such as life cycle costs. This stimulates a different way of thinking during the design process by bringing more awareness of environmental impact and by linking engineering decisions with environmental improvement analysis as early as possible when it offers the most leverage. As indicated earlier, the proposed tool is not intended to replace full LCA, but to exist alongside it, albeit at a much earlier stage of the design process and a much lower fidelity. Errors made in the earliest phases of assessments can be quickly corrected once more information and data become available during the development process. Furthermore, this information is not wasted, as it can still be used to perform a full LCA in later stages. Metaphorically, this tool is to full LCA what a quick sketch is to a carefully crafted painting: A quick, but conscious effort to provide the broad strokes for the improvement of environmental impact. Even though the design explored in this article has been directed towards train modernization, the principles themselves may also be generalizable to other, physical-assetoriented applications, both within and outside of the public transportation domain, as long as the goal and scope of the application are adjusted accordingly.

Author Contributions: Conceptualization, W.-J.R. and A.M.; methodology, W.H.; software, W.-J.R.; validation, A.M., W.H. and J.B.; investigation, W.-J.R.; resources, L.v.D., J.B.; writing-original draft preparation, W.-J.R.; writingreview and editing, W.H., A.M., J.B., L.v.D.; visualization, W.-J.R. and W.H.; supervision, A.M. All authors have read and agreed to the published version of the manuscript.

Funding: This research received no external funding.

Acknowledgments: The authors would like to thank the case company Nederlandse Spoorwegen and its Train Modernization department in Haarlem (NL) for their participation in this research.

Conflicts of Interest: The authors declare no conflict of interest. 


\title{
Chapter 7 - Integrating sustainability in asset management decision making: A case study on streamlined life cycle assessment in asset procurement
}

\begin{abstract}
:
DSO's are increasingly expected and motivated to improve the environmental impact of their assets. A key improvement opportunity can be found in the procurement process, as most characteristics that determine an asset's environmental impact are committed at this stage. Many DSO's look to LCA as the international industry standard for assessing and quantifying environmental impact. Full LCA however, is too complex and tedious to be pragmatically used in procurement processes, as these require simplicity and accessibility to provide equal opportunity for all participants. By only including only the most dominant input \& output parameters of a 'master' LCA, the process of performing an LCA on a specific asset can be greatly simplified. This simplified model is demonstrated and evaluated through a case study on the procurement of medium voltage switchgear. The streamlined LCA approach presented in this article maintains most of the relevance of full LCA, while greatly reducing the complexity and resources required for its use.
\end{abstract}

\section{Publication history:}

This chapter was presented at the CIRED 2019 conference in Madrid:

Haanstra, W., Gelpke, R., Braaksma, A. J. J., Karakoc, I., \& Den Hartog, C. (2019). Integrating sustainability in asset management decision making: A case study on streamlined life cycle assessment in asset procurement. Paper presented at 25th International Conference and Exhibition on Electricity Distribution, CIRED 2019, Madrid, Spain. 


\section{Introduction}

As one of the larger energy Distribution System Operators (DSO's) in the Netherlands, Liander has increasingly become aware of the sustainability of its energy distribution systems. Currently, several initiatives exist for improving its sustainability impact. As an asset management organization, Liander also wants to consider sustainability characteristics of its assets alongside traditional criteria like costs, performance, and compliance. As a part of a broader supply chain, the impact of the assets goes further than Liander's own bottom line, and so a life cycle perspective is required. Fabrycky \& Blanchard (1991) estimate that " $50 \%$ to $75 \%$ of the projected Life Cycle Costs (LCC) of a given system are committed (i.e., 'locked in') based on engineering design and management decisions made during the early stages of conceptual and preliminary design". The environmental impact potential of an asset is similarly determined in the early stages of development. A DSO, however, only has a limited direct influence on these design stages, as the actual design of the asset is carried out by the manufacturers, who mainly base their decisions on the expected requirements of DSO's. While it is technically possible to develop more environmentally friendly assets, manufacturers indicate that environmental impact is not always taken into account in the procurement process. As (the development of) more environmentally friendly assets are typically accompanied by higher costs, manufacturers are stimulated to forgo environmental improvement by procurement procedures that are mainly decided by technical performance and price. Overall, sustainable products and production of energy distribution assets are still in the early stages of development. 
As DSO's have critical roles in the asset selection process, they carry a social responsibility to take into account environmental impact in their procurement processes. However, Liander sources its assets internationally, mainly on the European market where knowledge, standards and supporting legislation varies among countries and where EU rules, standards or systems are not always in place. An internationally accepted approach to assessing a product's environmental impact over its entire lifecycle can be found in Life Cycle Assessment (LCA). Typical applications of LCA are in identifying opportunities for improving environmental performance, marketing and informing decision makers in industry and governmental \& non-governmental organizations (ISO 14040, 2006). As the industry standard for assessing environmental impact, Liander intends to use LCA in its procurement processes.

\section{Problem statement}

The standardization of LCA in the ISO 14040 series standards has both harmonized and increased the credibility of the methodology over the last few decades, leading to its widespread adoption in industry. The industry, however, also revealed the need for simplifications for many applications. Hence, streamlined life cycle assessment methods have been derived from experience with the complex full methods (M. Hauschild et al., 2005).

Procurement is a prime example of an application that can benefit from simplification as its process should be accessible and transparent whereas 'full' LCA can be difficult and tedious for the designers (Umeda et al., 2012). If DSO's intend to implement streamlined LCA for procurement of assets alongside other criteria of the procurement, a practically applicable approach to streamlined LCA is required as well as a means to subsequently integrate the results into the decision-making process of tenders. Currently, no clear solutions exist for this specific topic. Some DSO's have adapted LCA models intended for other industries (e.g., construction sector). However, these adaptations are not always aligned with the context of DSO asset management or are performed by people lacking a suitable level of LCA expertise. Consequently, these approaches tend to lack scientific rigor, use outdated data, have procedural errors and often only assess a single indicator (usually $\mathrm{CO}_{2}$ ). So, a new approach is needed that takes a broad view of environmental impact and is developed specifically for the procurement of assets by DSO organizations. 


\section{Design of a streamlined LCA model}

The objective of this research is to design a practically applicable method for implementing streamlined LCA in the process of asset procurement.

\subsection{Design criteria}

Rebitzer et al. (2004) propose criteria for streamlined LCA methods, citing relevance, validity, compatibility with computational procedures, reproducibility and transparency as the main principles. These principles are adapted into five design criteria that a simplified LCA model for use in asset procurement should meet:

- Relevance - To ensure accessibility and equal opportunity for all potential procurement participators, the procurement should be usable without expert knowledge on LCA or access to specialized LCA software and/or databases.

- Validity - To ensure validity, the results of a simplified LCA should not deviate more than $95 \%$ from that of a comprehensive LCA using similar goal \& scope definitions.

- Compatibility with computational procedures - To enable the integration of environmental impact into a single procurement score, the outcome of the simplified LCA should be compatible with other procurement criteria (e.g., costs, design criteria, etc.)

- Reproducibility - Different practitioners should arrive at the same LCA score or ranking result given identical asset characteristics (and goal \& scope definitions).

- Transparency - In order to be credible (i.e., remove any doubts about the model) and to identify improvement potential, the method should be transparent. In other words, it should be feasible for a practitioner to understand the calculation of the final result and origins of the main environmental issues. 
Relevance is addressed by simplifying both the input and output models of the LCA model by only including the most dominant elements, thus reducing the time and expertise required to create a Life Cycle Inventory ( $\mathrm{LCl}$ ) and to interpret the results. A spreadsheet model is used for the assessment of a group of similar products. This model incorporates unit process data for the relevant processes in the life cycle of the product. Compatibility with computational procedures is achieved by monetizing the outcome of the streamlined LCA and aggregating the monetized impact alongside financial impact. Reproducibility \& transparency are ensured by modelling the streamlined LCA using spreadsheet models, which are identical for all potential procurement candidates. This model shows intermediate results to allow for easier interpretation and improvement analysis. Validity is achieved by comparing the outcome of the streamlined LCA with the outcome of a comprehensive LCA.

\subsection{Simplification of LCA input \& output models}

LCA is a general instrument that is developed to be compatible with a wide range of possible applications. As such, some environmental indicators that are included in various Impact Assessment Methods (IAM's) are more relevant than others, depending on the context of the application. In procurement, however, the goal $\&$ scope of the LCA can be set by the DSO. As the application context is exactly the same for all potential suppliers, indicators that do not contribute significantly towards endpoint effects can be cut-off from the scope (ignored) without compromising accuracy. It is expected that a significant reduction in the number of indicators can be achieved when limiting the scope accuracy at the endpoint level (e.g., at 95\%). The reduction in the number of indicators drastically decreases the complexity of the LCA's output model and simplifies the interpretation of the results by only returning the most dominant environmental impact results. To allow the supplier to interpret the environmental impact of the asset, the tool provides feedback on both midpoint and endpoint impacts. Similarly, the input model can also be simplified as not all processes in the LCl model are dominant in their contribution to the endpoint damage. Streamlining efforts at the LCl phase have the greatest potential for savings, as it is the most time-consuming phase of LCA (Rebitzer et al., 2004). Using the strategy of selecting only the most dominant processes and resulting energy \& material flows in the LCI 
model, a greatly simplified and reduced input model can be constructed, once again trading-off little relevance.

(output simplification)

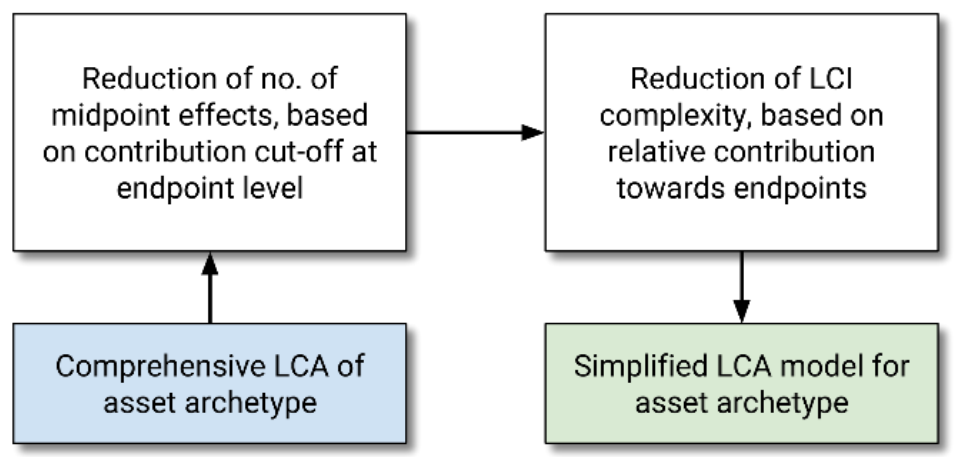

Consistency check: both models should be similar within acceptable limits

Figure 7.1: Conceptual model of LCA simplification process

In the selection of the $\mathrm{LCl}$ processes, it is important to consider whether the suppliers are be able to (easily) provide this data. This information into the dominant aspects in an asset domain can be used to develop a simplified (streamlined) LCA model that can be practically applied in existing tender processes (see figure 7.1).

\subsection{Monetization}

One way to integrate the financial impact for the decision maker and the environmental impact of that decision is to combine streamlined LCA with LCC analyses (Norris, 2001). In this approach, the direct costs of the decisionmaking organization are combined with indirect and less tangible environmental costs. This approach requires a monetization step where the environmental burdens are given a monetary value. Based on multiple case studies, Kara et al. (2007) conclude that streamlined LCA and monetization is an effective approach to evaluate environmental impact of a product as early as the conceptual design stage of a product. By integrating environmental and cost performance, a better understanding can be gained about inherent tradeoffs and optimization options in the asset lifecycle. 


\subsection{Integration in tendering process}

In the tendering process, simplified LCA results are included as a surplus external cost, by using the simplified LCA tool and assessing monetized environmental cost and adding these to the total cost of ownership and the other assessment criteria (see figure 7.2). Suppliers can use the tool to generate simplified LCA results, by modelling the lifecycle characteristics of their asset using the preselected input parameters of the spreadsheet model. The LCA result - at endpoint level: damage to human health in DALY, damage to ecosystems quality in species.years, and damage to resource availability in surplus costs to extraction - are subsequently monetized, based on internal valuation of the DSO and values from relevant academic literature, to find environmental costs (in $€$ ).

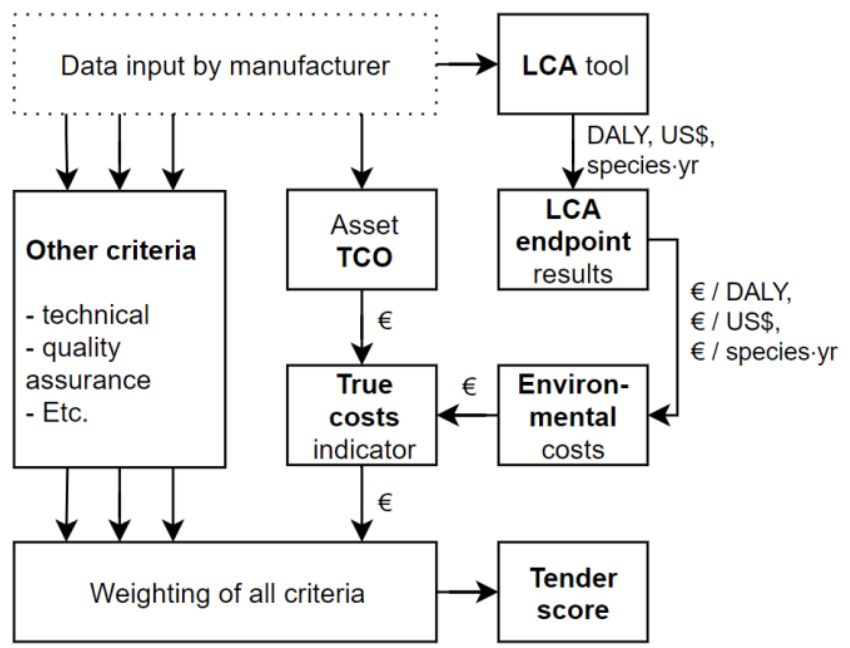

Figure 7.2: Inclusion of LCA in the tendering process

The environmental costs are then added to Total Cost of Ownership (TCO, also in $€$ ) to find a True Cost Indicator (TCl). This TCl is then used in the tender weighting table as if it were the actual price, thus comparing it to the other decision criteria. Tender entries from different manufacturers will subsequently be ranked based on their final tender score. 


\section{Case study}

The proposed streamlined LCA approach was demonstrated with a case study on medium voltage switchgear. Historical data from a previous tender was used to evaluate the developed approach. The use of historical data not only removes issues with data acquisition (tender processes can take more than one year to complete), it also imposes realistic limitations on input data requirements. If the new method is applicable using only existing data, its data requirements are not likely to be more complex than that of existing tenders. This ensures the relevance and the ability of suppliers to provide the required data (they have proven to do so in the past). Furthermore, it uses the same stakeholders and intended processes to simulate a real-world context.

\subsection{Output simplification}

In the case study, the ReCiPe 2016 (Huijbregts et al., 2017) IAM was used as this method is widespread in industry and scientific literature and contains both mid- and endpoint indicators. The mid-to-endpoint characterization factors were used to reduce the 17 midpoint indicators of ReCiPe down to only four midpoints, based on a threshold of $95 \%$ contribution towards the endpoint indicators (figure 7.3). For each endpoint, only one or two midpoint indicators were required to reach 95\% accuracy. Assuming all endpoint indicators are equally important, the relevant midpoint indicators were, in sequence of contribution: (1) Photochemical Ozone Formation, (2) Climate Change, (3) Fossil Depletion and (4) Fine Particulate Matter. In previous tenders, only Climate Change and Metal Depletion were included. Interestingly, this perspective proved to be incomplete, as three of the four most dominant indicators are not even considered in previous tenders (POF, FD and FPM).



Figure 7.3: Midpoint indicator contribution towards endpoint score in the case study (based on ReCiPe 2016) 


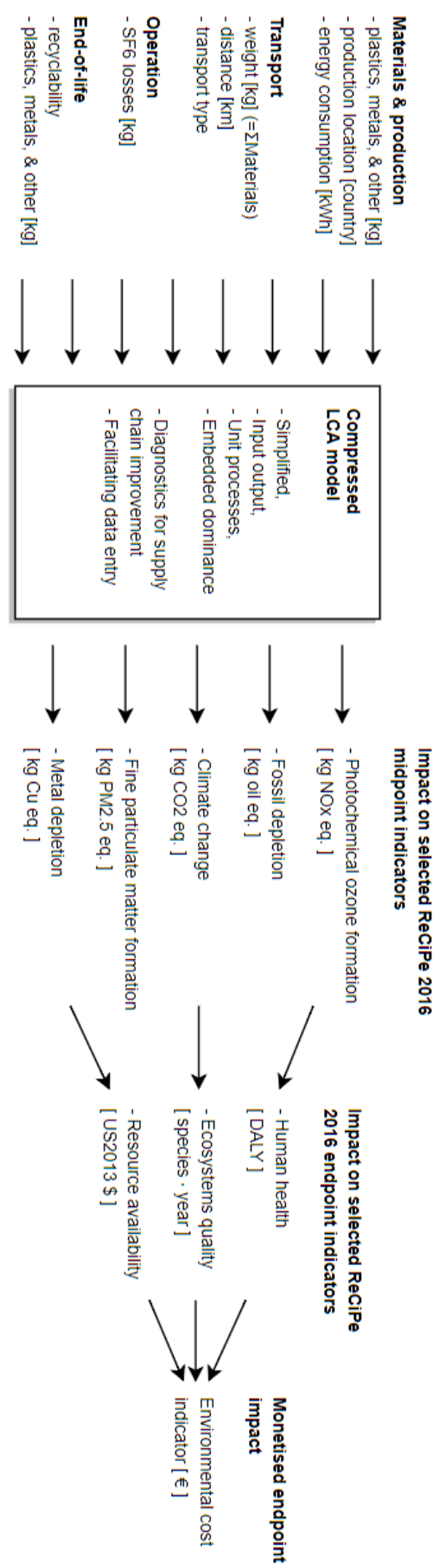

Figure 7.4: Image of simplified LCA black box for switchgear - including concrete inputs and outputs 


\subsection{Input simplification}

After establishing an inventory containing all relevant processes, materials and energy of the full LCA, the simplification process (see figure 7.4) was initiated. This was done by evaluating which life cycle phases have a significant contribution to the eventual impact. This is done for the raw materials, production, transport, operation, and end-of-life phases. The transport phase was the least dominant phase. However, there was a large variance in the type of transport and the production location. So, in some cases it did account for a contribution of up to $10 \%$. With this, it was concluded that no life cycle phase can be excluded before-hand. For each of the phases a number of critical parameters were set-up in a spreadsheet model. Filling the spreadsheet model was facilitated by providing the required level of significance and industry standard values. This way it is easier for Liander to detect anomalies. The unit process data was taken from dedicated LCA databases (e.g., ecoinvent v3 and Thinkstep database), complemented by industry data (e.g., from Eurofer, Worldsteel, and PlasticsEurope).

\subsection{Monetization}

Monetization was done in the case study for the three endpoint indicators of the ReCiPe 2016 IAM: damage to human health (years of human life lost in DALY's), damage to ecosystems quality (loss of biodiversity in species-years), and damage to resource availability (surplus costs of future extraction in US\$), were all expressed in $€_{2018}$. The damage to human health was monetized based on the internal valuation of loss of human life, as used in Liander's risk management. For the damage to ecosystems, no internal valuation currently exists at Liander. So, a monetization factor was adopted as proposed by Weidema (2008), based on a budget constraint method, which determines the willingness to pay for ecosystems quality at a certain area. The damage to resource availability is already monetized, and can be rewritten in the relevant currency. The constructed monetization values were cross-referenced to scientific literature and independent policy advises.

\subsection{Integration in procurement process}

The results from the case study are compared to the results from a previous tender (the source of the historical data). 


\section{Weight}

The average environmental burden in the case study was circa $€ 4.400$, the difference between the worst supplier in terms of environmental impact was circa $€ 2.300$, and the products in this lot of the tender have a price level of circa $€ 10.000$. This means that in the case study environmental impact would be considered at $23 \%$ relative to the TCO. The financial criterion had weight of $50 \%$. So, depending on the actual price environmental burden, when the approach of this article would have been used, the environmental impact would have a weight of $11,5 \%$. In the actual tender, sustainability had a weight of $10 \%$.

\section{Scoring}

When comparing the assessed sustainability with the actual tender (see table 7.1), interesting differences emerge. The suppliers with the two best scores on sustainability are reversed in the case study. The same holds true for the $4^{\text {th }}$ and $5^{\text {th }}$ place. Furthermore, whereas the difference between Supplier $C$ and $D$ received the same score in the actual tender, there is a large difference between them in the hypothetical case study. So, with an LCA-based environmental assessment, another supplier would receive the highest score for environmental impact. Other decision criteria are not considered in this comparison, and the actual tender was for dual sourcing, so the actual contracts would likely remain the same. However, more insight is gained in the actual impact of the suppliers.

Table 7.1: Comparison between sustainability score in the tender and case study

\begin{tabular}{|c|c|c|c|}
\hline Supplier & $\begin{array}{c}\text { Actual tender } \\
\text { score }\end{array}$ & $\begin{array}{c}\text { Case study } \\
\text { environmental } \\
\text { burden } \\
\text { (monetized) }\end{array}$ & $\begin{array}{c}\text { Case study score } \\
\text { (normalized) }\end{array}$ \\
\hline$A$ & $10.0\left(1^{\text {st }}\right)$ & $€ 3.635$ & $8.2\left(2^{\text {nd }}\right)$ \\
\hline$B$ & $6.5\left(2^{\text {nd }}\right)$ & $€ 3.230$ & $10.0\left(1^{\text {st }}\right)$ \\
\hline$C$ & $3.7\left(3^{\text {rd }}\right)$ & $€ 4.370$ & $5.0\left(3^{\text {rd }}\right)$ \\
\hline$D$ & $3.7\left(4^{\text {th }}\right)$ & $€ 5.505$ & $0.0\left(5^{\text {th }}\right)$ \\
\hline$E$ & $1.8\left(5^{\text {th }}\right)$ & $€ 5.105$ & $1.8\left(4^{\text {th }}\right)$ \\
\hline
\end{tabular}




\section{Conclusion}

In order to achieve the objective of this research while adhering to the aforementioned design criteria, two main design challenges were tackled. The first challenge consists of streamlining LCA so it becomes practically usable to be considered in Liander's procurement processes. This challenge was tackled by only including the most dominant material \& energy flows in the LCI phase as well as only including the most dominant midpoint effects when presenting the outcome of the LCA. Based on a full LCA, this focused reduction in scope significantly simplifies the LCA process for future use, while still retaining a high degree of validity. The streamlined approach, as demonstrated in the case study, retained a validity of at least $95 \%$ while reducing the $\mathrm{LCl}$ stage to only 11 input parameters and 4 midpoint effects. Interestingly, two of these four midpoint effects were previously overlooked. Moreover, it was discovered that an unconsidered indicator was the most dominant one.

The second challenge was to integrate the streamlined LCA approach into the procurement processes so they could be assessed alongside other criteria, such as LCC and asset performance. This can be achieved by monetizing the environmental impact profile and subsequently treating its impact similarly to the DSO's expected TCO. It was shown that using streamlined LCA only resulted in minor differences in the sustainability score of the suppliers. As the case study neglected the other decision criteria, and it was a dual sourcing tender, this would not likely influence the actual tender outcome.

The presented approach to streamlined LCA proved to be able to provide a mostly valid, yet easy-to-use insight into the environmental impact of an asset during the tendering processes. This result contradicts the commonly held belief that LCA is too complex and tedious to be reasonably considered in asset procurement. This outcome offers an opportunity for DSO's and manufacturers to take responsibility and break out of the catch-22 situation where manufacturers have few environmentally friendly assets to offer because DSO's are not including these factors when evaluating their asset acquisition decisions. 


\subsection{Recommendations}

The approach for streamlining LCA does require at least one comprehensive LCA study to be performed, requiring an initial investment in resources or expertise to be used, though this process can also be outsourced. Even though the method presented in this paper was demonstrated using the procurement process of switchgear, it can also be applied to other asset types. DSO's also generally manage a large number of technically similar assets in asset portfolios. Instead of needing to develop comprehensive LCA's for each asset individually, they can also be performed on an 'archetypical' asset, representing a typical example of an entire asset portfolio. This archetypical 'master' LCA can then be quickly re-used for various other purposes with little effort, such as life cycle planning or future tenders. Practitioners should be aware that the simplification is only valid as long as the goal and scope definitions of the LCA do not change.

\subsection{Limitations}

Design Science Research calls for demonstration in context. However, actual implementation using a real-world case study did not fit the timeframe of the research project. The method will be applied in an upcoming tender at Liander. Based on the results from this tender, the method will be improved and applied in the future in a continuous iterative learning cycle.

Another limitation is that the proposed method only works for IAM's that use mid- $\&$ endpoint effects, such as the ReCiPe IAM. Though it is conceptually possible to establish midpoint effect dominance based on normalized results, this would introduce new procedural challenges influencing the validity of the LCA results. 
Chapter 8 - Discussion and conclusion 


\section{Overview}

The research described in this dissertation set out to address an increasingly relevant question faced by organizations that are responsible for the management of physical assets:

"How can the life cycles of physical systems be assessed to support value-driven decision-making that benefits Asset Management organizations and their relevant stakeholders?"

This question has been investigated and answered over the course of the last six chapters (chapters 2-7), by following a mostly Design Science focused research strategy with an emphasis on participatory forms of implementation and evaluation of the designed artifacts. The data and information collected and processed during these design cycles were integrated into the design artefacts themselves, and implemented at two AM organizations. By reflecting on the design and application of these artefacts in their real-world context, it is possible to draw conclusions and recommendations, effectively answering the 'how'-type question based on the findings of the research. By designing decision-support instruments for asset life cycle-oriented decisionmaking at DSO Liander and railway organization Netherlands Railways, it became apparent that AM organizations have specific goals and preferences that are incompatible with the commonly applied technique of Life Cycle Costing, leading to a threefold knowledge gap.

A broader perspective than just costs is required in these decision contexts, as AM is concerned with creating value with assets for itself and its relevant stakeholders, not just about reducing costs. At Liander and Netherlands Railways this was reflected by the inclusion of non-financial factors such as reliability, environmental sustainability, and stakeholder costs. It also means that less-tangible forms of value creation need to be considered such as the benefits of using adaptable, flexible, future-proof energy grid architectures.

Furthermore, assets that interact with other assets, like those found in larger complex systems such as energy grids, also need their value creation assessed from a systems perspective. Individual assets such as transformers, switchgear, and trains are often part of a wider system of interconnected assets, such as energy grids and railway networks. Focusing only on the 
individual asset-lifecycle, like typical LCC applications tend to do, increases the likelihood of falling for the pitfall of sub-optimization.

Lastly, the demands of the socio-technical environments that assets exist in can change significantly over the life spans of many assets, that typically last decades. AM organizations, therefore, need to account for strategic aims and contextual change in their decision-making, something that is lacking in existing life cycle-oriented assessment approaches, especially the commonly applied approach of Life Cycle Costing (LCC). For DSO Liander, this long-term but steady socio-technical change is exemplified by the energy transition, in which the needs and requirements of the present are clearly different from those of the past and the future.

In this final chapter of the dissertation, a brief reflection will be given on how the designed artifacts are used to close the previously mentioned knowledge gap and provide an answer to the research question. This reflection is structured according to the two research themes, as discussed in the General introduction (chapter 1). This reflection is followed by a discussion on the design principles that were used in the design of these artifacts, resulting in a set of generalizable design principles. Then, the limitations of the research and their results will be discussed. Lastly, the implications for theory and practice are summarized, including suggestions for areas that require further research.

\section{Research theme 1 - Assessing the value created by assets over their life cycle}

The first research theme of the dissertation (as discussed in chapters 2-4) is centered around the LCV methodology and addresses the question of how asset value can be assessed over the life cycle. Chapter 2 discusses the limitations of LCC in the context of AM decision-making and how the fourphased assessment process for Life Cycle Assessment (LCA) may be used as a framework for such assessments.

The research shows that LCV assessments draw attention to the entire life cycle of the asset by requiring the assessor to think about all the life cycle phases in the lifespan of the asset, from cradle or present state, to grave. Furthermore, chapter 4 discusses how LCV models require assessors to come up with a Life Cycle Plan to achieve the intended organizational goals with their assets. This not only results in a (strategic) plan of what will (or needs to) happen at specific moments in time, it also draws attention to the long life 
span of many assets and the magnitude of the impacts associated with their entire life cycles.

As discussed in the Research Motivation (Chapter 1 - Section 3) the first challenge with using LCC is that it is mainly limited to the assessment of individual items. The four-phased process of the LCV methodology, which was borrowed from LCA, addresses this issue by inviting assessors to discuss the goal of the assessment in relation to the organizational goals. Furthermore, it draws attention to the limitations that assessing individual assets may have, especially when dealing with interconnected assets like those found in energy grids. The LCV assessment process (introduced in Chapters 2 and 3) enables assessors to declare which asset or assets are included, and which (parts) of the asset(s) or system(s) are out-of-scope (see Chapter 3 - Section 5.1).

To address the second challenge described in the Research Motivation, the LCV methodology supplements the conventional financial perspective, which is common in LCC, with a broader, more holistic non-financial perspective that is required for AM. This enables the simultaneous assessment of different types of costs and benefits for the organization and its relevant stakeholders beyond mere costs. Assessing costs and benefits alongside each other in this way, allows the assessor to (only) include factors that have any relevance to the values, objectives, and preferences of the organization and its stakeholders. This not just provides an assessment outcome that is tailored to the requirements and needs of the organization (Chapter 3 - Section 3.1), but it also helps align financial and non-financial functions within the organization (Chapter 4 - Section 7.2) by making the impacts on these functions explicit, and by integrating information and knowledge from multiple disciplines into a single life cycle model.

Lastly, the LCV methodology is designed to facilitate a discussion on the role that long-term uncertainty may play in the remaining life cycle. This discussion is facilitated by asking the assessor to reflect on the goal of the assessment in relation to the (long-term) organizational goals in the earliest stage of the assessment. Furthermore, alternative LCV assessments can be created for multiple strategic or tactical plans for assets, showing their expected impacts over the life cycle. These asset plans can contain actions, strategies, and design principles that are specifically aimed to make these assets better prepared for long-term changes under uncertainty (as discussed in Chapter 4 - Sections 6.4 and 7.3). 


\section{Research theme $\mathbf{Z}$ - Improving the usability of life cycle-oriented assessments in AM decision-making}

The second research theme discussed how usually complex and timeconsuming approaches such as LCA and sustainable design principles can be simplified. This theme is less focused on how it can be assessed (this was already addressed in the first research theme) but how it can be assessed effectively in a decision environment that is characterized by a 'firefighting' mentality and limited availability of information, time, and expertise.

Chapters 5-7 show how focused simplification efforts can make life cycleoriented assessments much more effective in practice, even allowing them to be applied in decision contexts that would otherwise be impractical. Especially application in the earliest design stages or earliest life cycle stages offer the most opportunity for improvement, as the impact over the entire life cycle can be leveraged, as discussed in chapter 5 . The downside of this 'front loading' strategy is that in these early phases, less is known about the life cycle and its impacts, making it difficult to accurately estimate what will happen with the asset over its lifespan.

One way to deal with this uncertainty is to use generic data when exact data is unavailable or of insufficient quality, a strategy that was applied in chapters 6 and 7. Another approach is to selectively assess only those factors that contribute most to the overall impact, thereby ignoring all impacts that are deemed insignificant, as discussed in chapter 7. This greatly reduces the parameters, and subsequently the amount of data, required to make assessments. This also, however, requires knowledge about which parameters are important and which can be safely ignored. Knowledge that is likely to require at least a more comprehensive preliminary assessment.

Even though these simplification strategies will never be as accurate as their more comprehensive counterparts, the time, resources, and expertise expenses saved by these strategies can outweigh the disadvantages. Especially during the earliest stages, when design options are still flexible, even imperfect assessments are still capable of identifying major development directions. Furthermore, because the design will still be flexible, there will be enough time to identify and correct any mistakes in later stages. In these cases, it may be better to have a slightly wrong understanding of the life cycle impact than it is to have no understanding of this impact at all. 


\section{Discussion and generalization of the adopted design principles}

As discussed in the General introduction (chapter 1), Design Science Research is not just about designing, implementing, and evaluating artifacts. An important characteristic of DSR is that it also allows for a deeper reflection on the design principles and their generalization. The core design of the proposed LCV methodology is based on well-established, empirically tested, and generalizable design principles, allowing for the method to be adapted to other organizations and asset types. Where the first section of this concluding chapter has answered the research question by explaining 'how' the life cycles of physical systems be assessed to support AM decision-making, this section reflects further on the research results by discussing 'why' the developed artifacts were effective from a design perspective. This section, therefore, discusses the generalizable design principles that underpin the research presented in this dissertation.

\subsection{Exposing causal links between life cycle planning and value creation}

Value-driven decisions are effectively about what you plan to do with the asset to achieve the intended outcome (i.e., value creation). As such, LCV models are built following a process that resembles Life Cycle Planning (LCP), which contains a holistic picture of the entire life cycle, includes strategies for multiple alternative options, and links these activities to external factors, as indicated by Umeda et al. (2012). The concept of Activity Based Costing (Emblemsvåg, 2003) is used to break down these strategies into recognizable and discrete life cycle elements (e.g., used to model acquisition, operation, maintenance, etc.) that can be mapped to specific moments in time in the life cycle, forming an Activity Breakdown Structure (ABS).

LCV models do not immediately translate all impacts in the life cycle of an asset into a one-dimensional unit, as is the case in the application of LCC (Gluch \& Baumann, 2004). Instead, LCV distinguishes between different kinds of financial and non-financial impacts, providing a multi-dimensional perspective of value that consists of different types of impacts that represent different costs and benefits. Depending on the goal of the LCV assessment, it is possible to regard this multi-dimensional outcome as an intermediate 'midpoint' in the calculation towards an overall one-dimensional 'endpoint' life cycle value impact indicator. Because 'midpoint' impacts can include wholly 
different types of impact (e.g., financial, environmental, technical impact, etc.) they are structured using a Value Breakdown Structure (VBS) before they are aggregated into a single indicator.

LCV models require the assessor to link the life cycle elements of the ABS to the various impacts that are defined in the VBS. As such, in completed LCV models, these links form a causal structure that connects strategically planned activities in the life cycle to the creation (or destruction) of value to the organization and its stakeholders, as illustrated using a Sankey diagram in figure 8.1. This mechanism allows LCV assessments to provide transparency about which types of impacts are generated by specific life cycle elements (i.e., activities in the life cycle) and enables the model to be seen from both a planning and a value perspective (as discussed later in section 2.4 ).

$\downarrow \begin{array}{lr}\text { Activity Breakdown } & \text { Value Breakdown } \\ \text { Structure } & \text { Structure }\end{array}$

Impact A

Life cycle

element 1



. 
itself and how it can be supported. Though many publications discuss the steps required in the assessment of life cycle impacts, they are not structured using generally applicable international guidelines (Toniolo et al., 2020).

In the practical application of LCA, assessors are continuously required to make and motivate decisions about the goal, scope, allocation, profiling, weighting, cut-offs, etc. These choices need to be made carefully as each choice will affect the outcome and the limitations of the assessment. As there are multiple options open to the assessor for each of these decisions, an important challenge for people performing LCA is to select the most sensible, logical, and reasonable choices from a wide range of possible methodological options. The existence of this challenge has not gone unnoticed in the literature on LCA, many of which are deemed to be unresolved problems (Reap, Roman, Duncan, \& Bras, 2008a, 2008b).

In LCC, these types of challenges are less frequently recognized. At first glance, LCC seems like a relatively straightforward calculation exercise that simply aggregates all costs in the life cycle of a product or system. Though this concept may be suitable for the assessment with narrow scopes, such as studies that investigate individual assets, that are purely focused on costs, are clearly defined, certain, and take place in an unchanging environment. The question that presents itself is if any decisions fit this narrow description in actual practice. Existing literature seems to suggest otherwise, drawing attention to the difficulties of LCC to deal with asset interdependencies in complex systems (Roda \& Garetti, 2014), non-financial impacts (Gluch \& Baumann, 2004), long-term contextual changes (Arja et al., 2009), and a lack of international context-dependent standards (Korpi \& Ala-Risku, 2008; Toniolo et al., 2020). As such, LCC can often be too simplistic and onedimensional to be an effective decision-support instrument. The findings of chapters 2, 3, and 4 of this dissertation confirm that these challenges are not just theoretical but that they also appear in practice, especially when it is applied in the broader and complex problem contexts of AM decision-making. In these uncertain and ambiguous application contexts, the benefit of applying techniques such as LCC no longer lies in calculating or predicting the best option but becomes more about a process of investigation and sensemaking (Thiry, 2001). As such, LCC calculations give practitioners a sense of a systematic and rational decision-making process, rather than supporting the decisions with detailed figures (Gluch, Gustafsson, Baumann, \& Lindahl, 2018). 
From this discussion, two opposing philosophies about LCC seem to emerge. The first, more 'classical' philosophy on LCC, assumes a clearly defined and mostly unchanging environment where the application of LCC serves the objective to calculate the true Total Cost of Ownership (TCO) figure or an optimum in a certain trade-off. The second, more 'relativistic' philosophy on LCC assumes that the environment itself is uncertain and continuously changing. From this line of thought, the application of LCC serves as a means to make sense of the life cycle, by providing more clarity in an otherwise unclear or uncertain environment. This 'relativistic' perspective also acknowledges that the outcome of the assessment is only valid in the context from which it is assessed and that different contexts may lead to different insights about what is considered the best decision, even when investigating the same asset or product. It should be noted that these philosophies, at their extremes, are incompatible with each other, as 'classical' LCC relies on complete data and well-defined problems to function, whereas 'relativistic' LCC is aimed at making sense of ill-structured problems and assumes that data limitations may apply. An important challenge for professionals that apply LCC is, therefore, to recognize which type of LCC philosophy application the decision context calls for in the grey area in between the two extremes, as illustrated in figure 8.2 .

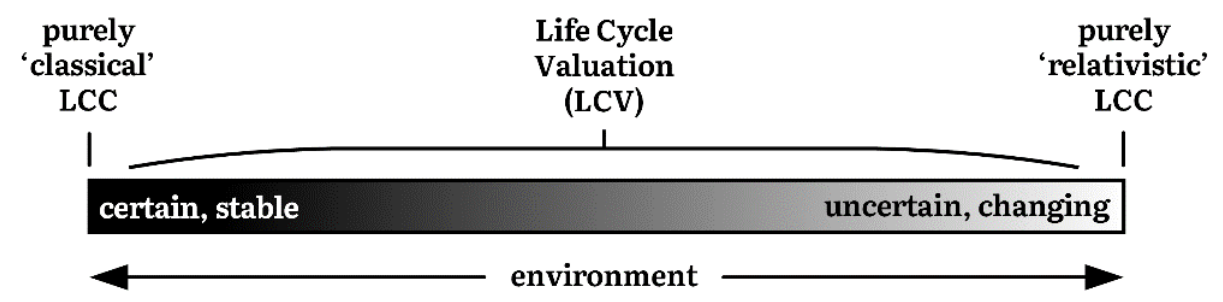

Figure 8.2: 'classical' and 'relativistic' LCC philosophies 
Relying on philosophy to tailor the application of LCC to decision contexts is unlikely to be usable in AM practice, where the 'firefighting' mentality still prevails (as discussed in chapter 1). In this research, therefore, applications of LCV are structured using an easier, four-phased framework that has been inspired by the application process of LCA. The adoption of this LCA process to guide LCC-oriented applications is proposed by multiple scholars (Bierer et al., 2013; Heijungs et al., 2013; Rebitzer \& Hunkeler, 2003; Swarr et al., 2011; Toniolo et al., 2020) and is acknowledged by international standards on LCA (ISO, 2006a, 2006b). Like LCA, the LCV process describes an iterative process (see figure 8.3) of (1) determining the goal and scope of the assessment, (2) creating the life cycle inventory, (3) performing an impact assessment, and (4) Interpreting the results.

- Determining the goal

- Defining the system of interest

- Determining the temporal scope

- Determining the Value Breakdown Structure (VBS)
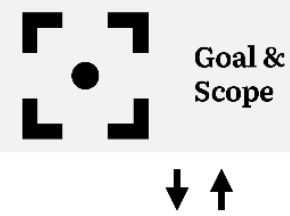

- Determining the Activity Breakdown Structure (ABS)

- Application of data,

multidisciplinary expertise and assumptions

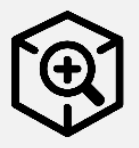

Life Cycle Inventory

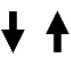

- Total LCV impact

- Activity-based impact profile

- Value-based impact profile

- Equivalent Annual Annuity (EAA)

- Comparison of alternatives

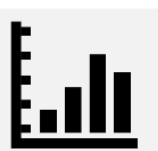

Figure 8.3: Four-phased process of the LCV methodology

This four-phased process serves two main functions. The first function is that it provides instructional guidance on how to perform an LCV assessment, encouraging the assessor to think about methodological choices and their effect on the outcome. The second function is aimed at stimulating and fostering a sensemaking process for assessments that take place in uncertain and ambiguous decision contexts. This sensemaking process is stimulated by drawing attention to methodological choices concerning the goal, scope, definition of value, life cycle planning, estimation, etc. while explicitly inviting the assessor to reflect on these choices in the interpretation phase. The creation of an LCV model, therefore, relies on the effective alignment of a wide spectrum of AM functions and management perspectives. In the application of 
the approach at case organization Liander, it also often served as a starting point that initiated a process of alignment. Examples of this were alignment between financial and non-financial impacts and alignment between the individual asset and its surrounding grid architecture. These findings not only seem to suggest that the four-phased framework of LCA can be adapted to the application of LCV, but that this framework helps foster a shared, multidisciplinary sensemaking process, that both requires and leads to increased alignment within the organization. In the uncertain and complex challenges faced by many AM organizations, the sensemaking and alignment effects of this process are arguably more important than the accuracy of the resulting TCO figure.

\subsection{Modular life cycle models that can be tailored to specific decision contexts}

The process indicated in section 2.2 is not enough to fully support LCV assessments. Another important factor in the application of the LCV methodology lies in the instrument that is used to support the assessment. Kambanou \& Lindahl (2016) state that from a practical point of view, LCC is always tailored to fulfill the requirements of its intended use (Asiedu \& Gu, 1998) and that it is also a reflection of the object that is assessed, the scope, the boundaries, etc. (Rebitzer \& Hunkeler, 2003). Korpi \& Ala-Risku (2008) also indicate that a wide variety of LCC types exist and that LCC has a strong context-specific nature. As LCC can be highly context-dependent and organizational objectives are in constant flux, it makes sense to design an assessment instrument that is easily adaptable and which enables an LCV assessment to be quickly tailored to suit a wide range of $A M$ preferences and decision-making contexts (Browning \& Honour, 2008).

This adaptability is reflected in multiple characteristics of the spreadsheetbased LCV tool that is used to create LCV models, which was developed and tested at case organization Liander. Firstly, the Value Breakdown Structure (VBS) can be easily expanded and adjusted, allowing different types of value (e.g., costs and benefits for various stakeholders) to be included and valuated in the assessment, depending on the organizational preference or the type of decision. This also allows for easy adjustments of the VBS when valuation changes are required. Secondly, the impact associated with specific life cycle elements can be easily modified by linking them to various impact categories in the VBS. Furthermore, the life cycle elements can also be easily adjusted in 
the Activity Breakdown Structure (ABS) by inputting and adjusting the amounts for each unit of each life cycle element at specific moments on a timeline. This enables a quick adjustment of the life cycle plans for assets and facilitates the creation of different scenarios for the life cycle. The combination of an adaptable VBS and ABS, allows the LCV model to be easily and quickly adjusted, as illustrated in figure 8.4.

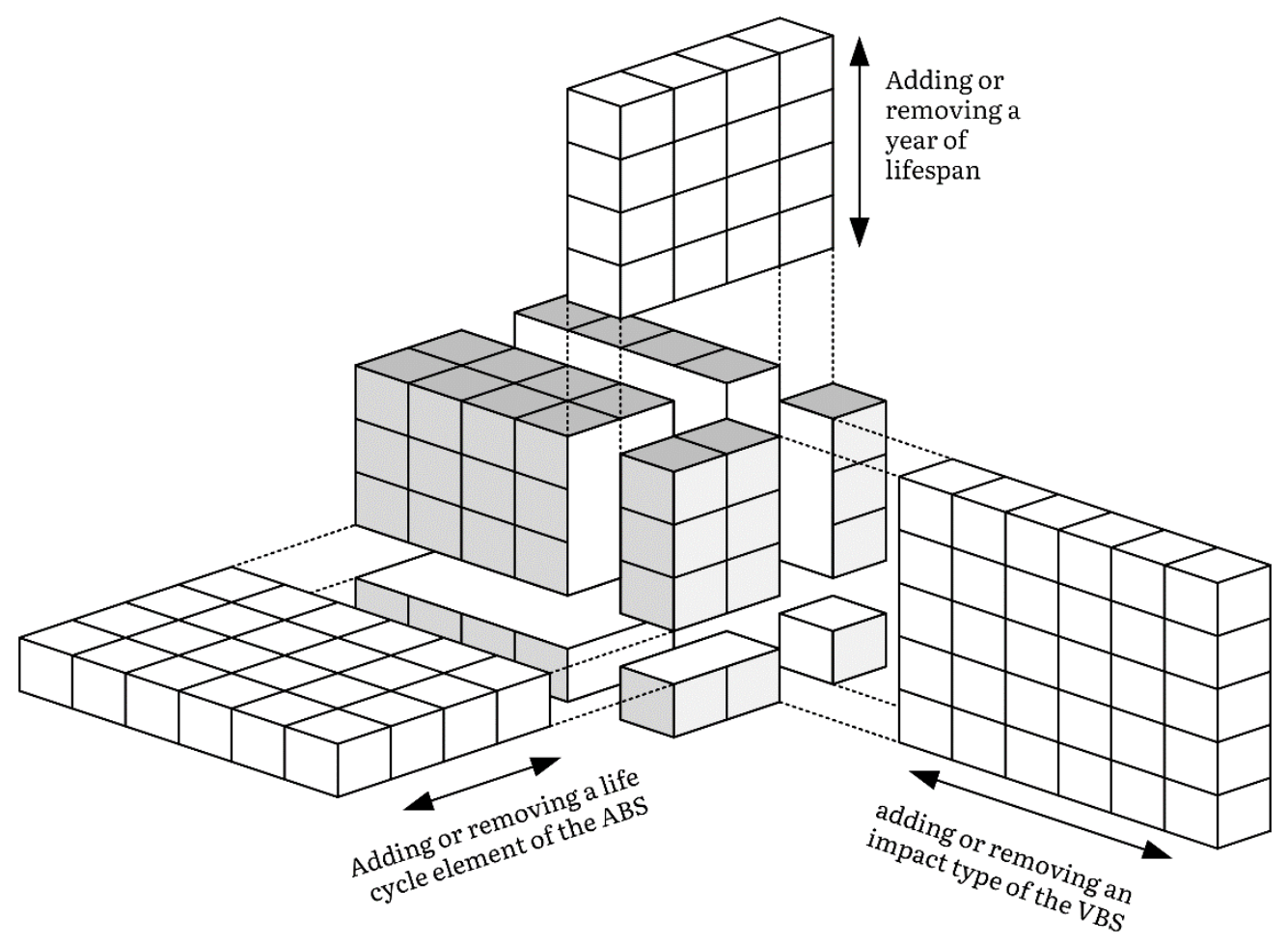

Figure 8.4: Adapting modular elements in an LCV model

The flexibility that this adaptability enables, allows assessors to 'play' with the LCV model by changing certain parameters and quickly see how these changes are reflected in the outcome. This not only provides a quick understanding of the life cycle that is modeled and its sensitivities, but it also enables professionals to progressively update LCV models as the understanding of the asset life cycle and its problem context grows. It also allows for the VBS to be updated when the organizational goals or preferences change. At Liander, for example, the way how $\mathrm{CO}_{2}$-emissions were valuated has changed during the four-year research period. Furthermore, the 
adaptability allows AM professionals to use the LCV tool to assess a wide range of different decision contexts by using different life cycle elements in the ABS or different impact categories in the VBS. Lastly, the modular nature of the models also allows for building upon existing LCV models and easy reuse of parts (e.g., valuations and life cycle elements).

Because of the context-dependent nature of LCV assessments, the LCV tool should not be seen as a standalone application. Instead, it is recommended to use it in conjunction with the assessment process discussed in section 2.2 , to further support the process of sensemaking.

\subsection{Interpreting the assessment from multiple complementary perspectives}

There are different types of benefits that AM organizations can consider. The LCV methodology facilitates the process of looking at life cycle costs and benefits from multiple, complementary perspectives. This is achieved by allowing the life cycle of the asset to be viewed with different 'lenses', allowing for different points of view.

The first set of these 'lenses' is to look at the assessment from both a quantitative and a qualitative side. Techniques like LCC, LCA, and LCV rely heavily on the quantification of costs, environmental impact, and stakeholder costs \& benefits. In practice, however, few (if any) decisions are based solely on quantitative analysis (Simpson et al., 2000). Over-confidence in quantitative data can go hand-in-hand with the marginalization of nonquantitative data, leading to insensitivity to uncertainty (Feldman, 2004). For $A M$, sense-making in an uncertain environment is essential for decisionmaking, as discussed in section 2.2. Additionally, qualitative approaches should not be neglected in assessments like LCA, LCC, and in social assessments, for areas where quantification is not (yet) possible (Hunkeler \& Rebitzer, 2005). Overall, the main addition of the LCV methodology is that it acknowledges the existence of qualitative factors that may influence a decision, but that are difficult to express in a quantitative manner.

The second set of 'lenses' used to look at LCV assessments consists of taking into account different costs and benefits for a wide range of relevant organizational stakeholders. A simple financial lens may be adopted to only look at the costs from the perspective of the asset owner, resulting in a conventional LCC application. Many firms, however, are not only interested in 
minimizing costs but pursue value creation (Gray et al., 2020). As explored in various case studies at Liander, a broader value perspective could be gained by also including costs and benefits for clients, and by accounting for externalities such as environmental impact. These impacts were consolidated in the LCV model using the Value Breakdown Structure (VBS). By viewing the LCV model from this perspective, a broader insight can be gained into the impact that the life cycles of assets have on the costs and benefits for various relevant stakeholders.

The third and last set of 'lenses' consists of the life cycle planning view, which is structured by the Activity Breakdown Structure (ABS). From this perspective, it is possible to have an overview of to what extent activities in the life cycle contribute to the overall impact. The combination of the second and third 'lenses' allow for different kinds of perspectives and cross-sections to be viewed, including a value perspective, a life cycle planning perspective, a time perspective (entire life span), as well as cumulative results, as illustrated in figure 8.5 .

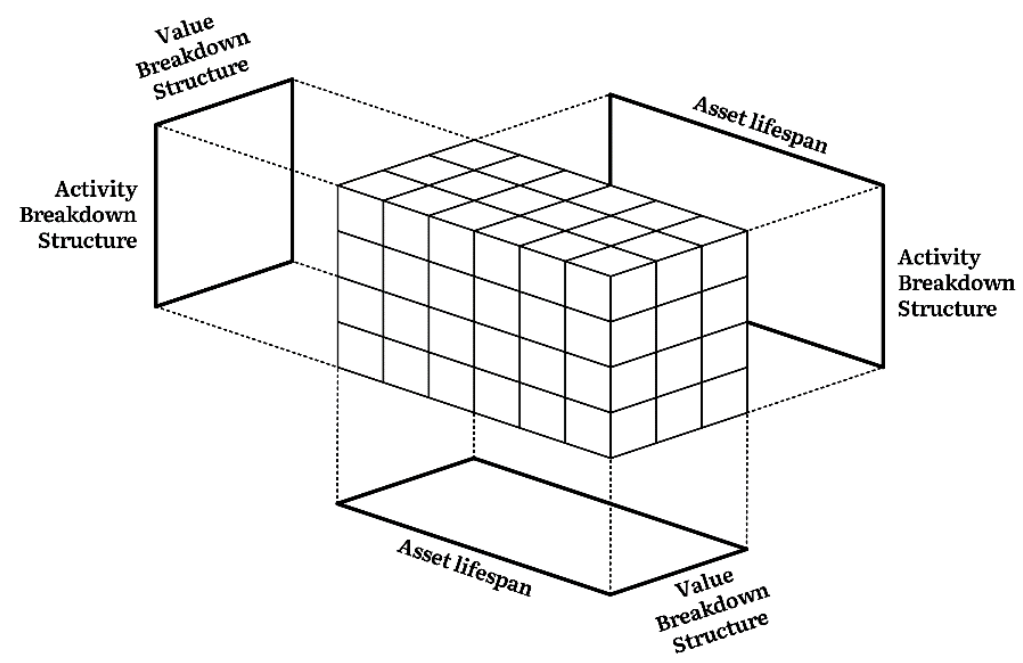

Figure 8.5: Three perspectives of an LCV model 
Having multiple perspectives from which to view the assessment is especially useful in more complex and ambiguous decision-contexts like those faced by DSOs in an energy transition. Being able to do this quickly and easily change these perspectives, as explained in section 2.3, further facilitates this assessment process. Overall, LCV promotes thinking of value as a multidimensional concept, instead of the narrow perspective of the total cost of ownership. Especially the interpretation phase of the four-phased LCV framework (see section 2.2) invites decision-makers to discuss factors such as qualitative aspects and how the results can be interpreted from different perspectives.

\subsection{Simplification and streamlining of assessments}

As the design science research strategy was followed through its many iterations, it became apparent in the earlier design stages that AM professionals generally perceived the developed methods and tools to be very useful, but also mentioned that these can be somewhat difficult or timeconsuming to use in practice. Especially in contexts that were severely time and resource-limited, it was important to improve the perceived ease-of-use. This focus on ease-of-use mirrored the Technology Acceptance Model (TAM) developed by Davis (1989), which posits that people's attitude towards using technology is influenced by both perceived usefulness and perceived ease-ofuse. Another reason to make assessments as simple as possible is to facilitate the communication of the results to all relevant stakeholders involved in decision-making (Bengtsson \& Kurdve, 2016). An answer to the research question of how the life cycle of physical systems should be assessed is, therefore, 'as easy as is reasonably possible'.

One improvement area for the ease-of-use was the development of the spreadsheet-based LCV tool, which performed much of the calculation on behalf of the user, enabled re-use of (parts of) existing LCV assessments, and could be pre-populated with regularly used data to serve as a template for common types of decisions. Another way to improve the ease-of-use was to focus on the interpretation of the results. The outcomes of LCV assessments usually showed a Pareto-like distribution pattern, where only a few activities in the life cycle were responsible for the majority of the overall impact profile (see figure 8.6). 


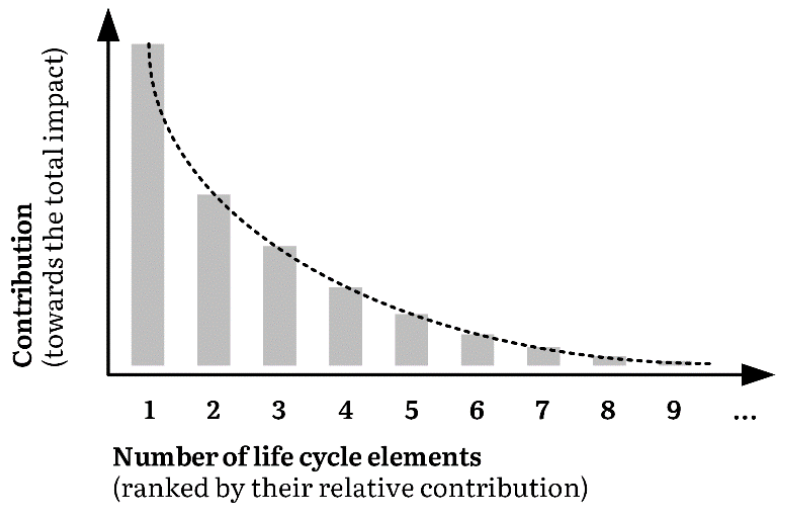

Figure 8.6: Illustration of a Pareto-like distribution pattern

This pattern was also used in sensitivity analysis and to motivate decisions under limited data availability. In these cases, the AM staff involved were confident that the 'dominant' value drivers in the life cycle were already sufficiently assessed, and that the impact of any unknown life cycle elements would not be large enough to change their decision in a significant way. This Pareto-like pattern also meant that modeling the life cycle in more detail by including additional life cycle elements was also a process of diminishing returns concerning the resources required for the assessment itself. From this pragmatic perspective, the most useful LCV assessments are those that are done quickly but result in accurately identifying the most important (i.e., dominant) factors in the life cycle.

This mechanism of quickly identifying the most important life cycle factors was further explored in three decision contexts that were not assessed using the LCV methodology. For these more narrow and specific decision-making contexts, that focused mainly on assessing environmental impacts effectively, new decision-support instruments were developed that more closely resembled LCA (whereas LCV resembles LCC more). In these applications (summarized in research theme 2 ) the challenge was to apply the decision support instrument as early as possible in the development of the life cycle of an asset. At this early stage, design decisions offer the most improvement opportunity but are also accompanied by the most uncertainty (Dewulf, 2013; M. Hauschild et al., 1999; Thomke \& Fujimoto, 2000). At DSO Liander, this challenge was presented by the procurement of new switchgear (paper chapter 7). By selectively including only the most important, dominant environmental impact drivers in assessments (i.e., purposefully ignoring insignificant impacts) it is possible to gain an assessment outcome that 
closely resembles that of a full assessment, but which requires far fewer resources to apply. At railway organization NS the early-design challenge presented itself in train modernization projects (paper chapters 5 and 6 ). The simplification strategy used in these cases was based on qualitative Designfor-Environment principles and design requirements, and the application of a streamlining LCA tool that uses generic data and is designed to be used by nonexperts in LCA.

These strategies of streamlining and simplifying assessments enable an early outlook on the most important improvement areas in the life cycle, making them practically feasible in circumstances that are otherwise too challenging because of time, data, and expertise limitations. Because not all simplifications may be accurate, these early assessments may need to be updated in later stages, in case new knowledge results in a different understanding of the best life cycle option.

\subsection{Using monetary valuation to speak 'the language of money'}

The research question also indicates the need for assessing multiple types of costs and benefits for AM organizations and their stakeholders. To address this need, the research presented in this dissertation makes use of monetary valuation in multiple instances. Monetary valuation is the practice of converting measures of social and biophysical impacts into monetary units and is used to determine the economic value of non-market goods, i.e., goods for which no market exists (Pizzol et al., 2015). Monetary valuation is used in the LCV methodology to allow for 'weighting' of different types of impacts for various stakeholders by assigning different equivalent monetary values (as discussed in paper chapters 3 and 4). It allows for non-financial impacts to be aggregated with financial impact under a common unit. Furthermore, simplified indicators of environmental and social impacts can be translated into external social and environmental costs, allowing integration with conventional cost assessments such as LCC (Kara et al., 2007). Overall, the 'language of money' that monetary valuation enables can be very effective in conveying the value of non-financial impacts because it is expressed in familiar financial terms.

This use of monetary valuation, however, is not without its drawbacks. Firstly, it can be difficult to interpret the non-financial value as something that cannot be bought, or which results in no actual loss or gain in money, if that non- 
financial value is expressed in monetary terms (e.g., using $€, \$$, $€$, etc.). This led to the design requirement of being able to separate the financial from the nonfinancial impacts in LCV assessments, calling financial costs 'cash-out' and the non-financial impact 'value' at Liander. Though consensus was achieved about how to valuate several non-financial impacts (e.g., the value of $\mathrm{CO}_{2}$ emissions expressed in $€$ ), some financial controllers advised being cautious of using financial units for non-financial impacts because of the risk of misinterpretation. Secondly, since monetary valuations are expressions of value, they are inherently subjective. Valuations must, therefore, be made transparent and carefully chosen to reflect the preference of the decisionmaker. As such, several valuations in use at Liander's LCV assessments and asset policy were discussed, agreed upon, and made public in close collaboration with the relevant organizational stakeholders from the Financial, Corporate Social Responsibility, and Asset Management departments at Liander (see paper chapter 4). It is, therefore, important to discuss and align these valuations together with the relevant organizational stakeholders and their respective interests, intending to arrive at a shared definition.

\subsection{Generalizable design statements}

One of the benefits of using a Design Science Research strategy is that a successful design outcome not only addresses a problem, it also creates knowledge about the nature of the problem and the nature of the solutions that were employed to solve it. Overall, the design principles discussed in sections 2.1-2.6 can be summarized into six succinct and generalized statements (see table 8.1). The combination of these statements not only provides a summary of the main design principles of the LCV methodology but also enables these principles to be transferred to other designs and to be tested in different contexts than those described in this dissertation. 
Table 8.1: Generalizable design statements

\# Statement

Linking what happens to assets in their life cycle to the various

1 types of impact, clarifies the relation between life cycle activities and the resulting impact on organizational value creation, allowing for more effective asset life cycle planning.

Following the four-phase structure of LCV allows for a process of

2 multidisciplinary alignment and shared sensemaking to take place, leading to more trust and increased acceptance in the assessment outcome than a single outcome figure can do on its own.

Flexible and adaptable assessment instruments can change with ever-changing organizational goals, enable compatibility with a 3 wide range of decision-making contexts, and allow decisionmakers to easily build and expand life cycle models that increase their understanding of the asset life cycle.

The ability to view the outcome of the assessment from different,

4 complementary perspectives facilitates and stimulates a process of interpretation, where the outcome of the assessment can be discussed in a broader context.

Simplification and streamlining strategies that include the most important life cycle impacts can compensate for a lack of data, time, or expertise. This allows for otherwise complex and timeconsuming assessments to be performed in earlier design stages, where they are most effective, thus improving their perceived usefulness.

Monetary valuation can be an effective instrument to convey the value of non-financial impacts, indicate a preference between multiple types of value, and allows for aggregating financial and non-financial impacts under a single unit. 


\section{Limitations}

Like any other research result, the outcome of the $\mathrm{PhD}$ research that is presented in this dissertation has inherent limitations. In each of the chapters that were based on publications (chapters 2-7), specific limitations have already been addressed. This section, therefore, focuses on discussing the most important limitations that apply to the entire $\mathrm{PhD}$ research project.

\subsection{Generalization from research predominantly performed at a single organization}

A large part of the research has taken place within the organization of DSO Liander, including the development and evaluation of the LCV methodology. This focus has an advantage over more detached forms of research, as it allows for a rich, contextualized, and empirical understanding of the research problem, which is beneficial in the creation of theoretically and practically relevant knowledge. This focus on a single organization, however, also comes with an important methodological challenge, as it can be difficult to generalize findings from a single case. Polit \& Beck (2010) captured this challenge concisely: "Research evidence can be used only if it has some relevance to settings and people outside of the contexts studied". During the course of the $\mathrm{PhD}$ research, care was taken to seek out the benefits of the rich research evidence, while addressing the issues associated with generalization from a single case. Methodological triangulation can be used to overcome the intrinsic biases arising from a single method, single-observer, or single-theory studies by combining multiple data sources, alternate observers, distinctively different theories, alternate methods, and varying empirics (Jack \& Raturi, 2006).

In this $\mathrm{PhD}$ research, this triangulation strategy was adapted in multiple, complementary ways. Within the AM organization of Liander, a wide range of assets and decisions was investigated using the LCV methodology, including multiple types of assets studied, providing a wide range of decision-contexts from various departments. Examples of these cases range from the assessment of an individual transformer to the assessment of an entire energy grid. These multiple embedded objects formed multiple data sources that provided significant opportunities for extensive analysis (Yin, 2003). 
Additionally, the research was performed in close collaboration with multiple observers. The LCV methodology was not just applied by the author in isolation, but practically always performed in multidisciplinary groups of 3 people or more. In the later stages of the research, some AM staff also applied the methodology with minimal support from the author, providing multiple observers. Additionally, the research results were discussed in quarterly steering group meetings, occupied with University researchers and Liander AM staff.

Furthermore, even though the initial research question formulated by Liander specifically addressed Life Cycle Costing, the developed LCV methodology consists not just of a single theory but multiple theories. LCV can be seen as a hybrid of LCC and LCA, which is designed to fulfill the requirements provided by a third theory, that of AM. Even though the theories of LCC, LCA, and AM overlap to an extent (i.e., having a life cycle focus), they are rooted in their respective theoretical frameworks, allowing for the research to be viewed and discussed from multiple theoretical perspectives.

Lastly, The designed LCV methodology and the design statements presented in section 2.7 can be tested in other application contexts, thus providing empirical generalization (Gregor \& Hevner, 2013). Furthermore, methodological triangulation was sought by supplementing the Design Science Research methodology with more participative research strategies that are borrowed from Action Research (AR). This not only resulted in the design of the LCV methodology (chapter 3 ) but also allowed for a longitudinal investigation of organizational change that resulted from the implementation of the designed artifacts (chapter 4). Even though DSR and AR are compatible and can share (many) similarities, there are always aspects of the two methodologies that are mutually exclusive (livari \& Venable, 2009), thus allowing for (at least partial) methodological triangulation.

\subsection{Theoretical limitations}

The research presented in this dissertation didn't focus on the efficacy of the lifecycle of the asset, but on the efficacy of the developed artifacts to aid in AM decision-making in an ever-changing environment. Due to the long lifespan of the assets investigated at Liander, it is infeasible to investigate the long-term effect on actual value realization in the span of the four years of a $\mathrm{PhD}$ research project. Furthermore, A/B testing of assessments with and 
without the application of the LCV approach is methodologically challenging because it is practically impossible to keep all external factors constant. Indeed, the opposite seems to apply, as in AM environments change seems to be the only constant factor

Another limitation is that Liander's income is largely dependent on client fees which are fixed under regulations for DSOs. This means that (with the exception of specific types of commercial clients) Liander's expenses are predominantly covered by the fees that are collectively paid by its customers. This turns the costs borne by Liander into an indirect societal cost. In addition, the constant income rate also means that the payback periods for assets are largely fixed. At Liander, value creation, therefore, tended to focus heavily on costs, as these were controllable through asset-related decision-making. It is expected that income would be more prominent in LCV assessments in nonregulated environments. A further explanation for the focus on the 'negative' side of value creation is that LCC and LCA, which LCV is based on, also focus predominantly on 'negative' impacts in the form of cost and environmental damages. In this research at least, it seemed that costs were indeed 'from Mars' and 'benefits from Venus', as posed by (Schuurman et al., 2008).

\section{Implications}

\subsection{Implications for Asset Management theory}

\section{Asset Management requires a broader perspective than LCC allows}

Asset Management needs a whole life cycle perspective and assets are costly. As such, the application of Life Cycle Costing may seem to be an obvious choice when considering large and long-term asset investments. This research, however, demonstrated that for many AM decisions, the concept of LCC appears to be the 'wrong tool for the job' as It fails to sufficiently address all the aspects that are relevant to AM organizations and their stakeholders. The pitfall of relying on LCC for AM decision-making is, therefore, that it fails to assume a similarly broad and systems-oriented perspective as AM. 
AM organizations deal with individual assets as well as groups of multiple assets such as complex asset systems and portfolios of similar asset types. Focusing only on one asset may risk sub-optimization with respect to the other assets. Furthermore, AM organizations need to fulfill the needs of many different stakeholders, whereas LCC does not necessarily state whose costs are being assessed. On top of that, AM organizations are not only interested in costs but pursue the creation of enduring value with their assets, a concept that goes beyond mere costs. Lastly, LCC assessments typically assume that the asset life cycle is constant. Very little attention appears to be given in literature to the discussion on how to address and to account for changing uncertain environments.

Instead of 'hiding' these methodological issues (as LCC is often simplified to just refer to all costs in the life cycle), the LCV methodology takes the opposite approach, drawing attention to them using the four-phased assessment approach and the adaptable LCV tool. This newly developed methodology may appear harder to use at first because of the added methodological steps. The LCV methodology, however, has been specifically designed to ensure that the assessor uses the assessment instrument in the most effective way possible by making them aware of, and providing them the ability to avoid the aforementioned methodological issues. The resulting approach that can be adapted to address different types of assets (including asset portfolios and asset systems), can capture stakeholder value through quantitative and qualitative assessment, and that allows for a discussion of the relation between the life cycle of the asset and how it contributes to long-term value creation. 
Life Cycle Valuation stimulates the alignment of financial and non-financial functions

One of the challenges in the domain of $A M$ is that of alignment between financial and non-financial functions. Even though literature exists that states that this type of alignment is important, for example in the form of standards and guidelines such as ISO/TC 251 (2017) and ISO 55020 (2019), little literature seems to address how this type of alignment is to be achieved. The research presented in this dissertation was able to help fill this knowledge gap. The LCV methodology requires input on both financial and non-financial impacts to function. Furthermore, the inventory process relies on multidisciplinary input, and the outcome is to be interpreted from operational as well as strategic perspectives. An LCV assessment can, therefore, be used to initiate and stimulate a process of alignment by consolidating the knowledge about the asset life cycle and its value into a single assessment model.

\subsection{Implications for Asset Management practice}

Even though the results of the research should be generalizable to other decision-making contexts from a methodological perspective, practical experience with the work presented in this dissertation has revealed that there are also practical implications to consider if the outcome is to be transferred to other, similar contexts.

First of all, the implementation of the LCV methodology is likely to take time to implement. Because of the novelty of the approach, it may take time for AM staff to learn and explain to colleagues how LCV works and how it is different from conventional LCC.

Secondly, LCV requires the AM organizations to have relatively well-defined objectives and requirements. These are not only a prerequisite during the goal formulation and the interpretation phases, but are also needed to be able to express non-financial impacts in financial terms (as discussed in section 2.6). 
Thirdly, the four-phased assessment process should be given proper attention during the assessment. Because the LCV methodology is designed to be versatile, it requires careful thought and motivation for internal methodological decisions about the goal, scope, inventory, and interpretation of the assessment itself, especially in the more high-profile and complex cases. To ensure that this process is not drowned out by the 'firefighting' mentality that is still common in many AM environments, it may be helpful to put some staff members in a process-focused coaching role.

Lastly, LCV is not necessarily about making assessments that are as objective as possible. Instead, LCV embraces the notion subjectivity is ever-present in life cycle-oriented assessments. The key to applying LCV is to create a shared, intersubjective insight into the life cycle and its impacts that is shared by all stakeholders involved in the assessment and the subsequent decision.

\subsection{Areas for further research}

During the research, several areas have been identified that represent gaps, that to the knowledge of the author, have not been addressed sufficiently in the existing literature. For two of these areas, a brief motivation is given about the potential future research.

Developing 'Impact Assessment Methods' for individual organizations or sectors

Several authors have indicated that LCC applications are greatly contextdependent, making generic international guidelines impractical (Kambanou $\&$ Lindahl, 2016; Korpi \& Ala-Risku, 2008; Toniolo et al., 2020). The research results presented in this dissertation seem to confirm this contextdependency, as discussed in section 2.3 of this chapter. This dissertation predominantly focused on the most detailed application contexts, in the form of decisions about (groups of) individual assets, within a single organization. Tailoring applications of LCC (and LCV) to specific decision contexts appears to be a highly effective strategy to support practical applications of the method. The grey area that exists between the context-specific and the generic application domains, however, remains largely unexplored. An interesting avenue for future research is to explore to what extent LCC and LCV applications can be standardized for different assets, departments, organizations, sectors, or even industries. 


\section{A 'living' life cycle model}

Another avenue for future research lies in the cyclical use of LCV models. Because of the long lifespan of assets, it is very likely that the socio-technical environment that an asset exists in will change within the asset's lifespan. Likewise, is to be expected that the objectives and preferences of the AM organization's most relevant stakeholders will also change. Good AM, therefore, means that the life cycle plans for assets need to be adjusted to suit these ever-changing needs. In line with principles such as PDCA (Plan, Do, Check, Act) and DMAIC (Define, Measure, Analyze, Improve, and Control) (Sokovic, Pavletic, \& Pipan, 2010) the LCV methodology could be part of a continuous improvement cycle. This cycle would be aimed at effective control of the asset over its life cycle with respect to the ever-changing needs and requirements of AM. Such assessments would not be static, one-off models like many LCC assessments are today, but could be dynamic, 'living' models that could be part of digital twins, similar to Building Information Models (BIM) in use in the construction sector (Kaewunruen et al., 2020). These 'living' models can be used to follow the costs and benefits for various stakeholders over time, and thus be helpful in the early identification of risks and opportunities. An important challenge in such research, however, is that the lifespans of assets are typically very long and that socio-technical change is gradual, especially compared to the length of usual research periods, such as the time required for $\mathrm{PhD}$ research. This means that the research methodologies applied to study this phenomenon need to account for challenges that arise from considering these extended time horizons. 


\section{References}

Adler, N., Shani, A. B. (Rami), \& Styhre, A. (2004). Collaborative Research in Organizations: Foundations for Learning, Change, and Theoretical Development. Tousand Oaks, California, USA: SAGE Publications.

Akkermans, H., Van Oppen, W., Wynstra, F., \& Voss, C. (2019). Contracting outsourced services with collaborative key performance indicators. Journal of Operations Management, 65(1), 22-47. https://doi.org/10.1002/joom.1002

Alliander. (2020). Annual report 2019 - Working together on transition. Arnhem, Netherlands. Retrieved from https://2019.jaarverslag.alliander.com/FbContent.ashx/pub_1037/downloads/ v200820123516/Alliander_Annual_Report_2019.pdf

Alsyouf, I., Alsuwaidi, M., Hamdan, S., \& Shamsuzzaman, M. (2018). Impact of ISO 55000 on organisational performance: evidence from certified UAE firms. Total Quality Management and Business Excellence, O(0), 1-19. https://doi.org/10.1080/14783363.2018.1537750

Amadi-Echendu, J., Willett, R., Brown, K., Lee, J., Mathew, J., Vyas, N., \& Yang, B.-S. (2007). What is Engineering Asset Management? In The 2nd World Congress on Engineering Asset Management (EAM) and The 4th International Conference on Condition Monitoring (pp. 116-129). Harrogate, United Kingdom.

Ander, Å., Bergendorff, M., Carlson, R., Dewulf, W., Duflou, J., Forsberg, P., ... Zimmermann, T. (2001). Integrating eco-efficiency in rail vehicle design: final report of the RAVEL project. (W. Dewulf, J. Duflou, \& A. Ander, Eds.). Leuven: Leuven University Press.

Appelbaum, S. H., Habashy, S., Malo, J. L., \& Shafiq, H. (2012). Back to the future: Revisiting Kotter's 1996 change model. Journal of Management Development, 31(8), 764-782. https://doi.org/10.1108/02621711211253231

Arja, M., Sauce, G., \& Souyri, B. (2009). External uncertainty factors and LCC: a case study. Building Research \& Information, 37(3), 325-334. https://doi.org/10.1080/09613210902863609

Arzoumanidis, I., Raggi, A., \& Petti, L. (2014). Considerations when applying simplified LCA approaches in the wine sector. Sustainability, 6(8), 5018-5028. https://doi.org/10.3390/su6085018

Asiedu, Y., \& Gu, P. (1998). Product life cycle cost analysis: state of the art review. International Journal of Production Research, 36(4), 883-908. https://doi.org/10.1080/002075498193444

Atia, N. G., Bassily, M. A., \& Elamer, A. A. (2020). Do life-cycle costing and assessment integration support decision-making towards sustainable development? Journal of Cleaner Production, 267, 122056. https://doi.org/10.1016/j.jclepro.2020.122056

Aurich, J. C., Mannweiler, C., \& Schweitzer, E. (2010). How to design and offer services successfully. CIRP Journal of Manufacturing Science and Technology, 2(3), 136143. https://doi.org/10.1016/j.cirpj.2010.03.002 
Avison, D. E., Davison, R. M., \& Malaurent, J. (2018). Information systems action research: Debunking myths and overcoming barriers. Information and Management, 55(2), 177-187. https://doi.org/10.1016/j.im.2017.05.004

Azzouz, L., \& Jack, A. (2020). Benchmarking the sustainability reporting of high-speed railways (HSRs): Towards a state-of-the-art benchmarking and reporting framework for HSRs. Journal of Cleaner Production, 250, 119505. https://doi.org/10.1016/j.jclepro.2019.119505

Bach, V., Lehmann, A., Görmer, M., \& Finkbeiner, M. (2018). Product environmental footprint (PEF) pilot phase-comparability over flexibility? Sustainability, 10(8). https://doi.org/10.3390/su10082898

Banister, D. (2007). Sustainable transport: Challenges and opportunities. Transportmetrica, 3(2), 91-106. https://doi.org/10.1080/18128600708685668

Barringer, H. P., \& Weber, D. P. (1996). Life Cycle Cost Tutorial. In Fifth International Conference on Process Plant Reliability (pp. 1-58).

Bengtsson, M., \& Kurdve, M. (2016). Machining Equipment Life Cycle Costing Model with Dynamic Maintenance Cost. Procedia CIRP, 48, 102-107. https://doi.org/10.1016/j.procir.2016.03.110

Bertoni, A., \& Bertoni, M. (2018). PSS cost engineering: A model-based approach for concept design. CIRP Journal of Manufacturing Science and Technology, 29, 176190. https://doi.org/10.1016/j.cirpj.2018.08.001

Bierer, A., Meynerts, L., \& Götze, U. (2013). Life Cycle Assessment and Life Cycle Costing - Methodical Relationships, Challenges and Benefits of an Integrated Use. In Re-engineering Manufacturing for Sustainability: Proceedings of the 20th CIRP International Conference on Life Cycle Engineering, Singapore 17-19 April, 2013 (pp. 415-420).

Bish, A. J., Newton, C. J., Browning, V., O'Connor, P., \& Anibaldi, R. (2014). An exploration of the professional competencies required in engineering asset management. European Journal of Engineering Education, 39(4), 432-447. https://doi.org/http://dx.doi.org/10.1080/03043797.2014.895701

Bohn, R. E. (2000). Firefighting By Knowledge Workers, 1-51.

Boller, C., Starke, P., Dobmann, G., Kuo, C. M., \& Kuo, C. H. (2015). Approaching the assessment of ageing bridge infrastructure. Smart Structures and Systems, 15(3), 593-608. https://doi.org/10.12989/sss.2015.15.3.593

Bosch-Mauchand, M., Belkadi, F., Bricogne, M., \& Eynard, B. (2013). Knowledge-based assessment of manufacturing process performance: Integration of product lifecycle management and value-chain simulation approaches. International Journal of Computer Integrated Manufacturing, 26(5), 453-473. https://doi.org/10.1080/0951192X.2012.731611

Bovea, M. D., \& Pérez-Belis, V. (2012). A taxonomy of ecodesign tools for integrating environmental requirements into the product design process. Journal of Cleaner Production, 20(1), 61-71. https://doi.org/10.1016/j.jclepro.2011.07.012

Braaksma, A. J. J., Klingenberg, W., \& Veldman, J. (2013). Failure mode and effect analysis in asset maintenance: A multiple case study in the process industry. International Journal of Production Research, 51(4), 1055-1071. https://doi.org/10.1080/00207543.2012.674648 
Browning, T. R., \& Honour, E. C. (2008). Measuring the Life-Cycle Value of Enduring Systems. Systems Engineering, 3(11), 187-202. Retrieved from http://ezproxy.lib.ucf.edu/login?url=http://search.proquest.com/docview/926 281441?accountid=10003\%5Cnhttp://sfx.fcla.edu/ucf?url_ver=Z39.882004\&rft_val_fmt=info:ofi/fmt:kev:mtx:journal\&genre=article氏sid=ProQ:ProQ: civilengineering\&atitle=Model+Based+Syste

Buchanan, R. (1992). Wicked Problems in Design Thinking. Design Issues, 8(2), 5-21.

Campbell, J. D., Jardine, A. K. S., \& McGlynn, J. (Eds.). (2011). Asset Management Excellence: Optimizing Equipment Life-Cycle Decisions (Second Edi). Boca Raton, FL, USA: Taylor and Francis Group. Retrieved from http://www.taylorandfrancis.com

Cerdan, C., Gazulla, C., Raugei, M., Martinez, E., \& Fullana-I-Palmer, P. (2009). Proposal for new quantitative eco-design indicators: a first case study. Journal of Cleaner Production, 17, 1638-1643. https://doi.org/10.1016/j.jclepro.2009.07.010

Chandrasekaran, A., de Treville, S., \& Browning, T. (2020). Editorial: Interventionbased research (IBR)-What, where, and how to use it in operations management. Journal of Operations Management, 370-378. https://doi.org/10.1002/joom.1093

Checkland, P., \& Holwell, S. (1998). Action Research: Its Nature and Validity. Systemic Practice and Action Research, 11(1). https://doi.org/10.3233/NRE-2010-0579

Chen, S., Wu, J., \& Zong, Y. (2020). The impact of the freight transport modal shift policy on China's carbon emissions reduction. Sustainability, 12(2). https://doi.org/10.3390/su12020583

Churchman, C. W. (1967). Free for All. Management Science, 14(4), 141-146. https://doi.org/https://doi.org/10.1287/mnsc.14.4.B141

Clark, G., Piperias, P., \& Traill, R. (1999). Life-Cycle Cost/Capability Analysis for Defence Systems. In Proc. of the Simulation Technology and Training Conference (SimTecT) (p. 5). Melbourne, Australia.

Coghlan, D. (2011). Action research: Exploring perspectives on a philosophy of practical knowing. Academy of Management Annals, 5(1), 53-87. https://doi.org/10.1080/19416520.2011.571520

Coghlan, D., \& Brannick, T. (2019). Doing Action Research in your own organization (Fifth Edit). London, England, United Kingdom: SAGE Publications.

Cole, R. J., \& Sterner, E. (2000). Reconciling theory and practice of life-cycle costing. Building Research \& Information, 28(5-6), 368-375.

Costa, E., Soares, A. L., \& de Sousa, J. P. (2020). Industrial business associations improving the internationalisation of SMEs with digital platforms: A design science research approach. International Journal of Information Management, 53(December 2019), 102070. https://doi.org/10.1016/j.ijinfomgt.2020.102070

Coughlan, P., \& Coghlan, D. (2002). Action research for operations management. International Journal of Operations \& Production Management, 22(2), 220-240. https://doi.org/10.1108/01443570210417515

Cross, N. (2001). Designerly ways of knowing: design discipline versus design science. Design Issues, 17(3), 49-55. https://doi.org/10.1162/074793601750357196 
Crul, M. R. M., \& Diehl, J. C. (2009). Design for Sustainability: A step-by-step approach. Paris, France: United Nations Environment Program.

Datta, P. P., \& Roy, R. (2010). Cost modelling techniques for availability type service support contracts: A literature review and empirical study. CIRP Journal of Manufacturing Science and Technology, 3(2), 142-157. https://doi.org/10.1016/j.cirpj.2010.07.003

Davis, F. D. (1989). Perceived Usefulness, Perceived Ease of Use, and User Acceptance of Information Technology. MIS Quarterly, 13(3), 319-340.

De Bruyn, S., Bijleveld, M., de Graaff, L., Schep, E., Schroten, A., Vergeer, R., \& Ahdour, S. (2018). Environmental Prices Handbook EU28 Version - Methods and numbers for valuation of environmental impacts. CE Delft, 175. Retrieved from file:///C:/Users/boldocsa/Downloads/CE_Delft_7N54_Environmental_Prices_H andbook_2017_FINAL.pdf

de Villiers, C., Venter, E. R., \& Hsiao, P. C. K. (2017). Integrated reporting: background, measurement issues, approaches and an agenda for future research. Accounting and Finance, 57(4), 937-959. https://doi.org/10.1111/acfi.12246

Denyer, D., Tranfield, D., \& Van Aken, J. E. (2008). Developing Design Propositions through Research Synthesis. Organization Studies, 29(3), 393-413. https://doi.org/10.1177/0170840607088020

Dewulf, K. (2013). Sustainable Product Innovation: The Importance of the Front-End Stage in the Innovation Process. In Advances in Industrial Design Engineering. Intech. https://doi.org/http://dx.doi.org/10.5772/52461

Dolezal, F., \& Boogman, P. (2016). Current State of the Discussion Between PEF and EPD as the Preferable Life Cycle Assessment Scheme for Wooden Construction Products. In COST Action FP 1407 2nd Conference (pp. 2-4). Brno. Retrieved from https://www.researchgate.net/publication/310978625_CURRENT_STATE_OF_T HE_DISCUSSION_BETWEEN_PEF_AND_EPD_AS_THE_PREFERABLE_LIFE_CYCLE_AS SESSMENT_SCHEME_FOR_WOODEN_CONSTRUCTION_PRODUCTS

Duflou, J. R., \& Dewulf, W. (2004). Eco-Impact Anticipation by Parametric Screening of Machine System Components: An introduction to the EcoPaS Methodology. In Product Engineering (pp. 17-30). Dordrecht, Netherlands: Springer. https://doi.org/10.1007/1-4020-2933-0_2

Dul, J., \& Hak, T. (2008). Case Study Methodology in Business Research (1st ed., Vol. 129). Oxford, UK: Elsevier.

Durairaj, S. K., Ong, S. K., Nee, A. Y. C., \& Tan, R. B. H. (2002). Evaluation of life cycle cost analysis methodologies. Corporate Environmental Strategy, 9(1), 30-39. https://doi.org/10.1016/S1066-7938(01)00141-5

Duran, O., Roda, I., \& Macchi, M. (2016). Linking the Spare Parts Management with the Total Costs of Ownership : An Agenda for Future Research. Journal of Industrial Engineering and Management, 9(5), 991-1002.

https://doi.org/http://dx.doi.org/10.3926/jiem.2083

El-Akruti, K., \& Dwight, R. (2010). Research methodologies for engineering asset management. ACSPRI Social Science Methodology Conference 2010, 1-20. Retrieved from http://ro.uow.edu.au/engpapers/5001

El-Akruti, K., Dwight, R., \& Zhang, T. (2013). The strategic role of Engineering Asset 
Management. International Journal of Production Economics, 146(1), 227-239. https://doi.org/10.1016/j.ijpe.2013.07.002

Eldeeb, G., \& Mohamed, M. (2020). Understanding the transit market: A personabased approach for preferences quantification. Sustainability, 12(9). https://doi.org/10.3390/su12093863

Eliasson, J., Kopsch, F., Mandell, S., \& Wilhelmsson, M. (2020). Transport mode and the value of accessibility-a potential input for sustainable investment analysis. Sustainability, 12(5), 1-14. https://doi.org/10.3390/su12052143

Elkington, J. (1997). Cannibals With Forks: The Triple Bottom Line of 21st Century Business. Oxford: Capstone Publishing.

Emblemsvåg, J. (2003). Life-cycle Costing: Using Activity-Based Costing and Monte Carlo Methods to Manage Future Costs and Risks. New Jersey: John Wiley \& sons.

EPD. (2020). Rolling stock - Product Category Classification UN CPC 495.

European Union. (2009). Directive of 2009/72/EC of the European Parliament and of the Council of 13 July 2009 Concerning Common Rules for the Internal Market in Electricity and Repealing Directive 2003/54/EC. Official Journal of the European Union, L211(August), L 211/55-L 211/93.

Fabrycky, W. J., \& Blanchard, B. S. (1991). Life-cycle cost and economic analysis. Prentice-Hall.

Fauzi, R. T., Lavoie, P., Sorelli, L., Heidari, M. D., \& Amor, B. (2019). Exploring the current challenges and opportunities of Life Cycle Sustainability Assessment. Sustainability, 11(3), 1-17. https://doi.org/10.3390/su11030636

Feldman, S. P. (2004). The culture of objectivity: Quantification, uncertainty, and the evaluation of risk at NASA. Human Relations, 57(6), 691-718. https://doi.org/10.1177/0018726704044952

Ferrin, B. G., \& Plank, R. E. (2002). Total cost of ownership models: An exploratory study. Journal of Supply Chain Management, 38(2), 18-29. https://doi.org/10.1111/j.1745-493X.2002.tb00132.x

Fiksel, J. (2011). Design for Environment: A Guide to Sustainable Product Development (2nd editio). Mcgraw-Hill Education - Europe.

Förster, O., \& Zdrallek, M. (2017). Efficient decision making supported by ISO 55000. CIRED - Open Access Proceedings Journal, 2017(1), 2711-2714. https://doi.org/10.1049/oap-cired.2017.1354

Fourie, C. J., \& Tendayi, T. G. (2016). a Decision-Making Framework for Effective Maintenance Management Using Life Cycle Costing (LCC) in a Rolling Stock Environment. South African Journal of Industrial Engineering, 27(4), 142-152. https://doi.org/10.7166/27-4-1526

Frangopol, D. M., \& Liu, M. (2007). Maintenance and management of civil infrastructure based on condition, safety, optimization, and life-cycle cost*. Structure and Infrastructure Engineering, 3(1), 29-41. https://doi.org/10.1080/15732470500253164

Frangopol, D. M., Saydam, D., \& Kim, S. (2012). Maintenance, management, life-cycle 
design and performance of structures and infrastructures: a brief review. Structure and Infrastructure Engineering, 8(1), 1-25. https://doi.org/10.1080/15732479.2011.628962

Fuller, S. K., \& Petersen, S. R. (1996). Life-Cycle Costing Manual for the Federal Energy Management Program. NIST Handbook 135. https://doi.org/10.1108/eb006413

Gallo, A. B., Simões-Moreira, J. R., Costa, H. K. M., Santos, M. M., \& Moutinho dos Santos, E. (2016). Energy storage in the energy transition context: A technology review. Renewable and Sustainable Energy Reviews, 65, 800-822. https://doi.org/10.1016/j.rser.2016.07.028

García-Olivares, A., Solé, J., Samsó, R., \& Ballabrera-Poy, J. (2020). Sustainable European Transport System in a 100\% Renewable Economy. Sustainability, 12. https://doi.org/doi:10.3390/su12125091

Garg, A., \& Deshmukh, S. G. (2006). Maintenance management: literature review and directions. Journal of Quality in Maintenance Engineering, 12(3), 205-238. https://doi.org/10.1108/13552510810877674

Garnier de Falletans, T. (2016). Levers for recyclable trains. In The 13th UIC Sustainability Conference. Vienna, Austria.

Gavrikova, E., Volkova, I., \& Burda, Y. (2020). Strategic aspects of asset management: An overview of current research. Sustainability (Switzerland), 12(15), 9-11. https://doi.org/10.3390/su12155955

Gay, L. F., \& Sinha, S. K. (2013). Resilience of civil infrastructure systems: Literature review for improved asset management. International Journal of Critical Infrastructures, 9(4), 330-350. https://doi.org/10.1504/IJCIS.2013.058172

Gibbert, M., Ruigrok, W., \& Wicki, B. (2008). What passes as a rigorous case study? Strategic Management Journal, 29(13), 1465-1474. https://doi.org/https://doi.org/10.1002/smj.722

Gluch, P., \& Baumann, H. (2004). The life cycle costing (LCC) approach: A conceptual discussion of its usefulness for environmental decision-making. Building and Environment, 39(5), 571-580. https://doi.org/10.1016/j.buildenv.2003.10.008

Gluch, P., Gustafsson, M., Baumann, H., \& Lindahl, G. (2018). From tool-making to toolusing - and back: Rationales for adoption and use of LCC. International Journal of Strategic Property Management, 22(3), 179-190. https://doi.org/https://doi.org/10.3846/ijspm.2018.1544

Goodland, R., \& Daly, H. (1996). Environmental sustainability: Universal and nonnegotiable. Ecological Applications, 6(4), 1002-1017. https://doi.org/10.2307/2269583

Götze, U., Koriath, H. J., Kolesnikov, A., Lindner, R., \& Paetzold, J. (2012). Integrated methodology for the evaluation of the energy- and cost-effectiveness of machine tools. CIRP Journal of Manufacturing Science and Technology, 5(3), 151163. https://doi.org/10.1016/j.cirpj.2012.04.001

Graedel, T. E. (1999). A structured approach to LCA improvement analysis. Journal of Industrial Ecology, 3(2-3), 85-93. https://doi.org/10.1162/108819899569430

Gray, J. V., Helper, S., \& Osborn, B. (2020). Value first, cost later: Total value contribution as a new approach to sourcing decisions. Journal of Operations 
Management, 66(6), 735-750. https://doi.org/10.1002/joom.1113

Gregor, S., \& Hevner, A. R. (2013). Positioning and presenting design science research for maximum impact. MIS Quarterly, 37(2), 337-355.

https://doi.org/10.2753/MIS0742-1222240302

Groop, J., Ketokivi, M., Gupta, M., \& Holmström, J. (2017). Improving home care: Knowledge creation through engagement and design. Journal of Operations Management, 53-56(August), 9-22. https://doi.org/10.1016/j.jom.2017.11.001

Gunasekaran, A. (1999). Agile manufacturing: a framework for research and development. International Journal of Production Economics, 62(1), 87-105. https://doi.org/10.1016/S0925-5273(98)00222-9

Haanstra, W., Braaksma, A. J. J., \& Dongen, L. A. M. Van. (2021). CIRP Journal of Manufacturing Science and Technology Designing a hybrid methodology for the Life Cycle Valuation of capital goods. CIRP Journal of Manufacturing Science and Technology, 32, 382-395. https://doi.org/10.1016/j.cirpj.2021.01.017

Haarman, M., \& Delahay, G. (2016). Value Driven Maintenance \& Asset Management. Mainovation.

Haffejee, M., \& Brent, A. C. (2008). Evaluation of an integrated asset life-cycle management (ALCM) model and assessment of practices in the water utility sector. Water SA, 34(2), 285-290.

Hauschild, M., Jeswiet, J., \& Alting, L. (2005). From Life Cycle Assessment to Sustainable Production: Status and Perspectives. CIRP Annals - Manufacturing Technology, 54(2), 1-21. https://doi.org/10.1016/S0007-8506(07)60017-1

Hauschild, M., Wenzel, H., \& Alting, L. (1999). Life Cycle Design - a Route to the Sustainable Industrial Culture? Annals of the CIRP, 48(1), 393-396. https://doi.org/10.1016/S0007-8506(07)63210-7

Hauschild, M. Z. (2017). Introduction to LCA methodology. In M. Z. Hauschild, R. K. Rosenbaum, \& S. I. Olsen (Eds.), Life Cycle Assessment: Theory and Practice (pp. 59-66). Cham, Switzerland: Springer International Publishing. https://doi.org/10.1007/978-3-319-56475-3_6

Heijungs, R., Settanni, E., \& Guinée, J. (2013). Toward a computational structure for life cycle sustainability analysis: Unifying LCA and LCC. International Journal of Life Cycle Assessment, 18(9), 1722-1733. https://doi.org/10.1007/s11367-012-0461-4

Heitz, C., Goren, L., \& Sigrist, J. (2016). Decision Making in Asset Management: Optimal Allocation of Resources for Maximizing Value Realization. In Proceedings of the 10th World Congress on Engineering Asset Management (WCEAM 2015) (pp. 259-268). Springer, Cham. https://doi.org/https://doi.org/10.1007/978-3-31927064-7_25

Hellweg, S., Hofstetter, T. B., \& Hungerbühler, K. (2003). Discounting and the Environment. International Journal of Life Cycle Assessment, 8(1), 8-18. https://doi.org/10.1007/BF02978744

Herrmann, C., Kara, S., \& Thiede, S. (2011). Dynamic life cycle costing based on lifetime prediction. International Journal of Sustainable Engineering, 4(3), 224-235. https://doi.org/10.1080/19397038.2010.549245

Hevner, A. R. (2007). A Three Cycle View of Design Science Research. Scandinavian 
Journal of Information Systems, 19(2), 87-92.

https://doi.org/http://aisel.aisnet.org/sjis/vol19/iss2/4

Higham, A., Fortune, C., \& James, H. (2015). Life cycle costing : evaluating its use in UK practice, 33(1), 73-87. https://doi.org/10.1108/SS-06-2014-0026

Hijdra, A., Woltjer, J., \& Arts, J. (2015). Troubled waters: An institutional analysis of ageing Dutch and American waterway infrastructure. Transport Policy, 42, 6474. https://doi.org/10.1016/j.tranpol.2015.05.004

Hochschorner, E., \& Finnveden, G. (2003). Evaluation of two simplified life cycle assessment methods. International Journal of Life Cycle Assessment, 8(3), 119128. https://doi.org/10.1007/BF02978456

Holmström, J., Ketokivi, M., \& Hameri, A.-P. (2009). Bridging Practice and Theory: A Design Science Approach. Decision Sciences, 40(1), 65-87. https://doi.org/10.1111/j.1540-5915.2008.00221.x

Hoogmartens, R., Van Passel, S., Van Acker, K., \& Dubois, M. (2014). Bridging the gap between LCA, LCC and CBA as sustainability assessment tools. Environmental Impact Assessment Review, 48, 27-33.

Huang, H. B. (2010). What is good action research?: Why the resurgent interest? Action Research, 8(1), 93-109. https://doi.org/10.1177/1476750310362435

Huijbregts, M. A. J., Steinmann, Z. J. N., Elshout, P. M. F., Stam, G., Verones, F., Vieira, M., ... van Zelm, R. (2017). ReCiPe2016: a harmonised life cycle impact assessment method at midpoint and endpoint level. International Journal of Life Cycle Assessment, 22(2), 138-147. https://doi.org/10.1007/s11367-016-1246-y

Hunkeler, D., \& Rebitzer, G. (2005). The Future of Life Cycle Assessment. The International Journal of Life Cycle Assessment, 10(5), 305-308. https://doi.org/http://dx.doi.org/10.1065/lca2005.09.001

Huppes, G., Rooijen, M. van, Kleijn, R., Heijungs, R., Koning, A. de, \& Oers, L. van. (2004). Life cycle costing and the environment. Report of a Project Commissioned by the Ministry of VROM-DGM for the RIVM Expertise Centre LCA, (April).

Hur, T., Lee, J., Ryu, J., \& Kwon, E. (2005). Simplified LCA and matrix methods in identifying the environmental aspects of a product system. Journal of Environmental Management, 75(3), 229-237. https://doi.org/10.1016/j.jenvman.2004.11.014

lacovidou, E., Busch, J., Hahladakis, J. N., Baxter, H., Ng, K. S., \& Herbert, B. M. J. (2017). A parameter selection framework for sustainability assessment. Sustainability, 9(9), 1-18. https://doi.org/10.3390/su9091497

IEC. (2017). Dependability management - Part 3-3: Application guide - Life cycle costing (IEC 60300-3-3:2017).

Igba, J., Alemzadeh, K., Durugbo, C., \& Eiriksson, E. T. (2017). Through-life engineering services of wind turbines. CIRP Journal of Manufacturing Science and Technology, 17(November 2014), 60-70. https://doi.org/10.1016/j.cirpj.2016.08.003

livari, J., \& Venable, J. (2009). Action Research and Design Science Research Seemingly similar but decisively dissimilar. Prooceedings of the ECIS 2009, Paper 73, 1-13. 
Ilg, P., Scope, C., Muench, S., \& Guenther, E. (2017). Uncertainty in life cycle costing for long-range infrastructure. Part I: leveling the playing field to address uncertainties. International Journal of Life Cycle Assessment, 22(2), 277-292. https://doi.org/10.1007/s11367-016-1154-1

Iris, Ç., \& Lam, J. S. L. (2019). A review of energy efficiency in ports: Operational strategies, technologies and energy management systems. Renewable and Sustainable Energy Reviews, 112(February), 170-182. https://doi.org/10.1016/j.rser.2019.04.069

ISO/TC 251. (2017). Asset Management - Managing Assets in the context of Asset Management.

ISO. (2006a). ISO 14040: Life cycle assessment - Principles and framework.

ISO. (2006b). ISO 14044: Life cycle assessment - Requirements and guidelines.

ISO. (2014). ISO 55000: Asset management - Overview, principles and terminology.

ISO. (2019). ISO 55010: Asset management - Guidance on the alignment of financial and non-financial functions in asset management.

Jack, E. P., \& Raturi, A. S. (2006). Lessons learned from methodological triangulation in management research. Management Research News, 29(6), 345-357. https://doi.org/10.1108/01409170610683833

Jajac, N., Kilič, J., \& Rogulj, K. (2018). An integral approach to sustainable decisionmaking within maritime spatial planning-A DSC for the planning of anchorages on the Island of Šolta, Croatia. Sustainability, 11(1).

https://doi.org/10.3390/su11010104

Janz, D., Sihn, W., \& Warnecke, H.-J. J. (2005). Product Redesign Using Value-Oriented Life Cycle Costing. CIRP Annals - Manufacturing Technology, 54(1), 9-12. https://doi.org/10.1016/50007-8506(07)60038-9

Järvinen, P. (2007). Action research is similar to design science. Quality and Quantity, 41(1), 37-54. https://doi.org/10.1007/s11135-005-5427-1

Jiyeon Ryu, Ik Kim, Eunsun Kwon, \& Tak Hur. (2003). Simplified life cycle assessment for eco-design. In EcoDesign 3rd International Symposium on Environmentally Conscious Design and Inverse Manufacturing (pp. 459-463). Tokyo, Japan. https://doi.org/10.1109/ECODIM.2003.1322714

Johansson, N., Roth, E., \& Reim, W. (2019). Smart and sustainable emaintenance: Capabilities for digitalization of maintenance. Sustainability, 11(13). https://doi.org/10.3390/su11133553

Kaewunruen, S., \& Lee, C. K. (2017). Sustainability challenges in managing end-of-life rolling stocks. Frontiers in Built Environment, 3(February), 10-12. https://doi.org/10.3389/fbuil.2017.00010

Kaewunruen, S., Peng, S., \& Phil-Ebosie, O. (2020). Digital twin aided sustainability and vulnerability audit for subway stations. Sustainability (Switzerland), 12(19), 1-17. https://doi.org/10.3390/SU12197873

Kaihara, T., Nishino, N., Ueda, K., Tseng, M., Váncza, J., Schönsleben, P., ... Takenaka, T. (2018). Value creation in production: Reconsideration from interdisciplinary approaches. CIRP Annals - Manufacturing Technology, 67(2), 791-813. 
https://doi.org/10.1016/j.cirp.2018.05.002

Kaipia, R., Holmström, J., Småros, J., \& Rajala, R. (2017). Information sharing for sales and operations planning: Contextualized solutions and mechanisms. Journal of Operations Management, 52(April), 15-29. https://doi.org/10.1016/j.jom.2017.04.001

Kambanou, M. L., \& Lindahl, M. (2016). A Literature Review of Life Cycle Costing in the Product-Service System Context. Procedia CIRP, 47, 186-191. https://doi.org/10.1016/j.procir.2016.03.054

Kampker, A., Burggräf, P., Wesch-Potente, C., Petersohn, G., \& Krunke, M. (2013). Life cycle oriented evaluation of flexibility in investment decisions for automated assembly systems. CIRP Journal of Manufacturing Science and Technology, 6(4), 274-280. https://doi.org/10.1016/j.cirpj.2013.07.004

Kara, S., Manmek, S., Kaebernick, H., \& Kaebemick, H. (2007). An integrated methodology to estimate the external environmental costs of products. CIRP Annals - Manufacturing Technology, 56(1), 9-12. https://doi.org/10.1016/j.cirp.2007.05.004

Kawauchi, Y., \& Rausand, M. (1999). Life Cycle Cost (LCC) analysis in oil and chemical process industries, (September).

Keating, C., Rogers, R., Unal, R., Dryer, D., Sousa-poza, A., Safford, R., ... Rabadi, G. (2003). System of Systems Engineering. Engineering Management Journal Vol., 15(3), 36-45. https://doi.org/10.1080/10429247.2003.11415214

Khan, M. A., West, S., \& Wuest, T. (2019). Midlife upgrade of capital equipment: A servitization-enabled, value-adding alternative to traditional equipment replacement strategies. CIRP Journal of Manufacturing Science and Technology, 29, 232-244. https://doi.org/10.1016/j.cirpj.2019.09.001

Kieser, A., \& Leiner, L. (2012, January). Collaborate with practitioners: But beware of collaborative research. Journal of Management Inquiry. https://doi.org/10.1177/1056492611411923

Kjær, L. L., Pagoropoulos, A., Hauschild, M., Birkved, M., Schmidt, J. H., \& McAloone, T. C. (2015). From LCC to LCA using a hybrid Input Output model - A maritime case study. Procedia CIRP, 29, 474-479. https://doi.org/10.1016/j.procir.2015.02.004

Komonen, K., Kortelainen, H., \& Räikkönen, M. (2012). Corporate Asset Management for Industrial Companies: An Integrated Business-Driven Approach. In Asset Management (pp. 47-63). Springer Netherlands. https://doi.org/10.1007/97894-007-2724-3

Korpi, E., \& Ala-Risku, T. (2008). Life cycle costing: a review of published case studies. Managerial Auditing Journal, 23(3), 240-261.

Kumar, V., Shirodkar, P. S., Camelio, J. A., \& Sutherland, J. W. (2007). Value flow characterization during product lifecycle to assist in recovery decisions. International Journal of Production Research, 45(18-19), 4555-4572. https://doi.org/10.1080/00207540701474633

Kunttu, S., Välisalo, T., Kettunen, O., \& Sakari Aulanko. (2016). Air conditioning. In K. T. Koskinen, H. Kortelainen, J. Aaltonen, Teuvo Uusitalo, K. Komonen, J. Mathew, \& J. Laitinen (Eds.), Proceedings of the 10th World Congress on Engineering Asset Management (WCEAM 2015), Lecture Notes in Mechanical Engineering (pp. 381- 
388). Tampere, Finland: Springer International Publishing Switzerland. https://doi.org/10.1007/978-3-319-27064-7_36

Kusumawardhani, M., Gundersen, S., \& Tore, M. (2017). Mapping the research approach of asset management studies in the petroleum industry. Journal of Quality in Maintenance Engineering, 23(1), 57-70. https://doi.org/10.1108/JQME-07-2015-0031

Lagerstedt, J. (2003). Functional and environmental factors in early phases of product development-Eco Functional Matrix. KTH Royal Institute of Technology. https://doi.org/10.16309/j.cnki.issn.1007-1776.2003.03.004

Langston, C., Chan, E. H. W., \& Yung, E. H. K. (2018). Hybrid input-output analysis of embodied carbon and construction cost differences between new-build and refurbished projects. Sustainability, 10(9). https://doi.org/10.3390/su10093229

Lanza, G., Peters, S., \& Herrmann, H. G. (2012). Dynamic optimization of manufacturing systems in automotive industries. CIRP Journal of Manufacturing Science and Technology, 5(4), 235-240. https://doi.org/10.1016/j.cirpj.2012.09.002

Larsen, K. R., Lukyanenko, R., Mueller, R. M., \& Storey, V. C. (2020). Validity in Design Science Research. International Conference on Design Science Research in Information Systems and Technology, (June), 1-15. Retrieved from https://www.researchgate.net/publication/341029864_Validity_in_Design_Scie nce_Research

Lave, L. B., Cobas-Flores, E., Hendrickson, C. T., \& Mcmichael, F. C. (1995). Using InputOutput Analysis to Estimate Economy-wide Discharges. Environmental Science and Technology, 29(9), 420A-426A. https://doi.org/10.1021/es00009a003

Lee, C. K., Kim, Y. K., Pruitichaiwiboon, P., Kim, J. S., Lee, K. M., \& Ju, C. S. (2010). Assessing environmentally friendly recycling methods for composite bodies of railway rolling stock using life-cycle analysis. Transportation Research Part $D$ : Transport and Environment, 15(4), 197-203. https://doi.org/10.1016/j.trd.2010.02.001

Lehmann, A., Bach, V., \& Finkbeiner, M. (2016). EU product environmental footprintmid-term review of the pilot phase. Sustainability, 8(1), 1-13. https://doi.org/10.3390/su8010092

Lewin, K. (1947). Change management model. new York, USA: McGraw Hill.

Luttropp, C., \& Lagerstedt, J. (2006). EcoDesign and The Ten Golden Rules: generic advice for merging environmental aspects into product development. Journal of Cleaner Production, 14, 1396e1408. https://doi.org/10.1016/j.jclepro.2005.11.022

Madni, A. M., \& Sievers, M. (2014). System of Systems Integration: Key Considerations and Challenges. Systems Engineering, 17(3), 330-347. https://doi.org/https://doi.org/10.1002/sys.21272

Maestrini, V., Luzzini, D., Shani, A. B., \& Canterino, F. (2016). The action research cycle reloaded: Conducting action research across buyer-supplier relationships. Journal of Purchasing and Supply Management, 22(4), 289-298. https://doi.org/10.1016/j.pursup.2016.06.002

Mahaux, M., Heymans, P., \& Saval, G. (2011). Discovering sustainability requirements: An experience report. In International Working Conference on Requirements Engineering: Foundation for Software Quality (Vol. 6606, pp. 19-33). Berlin 
Heidelberg: Springer.

Manojlović, A. V., Papić, V. D., Filipović, S. M., \& Jovanović, V. D. (2011). Fleet renewal: An approach to achieve sustainable road transport. Thermal Science, 15(4), 12231236. https://doi.org/10.2298/TSCI110504111M

Mardani, A., Jusoh, A., Nor, K. M. D., Khalifah, Z., Zakwan, N., \& Valipour, A. (2015). Multiple criteria decision-making techniques and their applications - A review of the literature from 2000 to 2014 . Economic Research-Ekonomska Istrazivanja, 28(1), 516-571. https://doi.org/10.1080/1331677X.2015.1075139

Markard, J. (2018). The next phase of the energy transition and its implications for research and policy. Nature Energy, 3(8), 628-633. https://doi.org/10.1038/s41560-018-0171-7

Marlow, D. R., Beale, D. J., \& Burn, S. (2010). A pathway to a more sustainable water sector: Sustainability-based asset management. Water Science and Technology, 61(5), 1245-1255. https://doi.org/10.2166/wst.2010.043

Martinsuo, M. M., Vuorinen, L., \& Killen, C. (2019). Lifecycle-oriented framing of value at the front end of infrastructure projects. International Journal of Managing Projects in Business, 12(3), 617-643. https://doi.org/10.1108/IJMPB-09-20180172

Mateo, C., Prettico, G., Gómez, T., Cossent, R., Gangale, F., Frías, P., \& Fulli, G. (2018). European representative electricity distribution networks. International Journal of Electrical Power and Energy Systems, 99(February), 273-280.

https://doi.org/10.1016/j.ijepes.2018.01.027

Mathieux, F., Froelich, D., \& Moszkowicz, P. (2008). ReSICLED: a new recoveryconscious design method for complex products based on a multicriteria assessment of the recoverability. Journal of Cleaner Production, 16(3), 277-298.

Matschewsky, J., Lindahl, M., \& Sakao, T. (2020). Capturing and enhancing provider value in product-service systems throughout the lifecycle: A systematic approach. CIRP Journal of Manufacturing Science and Technology, 29, 191-204. https://doi.org/10.1016/j.cirpj.2018.08.006

Melchers, R. E. (2001). On the ALARP approach to risk management. Reliability Engineering and System Safety, 71(2), 201-208. https://doi.org/10.1016/S09518320(00)00096-X

Melo, S. P., Barke, A., Cerdas, F., Thies, C., Mennenga, M., Spengler, T. S., \& Herrmann, C. (2020). Sustainability assessment and engineering of emerging aircraft technologies-challenges, methods and tools. Sustainability (Switzerland), 12(14). https://doi.org/10.3390/su12145663

Merciai, S., \& Schmidt, J. (2018). Methodology for the Construction of Global MultiRegional Hybrid Supply and Use Tables for the EXIOBASE v3 Database. Journal of Industrial Ecology, 22(3), 516-531. https://doi.org/10.1111/jiec.12713

Meredith, J. R. (1987). Automating the factory: Theory versus practice. International Journal of Production Research. https://doi.org/10.1080/00207548708919928

Merkisz-Guranowska, A., Merkisz, J., Jacyna, M., Pyza, D., \& Stawecka, H. (2014). Rail vehicles recycling. WIT Transactions on the Built Environment, 135, 425-436. https://doi.org/10.2495/CR140351 
Miah, J. H., Koh, S. C. L., \& Stone, D. (2017). A hybridised framework combining integrated methods for environmental Life Cycle Assessment and Life Cycle Costing. Journal of Cleaner Production, 168, 846-866. https://doi.org/10.1016/j.jclepro.2017.08.187

Miller, P., de Barros, A. G., Kattan, L., \& Wirasinghe, S. C. (2016). Public transportation and sustainability: A review. KSCE Journal of Civil Engineering, 20(3), 1076-1083. https://doi.org/10.1007/s12205-016-0705-0

Murthy, D. N. P., Atrens, A., \& Eccleston, J. A. (2002). Strategic maintenance management. Journal of Quality in Maintenance Engineering, 8(4), 287-305. https://doi.org/10.1108/13552510210448504

Myers, S. C. (1984). Finance Theory and Financial Strategy. Interfaces, 14(1), 126-137. https://doi.org/10.1287/inte.14.1.126

Nakamura, S., \& Kondo, Y. (2009). Waste Input-Output Analysis, LCA and LCC. In Sangwon Suh (Ed.), Handbook of Input-Output Economics in Industrial Ecology (pp. 561-572). Springer Science. Retrieved from http://link.springer.com/10.1007/978-1-4020-5737-3_27

Neugebauer, S., Forin, S., \& Finkbeiner, M. (2016). From life cycle costing to economic life cycle assessment-introducing an economic impact pathway. Sustainability (Switzerland), 8(5), 1-23. https://doi.org/10.3390/su8050428

Nicola, D. A., Rosen, M. A., Bulucea, C. A., \& Brandusa, C. (2010). Some sustainability aspects of energy conversion in urban electric trains. Sustainability, 2(5), 1389 1407. https://doi.org/10.3390/su2051389

Norris, G. A. (2001). Integrating life cycle cost analysis and LCA. International Journal of Life Cycle Assessment, 6(2), 118-120.

NS. (2019). NS Annual Report 2019. Retrieved from https://www.nsannualreport.nl/FbContent.ashx/pub_1001/downloads/v20041 6100644/NS_annualreport_2019.pdf

Okano, K. (2001). Life cycle costing - An approach to life cycle cost management : A consideration from historical development. Asia Pacific Management Review, 6(3), 317-341.

Oliva, R. (2019). Intervention as a research strategy. Journal of Operations Management, 65(7), 710-724. https://doi.org/10.1002/joom.1065

Ou, X., Zhang, X., \& Chang, S. (2010). Scenario analysis on alternative fuel/vehicle for China's future road transport: Life-cycle energy demand and GHG emissions. Energy Policy, 38(8), 3943-3956. https://doi.org/10.1016/j.enpol.2010.03.018

Överstam, U. (2016). Applying eco-design guidelines when designing rolling stock. In The 13th UIC Sustainability Conference. Vienna, Austria.

Peças, P., Götze, U., Henriques, E., Ribeiro, I., Schmidt, A., \& Symmank, C. (2016). Life Cycle Engineering - Taxonomy and State-of-the-Art. In Procedia CIRP (Vol. 48, pp. 73-78). Elsevier B.V. https://doi.org/10.1016/j.procir.2016.04.085

Peffers, Ken, Tuunanen, T., Gengler, C. E., Rossi, M., Hui, W., Virtanen, V., \& Bragge, J. (2006). The Design Science Research Process: A Model for Producing and Presenting Information Systems Research. Proceedings of Design Research in Information Systems and Technology DESRIST'06, 24, 83-106. 
https://doi.org/10.2753/MIS0742-1222240302

Peffers, Ken, Tuunanen, T., Rothenberger, M., \& Chatterjee, S. (2007). A design science research methodology for information systems research. Journal of Management Information Systems, 24(3), 45-77. https://doi.org/10.2753/MIS0742-1222240302

Pigosso, D. C. A., Zanette, E. T., Filho, A. G., Ometto, A. R., \& Rozenfeld, H. (2010). Ecodesign methods focused on remanufacturing. Journal of Cleaner Production, 18(1), 21-31. https://doi.org/10.1016/j.jclepro.2009.09.005

Pintelon, L., \& Parodi-herz, A. (2008). Maintenance: An Evolutionary Perspective. In Complex System Maintenance Handbook (pp. 21-48). London, UK: Springer.

Pizzol, M., Weidema, B., Brandão, M., \& Osset, P. (2015). Monetary valuation in Life Cycle Assessment: a review. Journal of Cleaner Production, 86, 170-179. https://doi.org/10.1016/J.JCLEPR0.2014.08.007

Polit, D. F., \& Beck, C. T. (2010). Generalization in quantitative and qualitative research: Myths and strategies. International Journal of Nursing Studies, 47(11), 14511458. https://doi.org/10.1016/j.ijnurstu.2010.06.004

Powell, J. P., González-Gil, A., \& Palacin, R. (2014). Experimental assessment of the energy consumption of urban rail vehicles during stabling hours: Influence of ambient temperature. Applied Thermal Engineering, 66(1-2), 541-547. https://doi.org/10.1016/j.applthermaleng.2014.02.057

Priddy, R. D. (2017). Sustainability: The train has left the station. MRS Energy 8 Sustainability, 4, 1-10. https://doi.org/10.1557/mre.2017.4

Pudney, S. (2010). Asset Renewal Decision Modelling with Application to the Water Utility Industry. Faculty of Built Environment and Engineering, Ph.D.(November), 271.

Qureshi, N., \& Shah, J. (2014). Aging infrastructure and decreasing demand: A dilemma for water utilities. Journal - American Water Works Association, 106(1), 51-61. https://doi.org/10.5942/jawwa.2014.106.0013

Rajala, R. P., \& Hukka, J. J. (2018). Asset Life Cycle Management in Finnish Water Utilities. Journal of Water Resource and Protection, 10(06), 587-595. https://doi.org/10.4236/jwarp.2018.106033

Rama, D., \& Andrews, J. D. (2016). Railway infrastructure asset management: The whole-system life cost analysis. IET Intelligent Transport Systems, 10(1), 58-64. https://doi.org/10.1049/iet-its.2015.0030

Reap, J., Roman, F., Duncan, S., \& Bras, B. (2008a). A survey of unresolved problems in life cycle assessment. Part 1: Goal and scope and inventory analysis. International Journal of Life Cycle Assessment, 13(4), 290-300. https://doi.org/10.1007/s11367-008-0008-x

Reap, J., Roman, F., Duncan, S., \& Bras, B. (2008b). A survey of unresolved problems in life cycle assessment. Part 2: Impact assessment and interpretation. International Journal of Life Cycle Assessment, 13(5), 374-388. https://doi.org/10.1007/s11367-008-0009-9

Rebitzer, G., Ekvall, T., Frischknecht, R., Hunkeler, D., Norris, G., Rydberg, T., ... Pennington, D. W. (2004). Life cycle assessment Part 1: Framework, goal and 
scope definition, inventory analysis, and applications. Environment International, 30(5), 701-720. https://doi.org/10.1016/j.envint.2003.11.005

Rebitzer, G., \& Hunkeler, D. (2003). Life Cycle Costing in LCM: Ambitions, Opportunities, and Limitations. International Journal of Life Cycle Assessment, 8(5), 253-256.

Rebitzer, G., Hunkeler, D., \& Jolliep, O. (2003). LCC-The Economic Pillar of Sustainability: Methodology and Application to Watewater Treatment. Environmental Progress, (4), 241-249.

Reddy, V. R., Kurian, M., \& Ardakanian, R. (2015). Life-cycle Cost Approach (LCCA): Framework and Concepts. In Life-cycle Cost Approach for Management of Environmental Resources (SpringerBr, pp. 17-37). Springer, Cham. https://doi.org/https://doi.org/10.1007/978-3-319-06287-7_2

Renkema, T. J. W., \& Berghout, E. W. (1997). Methodologies for information systems investment evaluation at the proposal stage: A comparative review. Information and Software Technology, 39(1), 1-13. https://doi.org/10.1016/09505849(96)85006-3

Ribeiro, J. S., \& Gomes, J. D. O. (2014). A framework to integrate the end-of-life aircraft in preliminary design. Procedia CIRP, 15, 508-513.

https://doi.org/10.1016/j.procir.2014.06.077

Roda, I., \& Garetti, M. (2014). The link between costs and performances for Total cost of Ownership evaluation of physical asset: State of the art review. 2014 International Conference on Engineering, Technology and Innovation (ICE). https://doi.org/10.1109/ICE.2014.6871544

Rødseth, H., Schjølberg, P., Kirknes, M., Bernhardsen, \& Inge, T. (2016). Increased Profit and Technical Condition Through New KPIs in Maintenance Management. In K. T. Koskinen, H. Kortelainen, J. Aaltonen, Teuvo Uusitalo, K. Komonen, J. Mathew, \& J. Laitinen (Eds.), Proceedings of the 10th World Congress on Engineering Asset Management (WCEAM 2015), Lecture Notes in Mechanical Engineering (pp. 505511). Tampere, Finland: Springer International Publishing Switzerland. https://doi.org/10.1007/978-3-319-27064-7_49

Rosqvist, T., Laakso, K., \& Reunanen, M. (2009). Value-driven maintenance planning for a production plant. Reliability Engineering and System Safety, 94(1), 97-110. https://doi.org/10.1016/j.ress.2007.03.018

Ross, A. M., Rhodes, D. H., \& Hastings, D. E. (2008). Defining Changeability: Reconciling Flexibility, Adaptability, Scalability, Modifiability, and Robustness for Maintaining System Lifecycle Value. Systems Engineering, 3(11), 246-262.

Rossi, M., Germani, M., \& Zamagni, A. (2016). Review of ecodesign methods and tools. Barriers and strategies for an effective implementation in industrial companies. Journal of Cleaner Production, 129, 361-373. https://doi.org/10.1016/j.jclepro.2016.04.051

Rousseaux, P., Gremy-Gros, C., Bonnin, M., Henriel-Ricordel, C., Bernard, P., Floury, L., ... Vincent, P. (2017). "Eco-tool-seeker"A new and unique business guide for choosing ecodesign tools. Journal of Cleaner Production, 151, 546-577. https://doi.org/10.1016/j.jclepro.2017.03.089

Ruester, S., Schwenen, S., Batlle, C., \& Pérez-Arriaga, I. (2014). From distribution networks to smart distribution systems: Rethinking the regulation of European 
electricity DSOs. Utilities Policy, 31(1), 229-237.

https://doi.org/10.1016/j.jup.2014.03.007

Ruitenburg, R. J. (2017). Manoeuvring physical assets into the future: Planning for predictable and preparing for unpredictable change in Asset Life Cycle Management. Univerity of Twente.

Ruitenburg, R. J., \& Braaksma, A. J. J. (2017). Mitigating change in the goals and context of capital assets: Design of the Lifetime Impact Identification Analysis. CIRP Journal of Manufacturing Science and Technology, 17, 50-59. https://doi.org/10.1016/j.cirpj.2016.05.008

Ruitenburg, R. J., Braaksma, A. J. J., \& van Dongen, L. A. M. (2014). A Multidisciplinary, Expert-based Approach for the Identification of Lifetime Impacts in Asset Life Cycle Management. Procedia CIRP, 22, 204-212.

Ruitenburg, R. J., Braaksma, A. J. J., \& van Dongen, L. A. M. (2016). Agility in Asset Management, or: how to be flexible with assets designed for stability. In Proceedings of the 23rd EurOMA Conference (p. 11).

Ruitenburg, R. J., Braaksma, A. J. J., \& Van Dongen, L. A. M. (2017). Aset life cycle plans: Twelve steps to assist strategic decision-making in asset life cycle management. In M. C. Carnero \& V. Gonzalez-Prida (Eds.), Optimum decision making in asset management (pp. 259-287). Hershey, PA, USA: IGI Global. https://doi.org/https://doi.org/10.4018/978-1-5225-0651-5.ch012

Rydh, C. J., \& Sun, M. (2005). Life cycle inventory data for materials grouped according to environmental and material properties. Journal of Cleaner Production, 13(1314), 1258-1268. https://doi.org/10.1016/j.jclepro.2005.05.012

Sakao, T., \& Lindahl, M. (2015). A method to improve integrated product service offerings based on life cycle costing. CIRP Annals - Manufacturing Technology, 64(1), 33-36. https://doi.org/10.1016/j.cirp.2015.04.052

Schöggl, J. P., Baumgartner, R. J., \& Hofer, D. (2017). Improving sustainability performance in early phases of product design: A checklist for sustainable product development tested in the automotive industry Calls for PapersUpcoming Special Issues and Books on Sustainable Business Models View project AKRosA. Journal of Cleaner Production, 140, 1602-1617. https://doi.org/10.1016/j.jclepro.2016.09.195

Schrijvers, D., Loubet, P., \& Sonnemann, G. (2020). Archetypes of Goal and Scope Definitions for Consistent Allocation in LCA. Sustainability, 12, 2-3. https://doi.org/doi:10.3390/su12145587

Schuman, C., \& Brent, A. C. (2005). Asset life cycle management: towards improving physical asset performance in the process industry. International Journal of Operations \& Production Management, 25(6), 566-579. https://doi.org/10.1108/01443570510599728

Schuurman, P., Berghout, E. W., \& Powell, P. (2008). Benefits are from Venus, Costs are from Mars. Sprouts, 9(2009), Working Paper.

Sein, M. K., Henfridsson, O., Purao, S., Rossi, M., \& Lindgren, R. (2011). Action design research. MIS Quarterly: Management Information Systems, 35(1), 37-56. https://doi.org/10.2307/23043488

Settanni, E., Newnes, L. B., Thenent, N. E., Parry, G., \& Goh, Y. M. (2014). A through-life 
costing methodology for use in product-service-systems. International Journal of Production Economics, 153, 161-177. https://doi.org/10.1016/j.ijpe.2014.02.016

Settanni, E., Thenent, N. E., Newnes, L. B., Parry, G., \& Goh, Y. M. (2015). To Cost an Elephant: An Exploratory Survey on Cost Estimating Practice in the Light of Product-Service-Systems. Journal of Cost Analysis and Parametrics, 8(1), 1-22. https://doi.org/10.1080/1941658x.2015.1016588

Shah, R., McMann, O., \& Borthwick, F. (2017). Challenges and prospects of applying asset management principles to highway maintenance: A case study of the UK. Transportation Research Part A: Policy and Practice, 97, 231-243. https://doi.org/10.1016/j.tra.2017.01.011

Shani, A. B. (Rami), Coghlan, D., \& Cirella, S. (2012). Action Research and Collaborative Management Research: More than Meets the Eye? International Journal of Action Research, 8(1), 45-67.

Shani, A. B., \& Pasmore, W. . . (1985). Organization inquiry: Towards a new model of the action research process. In D. D. Warrick (Ed.), Contemporary organization development: Current thinking and applications (pp. 438-448).

Sharifi, H., \& Zhang, Z. (1999). Methodology for achieving agility in manufacturing organisations: an introduction. International Journal of Production Economics, 62(1), 7-22. https://doi.org/10.1016/S0925-5273(98)00217-5

Sherif, Y. S., \& Kolarik, W. J. (1981). Life Cycle Costing: Concept and Practice. OMEGA The International Journal of Management Science, 9(3), 287-296.

Si, X. S., Wang, W., Hu, C. H., \& Zhou, D. H. (2011). Remaining useful life estimation - A review on the statistical data driven approaches. European Journal of Operational Research, 213(1), 1-14. https://doi.org/10.1016/j.ejor.2010.11.018

Silva, R. F., \& Kaewunruen, S. (2017). Recycling of rolling stock. Environments, 39(4), $1-$ 18. https://doi.org/doi:10.3390/environments4020039

Simionescu, V., \& Silvius, G. (2016). Assessing Sustainability of Railway Modernization Projects; A Case Study from Romania. Procedia Computer Science, 100(December), 458-465. https://doi.org/10.1016/j.procs.2016.09.182

Simon, H. A. (1973). Does scientific discovery have a logic? Phllosophy of Science, 40(4), 471-480.

Simpson, G. S., Lamb, F. E., Finch, J. H., \& Dinnie, N. C. (2000). The application of probabilistic and qualitative methods to asset management decision making. Proceedings of the SPE Asia Pacific Conference on Integrated Modelling for Asset Management, 519-529.

Sokovic, M., Pavletic, D., \& Pipan, K. K. (2010). Quality Improvement Methodologies PDCA Cycle, RADAR Matrix, DMAIC and DFSS. The Journal of Achievements in Materials and Manufacturing Engineering, 43(1), 476-483.

Spiliotis, K., Ramos Gutierrez, A. I., \& Belmans, R. (2016). Demand flexibility versus physical network expansions in distribution grids. Applied Energy, 182, 613-624. https://doi.org/10.1016/j.apenergy.2016.08.145

Spreafico, C., \& Russo, D. (2020). Exploiting the Scientific Literature for Performing Life Cycle Assessment about Transportation. Sustainability. 
Srinivasan, R., \& Parlikad, A. K. (2017). An approach to value-based infrastructure asset management. Infrastructure Asset Management, 4(3), 87-95. https://doi.org/10.1680/jinam.17.00003

Stapelberg, R. F. (2006). Professional skills training in integrated asset management: How to develop and implement the essential organisational asset management functions. In Proceedings of the 1st World Congress on Engineering Asset Management (WCEAM) (pp. 1243-1251). Gold Coast, Australia.

Stjernborg, V., \& Mattisson, O. (2016). The role of public transport in society-A case study of general policy documents in Sweden. Sustainability, 8. https://doi.org/10.3390/su8111120

Suh, S, \& Huppes, G. (2001). Applications of input-output analysis for LCA-with a case study of linoleum. In Annual SETAC-Europe Meeting. Madrid, Spain.

Suh, Sangwon, \& Huppes, G. (2005). Methods for life cycle inventory of a product. Journal of Cleaner Production, 13(7), 687-697. https://doi.org/10.1016/j.jclepro.2003.04.001

Swarr, T. E., Hunkeler, D., Klöpffer, W., Pesonen, H.-L., Ciroth, A., Brent, A. C., \& Pagan, R. (2011). Environmental life-cycle costing: A code of practice. International Journal of Life Cycle Assessment, 16(5), 389-391. https://doi.org/10.1007/s11367-0110287-5

Syed, Z., \& Lawryshyn, Y. (2020). Multi-criteria decision-making considering risk and uncertainty in physical asset management. Journal of Loss Prevention in the Process Industries, 65(September 2019), 104064. https://doi.org/10.1016/j.jlp.2020.104064

Taylor, W. B. (1981). The Use of Life Cycle Costing in Acquiring Physical Assets. Long Range Planning, 14(6), 32-43. https://doi.org/10.1016/0024-6301(81)90058-3

Thiry, M. (2001). Sensemaking in value management practice. International Journal of Project Management, 19(2), 71-77. https://doi.org/10.1016/S02637863(00)00023-5

Thomke, S., \& Fujimoto, T. (2000). Effect of 'front-loading' problem-solving on product development performance. Journal of Product Innovation Management, 17(2), 128-142. https://doi.org/10.1016/S0737-6782(99)00031-4

Thong, M., \& Cheong, A. (2012). Energy Efficiency in Singapore's Rapid Transit System. In Journeys: Sharing Urban Transport Solutions (pp. 38-47). Singapore: LTA Academy.

Tinga, T. (2013). Principles of Loads and Failure Mechanisms: Application in Maintenance, Reliability and Design. (H. Pham, Ed.). Den Helder, The Netherlands: Springer London Heidelberg New York Dordrecht. https://doi.org/10.1007/978-1-4471-4917-0

Toniolo, S., Tosato, R. C., Gambaro, F., \& Ren, J. (2020). Life cycle thinking tools: Life cycle assessment, life cycle costing and social life cycle assessment. Life Cycle Sustainability Assessment for Decision-Making. Elsevier Inc. https://doi.org/10.1016/b978-0-12-818355-7.00003-8

Towle, I., Johnston, C., Lingwood, R., \& Grant, P. S. (2004). The Aircraft at End of Life Sector: a Preliminary Study. Oxford, UK. Retrieved from http://users.ox.ac.uk/ pgrant/Airplane_end_of_life.pdf 
Tranfield, D., Denyer, D., \& Burr, M. (2004). A framework for the strategic management of long-term assets (SMoLTA). Management Decision, 42(2), 277-291. https://doi.org/10.1108/00251740410518516

Umeda, Y., Takata, S., Kimura, F., Tomiyama, T., Sutherland, J. W., Kara, S., ... Duflou, J. R. (2012). Toward integrated product and process life cycle planning - An environmental perspective. CIRP Annals - Manufacturing Technology, 61(2), 681-702. https://doi.org/10.1016/j.cirp.2012.05.004

van Aken, J., Chandrasekaran, A., \& Halman, J. (2016). Conducting and publishing design science research: Inaugural essay of the design science department of the Journal of Operations Management. Journal of Operations Management, 4748, 1-8. https://doi.org/10.1016/j.jom.2016.06.004

van Aken, J. E. (2004). Management Research on the Basis of the Design Paradigm: the Quest for Field-tested and Grounded Technological Rules. Journal of Management Studies, 41(2), 219-246.

Van Aken, Joan E. (2004). Management Research Based on the Paradigm of the Design Sciences: The Quest for Field-Tested and Grounded Technological Rules. Journal of Management Studies, 41(2), 219-246. https://doi.org/10.1111/j.14676486.2004.00430.x

Van Breugel, K. (2017). Societal burden and engineering challenges of ageing infrastructure. Procedia Engineering, 171, 53-63.

Veldman, J., Klingenberg, W., \& Wortmann, H. (2011). Managing condition-based maintenance technology A multiple case study in the process industry. Journal of Quality in Maintenance Engineering, 17(1), 40-62. https://doi.org/10.1108/13552510810877674

Venable, J., Pries-Heje, J., \& Baskerville, R. (2016). FEDS: A Framework for Evaluation in Design Science Research. European Journal of Information Systems, 25(1), 7789. https://doi.org/10.1057/ejis.2014.36

Venable, J. R., Pries-heje, J., \& Baskerville, R. (2012). A Comprehensive Framework for Evaluation in Design Science Research. In K. Peffers, M. Rothenberger, \& B. Kuechler (Eds.), Design Science Research in Information Systems. Advances in Theory and Practice (Vol. 7286, pp. 423-438). Berlin, Germany: Heidelberg: Springer. https://doi.org/10.1007/978-3-642-29863-9

Verbong, G., \& Geels, F. (2007). The ongoing energy transition: Lessons from a sociotechnical, multi-level analysis of the Dutch electricity system (1960-2004). Energy Policy, 35(2), 1025-1037. https://doi.org/10.1016/j.enpol.2006.02.010

Wanke, P., Chen, Z., Zheng, X., \& Antunes, J. (2020). Sustainability efficiency and carbon inequality of the Chinese transportation system: A Robust Bayesian Stochastic Frontier Analysis. Journal of Environmental Management, 260, 110163. https://doi.org/10.1016/j.jenvman.2020.110163

Weidema, B. P. (2008). Using the budget constraint to monetarise impact assessment results. Ecological Economics, 68, 1591-1598.

https://doi.org/10.1016/j.ecolecon.2008.01.019

Wen, B., Jin, Q., Huang, H., Tandon, P., \& Zhu, Y. (2017). Life cycle assessment of Quayside Crane: A case study in China. Journal of Cleaner Production, 148, 1-11. https://doi.org/10.1016/j.jclepro.2017.01.146 
Wenzel, H. (1998). Application dependency of LCA methodology: Key variables and their mode of influencing the method. International Journal of Life Cycle Assessment, 3(5), 281-288. https://doi.org/10.1007/BF02979837

White, G. E., \& Ostwald, P. F. (1976). Life Cycle Costing. Management Accounting, 57(7), 39-42.

Wieringa, R. J. (2014). Design Science Methodology for Information Systems and Software Engineering. Berlin Heidelberg: Springer-Verlag. https://doi.org/10.1007/978-3-662-43839-8

Willis, H. L., \& Schrieber, R. R. (2013). Aging power delivery infrastructures (Second Edi). Taylor \& Francis Group.

Winter, R. (2008). Design science research in Europe. European Journal of Information Systems, 17(5), 470-475. https://doi.org/10.1057/ejis.2008.44

Woodhouse, J. (2015). Setting a good standard in asset management. Times, 1-4.

Woodward, D. G. (1997). Life cycle costing-Theory, information acquisition and application. International Journal of Project Management, 15(6), 335-344.

Wulf, C., Werker, J., Ball, C., Zapp, P., \& Kuckshinrichs, W. (2019). Review of sustainability assessment approaches based on life cycles. Sustainability, 11(20). https://doi.org/10.3390/su11205717

Xu, Y., Elgh, F., Erkoyuncu, J. A., Bankole, O., Goh, Y., Cheung, W. M., ... Roy, R. (2012). Cost engineering for manufacturing: Current and future research. International Journal of Computer Integrated Manufacturing, 25(4-5), 300-314. https://doi.org/10.1080/0951192X.2010.542183

Yang, Y., Ng, S. T., Xu, F. J., Skitmore, M., \& Zhou, S. (2019). Towards resilient civil infrastructure asset management: An information elicitation and analytical framework. Sustainability (Switzerland), 11(16). https://doi.org/10.3390/su11164439

Yarwood, J., \& Eagan, P. (1998). Design for Environment Toolkit: a competitive edge for the future. Matrix. Minnesota, USA.

Yin, R. K. (2003). Case Study Research: Design and Methods (Vol. 5). SAGE Publications. https://doi.org/10.1300/J145v03n03_07

Ylmén, P., Berlin, J., Mjörnell, K., \& Arfvidsson, J. (2020). Managing choice uncertainties in life-cycle assessment as a decision-support tool for building design: A case study on building framework. Sustainability, 12(12). https://doi.org/10.3390/su12125130

Yuan, H. (2017). Achieving Sustainability in Railway Projects: Major Stakeholder Concerns. Project Management Journal, 48(5), 115-132. https://doi.org/10.1177/875697281704800508

Zhang, Wenjuan, \& Wang, W. (2014). Cost modelling in maintenance strategy optimisation for infrastructure assets with limited data. Reliability Engineering and System Safety, 130, 33-41. https://doi.org/10.1016/j.ress.2014.04.025

Zhang, Wujie, Guo, J., Gu, F., \& Gu, X. (2018). Coupling life cycle assessment and life cycle costing as an evaluation tool for developing product service system of high energy-consuming equipment. Journal of Cleaner Production, 183, 1043- 
1053. https://doi.org/10.1016/j.jclepro.2018.02.146

Zhang, X., Lam, J. S. L., \& Iris, Ç. (2020). Cold chain shipping mode choice with environmental and financial perspectives. Transportation Research Part D: Transport and Environment, 87(September), 102537. https://doi.org/10.1016/j.trd.2020.102537

Zhuang, O.., \& Janssen, A. (2015). Managing Strategic Risks in the Electricity and Gas Distribution Sector - A Conceptual Model and Its Examples Managing Strategic Risks in the Electricity and Gas Distribution Sector - A Conceptual Model and Its Examples, (September 2015).

Zimek, M., Schober, A., Mair, C., Baumgartner, R. J., Stern, T., \& Füllsack, M. (2019). The third wave of LCA as the "decade of consolidation." Sustainability, 11(12). https://doi.org/10.3390/su10023283

Zoeteman, A. (2001). Life cycle cost analysis for managing rail infrastructure. European Journal of Transport and Infrastructure Research, 1(4), 391-413. Retrieved from http://www.ejtir.tbm.tudelft.nl/issues/2001_04/index.asp 


\section{Appendix A}

\section{Question}

A1 Are lightweight materials used in the train where possible?

A2 Have structural reinforcements for making parts more lightweight been considered?

A3 Is the train energy efficient according to current standards?

A4 If possible, is energy regenerated in the train's systems and used in another system or fed back to the catenary?

A5 Is friction in the train's systems or at the system boundaries minimized?

A6 Is electrical resistance in the systems minimized?

A7 Is a proper energy monitoring system installed and certified?

A8 Is it possible to switch off systems when not in use? Is it possible to do this remotely or automatically?

B1 Does the train use materials with low embedded GHG emissions?

B1 Are suppliers selected based on or encouraged in their energy conservation practices?

C1 Are the used components vandalism proof?

C2 Is environmental impact considered when choosing materials?

C3 Does the train use renewable materials when possible?

C4 Is the amount of material used by the system kept to a minimum?

C5 Is the amount of parts that are reused during modernization as high as possible?

D1 Are recycled materials used when possible?

E1 Are used materials easily recyclable at the end of their life cycle?

E2 Are used materials easily separated?

E3 Are components easily disassembled?

E4 Is the amount of different materials used kept to a minimum?

E5 Is recyclability of components demanded from suppliers?

E6 Are the origin and composition of materials well documented?

F1 Is information regarding recycling well documented?

F2 Are parts easy to source or reproduce, even years after production has ended?

F3 Is compatibility of components with other train series maximized?

F4 Are the train's systems designed to be easily repairable?

F5 Is the system architecture modular, so that damaged components can easily be exchanged?

F6 Is the train designed in such a way that the use of disposable components is avoided?

F7 Is the lifespan of the train's systems and their components optimized for the train life cycle? 
G1 Is the train designed to minimize the use of lubricants, grease, and oils?

G2 Is the train designed to minimize the use of cleaning products?

G3 Does the train facilitate the use of nonhazardous cleaning products?

G4 Is the train designed to minimize contact with and emission of harmful materials during maintenance?

G5 Is the train designed to minimize the application and impact of graffiti?

H1 In case a hazardous substance is used, have alternatives been thoroughly investigated?

H2 In case a hazardous substance is used, is a closed material loop facilitated?

Are suppliers selected based on or encouraged in their reduction of the use of hazardous substances?

H4 Are wear-resistant materials used to avoid emissions from wear during use?

H5 Are components that include hazardous substances isolated and protected from leakage and corrosion?

H6 Is information regarding toxicity of the train well documented?

I1 Is discarded material from the old train $100 \%$ recycled or reused?

12 Are proper precautions taken to mitigate the effects of any spills of hazardous substances during disassembly?

J1 Is the amount of energy used during manufacturing minimized?

J2 Is waste heat in manufacturing used for other processes?

J3 Is waste material from manufacturing minimized and when possible reused or recycled?

14 Is a proper ventilation system for particulate matter in place in the manufacturing process?

J5 Does the manufacturing site use renewable energy for its processes and vehicles?

K1 Are components sourced as closely to the assembly site as possible?

K2 Is the logistics process optimized for as few truck movements as possible?

K3 Is the amount of packaging used to ship components minimized by suppliers?

K3 Is the same packaging used multiple times during the project?

K4 Is reused or recycled material used for the packaging?

K5 Is the number of unusable products kept to an absolute minimum?

L1 Does the train use any showcase environmental techniques?

L2 Does the train include features to stimulate its use over cars?

L3 Is the use of reused and recycled material visible in the train?

L4 Are the taken energy reduction or generation measures visible in the train? 


\section{Appendix B}

\section{Case study questions}

1 What is the goal of the assessment?

2 What is the scope of the assessment?

- Which asset(s) are included?

- What timeframe is being considered?

- Which type of impact is quantified?

3 What are the dominant cost drivers in the assessment?

4 What financial \& non-financial costs can be identified through the outcome of the assessment?

5 What financial \& non-financial benefits can be identified through the outcome of the assessment?

$6 \quad$ Which lifecycle option is preferred, and why? 


\section{Dankwoord}

Hoewel het niet voor de hand ligt voor een industrieel ontwerper om te promoveren, had ik na het afronden van mijn masteronderzoek sterk het gevoel dat ik nog steeds niet klaar was met de wetenschap, en de wetenschap nog niet met mij. Als onderzoeker met een ontwerpachtergrond heb ik me daarom proberen te onderscheiden door op zoek te gaan naar onderwerpen waarbij de theorie en de praktijk met elkaar verbonden kunnen worden en waarin de levensduur van apparaten centraal staat. Het uiteindelijke resultaat van deze zoektocht is dit proefschrift. Hoewel ik in dit boekje voor ruim vier jaar aan gedachten, frustraties, bloed, zweet, tranen en koffie heb gestopt, was het niet iets wat ik ooit in mijn eentje had kunnen doen. Ik heb ontzettend veel steun en inspiratie van, en door mijn omgeving gekregen. Ik wil jullie daar allemaal oprecht en van harte voor bedanken hiervoor. Zonder jullie had ik dit nooit durven en kunnen doen.

Allereerst zou ik mijn promotor professor Leo van Dongen, copromotor Jan Braaksma, en dagelijkse begeleider bij Liander, Ihsan Karakoc, willen bedanken. Jullie begeleiding en gedeelde visie waren essentieel in het uitvoeren van het onderzoek en het uitdragen van de resultaten ervan. Ik waardeer niet alleen jullie inbreng van waardevolle wetenschappelijke kaders en inzichten, maar ook de vrijheid die jullie gegeven hebben om het onderzoek zelfstandig op te zetten en uit te voeren. Ik ben ook erg dankbaar voor de dagelijkse wetenschappelijke begeleiding van Jan. Ik waardeer vooral de open en reflectieve sfeer waarmee wij het onderzoek en de academische wereld besproken hebben. Ik heb ook goede herinneringen aan de conferenties in Innsbruck en Madrid, inclusief de heen- en terugreizen. Ik wil ook graag Ihsan bedanken voor zijn inzicht, betrokkenheid, inspanning, en het introduceren van de juiste stakeholders als dagelijkse begeleider bij Liander. Ik ben nog steeds onder de indruk van jouw werkethiek en de verantwoordelijkheid die je voelt voor je collega's en voor de omgeving.

Ook dank ik mijn collega's van de UT waarmee ik het voorrecht heb gehad om mee samen te werken. Tox, bedankt voor het mentorschap tijdens mijn masteropleiding, de inhoudelijke brainstorms en voor de inspiratie om te gaan promoveren. Richard, bedankt voor de vruchtbare grond die je achter hebt gelaten voor onderzoek binnen Liander en voor het geven van het goede voorbeeld. Alberto, Jan-Jaap, Wieger, Sukon, Nina, Merishna, Yawar, Sara, Henrike, bedankt dat ik de smarten en de vreugde van wetenschappelijk onderzoek met jullie heb mogen delen. De paper review sessies met elkaar zijn erg waardevol en leerzaam geweest. Hoewel onze kamer op de UT, met name tijdens de COVID-pandemie, soms misschien iets te krap was, is het wel altijd ontzettend gezellig geweest. Ik zou ook graag de afstudeerders willen bedanken voor de interessante onderwerpen en discussies waarover met elkaar de diepte in zijn 
gegaan. Rolf, Tom, Folkert, Niels, Nina, Willem-Jan, Laura, het was een genoegen om bij jullie onderwerpen betrokken te zijn geweest.

Dit onderzoek had niet kunnen plaatsvinden zonder de financiering van Liander. Ik ben daarom dankbaar voor de inspanning van o.a. Leo, Ihsan, Camiel, Co en Peter vanuit Liander en van Leo en Jan vanuit de UT voor het mogelijk maken van de unieke samenwerking tussen de UT en Liander. Jan, Leo, Tox, Ihsan, Camiel, Pim, Elias, Co en Alex, bedankt voor jullie rollen en bijdrage in de stuurgroep en voor de waardevolle inzichten en reflectie. Vooral de gesprekken tijdens de stuurgroepoverleggen waren soms zo rijk dat die vaak nog bij een koffiemachine of op een treinperron voortgezet moesten worden. In het departement van Design, Production \& Management wordt vaak gezegd dat de industrie het laboratorium is waarin onderzoek wordt uitgevoerd. Ik kan met plezier terugkijken op ruim vier jaar onderzoek binnen Liander, wat ik met veel interesse heb uitgevoerd. Hoewel ik met een duidelijk onderzoeksdoel te werk ben gegaan, heb ik me tijdens het 'veldwerk' binnen Liander vaak als één van de collega's gevoeld. Alex, Bas, Evert, Frans, Fransien, Hein, Jasper, Jochem, Joris, Kasia, Kees, Lars, Manon, Martijn, Massimiliano, Nico, Paul, Peter, Robben, Robert, Sebastiaan, Sophie, Tongyou, Wim, en vele anderen: Bedankt voor jullie collegialiteit en openheid tijdens jullie werk. Liander was niet alleen een interessante en uitdagende omgeving om wetenschappelijk onderzoek in te doen, maar ik heb ook de overleggen, casussen, demo's en algemene werksfeer als zeer prettig ervaren. Zo hebben we gekeken naar de financiële en de maatschappelijke impact van de levensduur van transformatoren, kabels, schakelinstallaties, complete deelnetten, en de ontwikkeling van flexoplossingen. Ik blij dat ik bij heb kunnen dragen aan de vraagstukken over hoe energienetwerken betrouwbaar, betaalbaar, bereikbaar, veilig en duurzaam gemaakt kunnen blijven, nu en in de toekomst.

Ik word nog altijd vrolijk van de gedachte dat wij als vrienden van 'het bankje' sinds de middelbare school nog steeds zo hecht zijn. Marten, Elize, Mark, Nadine, Wicher, Anemoon, Jasmijn, Johannes, Simone, Martijn, Gert, Dominique, Jeroen, Els. Soms vergeet ik dat ik velen van jullie nu al meer dan de helft van mijn leven ken. We hebben meegedaan aan talloze familietoernooien voor voetbal en korfbal, herleven regelmatig vergane gloriedagen tijdens LAN parties en gaan nog steeds samen op vakantie. Jullie zijn als een soort van tweede familie voor mij, een familie die steeds groter wordt. Gert, Martijn, Sander, Frederiek, jullie hebben mij in het bijzonder geïnspireerd om ook te gaan promoveren, ondanks de uitdagingen en frustraties die daarmee gepaard gaan. 
Ik ben blij dat ik ben opgegroeid in een liefdevolle en behulpzame familie. Ik vind het mooi om te zien hoe we, bijvoorbeeld bij klussen en verhuizen, elkaar helpen en het gezellig maken. En dat we er voor elkaar zijn als het er toe doet. Papa en mama, jullie hebben mij altijd ondersteund en veel vrijheid gegund in mijn studiekeuzes. Bedankt voor al het geduld en vertrouwen dat jullie mij al die jaren in mij gehad hebben. Ik kan me nog herinneren dat Papa het op de Prinsenstraat in Oosterwolde er over had over dat hij had kunnen starten met een promotie, maar dat hij daar door een andere roeping nooit aan toe gekomen was. Misschien was er toen al een zaadje geplant in mijn gedachten om de kans op promoveren te pakken als die zich voordoet. Ik had zelf toen ik van de middelbare school ook niet gedacht dat ik later net als jullie ook (wetenschappelijke) 'preken' zou geven of voor de klas zou staan als promovendus. Dankzij jullie heb ik mezelf kunnen ontwikkelen tot wie ik vandaag ben. Jonate, jij hebt niet meer mogen meemaken hoe ik ben begonnen met mijn promotie-avontuur. Toch heb ik nog goede herinneringen dat wij elkaar tijdens onze studie geholpen hebben aan de keukentafel, vooral als er wiskunde bij kwam kijken. In mijn gedachten heb je me nog steeds geholpen in de afgelopen jaren. Daan en Rienk, ik heb jullie zien opgroeien van kleine broertjes, die op de nek of rug naar school gedragen moesten worden, tot grote broers met een sterke wil en karakter. We hebben in de tussentijd veel nintendo, gameboy en wii spellen met elkaar gespeeld en zijn uiteindelijk in verschillende windstreken gaan wonen. Met versterking van Goor en Kelly is de familie een heel stuk interessanter geworden en zijn jullie in goede handen.

Vielen Dank auch an Ulla, Dieter und Nicolai. Ich finde es schön, dass ich ein Teil Ihrer Familie sein kann. Obwohl ich mich anfangs an die Sprache gewöhnen musste, fühle ich mich in Marl seit langem schon wie zu Hause.

Lieve Melina, ik ben ontzettend gelukkig dat ik mijn leven met jou mag delen. Vanaf het moment dat wij bij elkaar zijn heb jij mijn leven interessanter en vrolijker gemaakt. Jij hebt ook meegeleefd met alle voor- en tegenslagen in de afgelopen jaren, waarvoor ik ontzettend dankbaar ben. Zonder jou zou ik mezelf niet kunnen zijn. Hoewel dit hoofdstuk afgesloten is, kijk ik nu al uit naar onze toekomst samen.

Willem Haanstra

April 2021

Hengelo 